

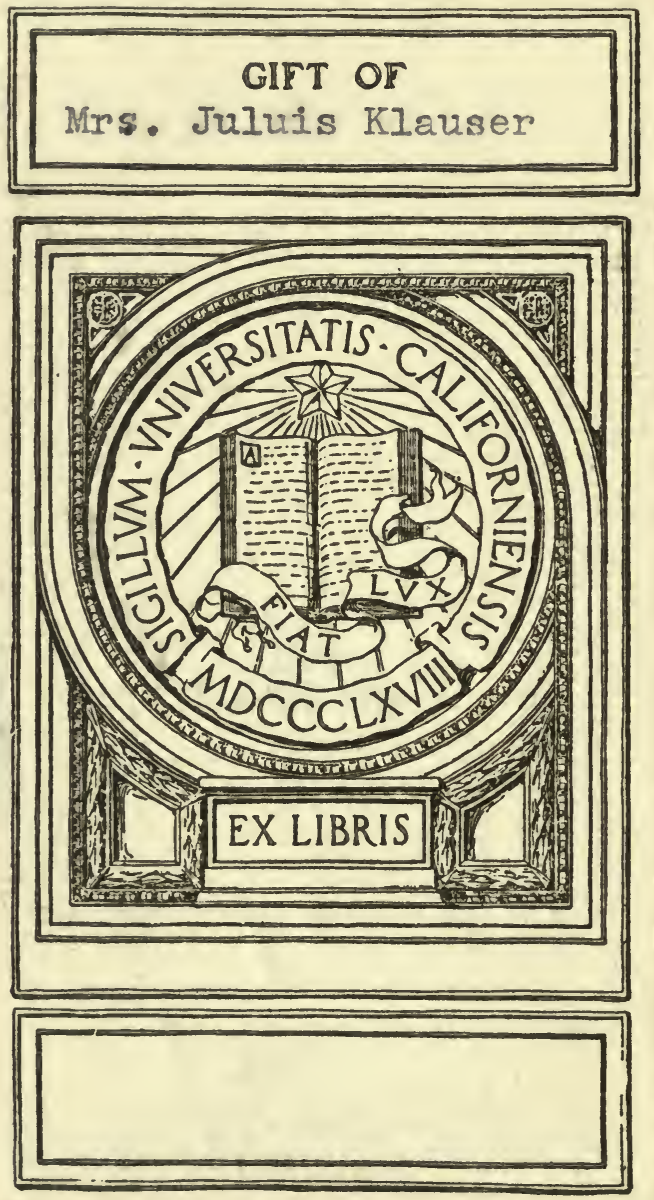



Digitized by the Internet Archive in 2008 with funding from Microsoft Corporation 



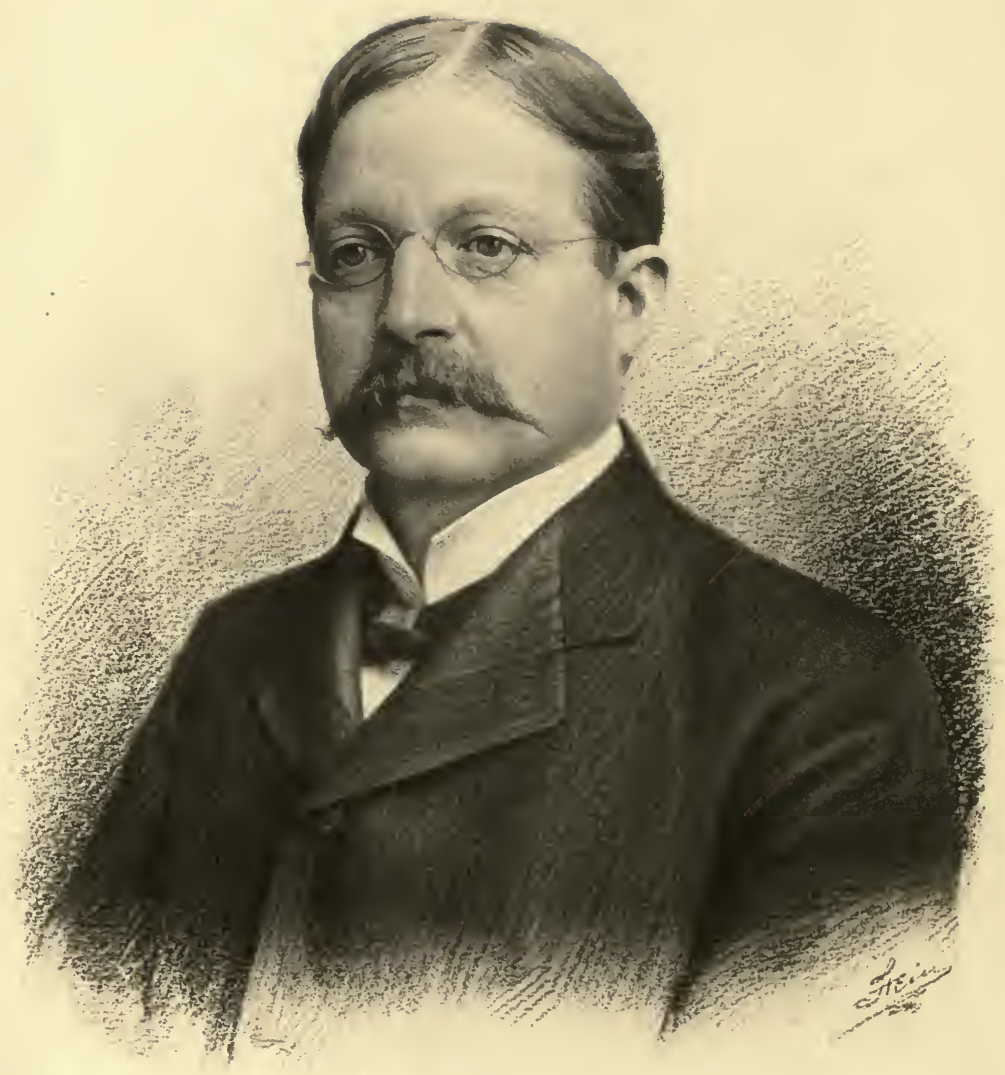

Julins Nbuner 


\section{THE NATURE OF MUSIC}

ORIGINAL HARMONY IN ONE VOICE

BY

JULIUS KLAUSER

II

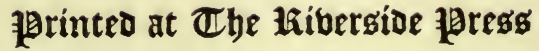

CAMBRIDGE 
$\angle 3800$

$\times 6$

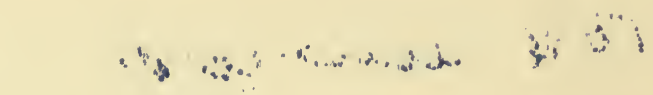

$\therefore$, . 1...

Lilco Aro. fillis thanser, COPYright, Ig09, BY L. E. KLAUSER Stiles, this, ALL RIGHTS RESERVED 



\section{PREFACE}

THis work was originally planned in two parts, but only six chapters and one section of Chapter VII which was to conclude Part I, were written at the time of the author's death, Monday, April 22, 1907.

The one section of Chapter VII has been omitted from the book because it was not left in the form in which it would have been published. The title of the chapter is "Potential Harmony of Melody. Expansion of Tonality. Chromatic Harmony. Modulation."

Asterisks in the manuscript have been preserved in the text; they indicate where footnotes were to have been supplied.

Dates in the manuscript show that Chapter III was finished during September, 1904, and Chapter IV April 9, 1905.

These six chapters unrevised are published as they were left, with one exception. To make space for the examples on page 238 a sentence has been omitted. It reads, "Thus the full thorough-bass index of the above terce-form would be ${ }_{3}^{6}$ of which 6 is the abbreviation."

The Bird-songs published as an appendix were probably not intended to form a part of the book, but I wish to preserve them and they may be of interest. Twenty-five, Nos. 62-86, are entitled "Birds of Idlewild 1903," however with the exception of a few from Silver Lake near Oconomowoc most of these songs were heard and recorded during several summers at Idlewild near Sturgeon Bay, Wisconsin. In the 
manuscript Nos. 1-9 and 43-86 were written on the staff, but Nos. 10-39 were indicated only by syllables and 40-42 by letters, in consequence of which the pitch of these songs is not quite certain.

To Miss Luise Haessler I wish to acknowledge my thanks for the help she has given me in copying most of the examples, all of the bird-songs and in supplying a paragraph of explanation page 254 and three examples pages $230-252$.

\section{E. K.}

Wrulamstown, Massachusetts, June, 1909. 


\section{CONTENTS}

\section{CHAPTER I}

\section{Introducing First Principles}

SEC.

1. Questions............................ 1

2. Homophony or Music in One Voice........... 4

3. Origin of Music.................... 6

4. Music-Feeling, the Source and Fountain of Music.... 8

5. Cause of Union. Shaping Principle.......... 10

6. World-Energy ...................... 11

7. World-Rhythm. Universal Form............. 12

8. World-Harmony. Universal Principle of Form and

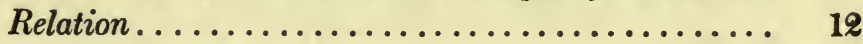

9. Cardinal Principle.................. 15

10. One Music........................ 15

11. Rationale of Music.................... 17

12. Common Reports of Common Feeling........... 17

13. Elemental Form...................... 22

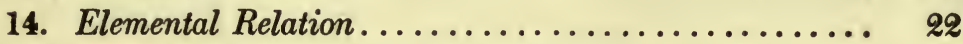

15. Melody, a Composite, not an Element......... 23

16. The Efficient Accent and Regnant Harmony....... 24

17. Principle of Potential Harmony............. 26

18. Basis of Verification.................. 27

\section{CHAPTER II}

\section{Rhythm and Tone}

19. Definitions........................ 30

20. Analysis of Rhythm.................. 31

21. Analysis of Tone.................. 33 
BEC.

22. A Tone's Harmonic Thread................ 35

23. Harmony in One Voice. Common Reports........ 36

24. Harmonic Evolution. The Major Tonic......... 40

25. Rhythm-Cadence and Rhythm-Repose......... 42

26. Tone-Cadence and Tone-Repose............ 45

27. Melody, Harmony and Rhythm........... 48

\section{CHAPTER III}

Original Dissonance and Consonance in One Voice

28. Genesis of the Major Consonance, Music's First Regnant Harmony ........................

29. Genesis of Cadence-Harmony or Original Dissonance in One Voice......................

30. Distinction between Original Harmony in One Voice and Chord-Harmony ................... 68

31. The Seven Original Tones. Analysis.......... 75

32. On Symbols........................ 86

33. The Five Components of Harmony........... 89

34. The Five Original Cadences. Mode Defined...... 91

35. Progression and Resolution................. 96

36. A First Music-Lesson................... 98

37. Work for Students.................... 101

\section{CHAPTER IV}

The Efficient Accent and Regnant Harmony of Melody

38. Regnant Harmony in One Voice and Its Principle of Genesis Explained.................... 102

39. Chords Derived from the Original Consonance and Dissonance in One Voice.................. 133

40. The Tone-Region. Its Diatonic Scales.......... 141

41. Musical Moments. Power and Originality of Music 149

42. Subrhythm and Rhythm-Expansion. Music's Classic

Form........................... 160 


\section{CHAPTER V}

\section{Origin and Nature of Minor}

SEC.

43. Origin of the Minor Consonance........... 176

44. Original and Duplicate Forms of Harmony ....... 184

45. Origin in One Voice of the Minor Form of Dissonance. Original Cadences of the Minor Mode...

46. Three Regnant Minor Harmonies and Their Bytones and Cadences....................... 198

47. Harmonic Percepts of Minor Origin........... 222

48. A Tone's Harmonic Pedigree................ 224

49. Chords Derived from the Minor Forms of Consonance

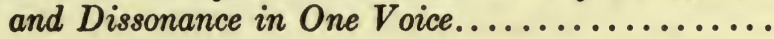

\section{CHAPTER VI}

Chords in the Light of Their Origin

50. Description and Summary of Chords Thus Far Derived.

51. Simple and Compound Chords Defined..........

52. Melody the Original Reporter of Harmony, Therefore the Natural Preceptor and Guide in the First Studies in Chords.............................

Bird Songs .......................... 291

Explanation of Symbol Numbers............. 305 Index ......................... 307 



\section{CHAPTER I \\ INTRODUCING FIRST PRINCIPLES}

\section{Questions}

ScIence has not yet fathomed the mystery of the origin and early evolutional stages of music. Our knowledge of the evolution of music is confined to the records of a few thousand years of history. Its history plainly shows that music has passed through progressive stages of evolution from simplicity to complexity. But how it began far back in the ages, the causes of its genesis, its shaping energies and forces, its essential nature, these and like questions still wait for a scientific solution. Sound emerges from and evanesces in silence. We assume that incalculable ages ago there was a time when music as yet unborn, unheard, lay dormant in silence, a mere potentiality. The evolutional study of music therefore begins with silence. All that is music is potential in and an evolution of an embryo, namely, the composite of elements upon the genesis of which depended the genesis of music. What is this composite? What are its elements? What is the principle or cause of their union? Where and how did and does this union take place? These are leading questions which confront us in this study. We investigate melody, rhythm, harmony, tonality, the tone-realm or tone-system. What are all these things? What is the origin and nature of each? 
Which are elements and which are composites? Which is the original and all-inclusive composite? the raison d'etre of all the others, in short, the essence of music? Theoretical predilections or subjective bias cause some of us to give the supremacy to melody, others to harmony. We still speak and write about "the intimate connection between melody and harmony," about "harmonized melody" and "melodized harmony." All this plainly implies a common belief that melody and harmony are separable. Are they, have they ever been separable or separated? If not, one of the two is an element of the other. In fact, one of the two includes, is the raison d'etre of the other. Which is it? Science has produced no final answers to these questions. Let any one, musician or layman, consult the testimony of his unprejudiced inner feeling and experience of music and he will say with Mozart, "Melody is the essence of music." I quote Mozart because he was completely free from theoretical bias. He felt and knew this to be true, he felt and knew it instinctively just as we all do. In other words, the truth of this common testimony of common feeling has not been scientifically proved. Nor has it been disproved. Why not? Primarily because the nature of its source, that is, the nature of common music-feeling, has not been fathomed. Yet the existence of this common feeling is everywhere recognized in the books, this feeling is the source of every truth that has entered the books, its testimony is everywhere appealed to and is our only resource in every last analysis wherever and whenever rules fail to apply or cannot be ascertained. The situation has a pe- 
culiar interest. We all share in this common feeling, yet do not succeed in translating it into common thought, do not succeed in expressing it in so many words. Unless this can be done it will be impossible to answer any of the above questions. If it really be true that melody is the essence of music, the original and all-inclusive composite of music's elements and principles, then it is also true that melody is the raison d'être of harmony, in other words, that harmony is and from the beginning always has been an element of melody. I shall endeavor to demonstrate in the following pages that this is true. But how can it be true? It is flatly contradicted by the entire history, theory and practice of music. All the books teach us that melody antedates harmony by unknown ages and that harmony was discovered and introduced only a few centuries ago. Is not this evidence conclusive, final, insuperable? Here let us ask a plain question. What do the books or authorities mean by harmony? Without exception they mean chords, that is, combinations or concords of several tones. No other form or conception of musical harmony has thus far appeared. To speak of harmony is to speak of chords. To study harmony is to study chords. Every treatise on harmony is a treatise on chords. It is the common belief and teaching over the whole musical world that the chord is the one and only, therefore by implication, the original form of musical harmony. The evolutionist has the hardihood to question the truth of this common belief and teaching, he does not regard the complex chord as a spontaneous generation, he reasons that so complex a form as the 
chord is rooted in and evolved from antecedent simpler forms of harmony, that the development of harmony is a progressive evolution from simple to complex which began with the genesis of music in one voice. This explains the subtitle of this book, "Original Harmony in One Voice." Everything hinges on the question of the origin and nature of music's specific forms of harmony, that is, of consonance and dissonance. All harmonists know that this question still remains unanswered. A single obstacle has stood in the way of its scientific solution, namely, the prevailing chord-idea and chord-view of harmony based on physical acoustics. The age of the chord reaches back a few centuries. The age of harmony reaches back through all the ages to the genesis of music in one voice. The development of original harmony in one voice occupies the entire period of homophony, the first and longest evolutional chapter in music and the most important chapter for scientific research.

\section{Homophony or Music in One Voice}

The term homophony is used in these pages strictly in the sense of music in one voice or part as distinguished from polyphony and chorded music in several voices or parts. The material for the evolutional study of homophony is complete. We find it in the simple songs of birds and primitive man, in ancient and mediæval melodies, in folksongs and dances, in modern music down to our own time, for the works of all the great composers contain countless motives, phrases and passages in one voice. Thus homophony, the 
form in which music first arose, survives to this hour. In essence and trend there is no difference between the homophony of to-day and that of all the past, between that of a song-sparrow and that of Bach, Mozart, Beethoven and Wagner. We here confront facts of prime importance. Homophony is the one and only form common to all music past and present. Homophony is therefore the one and only tie connecting all music of all time. Nowhere but in homophony can we study and discover origins, first principles and causes, the energies and forces from which music proceeds, the incipient stages of progressive evolution from tone to tone, relation to relation, harmony to harmony, in self-fulfilment of inherent laws, in short, nowhere else can we find the explanation of the essential nature of music and of common music-feeling. Hence the importance of homophony as a field for scientific research. Homophony presents and verifies its facts in a most unique and convincing manner since its reports completely exclude personal prejudice and eliminate the personal equation. The personal element of choice and bias did and does not enter into music until a second voice or part was and is added to a first voice or part, that is, until we add other voices to a given melody. Homophony discovers this remarkable psychological fact. Its reports are self-reports, that is to say, they are not what you and I or ten thousand others may think, elect and debate, they are what homophony itself elects, asserts and reports. These self-reports are common to all of us, they are the common reports of common feeling and apperception, moreover, they are immutable and discover the funda- 
mental data of music and music-feeling. In the field of homophony all investigators therefore stand on firm and common ground; here we set out with a common point of view and may join in a common purpose, namely, the translation of self-reports into the simple words of common thought. By nature we are all homophonists; the music-consciousness has its awakening in homophony; we sing and whistle homophony; each of us has the power within himself to produce and reproduce in feeling and thought any homophonic melody; each of us may observe, studyand analyze homophony at his leisure in himself and in others and may learn to translate its self-reports into words; each of us may verify these reports in himself and others; in short, the study of the psychology of homophony lies within the reach of every musical layman. The conditions for the evolutional study of homophony are favorable for another reason. The awakening of music-consciousness and the evolutional sequence of tones, relations and harmonies in the development of each individual musical mind correspond with the genesis and early developmental stages of music itself. Supposing then that the material representing the early stages of homophony did not exist, we could reproduce that material by tracing the psychological development of the musical mind from tone to tone, relation to relation, harmony to harmony.

\section{Origin of Music}

The origin of music is due to the union of two elements. The two elements are rhythm and tone. Rhythm was intoned, and forever after there was 
music. Let any one intone a simple rhythm and he will then and there unite the two elements and engender music in its original form of homophony. What is intoned rhythm? Simply, tone-rhythm, the original and indissoluble composite of music's elements and principles, the embryo in which all that is music is potential. What is rhythm? Universal form of motion. What is tone? The specific form of sound peculiar to music. What is this specific form? Harmony of sound, in one word, harmony. In music, a tone is and always has been a harmony. We shall see that the harmonies of music are the harmonies of relations, that they assume one of two forms peculiar to music, namely, the form of consonance or that of dissonance. The original forms of consonance and dissonance had their genesis in one voice, that is, they arose in homophony. Thus when we intone rhythm, each tone that we express is one or the other, a consonance or a dissonance. This is true of every tone in the homophony of birds and man. Subsequent analysis will show that the genesis of music depended on the genesis of its first harmony. The first harmony is the perfect or major consonance which we call the tonic. Let any one rhythmically reiterate one and the same tone thus: $|\rho| \rho, i \mid \rho$ etc. He will then and there engender and express the first harmony which far back in the ages emerged from silence and announced the genesis of music. At bottom, music per se is tone-rhythm. At bottom, our common feeling of music is the feeling of music per se, that is, the feeling of tone-rhythm. As we proceed let us bear the following points in mind. In music, tone is 
not separable from rhythm. All relations of tones are tone-rhythmic relations. All forms of tones are tone-rhythmic forms. Music's specific original forms of consonance and dissonance could not arise apart from rhythm. These original forms lie at once at the foundation of music and of common music-feeling. In our common feeling of music itself, as just defined, let us seek to discover the true nature and fundamental principles of music.

\section{Music-Feeling, the Source and Fountain of Music}

Where did and does this Union of Elements take place? Within the organism, within us, in feeling. Hence, music-feeling, the source and fountain of music. The harmonic forms of tone specific to music had their genesis in feeling and are the direct products of causes operating in feeling. The voice of music is an inner voice, a spiritual voice. Thus music dwells within, proceeds from within, is understood within. The germ or raw material of musical sound entered into feeling from without. But until that germ had been planted and had taken firm root in feeling it could not develop and blossom into the perfect tone or consonance upon the genesis of which depended the genesis of music. Feeling alone could, did and does transmute the raw material of external physical sound into the perfect harmonic form of tone with which music began. Why? Because the causes of this transmutation are psychical or spiritual causes which exist nowhere outside of feeling, that is, outside of the mind. These causes explain why it is that every first crude effort to intone rhythm is an 
effort to shape and express the perfect tone or consonance with which music began; they explain why it is that the perfect tone or consonance exists nowhere outside of feeling, outside of the mind. This is conclusively proved by the ascertained fact that under acoustical analysis every tone is a dissonance. But even the form of this acoustical dissonance is not the same as that of the original dissonance of music. That and why this is so is explained by the proximate or immediate cause of the psychogenesis of the specific harmonic forms of music. This cause is relation. A tone's specific relation is the immediate cause of its specific harmonic form. From first to last the original harmonies of music, headed by the perfect tone or consonance, arose one by one in an evolutional sequence of relations in obedience to an inherent shaping principle. As we proceed to trace the psychogenesis of this evolutional sequence of correlated harmonies we shall obtain a view of music in the light of its origin and development and so discover the nature of our common feeling of music. Let us be explicit as to exactly what is here meant by feeling of music. By music-feeling I mean simply and only the feeling of music per se, that is, the feeling of tone-rhythm, that is, the feeling of united rhythm and harmony, that is, the feeling of melody, the essence of music. Here at the outset let us understand that this study is not concerned with an analysis of feeling in its connection with any specific emotions, sentiments and associated ideas which are evoked by music. All these are most important precisely because they are purely personal, but their proper place is in poetry, 
autobiography and æsthetics. In a study like this such an analysis of personal experience would be out of place and would lead us into the cloudland of vagueness, mysticism and speculation. Here let us seek the common truth in our common experience of music. We shall, however, consider certain fundamental emotions, first because they are common to all of us and next because they are inseparable concomitants of tone-rhythmic feeling. The spirit and the matter of music are inseparably united as idea and form, as message and messenger of truth and beauty. The tone-rhythmic messenger is the bearer of the spiritual message. Our common knowledge of that message is confined to what can be learned from the messenger.

\section{Cause of Union. Shaping Principle}

Both rhythm and tone are forms of balanced motion. A shaping principle common to both is the cause of their affinity and union. This shaping principle is equilibrium. Equilibrium is harmony. Harmony is equilibrium. Tone-rhythmic equilibrium is tonerhythmic harmony. Tone-rhythmic harmony is tonerhythmic equilibrium. The feeling of tone-rhythmic equilibrium or harmony is our common feeling of music. The feeling of tone-rhythm and its shaping principle, while it explains why every initial effort to intone rhythm is an effort to shape and express the perfect harmonic form of tone essential to the genesis of music, it does not explain why that effort is made, that is, it does not explain the cause which gave and gives the impulse to that effort. What is this impelling cause? It is a spiritual cause, a common 
emotion, an inseparable concomitant of tone-rhythmic feeling, namely, the innate desire to shape and express with no other end and aim than the pleasure of gratifying that desire. This impelling desire of the inner life or human spirit to give form to its moods and tenses for pure joy and love of expression is the creative impulse to which all the arts owe their rise and development. Goethe's dictum "art is but form" is comprehensive, since form in art is the direct product of the human spirit and is not separable from the idea which it embodies. Equilibrium or harmony is the shaping principle of all form of motion, of all physical form of expression, of all spiritual form of expression. We are here confronted by a world-principle, a principle inherent in the physical and psychical forces, a principle governing all animate and inanimate form of cosmic expression. This universal principle of harmony and the principle of harmony in music are one and the same. This principle is the efficient cause of the genesis in feeling of the original forms of harmony, the evolutional antecedents of chords.

\section{World-Energy}

World-energy is manifested in motion. Its manifestations may be summarily divided as follows: First, motion in process. Second, record of previous motion or process. The first includes all sensible motion within and about us. The second includes all the forms or works of nature and all the works of man. All motion is accentual, wherefore all process and record of motion are accentual. 


\section{World-Rhythm. Universal Form}

World-motion is accentuated motion, in one word, is rhythm. Rhythm is form not law of motion. Let us not confound form, which is rhythm, with the principle or cause of form, which is inherent in and proceeds from energy itself. World-energy is manifested in world-rhythm. Hence this principle. Rhythm is the universal form of expression. At bottom, the terms expression, manifestation, language, are synonymous. Not man alone speaks. All things speak, each in its own peculiar language, but all in common rhythmic accents in time and space. Vibration, pulsation, undulation, are so many names for accentuated motion, that is, for regularly recurring periods of rhythm.

8. World-Harmony. Universal Principle of Form and Relation

World-rhythm everywhere makes for world-harmony, world-equilibrium. World-energy persists in its.perpetual rhythmic struggle for the maintenance of world-harmony, world-equilibrium. Hence this all-pervading, all-shaping, all-governing principle. Harmony (equilibrium) is the universal principle of form and relation in time and space. The universe is one rhythm-proceeding from one energy and maintaining one equilibrium to which the rhythm and equilibrium of all its parts from greatest to smallest are relative. Hence the harmony and unity of the universal whole, the interdependence and interrelation of all things, the reign of law and order 
in time and space. In this connection, harmony, equilibrium, balance, unity, are interchangeable terms. The ceaseless rhythmic struggle and "stream of tendency" within us and all about us ceaselessly makes for harmony. This rhythmic struggle and its governing principle are manifested throughout inorganic and organic nature in every movement and every form or record of movement. Harmony (equilibrium) is a fundamental principle of evolution. In fulfilment of this inner principle of "being and becoming," all things pass through rhythmic stages of progression and resolution, that is, rhythmic stages of evolution. Life from moment to moment is a rhythmic struggle for equilibrium. The works of man are records of his physical, mental, moral and spiritual struggle for equilibrium. In his musicworks man has recorded and will continue to record the essence of his universal and spiritual experience in his only universal and purely spiritual language, music. The realm of music, the tone-realm, is an evolutional product of the inner life or spirit; it is the spiritual counterpart and image of the universal whole, of its perfect law and order in time and space. Music is the concrete language of universal harmony, law and order. Music-feeling is universal feeling, that is, the concrete feeling of universal harmony, law and order. I emphasize concrete because all that is music and music-feeling is concrete reality, a concrete and vivid inner experience, a common experience in all of us. In music, rhythm is form, relation, law and order in time; tone (harmony of sound) is form, relation, law and order 
in space; the tone-rhythmic embryo or composite of the two unites pure time-form and pure spaceform, pure time-relation and pure space-relation; this composite, as we shall demonstrate, is melody, the essence of music, the free spirit of the free tonerealm. Melody makes for pure and perfect harmony in time and space and thus fulfils the inner law and purpose of its being. In our common feeling of melody we shall discover the identity of harmony and equilibrium. As we proceed to trace the evolution of tone-rhythm we shall observe the operation of this universal principle in the domain of the mind. Harmony (equilibrium) is the governing principle, the will of the material and spiritual universe. In the human spirit this principle manifests itself in a common emotion, in a common desire for and love of harmony, to gratify which is to be led by, to follow, to obey, the universal will. This spiritual desire and love discovered its voice in melody, rhythm was intoned; the heart thus found a perfect vehicle for all its moods and tenses. Hence music, its genesis, its raison d'être, its function, its messenger, its message. Thus music and its formative principle are deeply rooted in what Goethe calls "eternal things" and "the great whole;" its composite rhythmo-harmonic relations are what that poet-evolutionist calls "abiding relations." In the light of the principle of world-harmony I understand Schopenhauer's definition of music, "das innere Bild der Welt." 


\section{Cardinal Principle}

Harmony (equilibrium) as just defined is the cardinal principle responsible for the genesis and evolution of music and music-feeling, for all that is law, order, form, relation, proportion and structure in music. Thus all the principles and laws of music, of its elementary forms and their original relations and of the gradual expansion of its forms and relations, are so many different manifestations of the operation of this one all-shaping and allexplaining principle. Under the impulse of principles and laws operating in feeling music sprang into being and, passing through a series of natural and interdependent stages, evolved from simple to more and more complex forms, from a state of nature to an art. Nature-music and art-music differ only in degree, not in kind; the same fundamental principles and laws underlie both.

\section{One Music}

Nature-music includes the songs of birds and all those human melodies of the homophonic period in the production of which man was guided wholly by intuition and the impulses of the heart and simply obeyed his innate feeling of the principles and laws of tone-rhythm. This intuitional evolution of naturemusic reached its culmination in that lovely and perfect flower, the folksong. Nature had spent incalculable ages in the production of this perfect form of melody, had thus fulfilled her mission and laid the foundation for the art of pure music. From the 
simplest homophonic motive and phrase to the perfect symmetry of the folksong this nature-music is the pure music of intuition and the heart, the pure expression of concrete music-feeling. Nature had not only produced the germs which were destined to develop into the great art of pure music but had chosen, followed, prepared and pointed out the true path for the development of this art. This path of intuition and concrete music-feeling was chosen and followed by the only art of pure music which the world has produced. This pure art is modern music which is distinctively the product of Western civilization and the only music-art directly connected with and based on nature-music. Hence one music, one continuous evolution from the earliest beginnings of nature-music to the art of the present time. This one music is the only music which concerns us in these pages. Whatever else may be said of the manifold theories to which the modern art of music has given rise, one thing is true of all, namely, all seek to explain and conform with the nature and testimony of intuitive music-feeling in their common endeavor to discover and present the true principles and laws of the art of music. Man has produced other species of music-art whose forms and theories are not based on intuition and concrete feeling. An extinct art of this species is that of ancient Greece. An extant art of this species is that of China. Yet when we consider the beautiful tributes paid to music by Homer and Confucius we are led to infer that these two unmusical arts had been preceded by an evolutional period of 
nature-music when both Greek and Chinaman were guided by intuition and the heart, when like the birds they freely sang just as they happened to feel. Why in those two cases the natural attitude toward music was forsaken in favor of arbitrary theories is a question closely connected with the life and spirit of the two nations, a discussion of which does not enter into the plan of this book. Our subject has been defined, it is one music, in the nature-stages of which human selection was unconsciously governed by natural selection, in the art-stages of which human selection was consciously governed by natural selection.

\section{Rationale of Music}

The elemental what of music is form and relation of united rhythm and tone. The explanation of this form and relation, their inherent principles and laws, will discover not alone the true nature of this elemental what, but also answers to its how? and why? Elemental tone-rhythm and its indwelling principles and laws of self-development therefore constitute the what, how and why, in a word, the rationale of music. What? is the question of ultimate importance. Until this essential question is answered the inquiries how? and why? are futile since they lack a subject, since, in other words, we do not know what we are inquiring about.

\section{Common Reports of Common Feeling}

Whether their theories are based on acoustics, physiology or psychology, all investigators set out with a common view of the ultimate question What 
is music? a question so often set aside as an insoluble mystery. This common view of theorists is shown in three significant essentials the importance of which is greater than at first appears.

First: Admittedly or tacitly all premise that music is what we hear it to be and thus transmute the form of the ultimate question What is music? into What do we hear music to be? or briefly, What do we hear? That music is what we hear is not a remarkable observation for what else could it be? However, the question What do we hear? really means What do we all hear in common? and this question no one has as yet succeeded in answering. Second: At the outset all agree that what we hear is consonance and dissonance. This again transmutes the form of the ultimate question into What is consonance and what is dissonance? A scientifically verified answer to this question has not yet appeared in the books, and there are those who believe that this answer cannot be discovered in the three sciences mentioned above, wherefore it should be sought elsewhere.*

Third: All acknowledge the existence of such a thing as common music-feeling to which the appeal is general whenever and wherever laws and rules either fail to apply or cannot be found. This general appeal to music-feeling is equivalent to a general belief in its essential validity, a general belief that in it the ultimate and whole truth of music lies dormant, a general belief that the feeling is common to all. If there is such a thing as common musicfeeling, then there are such things as common music- 
perception, as common reports of common feeling verifiable by common observation. What are these common reports and their immutable principle? This question has not yet been answered. The answer to this question would discover the true basis of music and its science, it would be the initial step toward a common conception of the ultimate what of music, it would eventually result in a common recognition and adoption of the one true basis.

In these pages it is my purpose to show that such things as common reports verifiable by common perception do exist and may be clearly presented and explained. The ultimate question What is music? now assumes the following form: What are the common reports of common feeling and perception of consonance and dissonance, their inherent principles and laws? It is clear that this is a psychological question, a question addressed to the inner ear of the mind, a question of psychological acoustics, not of physical acoustics. Though this question places the present writing upon an independent basis and defines the writer's position, the psychology of this position still requires some explanation.

We are told by M. Hauptmann* that it is customary to begin a treatise on harmony with a learned chapter on acoustics the half-truths in which, however, have little if any influence upon and are often not again referred to in the subsequent chapters of the book. Acoustics treats the question What do we hear? on its physical side and therefore objectively, as every one knows. Music as we hear it does not 
exist objectively, as we shall see. The acoustic series, consisting of fundamental and overtones, teaches us that every tone is a dissonance and proves this to be a fact, and thus at the outset music and acoustics are irreconcilable antagonists. But this physical tone is not a dissonance in the specific musical sense of the term; it is in truth a discord, and discords have nothing to do with music. Although it is the custom in music-treatises to present only the first six tones of the acoustic series, yet this arbitrary omission of the remaining objectionable because discordant overtones does not eliminate them, they are there just the same, and are met as they should be by physical science. Whatever be their pitch all tones have the same internal physical formation, therefore all tones are discords. If one tone is a discord what a blood-curdling horror such an amorphous physical composite as the chord ought to be! But common music-feeling and perception reject all this as false. If we really heard tones in their actual physical forms all hands would be raised to stop the ears. Notwithstanding all this most of our music-theories are based on physical acoustics; a scientific basis for music being required, and no other being at hand we seize upon physics for an initial chapter. Music's pure and perfect consonance, music's specific form and relation of tone, these things do not exist objectively, they are subjective products of psychological development, direct products of music-feeling, which is the feeling of composite rhythm and harmony. Roughly stated, elemental tone-rhythmic feeling impelled by an 
inherent immutable principle, equilibrium, has resolved objective physical sound or discord into subjective harmony.

The rejection by music-feeling and perception of physical acoustics as a basis directly points to psychology for the solution of music's ultimate problems and the discovery of music's cardinal principle. Though the conviction that there is such a principle has often been expressed the psychologist has thus far been unable to explain what it is; he has left the true nature of common music-feeling shrouded in mystery and, like the physicist and physiologist, has left the problem of consonance and dissonance unsolved. The psychologist has followed one of two courses: either he has made a comparative study of music and music-feeling in the light of the data of physics and physiology, like C. Stumpf, or he has delved more or less deeply into metaphysical speculations and æsthetics. The physiologist deals with the physical organ of hearing and its function, and in his hands the question What do we hear? assumes the form How do we hear? which is a subordinate question that predicates a knowledge of music's ultimate what. When psychology has once answered the ultimate question, then only will physics and physiology gain a legitimate subject for musical research the importance and value of which to music can 'alone be estimated in the future.

The writer's position thus roughly sketched may be summed up as follows: The true nature of music per se, of its specific forms and relations, of its 
inherent principles and laws, are problems of psychology the solution of which can alone be found in what I have called the common reports of common feeling verifiable by common perception.

\section{Elemental Form}

Form is vehicle or messenger, not message, but bearer of message. We are here primarily concerned with the messenger, not with the message of music, since all that can be learned of the latter depends upon what can be learned of the former. The two should not be confounded. Elemental form or messenger of music is united rhythm and tone. In this elemental form lies music's elemental truth and beauty, the study of which involves neither vagueness nor speculation and alone concerns us in these pages. Vague, mysterious, inscrutable, yet none the less real and important is the spiritual message of music, a message of universal harmony and unity. However, the spiritual message of truth and beauty, the emotions, poetic and religious sentiments and the æsthetic and metaphysical speculations and theories to which it gives rise, belong not to music alone, but to all the arts and to all things. By the word feeling in connection with music I mean simply and only feeling of united rhythm and tone, which is musicfeeling per se and common to all of us.

\section{Elemental Relation}

A tone's relation in time is its rhythmic relation. A tone's relation in space is its harmonic relation. Thus tone-relation is a composite of time-relation 
and space-relation, in one word, is a rhythmo-harmonic relation. Every tone in music is heard, felt, thought, expressed and recorded in such a composite relation, every tone-moment is a rhythmoharmonic moment. It is true that in analysis we seem to separate this composite, now observing the rhythmic form and relation and now the harmonic form and relation, yet we do not and cannot fully comprehend the one apart from its relation to the other. The word harmony in its specific musical sense means harmony of sound, which is tone. In this sense one tone, every tone is a harmony, as will be explained in the next paragraph.

\section{Melody, a Composite, not an Element}

Nothing could be more untrue than the timehonored teaching and belief that melody, harmony and rhythm are the three elements of music. Music has two, not three elements. Rhythm is an element. Harmony (tone) is an element. Melody is not an element. Melody is a composite of music's two elements, rhythm and harmony (tone). It is impossible to conceive of melody either without rhythm or without harmony (tone). Hence the obvious truth that melody is a composite and not an element. Everything from a motive in two tones onward, whether it issues from the throat of a bird or was penned by a classic composer, is a melody, a composite of rhythm and harmony (tone). Melody is the essence of a music-idea or thought. Melody is the original and essential vehicle of music. Melody is the original, universal and sovereign voice and 
genius of music. Conversely, music ever has been, is, and ever will be melody. Melody is the raison d'être of music's harmony. Why this rhythm? Why that harmony? The answers to these questions lie in melody. Love of music and love of melody are one. No melody, no music-idea or thought. No melody, no harmony. No melody, no music. The great and greatest in music are its melodies; types in music are types of melody and from first to last music's great masters are melodists.

The above conclusions are verified by common report of common feeling and perception of original harmony in one voice. In a book ${ }^{1}$ published in 1890 , the writer introduced the subject of harmony in one voice naming it meloharmony, the inherent harmony of melody.

\section{The Efficient Accent and Regnant Harmony}

In a preceding paragraph it was stated that the principles and laws of music are rooted in the cardinal shaping principle, equilibrium. The rhythmo-harmonic forms and relations of music in one voice or homophonic melody discover the nature and operation of two evolutionary principles which next require provisional introduction and explanation. First and most important of the two is the efficient accent which is the efficient cause of the genesis of tones and tone-relations, that is, of music's specific and basic harmonies.

The efficient accent is the heavy periodic accent of rhythm, it is the harmony-generating and harmony-

1 The Septonate and the Centralization of the Tonal System. 
maintaining accent of music. Under the name rhythmo-harmonic accent or point, I presented this subject fourteen years ago in the book abovealluded to.

In one-voice music, not only is each tone in a melody a harmonic, that is, a root or third or fifth or seventh or ninth, but every moment in a melody is ruled by a particular harmony which I call the regnant harmony.*

In one voice the regnant harmony arises on the line of least resistance, it elects and asserts itself, it is generated in feeling by the efficient accent, it determines and reports the exact harmonic form and relation of each tone; these forms and relations are immutable, since in every given case we all of us hear and perceive the same form and same relation.

We shall see that the original harmonies entered into being one by one as integral and correlated threads of an ever increasing web of forms and relations in an orderly sequence of regnant harmonies, a sequence which nolens volens repeats itself in the development of every musical mind, thus establishing a traceable psychological connection between music's present and past. We cannot study and trace this evolutionary sequence and psychological development in multi-voice music for the simple and obvious reason that in such music the regnant harmonies are due to personal election, fancy and taste. In one voice the regnant harmony elects itself, while in more than one voice the choice of harmonies is personal. In one voice we perforce agree, while in several voices we are at liberty to disagree. 


\section{Principle of Potential Harmony}

The next evolutionary principle to be introduced is that of potential harmony, which I define as follows: Every harmonic relation in experience is potential in every tone in experience. Thus all harmonic relations are potential in all tones. In other words, any harmonic relation may be duplicated on any tone. Let us explain.

There are original tones, original harmonic forms, original harmonic relations. The seven tones of the major scale constitute the first group of original tones. Certain of these tones first arose in the harmonic form of consonance, certain others in that of dissonance. This specific consonance and this specific dissonance are therefore the original harmonic forms. Again, each of these seven originals first arose in a certain definite harmonic relation as a root or third or fifth or seventh or ninth. The original relation of a tone is therefore the relation in which a tone first arose. Everything is and has been derived from relation; harmonic form and harmonic relation are connate; the former is due to the latter, the former changes when the latter changes. Since each original tone entered into being in a certain original relation, the fundamental importance of relation is manifest.

In the psychological process of development each tone and relation entered into experience first as a mere feeling, it remained latent in feeling until it was seized upon by consciousness when it became a percept, and last of all it became a concept. The 
harmonic idea of music is therefore a complex of harmonic percepts, each of which is either an original harmonic relation, or has been derived from an original relation. How derived? Through the evolutionary principle of potential harmony in coöperation with the efficient accent, the principle of harmonic genesis, roughly as follows: Each tone's original relation is duplicated on other tones. For example: the tone known as the Tonic (also called keynote) first arose as a root and eventually appeared as third, fifth, seventh and ninth, thus duplicating the original relations of other tones. Like duplications were in time effected on other original tones which had their genesis in other relations. We shall see that these duplications are responsible for the genesis of new tones and new harmonic relations thus opening the way to new duplications, and we shall see that the expansion of harmonic relations and of the tone-system is the direct product of this psychological process, in short, that harmonic relation and our tone-system are inseparably linked in their development as cause and consequence. But how did the seven original tones arise? How did the first consonance and first dissonance arise? Unless these origins can be explained the principle of potential harmony has no material to develop, no valid basis to rest on, is but an empty phrase. The above questions will be answered in the two subsequent chapters.

\section{Basis of Verification}

A brief summary of the position outlined in the preceding paragraphs will lead the way to a simple 
explanation of how the test of truth is to be applied in the subsequent study and analysis of music. The essential points are as follows:-

The "being and becoming" of music are due to the union in feeling of rhythm and tone.

Form and relation are form and relation of united rhythm and tone.

All tones are harmonic. Original harmony is harmony in one voice; it asserts itself and is latent in common music-feeling, therefore in all of us. Harmony in one voice reports the same relations in all of us.

Melody is the composite of the two elements, rhythm and harmony (tone); it is the original and universal voice of music.

Common music-feeling is united rhythm-feeling and tone-feeling.

One music, one basis of music, one common musicfeeling, one all-shaping principle in which all principles and laws are rooted. This cardinal principle is equilibrium, is common to and inherent in both rhythm and tone, and is the cause of their union, and it dwells and operates in common feeling in all of us.

All who take any degree of pleasure in music are musical and share in the common feeling. All such may by guidance and study transmute latent feeling of united rhythm and tone into definite observation, intelligent appreciation, understanding.

Community of feeling leads to community of perception and thence to community of conception. All may learn the common reports of common feeling and verify such reports by personal observation. 
The test of truth here indicated is the simplest. What all perceive or observe in common is the truth. Truth is the correspondence of an expressed idea with common experience. The truth of music lies in music itself, in music stripped of all associated ideas and sentiments; it lies in tone-rhythm, and in tonerhythm we will seek it. Two simple examples will illustrate our test of truth.

1. Whether we know it or not we all feel and express a dual rhythm in dual periods, a triple rhythm in triple periods. Hundreds and thousands sing, beat time and march to the music of a national air in complete ignorance of the rhythm which they feel and express in common. However, the moment we learn to observe a dual rhythm by its dual periods and a triple rhythm by its triple periods, we all acquire the same knowledge in the same way, namely, by transmuting a common feeling into a common perception or observation.

2. Whether we know it or not we all feel and express tones as roots, thirds, fifths, sevenths and ninths, some in cadence, some in repose. The same hundreds and thousands feel and express these harmonic relations of tones with the same complete ignorance of what they are. When these harmonic relations are learned they are learned in the same way, namely, by transmuting common feeling into common observation. 


\section{CHAPTER II}

RHYTHM AND TONE

\section{Definitions}

Rнүтнм is balanced motion. Tone is balanced sound.

Rhythm is order, form and relation in time. Tone is order, form and relation in space (pitch).

Rhythm is harmony (equilibrium) in time. Tone is harmony (equilibrium) in space (pitch).

United rhythm and tone is united order, form, relation and harmony in time and space.

The elemental forms and relations of rhythm which underlie all music-rhythms are not specific to music, they exist everywhere.

The elemental harmonic forms and relations of tone which underlie all harmonic forms and relations of music are specific to music, they exist in music alone.

Numbers are symbols of order and relation. The numbers 2 and 3, their multiples and combinations are the symbols of rhythmic order and relation of tones, of order and relation in time. The numbers $1,3,5,7,9$ which indicate a root or fundamental, its third, fifth, seventh and ninth are the symbols of harmonic order and relation of tones, of order and relation in space (pitch). 
20. Analysis of Rhythm

Rhythmic balance is generated and maintained by regularly recurring accents. Common rhythmic feeling impels us to follow up an initial group of two pulses by another, two such groups by two more, and so on. Likewise we are impelled to follow up an initial group of three pulses by another, two such groups by two more, and so on. Examples are given:

1. TWO-PULSE RHYTHMS

a)

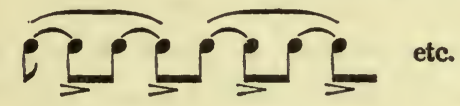

b)

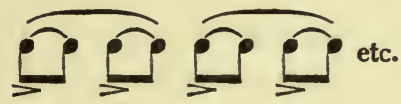

2. THREE-PULSE RHYTHMS

a)

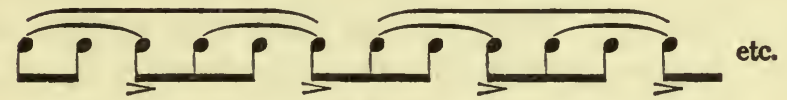

b)

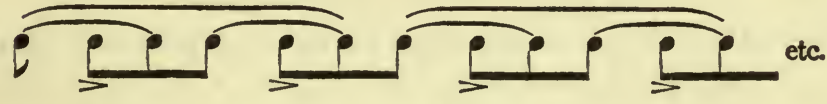

c)
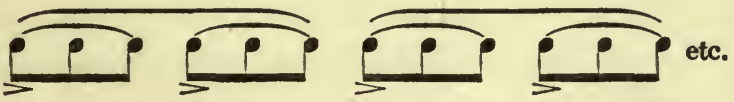

Our spontaneous desire to arrange pulses in regular accentual groups, and to repeat and develop an initial group, is no more nor less than the natural desire to keep balance, to keep time, to obey the inherent and innate shaping principle, equilibrium. To keep time is to keep balance, to keep balance is to keep time. 
In the above examples each pulse, each group of pulses, each combination of groups, is a period of rhythm. Henceforth in these pages the term period will be employed exclusively in this connection with rhythm. Rhythm-periods are balanced time-periods. Rhythmic accents are balance-generating and balancemaintaining time-accents. A period of time is a rhythmic moment, a time-accent is an accentual moment in feeling and consciousness. Under the sway of innate rhythm the inner consciousness moves forward in time from pulse to pulse, from accent to accent, in other words, from moment to moment, from now to now. We shall analyze this forward movement in time, and shall study the psychology of this moment, this accent, this now; it holds the secret of music and of common music-feeling.

Rhythmic feeling, in obedience to the indwelling shaping principle, impels us to vary the accents of successive pulses or moments so that heavier accents so alternate with lighter accents that they recur at regular intervals of time, thus forming regular groups and maintaining the rhythmic balance. In the above examples the sign > indicates the heavy accents, and the examples show that the difference between one elementary rhythmic form and another is a difference in the order of heavy and light accents. Thus the two forms of dual rhythm are light-heavy and heavy-light, while the three forms of triple rhythm are light-lightheavy, light-heavy-light, heavy-light-light. All musicrhythms are based upon these five elementary forms. These accents of varying intensities, their regular alternations and the recurrent heavy accents are of 
the utmost importance; their psychology will discover the hitherto overlooked key to the origin and true nature of music's specific and basic harmony.

Metre and rhythm are not alone often confounded, but are sometimes treated as identical, which is wide of the truth. Rhythm is not metre, metre is not rhythm, neither in music nor in versification. Metre is measure of rhythm-periods, that is, of time-periods of tones. Our metrical symbols are symbols of measurement; they symbolize rhythm, time. Metrical accents so-called do not exist. Feeling of rhythm came first, perception of rhythm came next, metrical and numerical symbols of rhythm came last.

\section{Analysis of Tone}

Sound that wavers in pitch is unbalanced, is unmusical, is not harmonious, is not tone. Sound maintained at an unwavering pitch is balanced, musical, harmonious, in a word, is tone, the unique voice of music. The shaping principle, equilibrium, which is inherent in common feeling, impels us to make for balanced sound or tone just as it impels us to make for balanced motion or rhythm. So long as we maintain sound at an unwavering pitch, so long do we generate in feeling the perfect balance or harmony of tone. This pure harmonic form of tone to the genesis of which in feeling music owes its origin and existence is the major consonance, music's first or original consonance which to-day we call the Tonic-harmony of the Major mode, the harmony of complete repose. This perfect tone or harmony opens the first chapter of tone-genesis, a new subject in our science; it is an 
inner product of feeling, has no existence outside of feeling and now requires psychological analysis. In thought or voice maintain a sound at an unwavering pitch and you will generate this perfect tone or harmony in feeling. Whatever the pitch may be the result will be the same. For convenience and clearness of illustration therefore we will suppose the pitch to be that of $\mathrm{C}$. While mentally sustaining this tone we are at first conscious only of a single tone as at $a$ ) in the example below. Analysis will, however, soon discover that instead of sustaining only a single tone we are in truth sustaining a harmonic complex of tones comprising a root or fundamental, its major third, pure fifth and octave, as shown below at $b$ ).

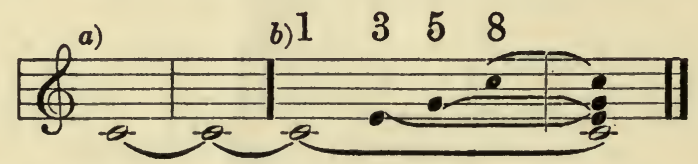

To be more explicit, while at first, we are conscious only of the single tone $\mathrm{C}$, which is a root or fundamental, analysis soon discovers the presence of a third (E), a fifth (G) and an octave (C), which are concomitant elementary tones or harmonics and which together with the root make up the harmonic form of this isolated tone. Hence this truth: Every isolated tone is a harmonic complex of root and elementary harmonics, that is, a composite of root, major third, pure fifth and octave; in short, an isolated tone is always a major consonance. Each reader may verify in and for himself that this is so; why it is so will be explained presently. The fact here requiring emphasis is this: An isolated tone always reports itself 
as the root of a major consonance. The word root defines the harmonic relation; the term major consonance defines the harmonic form. We shall soon find tones reporting themselves as a third or fifth of this consonance and in many other forms and relations. In each of these relations we shall discover that the tone arises in the mind together with elementary harmonics, that the form varies with the relation, that the form and relation of every tone are therefore harmonic; in fine, that every tone is a harmony. Meanwhile the original major consonance requires further analysis.

\section{A Tone's Harmonic Thread}

The harmonic complex which a tone generates and reports in common feeling may be called the harmonic thread of a tone. The harmonies of music form a closely wrought web of innumerable harmonic threads. Consciously and unconsciously we feel a tone's harmonic thread, but unless we accurately observe its harmonic thread we cannot appreciate the exact form and relation of a tone. The thread of the major consonance in the above example presents a root, third, fifth and octave. Each higher and lower octave is another root of a like series of harmonics wherefore we may change the octave-number 8 into a rootnumber 1 as follows:-

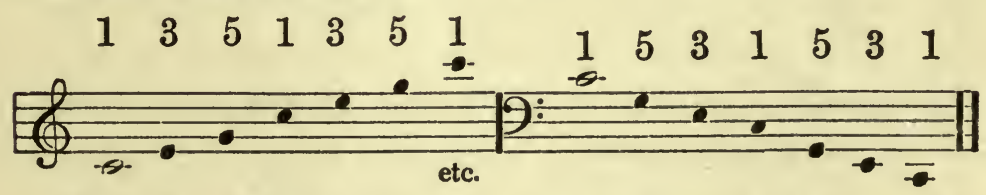

This shows that the harmonic thread of a major consonance extends through the whole range of tone- 
pitch. Once generated in feeling we move at pleasure up and down from tone to tone on this thread taking the tones in the above order or making leaps, since in doing this we but follow the line of least resistance in obedience to the inherent shaping principle, equilibrium. This first of music's harmonic threads introduced a variety of intervals into experience, namely, the pure octave, fifth and fourth, major and minor thirds, sixths and tenths, as shown below:-
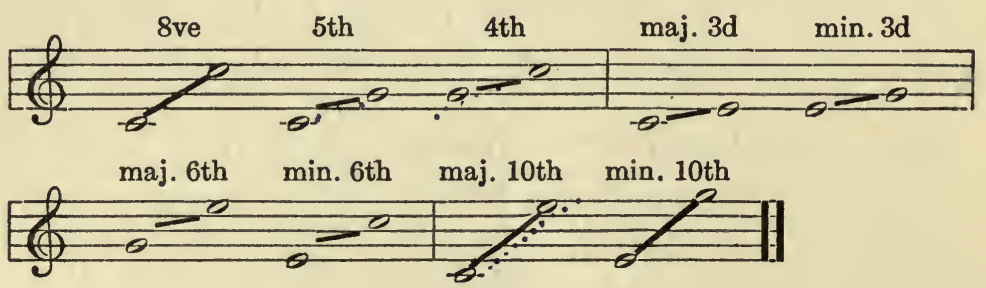

There is however something vastly more important than these intervals or steps from tone to tone. It is the tones themselves which give rise to all these intervals and which resolve themselves into three harmonic percepts, namely, a root, a major third, a pure fifth. Briefly, each tone in the above intervals is one of these three harmonic percepts. The harmonic percept is therefore the thing of primary importance, the essential thing to understand and to know. As we proceed it will be well to bear this distinction between an interval and a harmonic percept in mind.

\section{Harmony in One Voice. Common Reports}

As we have seen, the major consonance is a complex of three tones or harmonics. Like the root, each of the other two tones generates in feeling the entire 
consonance-thread, therefore each includes the other two as concomitant elementary harmonics, or briefly, as concomitants. Thus the root includes third and fifth as concomitants; the third includes root and fifth as concomitants; the fifth includes root and third as concomitants. All three appear in the following melody, in each tone of which we all hear and feel the same harmonic complex or form and the same harmonic relation as specified by the harmonic numbers $1,3,5$ over the notes.

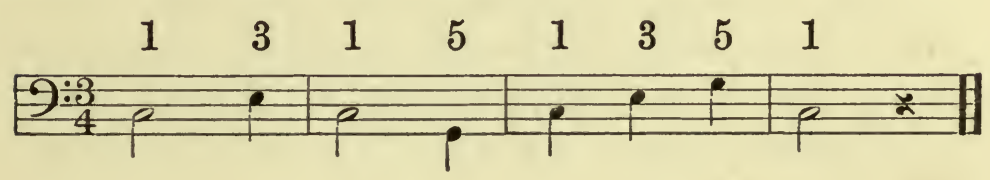

This provisionally illustrates what I mean by original harmony in one voice, which asserts and reports itself without chords. The numbers $1,3,5$ explain what I mean by the common reports of common feeling and perception, since they faithfully register the inherent relations which we all hear and feel in common. The number 1 indicates a root. The numbers 3 and 5 imply a root and indicate the relation of a tone to its root. I have said that an isolated tone generates and opens up its thread of harmony both above and below and that we follow the thread up or down at will. In the above melody we move from root up to third, then back to root, then down to fifth and so on. That every tone arises in a thread of harmony is not the only point to be emphasized. In this melody we are now on a root, now on a third, now on a fifth of a thread. The word now is used with pur- 
pose. It means that each tone fills a moment in consciousness, a rhythmic moment or period of time; it means that in music a tone is indissolubly united with rhythm from the moment it enters until it makes its exit. In its rhythm we find the time-relation of a tone. In its harmonic thread we find the pitch- or space-relation of a tone. Rhythm or balanced motion, and tone or balanced sound, are thus inseparably united. This union of two balances or harmonies of time and space, which holds the secret of music's original harmony, requires careful analysis. This moment of union, the product of which is pure harmonic tone, is an accentual moment. The principle of harmonic genesis I have already named the efficient accent.

The subject of original harmony in one voice and its common reports here introduced may now be more fully illustrated by a few examples which contain other tones, harmonic relations and harmonic percepts which will be explained in the proper place. At present it is enough to demonstrate that such things as harmony in one voice and common reports really exist. The first example adds four other tones, a number of other harmonic relations and two other harmonic percepts, the minor seventh and major ninth:-

(') $\quad \begin{array}{llllllllllllllllllll} & 3 & 1 & 5 & 3 & 3 & 5 & 9 & 3 & 1 & 7 & 3 & 3 & 1 & 3 & 7 & 3 & 5 & 3 & 1\end{array}$

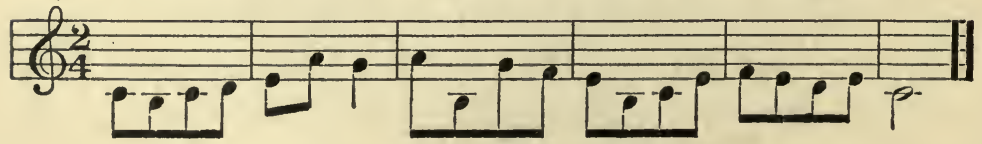

1 The harmonic numbers indicate either root or relation to root. These numbers are large for major and small for minor intervals. From Chap. III. L. E. K. 
The next example adds two chromatics:-

$$
\begin{array}{lllllllllllllllll}
1 & 3 & 5 & 3 & 1 & 7 & 3 & 1 & 3 & 7 & 5 & 5 & 5 & 3 & 5 & 1
\end{array}
$$

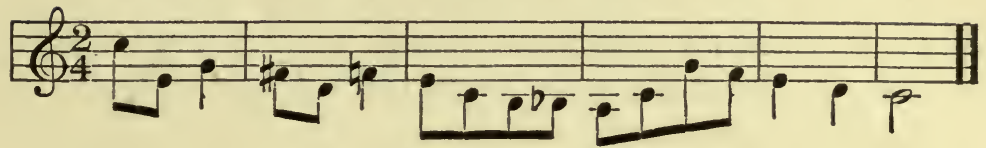

The harmonies and harmonic relations reported in these melodies assert themselves spontaneously; they are immutable because common to all of us; you cannot change them unless you add other voices or chords; but even though you add only one more voice, in so doing you add something of your own choice and are no longer dealing with harmony in one voice, which chooses itself. In order to understand the sequel it is imperative that this distinction between that which elects itself and that which you and I elect should be clearly apprehended. The common reports of selfasserting harmonies and harmonic relations are specific to music in one voice. I have made observations for more than twenty years and have met no one even of moderate musical endowment, whether child or adult, whether student, musician or layman, who did not readily appreciate a tone's inherent harmony and therefore harmony in one voice. For the first time in our science we find in these common reports of harmony in one voice the explanation of the genesis and development of tonality and of our tone-system. In passing it may be stated that our tonality and our tone-system are inseparably linked in evolution as cause and consequence. 


\section{Harmonic Evolution. The Major Tonic}

The evolution of music's harmonies beginning with the genesis of the major consonance is a psychological process as beautiful as it is simple. Harmonies have succeeded each other one by one in an orderly and clearly traceable sequence of antecedents and consequents, perhaps the only complete sequence of any kind thus far presenting itself to psychology and therefore of importance to that science. Apart from original harmony in one voice and its inherent principles this evolutionary sequence of harmonies could not be traced. Why? Because harmony in one voice asserts itself and its reports are common reports and it excludes the personal equation. When we consider that there is such an evolutionary sequence and that the first series of harmonies in this sequence is repeated nolens volens in every developing musical mind, we readily realize the signal importance of this sequence alike to the science and history of music and to musiceducation. The harmonies of the individual tones in the above melodies are latent in all of us, each tone being a harmonic complex containing elementary harmonics or concomitants. We have seen that an isolated tone at first appears to be a single tone, that later we discover it to be a complex of root, third and fifth. This third and fifth were always present in the tone as elementary harmonics or concomitants. A tone without concomitants does not exist. This third and fifth were therefore latent in feeling and eventually they were perceived and differentiated, whereupon they were expressed in melody and together with 
their common root became the harmonic basis of tonality. We shall see that newly differentiated tones in their turn generate new harmonic complexes containing new elementary harmonics which in their turn are differentiated and generate new harmonies with new elementary harmonics, and so on. This psychological change from latent feeling to perception and expression roughly describes this evolutionary process.

The tonality of the major consonance of an isolated tone has already been identified as the Tonic of the Major mode. Alike we all feel its purity, stability, repose, perfect balance and unity; to all it is a centre of gravity, restful and satisfying. We have explained all this as due to its perfect harmonic form, this unique form as due to the union of elements, this union as due to the inherent shaping principle, equilibrium. However, the mere fact that an isolated tone is always a major consonance and always the Major Tonic, though so obvious, does not suffice. It requires explanation. Why does an isolated tone always report this consonance? To say that the shaping principle is the vera causa is but a statement and does not answer this question. It therefore remains to explain how this principle operates, how it shapes these harmonies in feeling. The above melodies present roots, thirds, fifths, sevenths and ninths. Each tone arises in a thread of harmony. On certain tones the harmony changes: one tone now reports itself a root and now a fifth; another tone reports itself now a third and now a ninth; another tone reports itself now a seventh and now a root. Analysis will show that all these harmonic complexes, percepts and relations are due to the in- 
fluence of rhythm as implied by the word now. A tone being an accentual moment, a series of tones is a series of accentual moments. We will study and analyze these accentual moments. I have already said that they hold the key to the harmonic form and relation of tone, which is the secret of music. This key is latent in all of us; all may discover it.

\section{Rhythm-Cadence and Rhythm-Repose}

The analysis of rhythmic periods of time is the subject before us. Each period is marked by an accent. Some accents are heavier, some are lighter. Heavier and lighter accents alternate in such a way that the heavier accents recur regularly in time. These alternating accents are alternating accentual moments. Periods marked by heavier accents are called heavy periods, those marked by lighter accents are called light periods. Heavy periods marked by heavier accents are moments of stability, repose, balance, centres of gravity, moments of equilibrium. Light periods marked by lighter accents are moments of instability, unrest, unbalance; they are in relative equilibrium, in cadence; they impel us to move forward to a heavy period for repose, balance. Rhythmically we are therefore in cadence on lighter accents, in repose on heavier accents. This rhythmic movement of regularly alternating cadence-moments and reposemoments is illustrated below:-

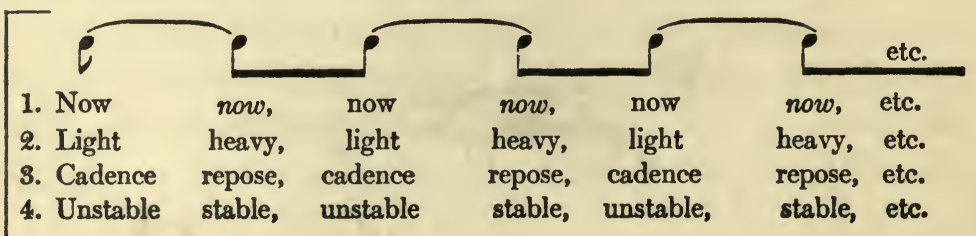


The four texts in this example describe and analyze our common feeling and perception of elemental dual rhythm. The alternating accentual moments marked now-now are explained by the terms light-heavy, cadence-repose, unstable-stable equilibrium. Rhythm, as I have previously stated, is the universal form of expression, all form of expression being either process or record of the rhythmic accentuation of energy making for equilibrium. Hence we speak of the universe as one energy, one rhythm, one equilibrium. It is common to speak of accented and unaccented tones in music and syllables in poetry, but in truth there are no unaccented tones or syllables. Every movement of energy in the whole universe, be it ever so slight and delicate, is an accent. Moreover, all movements are in correlation, wherefore all accents are relative and the term light-heavy expresses this relativity. We cannot therefore truly speak of one movement or accent since movements and accents succeed each other periodically and are inseparably related as light-heavy. Regular alternations of light and heavy accents appear in walk as well as in march, in run as well as in dance, in speech as well as in song, in prose as well as in poetry, in all work as well as in all play, in all movements of body, mind and spirit. Observe, for example, the nondescript sounds which we spontaneously utter in place of the affirmative yes and negative no. The order of relative accents in the former is light-heavy; in the latter it is the reverse, heavy-light. These relative accents are the same in our expression of yes and no by a movement of the head. In nodding yes the head moves slightly backward on a 
light accent and is then brought forward on a heavy accent. In no the head is jerked to one side on a heavy accent and then moves back on a light accent. Similar dual movements and successions of relative accents appear in our spontaneous positive and negative gestures. Positive certainty, conviction and assertion are expressed by raising the hand on a light accent and bringing it down on a heavy accent. Uncertainty, surprise and interrogation cause us to raise the hands on a heavy accent, then to relax and drop them on a light accent. Down-accents are heavy accents of positive gravity.

This analysis shows that every rhythmic moment in consciousness is either a repose-moment or a cadencemoment. Rhythm-repose is perfect balance; rhythmcadence is relative balance tending to perfect balance. This relation of cadence and repose is inseparable in our feeling, percept and concept of rhythm. In other words, there must be a play of light accent upon heavy accent, else there is no feeling or perception of rhythm. The play of one light accent upon a heavy accent is the embryonic form of rhythm, and a motive consisting of two such accents is the shortest conceivable motive in music. This inseparable relation of cadence and repose is an important fact as we shall presently see. Of the two elements, rhythm and tone, rhythm is first, universal and fundamental, while tone owes its specific musical form to rhythm. Cadence and repose first appeared in rhythm, and their inseparable relation is the basis of all rhythmic form and relation in music. The study of this relation in tone is our next step in analysis. 
26. Tone-Cadence and Tone-Repose

Every tone in music is in cadence or in repose. Tone-cadence originated in rhythm-cadence. Tonerepose originated in rhythm-repose. Not only are tone-cadence and tone-repose directly derived from rhythm-cadence and rhythm-repose, but this relation of cadence and repose is inseparable in tone as it is in rhythm, it is the basis and explanation of the harmonic form and relation of tone as it is that of rhythmic form and relation. These truths assert themselves overwhelmingly in our common feeling and perception of every measure of music; they report themselves moreover in every measure of music in one voice, in which they first arose. The connection of the two truths, first, that all tones are harmonic, second, that all tones are either in cadence or in repose, straightway leads us to the logical conclusions that there is an original cadence-harmony as well as an original repose-harmony, and that in their genesis these two harmonies are inseparably related, that both cadence-harmony and repose-harmony arose one in relation to the other, in short, that they arose together. This inseparable relation of cadence and repose is the key to the mystery of harmonic form and relation of tone called consonance and dissonance, the subjects of the next chapter, in which the truth of these conclusions will be subjected to the explanation and test of common reports of common feeling and perception.

The major consonance of an isolated tone already identified as the Tonic-harmony in Major is the original repose-harmony, and its three components I name 
repose-tones. Over and under these repose-tones and in relation to them have arisen four other tones which tend, some up, some down, into the three. These four are components of the original cadence-harmony, and I name them cadence-tones. Repose-tones had their genesis on heavy rhythmic accents, cadencetones on light rhythmic accents. If it is true that cadence-harmony and repose-harmony could not have arisen except in inseparable relation one to the other, how are we to explain the undeniable fact that the repose-harmony not only came first and was first voiced in melody, but came alone and unattended by any other harmony! Granting the inseparability of the relation of cadence and repose and the interdependence of their respective harmonies, how is it possible to explain the origin of the repose-harmony except it be the direct result of the resolution of a previously existing cadence-harmony. This is a subtle point, and it strikes at the root of the problem to be solved. Subsequent analysis will show that the genesis of this unique major consonance or repose-harmony was due to the resolution of a latent feeling of dissonance or cadence-harmony. The three original repose-tones and four original cadence-tones, which together represent the seven diatonics of the Major mode, are the subjects of our next example:-

a)

b)

$\begin{array}{lllllll}1 & 3 & 5 & 3 & 5 & 7 & 9\end{array}$

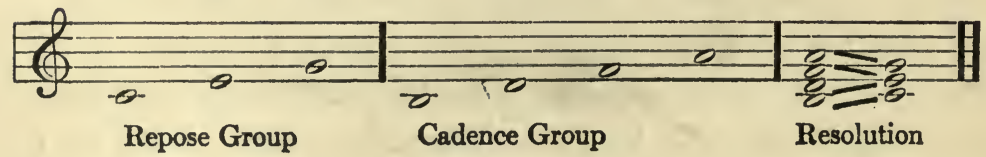


The Major Tonic is the root of the original reposeharmony. The Major Dominant is the root of the original cadence-harmony. This Tonic-thread comprises root, third and fifth. The Dominant-thread comprises root, third, fifth, seventh and ninth. Though the root of the Dominant-thread is omitted at $b$ ) and $c$ ) the four cadence-tones report this to be their common root and harmony as the numbers imply. The two subjoined melodies include both groups of tones, and the accompanying numbers indicate the common reports of original harmony in one voice:-

a)

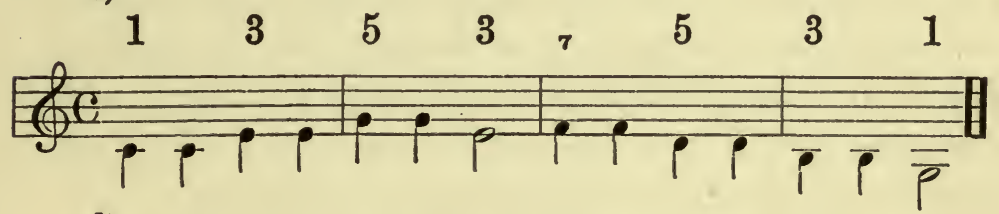

b)

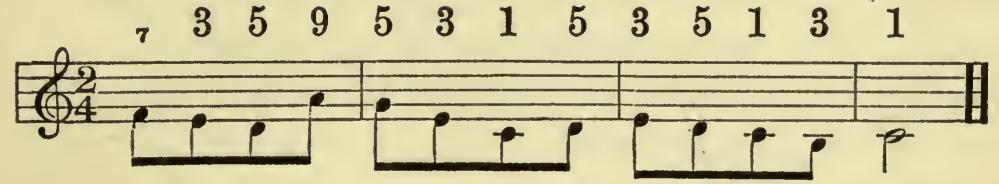

These melodies, like those already presented, are but provisional illustrations of harmony in one voice and its common reports. We shall presently enter into the minutest analysis of these self-reporting relations in order to study and explain their inherent principles and laws. Meanwhile we will note these salient points: the formative influence of rhythm upon tone and the indissolubleness of the two; the inseparability of the relation of cadence and repose, the universality of this relation, its appearance first in 
rhythm, then through rhythm in tone; hence composite tone-rhythm, melody, music. Neither cadence nor repose can be felt, perceived or conceived except in relation one to the other, not in rhythm, not in tone. Except for this basic relation there would be, could be, no harmonic form and relation of tone, no melody, no music. Cadence seeks repose, that is, seeks resolution in repose, equilibrium. This is illustrated in the second last example at $c$ ). But resolution is not a principle or cause, as some theorists declare, nor is progression; ${ }^{1}$ the shaping principle and causa causarum is equilibrium. It may be stated in passing that music's great multiplicity of harmonies, modes and keys are derived from the two original harmonic genera of tones, cadence-harmony and reposeharmony.

\section{Melody, Harmony and Rhythm}

Terms if not carefully defined lead to inevitable confusion. The progress of knowledge under the impulse of new discoveries modifies old and attaches new meanings to familiar terms. In the opening chapter I pointed out the fallacy of the common teaching that melody, harmony and rhythm are the three elements of music and have since demonstrated that melody is not an element in any sense but is the composite of music's two elements, rhythm and harmony. The meaning of the term melody thus undergoes a complete and unavoidable change. In music itself melody and harmony have never been separable or separated. In view of this truth the time-honored separation of the ${ }^{1}$ See The Septonate, Chap. II. L. E. K. 
two which still prevails as the direct result of false theories can no longer be continued. Separate books on melody and separate books on harmony will be valueless and will not be written in the future. Such phrases as "the intimate connection between melody and harmony" no longer have any sense. Never having been separable or separated, melody and harmony do not require connecting. Another conception of melody, namely, a conventional form constructed by rule and composed of certain specified groups of phrases in a variety of "geometrical patterns," also requires modification, a modification clearly and eloquently trumpeted in the works of Liszt, Berlioz and Wagner, of Schumann, Brahms and MacDowell. Formalism in our classics has played not only an important but an essential part in music's evolution and masterpieces. But here we are concerned with melody. Than its form, nothing could be at once more free and more law-abiding yet less subject to any given or conceivable code of rules. Melody is as free as thought and imagination, and its forms are as limitless as are the forms of nature; it is the essence of music. Anything from a succession of two tones onward is a melody, a music-idea, and out of such ideas do genius and craft evolve masterpieces of musicart. It is jejune folly to say that melody is exhausted, that new forms cannot be created.

The term harmony is universally used in the sense of chord, and everywhere the study of harmony means the study of chords. But the accepted meaning of this term is completely changed by the discovery that original harmony asserts itself in one voice without 
chord, that original harmony in one voice and chordharmony in several voices require the most careful distinction, that the former is the evolutionary forerunner of the latter and that the latter is rooted in and explained by the former. Harmony and chord therefore can no longer be regarded as synonymous terms. The identification of music's harmony and shaping principle with universal harmony and the universal shaping principle adds new, truer and deeper meaning to this term.

The new meaning and importance attached to the term rhythm in preceding definitions and analyses cannot be overemphasized. After all it is not so long ago that G. Weber told us that "rhythm is of no consequence." Now we discover that rhythm is at the bottom of everything in music, that the relation of cadence and repose had it not first existed in rhythm could not have appeared in tone, that cadence and repose are two interdependent and inseparable elements at the foundation of rhythmic and harmonic relation, that rhythm-cadence and rhythm-repose at once explain the origins and solve the problems of form and relation, of dissonance and consonance. Therefore everything in music is relation and has been derived through relation. From light to heavy accent, from cadence to repose, from unstable to stable equilibrium, such are rhythmic form and relation, such through rhythm have arisen harmonic form and relation.

Elsewhere I have defined music as follows: Melody, the flower; harmony, the plant that bears the flower; rhythm, the root of the plant that bears the flower. 
Although this legendary definition omits the seed, tone or balanced sound; the nursery, common feeling; the potential life, energy; the inherent shaping principle, equilibrium; and although this definition is not in complete accord with the facts presented in the foregoing pages, yet it has a psychological value inasmuch as it indicates the true sequence of observation which is always the inverse of the evolutionary sequence. To explain: Observation always proceeds from what is most apparent to what is less and less apparent. This inverse sequence has been followed by musicobservers. Melody, the flower, was observed first, was the first subject of music-theory. Next, but yesterday, came the observation and theory of harmony, the plant, in the form, however, of chords. Then last of all came rhythm, the root. In fact, the scientific inquiry by musicians into rhythm is so recent that we can truly say it has just begun.* Thus far this subject has been in the hands of those who may be called separatists who separate the inseparable, namely, music's rhythm, harmony and melody. Melody without harmony, a tone without harmony, are unfeelable, unperceivable, do not exist. The moment of tone-genesis being a rhythmic moment it follows that rhythm, harmony and melody have never been separable in feeling. Because this inseparability was not perceived, rhythm, harmony and melody were separated in theory, but not in practice. Today they are united in common feeling, and it is safe to postulate that they always have been united. We judge of what has been by what is. The music of to-day is connected with the music of all the past in 
a sequence of effects and causes, each cause being the effect of a previous cause. I have proved, and will adduce further proof, that melody is the composite of rhythm and harmony. This is nothing new to musicfeeling where melody always has been a composite, but it is new to theory and, owing to its discovery of harmony in one voice, completely changes the point of view of theory.

Knowledge is evolution of perception. Truth persistently knocks at the door of consciousness, sure of being admitted sooner or later to enrich the store of knowledge and experience. 


\section{CHAPTER III}

ORIGINAL DISSONANCE AND CONSONANCE IN ONE VOICE

28. Genesis of the Major Consonance, Music's First Regnant Harmony

THE fundamental forms of tone are dissonance and consonance. Both are products of feeling, both first arose in one voice, both are offsprings of the elemental relation of rhythm-cadence and rhythm-repose. Briefly, form is derived from relation, the forms of dissonance and consonance from the rhythmic relation of cadence and repose. This truth lifts the veil of mystery which has hitherto hidden from view the true nature and origin of dissonance and consonance. What man did not feel he could not, it is safe to say, did not express, and music from first to last is a creation and expression, of music-feeling. Man's first expression of tone was admittedly in song. We will study these first utterances.

The first attempts to pitch a tone comprise two moments of time: first, a sliding; second, an arriving. These two moments, previously described as nownow, light-heavy, cadence-repose, unstable-stable, are two correlated and interdependent rhythmic accents which are inseparable in feeling, perception and conception. Of the two, the first is tend, the second is end; the first resolves into the second, the second is attainable only through the first, since apart from the feeling of tend there is no feeling of end. Below I 
indicate cadence or tend by a wave-line which resolves into repose or end as shown by a straight line:-

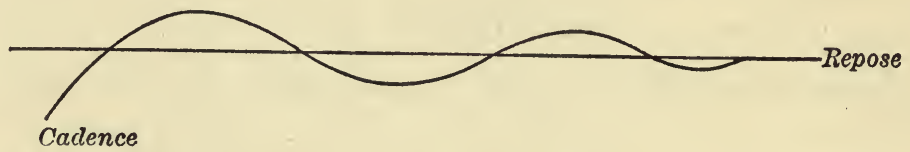

The first or sliding moment in pitching a tone is cadence, unstable equilibrium, relative harmony, tend; in it the entire cadence-thread of harmony is potentially present. The second or arriving moment is repose, stable equilibrium, perfect harmony, end; in it the entire repose-thread of harmony is potentially present.

Feeling thus resolves wavering into unwavering pitch, unstable into stable equilibrium, relative harmony into perfect harmony, apparent chaos into perfect order and unity, a light accent into a heavy accent, cadence into repose, aspiration into attainment, tend into end, latent feeling of dissonance into consonance.

This heavy accent of rhythm I have already named the efficient accent of tone-genesis, that is, of the genesis of harmony. This end of tend was the genesis of music's first tone, the birth of music itself, of melody. This first tone was not only the first harmony, but was the first regnant harmony generated by the efficient accent. This first harmony is the genus consonance, our Major Tonic-harmony.

The power to place a tone in the voice and to express exact pitch was acquired through the evolutionary process of resolution above described. In the first crude attempts at pitch the entire process of sliding and arriving is intoned. But when the power to ex- 
press exact pitch has been acquired the first or sliding part of the process is carried out silently. Though when trained we place tones automatically, nevertheless the voice has to be adjusted to each tone, infinitesimally short though this moment of adjustment may be.

The process of resolution just analyzed explains why when we pitch an isolated tone we invariably make for the efficient accent and generate in feeling the repose-thread of the original major consonance, our Major Tonic-harmony, music's first regnant harmony, as follows:-

a)

b)

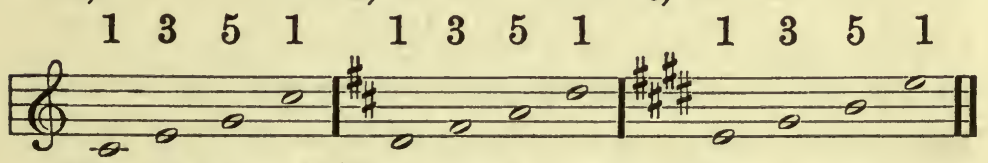

The origin of this genus consonance is now explained. How and why this genus-harmony came first is now explained. Its genesis is due to the resolution of the latent feeling of dissonance (relative harmony) into the major consonance (perfect harmony). The operative cause is the efficient accent which on the line of least resistance makes for complete equilibrium. Briefly, the efficient accent is the cause of resolution. Man first felt and expressed the relation of cadence and repose rhythmically, but when he joined sound to this rhythmic relation he eventually evolved the feeling and expression of tone-cadence and tonerepose. Tone-cadence is dissonance, it first arose in one voice. Tone-repose is consonance, it first arose in one voice. How music's original dissonance arose in relation to music's original consonance will be considered presently. Meanwhile, it may be observed 
that music springs from one source, not from two sources. At the basis of music there is unity, not a duality as many think and teach. Music started with one harmony, the Major Tonic-harmony, and all subsequent harmonies are traceable through a chain of relations back to the first. Major and Minor are two modes, but Major preceded Minor and Minor was derived from Major. Major and Minor are therefore not two tonalities, they are two modes of one tonality, hence the unity of tonality. Tonality is the sum of tone-relations, and music began the development of tonality with the regnant Tonic-harmony of the Major mode. Again: rhythm and harmony are two elements, but in tone, in melody, in music, the two are indivisible, one, hence unity. If there be any duality it should be cadence and repose. But is this duality? No. Cadence and repose are the two inseparable and interdependent elements of the unity relation.

The simplest songs of birds, the simplest specimens of primitive human music, the improvised songs and intoned calls of children, the intoned cries of streetvenders, all these songs, calls and cries are based upon the genus consonance, our Major Tonic-harmony. Since in evolution birds antedate man, we may assume that the birds were the first singers, concert-givers and music-teachers. Japan, for example, has few or no singing birds, therefore no feathered music-teachers. Perhaps this explains why Japan is a nation without song. From a collection of bird-songs observed by me and accurately written both as to rhythm and harmony, a few are here selected and arranged in three groups which exemplify three stages of develop- 
ment from simple to more and more complex. The first group marks an early stage in which only the tones of the Major Tonic-harmony appear.

1.

2.

3.

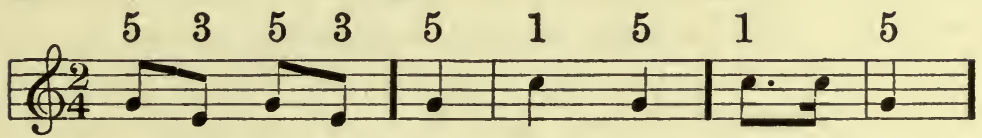

4.

5.

6.

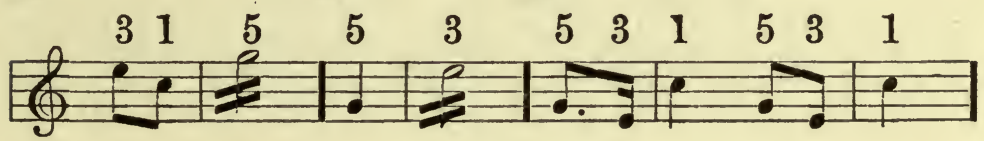

7.

8.

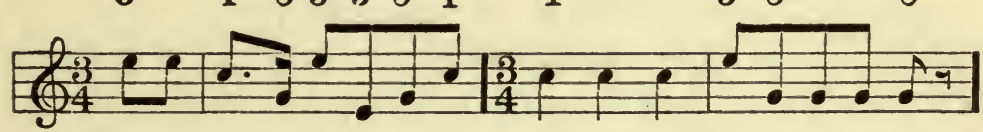

9.

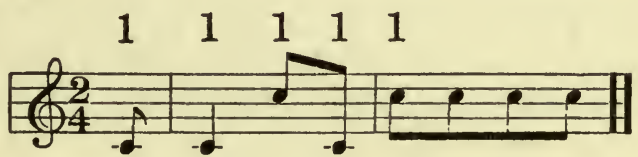

The next group adds two cadence-tones, marked $\ddot{x}$, to the regnant Tonic-harmony.

1.

2.

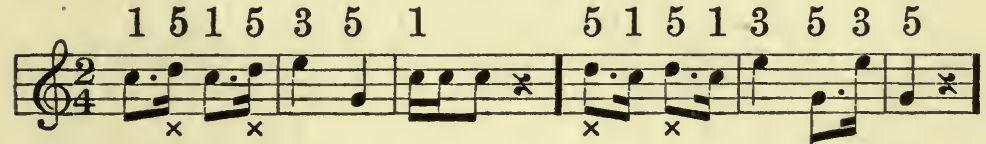

3.

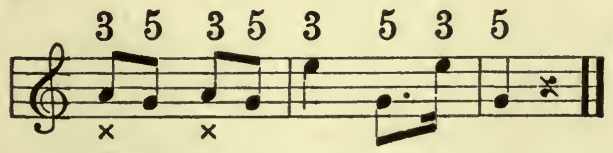

The appearance of the above cadence-tones marks a more advanced stage of development. A much 
higher stage is exemplified in the next group of songs which introduce two additional regnant harmonies, namely, the Dominant-harmony (marked V) and the Subdominant-harmony (marked IV), both of which arise in relation to the Tonic-harmony (marked I).

1.

2.

3.

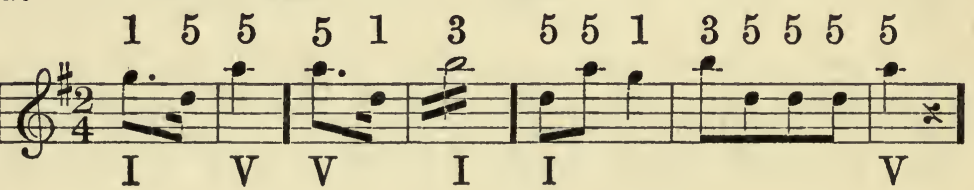

4.

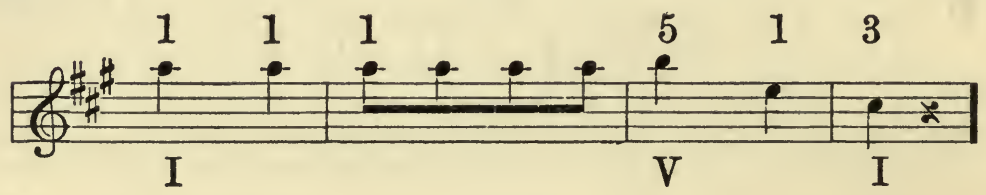

5.

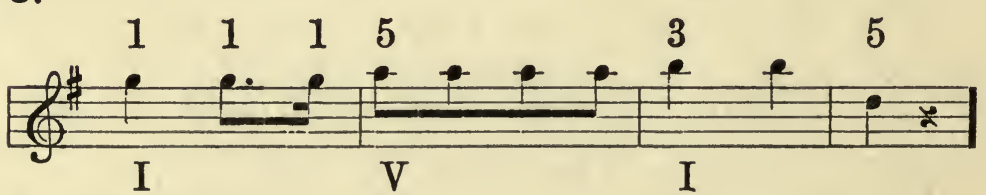

6.

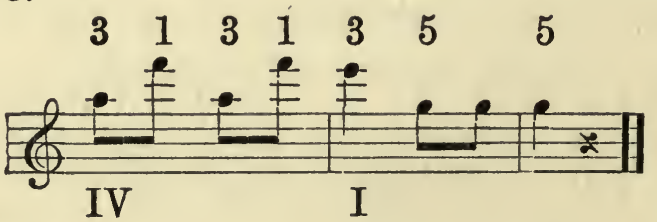

In these few bird-songs the harmonic basis of music is plainly revealed, and the subject of tone-relations is fully opened up. The harmonic numbers symbolize the common reports of inherent relations. The harmonic analysis of the cadence-tones and cadenceharmonies and the connection of the successive stages 
of development here suggested will engage our attention later on. Also for future reference I here add three more bird-songs, the first two of which report the Minor consonance and mode, while the last introduces a chromatic marked by a star.

1.

2.

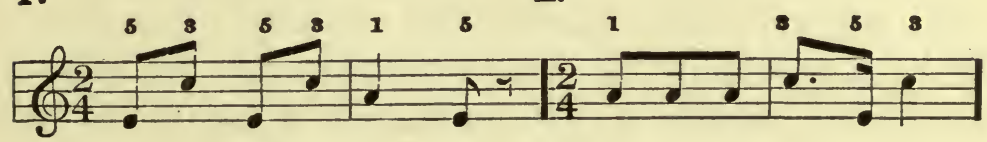

3.

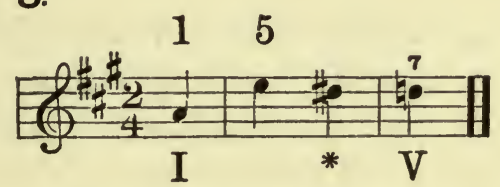

In their first efforts to discriminate the concomitant harmonics of an isolated tone, students most frequently feel and express the octave first, next the fifth, last of all the third, as follows:-

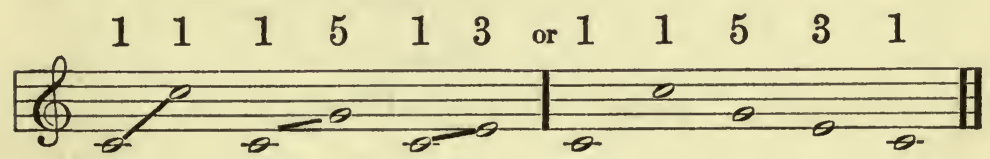

The psychological law here operative is this. The closer the proximity of tones the more difficult is it to perceive, differentiate and express them. By implication the larger intervals were expressed first, the smallest last. Thus octaves, fifths and fourths, thirds and sixths came before the whole step, and last of all came the half step. All the first-named intervals are present in the Major Tonic-thread of harmony and appear in the first group of the above bird-songs. The cadence-tones in the second and third groups of these 
songs exemplify the introduction of the whole step and half step. The evolutionary sequence of regnant harmonies begins with the Major Tonic. The evolutionary sequence of intervals begins with the intervals formed by the tones of this first regnant harmony. The Major Tonic-harmony is the only harmony which has entered into consciousness by way of its root. We shall see that the Dominant-harmony was introduced by its fifth, the Subdominant-harmony by its third.

While we may affirm with certitude that the Major Tonic-harmony was the first of all harmonies, we cannot tell what was its exact pitch or key, simply because we do not know. However, the terms Major and Tonic imply mode, relation, tonality and also relative pitch but not fixed pitch, since this Major Tonic arises on any isolated tone of any pitch. Like the birds we sing melodies and correctly express their inherent harmonic relations or tonality, completely unconscious the while of fixed pitch or key, although we are expressing key-relations. Fixed pitch is indicated when we say C Major, D Major, E Major, and so on, by which we mean that the Major Tonic is pitched or keyed on C, D, E, wherefore the notes C, D, E are called keynotes and wherefore the terms keynote and Tonic are used interchangeably. Because the feeling of the harmonic relations we call tonality are common to all of us, because they underlie all music of bird and man, because they would exist even though systems of fixed pitch and notation had never been invented and adopted, because they are the essential thing to appreciate and know, because our complex system of nota- 
tion so completely conceals the unity and simplicity of harmonic tonality, for these and other reasons unnecessary to mention, nothing could bring us closer to these innate relations, or prove a greater desideratum and simplification than a set of symbols which disregards any fixed pitch and which is uniformly the same in every key. The syllables do, re, mi, etc., supported by the harmonic numbers adduced from original harmony in one voice fully meet the case. Music's first harmony and genus consonance, our Major Tonic-harmony, is now presented thus:-

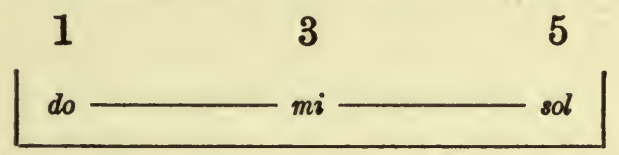

We may say with certitude that do was the first Tonic and root, that $m i$ was the first major third and that sol was the first pure fifth. These are the only three tones and harmonic percepts in our first group of bird-songs. In the second group of songs note the first cadence-tones, re and la, the former as fifth introducing the Dominant-harmony, the latter as third introducing the Subdominant-harmony. But we are advancing too fast and will next consider the origin of the genus dissonance.

\section{Genesis of Cadence-Harmony or Original Dissonance in One Voice}

We say that a leading-tone tends up, a seventh tends down. Tend is cadence; its object or end is repose. No chord is required to generate and illustrate this re- 
lation, since it reports itself in one voice as exemplified below:-

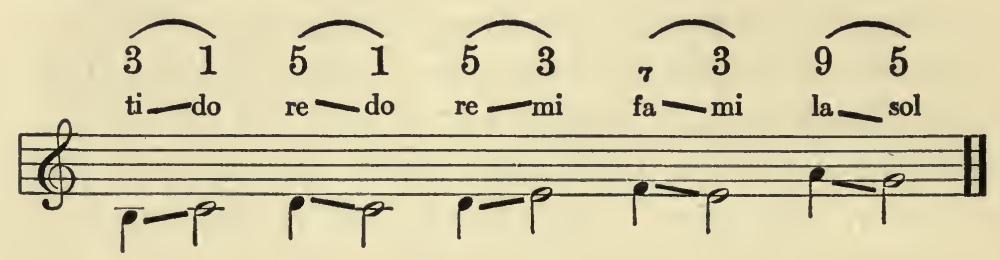

Cadence connotes cadence-harmony, dissonance, incompleteness, hence the tend to repose in the above cadence-tones $t i, r e, f a, l a$. Repose connotes reposeharmony, consonance, completeness, hence no tend but an end as reported by the above repose-tones $d o$, $m i$, sol. Our example presents no chords, but it does present harmonies, since each tone arises in the mind together with concomitant harmonics and is therefore a harmony. Thus a cadence-tone reports one harmony, a repose-tone reports another harmony, and the resolution of one tone into another is the resolution of one harmony into another. Were it not for the inherent harmony of tone there would be neither the feeling of cadence nor the feeling of repose, no form and relation of tone in the musical sense. Because of this harmonic form and relation inseparable in tone we all share in the common feeling of the above cadences, of harmony and harmonic relation, of dissonance and consonance in one voice.

Our example introduces four cadence-tones $t i, r e$, $f a, l a$ in addition to the three repose-tones $d o, m i$, sol. These four cadence-tones are components of the genus dissonance; they lie directly over and under the three repose-tones of the genus consonance in relation to 
which they first arose. In correlation the repose-tones of the genus consonance report do as common root or root of this genus. In correlation the cadence-tones report sol to be their common root and the root of the genus dissonance. Examples follow:-

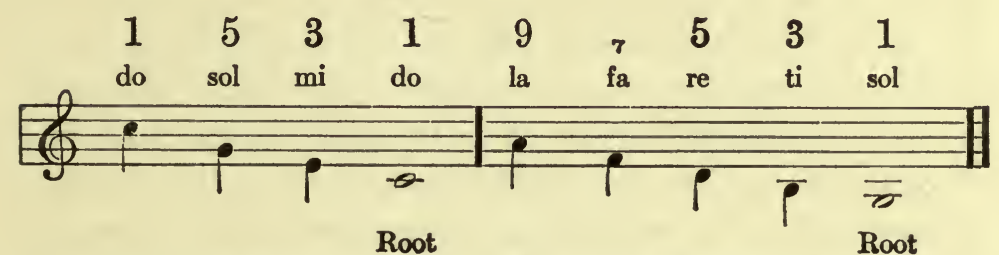

1. Genus Consonance. 2. Genus Dissonance.

The genus-root do is the Major Tonic. The genusroot sol is the Major Dominant. Tones are ninths or sevenths or fifths or thirds or roots of harmonic threads, and the number over each indicates a root or relation to root. Sol first arose as fifth in the genus consonance, thereafter asserted itself as root of the genus dissonance. Sol is therefore the first nexus, common tone or bond-tone of two harmonies, since it connects the two genera, dissonance and consonance, as shown below:-

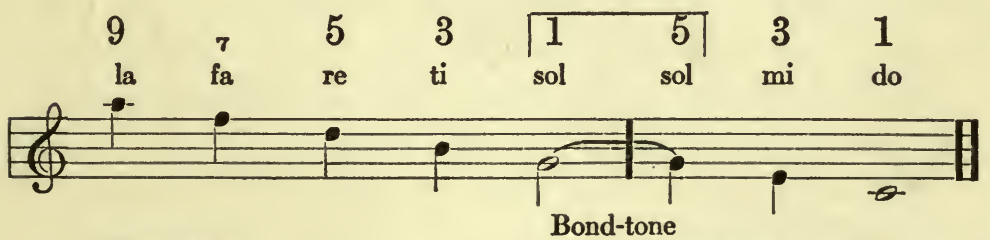

Dissonance

Consonance

The origin in rhythm of the inseparable relation of cadence and repose, the consequent genesis of the 
latent feeling of dissonance and consonance, and the genesis of consonance through the resolution of this latently felt dissonance, these important points were explained in the foregoing section. One by one these latent cadence-tones of dissonance were perceived, differentiated and expressed. First of these to appear in melody were the whole steps re in relation to do and $m i, l a$ in relation to sol. Much later came the half steps $t i$ in relation to $d o, f a$ in relation to $m i$. In our example of cadences re tends down to do and up to $m i$, $l a$ tends down to $s o l, f a$ tends down to $m i$, $t i$ tends up to do. For practical and theoretical reasons too obvious to require mention I name $t i$ the upleader, fa the downleader.

The evolutionary sequence of cadence-tones in this order, namely, $r e, l a, f a, t i$, is supported by history in its records of primitive scales and melodies. As evidence witness the so-called great scale, small scale and the pentatonic scale in which the great and small scales are united. In these scales there are no half steps, since $f a$ and $t i$ do not appear. All are given and analyzed below:-

1.
2. Small. 3. Pentatonic.
Great.
15
3
$\begin{array}{llll}5 & 3 & 1 & 5\end{array}$
do re mi sol la do re $\mathrm{mi}$ sol la

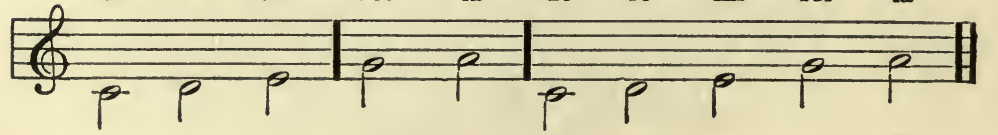

The harmonic numbers indicate the common reports of original harmony verified by common perception. The Major Tonic-harmony is regnant, the 
tones re and la cadence up and down into do-mi-sol, the regnant harmony. Ascend or descend on this pentatonic scale in every conceivable rhythm, yet the harmonic relations remain unchanged. However, the analysis of a scale has little purpose, for a scale is but a record of tones in use during a certain period of history; briefly, scales are so many tone-systems of history. What is of essential importance is the analysis of the melodies which are responsible for these tonesystems the progressive development of which has resulted in our present complex system. Thus far we have accounted for and exemplified but one regnant harmony, the Major Tonic. How a second and a third regnant harmony were generated are subjects presently to be considered. Here an important fact to which we shall revert later on may be mentioned. It is this: During the regnancy of the Major Tonicharmony la always reports itself as third of fa, while the remaining tones of the genus dissonance during this regnancy of the Tonic always report themselves in their genus-relations, $t i$ as third, re as fifth, $f a$ as seventh of sol, the Dominant. La reports itself as ninth only during the regnancy of the Dominantharmony, which is the genus dissonance. The tone $l a$, as we shall see, plays a leading and significant part in the development of harmony and tonality.

The above explanations of the genesis of the four cadence-tones and the order of sequence in which they arose are further supported by deduction and by induction; by deduction from the principles of causation and harmonic genesis set forth in these pages, by induction through data derived from exact analysis 
of bird-music, primitive music, music-feeling and progressive mental development in music. I say exact analysis advisedly, since in the past no basis for exact analysis of primitive music and common musicfeeling has been discovered. For the first time in the history of music-science such a basis presents itself in original harmony in one voice. The principles, causes and conclusions thus far presented and exemplified are directly due to the discovery of original harmony in one voice, and its incontrovertible evidence in the common reports of common feeling and perception. Thus original harmony and its common reports place all observers and analysts on common ground, a common basis from which to make observations and draw conclusions from such observations, a point of view at once new and common. Dissonance and consonance, the most fundamental and perplexing, therefore the foremost problem of music-science, have remained a mystery, an unsolved problem, and now find a simple solution through original harmony and its common reports. Some musicians may object as follows: Everybody knows that dissonance and consonance did arise and are at the foundation of music, that the cadence-tones not only did appear over and under the three tones of the Tonic chord, but arose in relation to this Tonic-triad and came to stay. The facts are self-evident. Why not stop here and be satisfied? It is otherwise with the scientific observer who seeks causes; he cannot stop and has no rest until he finds the causes that explain how forms and relations came to be what they are. Our story of genesis is simply this. In obedience to inherent principles 
rhythm and tone met, merged and became one, then rhythm-cadence and rhythm-repose became tonecadence (dissonance) and tone-repose (consonance), and forever after there was music.

The foregoing analyses and examples conclusively prove, first, that original harmony is harmony in one voice, that tones are heard, felt and expressed in cadence or repose as roots or thirds or fifths or sevenths or ninths, that tone and tone-relation connote harmony and harmonic relation, that harmonic form and harmonic relation in one voice are self-asserted, fixed and immutable, and by implication that the reports of original harmony are common reports; second, that dissonance like consonance had its genesis in one voice, that the genus dissonance and the genus consonance are respectively the harmonies of the Major Dominant and Major Tonic, and by implication that tonality is fundamentally and wholly a question of harmony, and that original harmony in one voice is its basis; third, that the Major Tonic was the first regnant harmony, and this implies the priority of Major tonality ; fourth, that melody instead of being an element, as generally supposed, turns out to be a composite of rhythm and harmony, and by implication that melody is the original vehicle of dissonance, consonance and tonality, in short, of music per se; in fine, that dissonance is neither more nor less a harmony than consonance, the former being unstable and relative equilibrium, the latter, stable and perfect equilibrium. 
30. Distinction between Original Harmony in One Voice and Chord-Harmony

Music-history everywhere identifies the beginning of harmony with the first use of chords. Every treatise on harmony is a treatise on chords. The concurrence of at least two tones, therefore a chord, is everywhere considered indispensable to the perception, conception and presentation of a consonance and a dissonance. Everywhere the study of harmony and harmonic analysis means the study of chords and chord-analysis, and no other basis having been discovered, the chord is everywhere regarded as the basis of harmony. These facts plainly show that the conception of harmony as chord is universal. The reasons for my dissent from this common view are rooted in the following facts and conclusions. The chord is a form of harmony, but is not the original form, therefore the chord is not the basis of harmony. The original form is the basis, it is dissonance (cadence) and consonance (repose) in one voice. The concurrence of two or more tones, that is, a chord, is not requisite to hearing, feeling, perceiving, conceiving and presenting a dissonance and a consonance. A single tone suffices for all this since, as has been demonstrated, each of a series of single tones is a dissonance or a consonance. Harmony is a discovery, not a "modern invention" as Spencer declares. Original harmony in one voice, old as music itself and belonging to all time, is the spontaneous product of feeling; it antedates chord-harmony and belongs to the historic and prehistoric periods of homophony. 
Chord-harmony, on the other hand, is a comparatively recent product, a product of reflection and theory, and its roots reach deep down into original harmony from which it is a psychological evolution. Though their connection has so long remained concealed, it is safe to infer that the two, original harmony and chord-harmony, have never been separated in feeling, and that the feeling of the former has ever directed and guided the course of development of the latter. The feeling of original harmony in one voice, being the universal and basic harmonic sense, may be designated as the common harmonic sense. The truth of this is demonstrated and proved by the common reports of common feeling and perception.

The common view of the chord as the only form and as the basis of harmony has not alone created much confusion in the theories of music, but its general acceptation as an ultimatum has acted as a check upon scientific research. The questions What is music? and What is common music-feeling? so often set aside as insoluble mysteries, are not separable since the answer to the first lies hidden in and awaits the answer to the second. But these primary questions could not be answered until the solution of the basic problem of consonance and dissonance had been discovered and a theory of music based on this solution had been expounded. The curious, among whom I count myself as most curious, may well ask why so simple a solution of the problem as that of cadence and repose in one voice has so long remained concealed. This oversight may be assigned to two principal causes and fallacies already suggested: first, to the chord-basis of har- 
mony; second, to the persistent and futile attempts to base the theory of music on physical acoustics. There are three evolutionary chapters of harmony which may be provisionally indicated here.

1. Homophonic Harmony. This is original harmony in one voice, which is the inherent harmony of single melodies. By single melodies I mean all music in one voice. This chapter represents the primary age of music.

2. Polyphonic Harmony. This is the inherent harmony of combined melodies, that is, of two, three or more coincident melodies. This chapter may also be called contrapuntal harmony and constitutes music's middle age.

3. Chord-harmony. This, the only form thus far recognized, is the supporting and accompanying harmony of single and combined melodies. This chapter represents music's modern age.

These three chapters and corresponding ages overlap; they mark a psychological advance from simple to complex and from the indefinite to the definite; they correspond to the three psychological stages of music's childhood, adolescence and maturity. The golden thread by which all these forms of harmony are connected in evolution has preserved only what was favorable and useful, so that in modern music all three are employed in composition. The distinction here under consideration may now be carried a step farther.

Original harmony (one voice always understood) is natural harmony by natural selection. Chord-harmony is personal harmony by personal selection. The forms of original harmony select, assert and present 
themselves; in any single melody they are identical in all of us, they are completely free from personal selection and therefore from the personal equation. Concisely stated, personal selection cannot enter into original harmony, in which the forms are uniformly the same. In chord-harmony, on the other hand, we are compelled to make a personal selection not only of this or that series of specific constituent chords, but also of the number of voices to be employed. Briefly, a melody may be chorded in many ways while the original harmony of a melody is uniformly the same. Thus it is clear that the forms of original harmony are immutable since they cannot be changed except by adding other voices or chords. But the moment we do this, two things happen simultaneously: first, the harmony is no longer in one voice; second, personal selection usurps the place of natural selection in that we add our own thought, and thus transform something that was universal into something that is personal. Hence the distinctions between natural and personal harmony, between natural and personal selection. The examples shown on page 72 illustrate these distinctions and will suggest others.

The common and immutable forms at $a$ ) are due to natural selection, while the forms in all the subsequent examples are due to personal selection. Concisely stated, everything in more than one voice is personal. The harmonic numbers in examples $b$ ), c), d) and $e$ ) agree with those in example $a$ ), whereby it is shown that the chord-forms of personal selection may reproduce and elaborate the original forms of natural selection in a variety of ways. Original harmony is there- 
fore not only the basis of chord-harmony, but the inseparable bond between the two is that of feeling and thought, of the simple and more complex, of lower and higher forms corresponding to lower and higher evo-

a)

b)

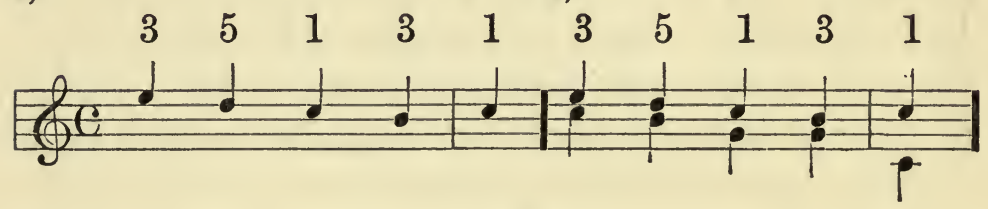

c)

d)

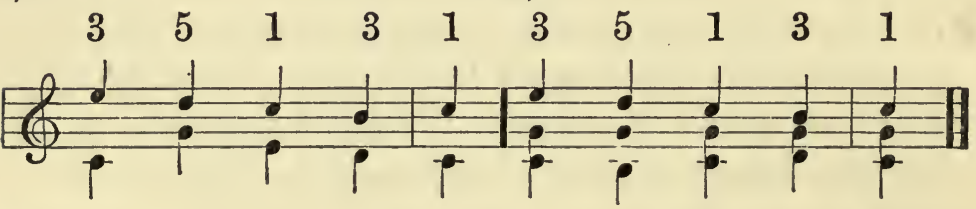

e)

f)

g)

$\begin{array}{llllllllllllllll}3 & 5 & 1 & 3 & 1 & 3 & 1 & 1 & 3 & 1 & 3 & 1 & 3 & 5 & 3\end{array}$

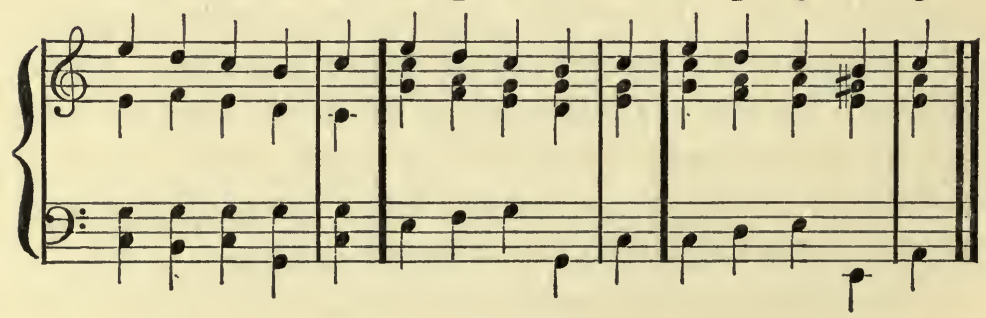

lutionary states of mind. Not alone may original forms be reproduced in chord-forms, but as seen in examples $f), g$ ) and $h),{ }^{1}$ a single melody may imply a great variety of other chord-forms, and these examples exhibit a more advanced state of personal selection than those which precede.

${ }^{1}$ Ex. $h$ ) could not be deciphered. L. E. K. 
The eye and ear are concerned in the following distinction. In a written series of single notes, as in example $a$ ), you can see the notes, but you cannot see the harmonies, because single notes present no visual images of harmonic forms. Therefore in one voice you are compelled to hear. With chords it is different. In a series of written chords you not only see the notes, but you can also see the chords, because each chord presents a distinct visual image easily remembered. This explains why in the study of chords or harmony, as it is called, students so readily fall into the pernicious habit of guidance by sight in place of guidance by hearing. It explains why most students recognize a chord when they see it, while so few recognize a chord when they hear it; why most students do their work at the piano and cannot hear what they have written unless they play it, while so few hear before they write and hear what they write as they write. In original harmony the forms are invisible; in chord-harmony they are visible. In the former the exercise of harmonic feeling, perception and conception is unavoidable and a necessity from the start; in the latter this exercise is interfered with, and in most cases is excluded by the insidious visual habit just described, and the necessity for this exercise is constantly urged upon students. In the former you cannot move one step without hearing; in the latter, owing to the visual habit, it is possible to work through an entire treatise without hearing. First the idea, then the sign; first hear, then write; this subordination of symbol to idea, of sight to hearing, should be a matter of course.

Original harmony and chord-harmony are con- 
trasted in the next examples for a special purpose. In $a$ ) we hear Weber, in $b$ ) we hear Wagner.

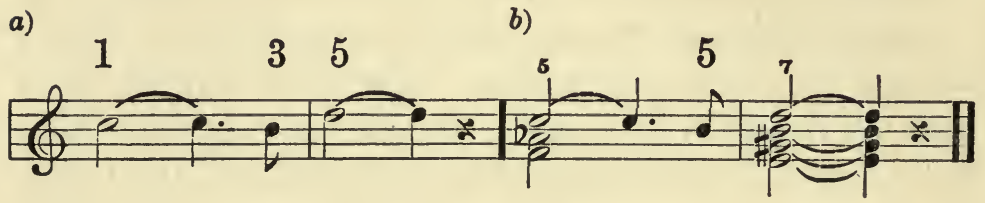

In common parlance we would say that these two examples present one and the same melody, and that $b$ ) is a harmonization of $a$ ). This is not true. It would be true were melody an element; it is not true, because melody is a composite of two elements, rhythm and harmony. The two melodies look alike but how unlike they sound. Are we to believe the eye or the ear? The harmonic numbers indicate the ear's testimony. Compare these numbers in the two examples. Melodies are thoughts. As melodies and thoughts, $a$ ) and $b$ ) are distinct; both are equally individual and natural. It is true that a given single melody as at $a$ ) suggests a variety of different harmonizations, but let us remember that it is also true that every such harmonization results in the transformation of one distinct and individual melody and thought into another distinct and individual melody, and thought, no two of which can possibly be the same. In a separate chapter I will present the potential harmonies of a tone, which subject includes that of the potential harmonies of a melody. Here it is enough to have pointed out the germinal, essential and individual force and character of melody as thought both spontaneous and constructive. When a composer 
presents one or more phrases or sentences in the form of one voice, he employs this form of thought for purely artistic and æsthetic reasons, the selection of the specific form of thought whether in one or more voices always being personal. Not so with the harmony. While the composer's selection of one voice is always personal, the inherent harmony of this one voice is never personal; it is always original, universal, immutable harmony. This distinction between one-voice and multi-voice harmony will appear in other connections in subsequent sections.

\section{The Seven Original Tones. Analysis}

The seven original tones are the components of the two harmonic genera, consonance and dissonance. Three of the seven are derived from the former, four from the latter. These seven tones are the seven diatonics of the Major mode. Their minute analysis being our immediate concern, they are again presented.

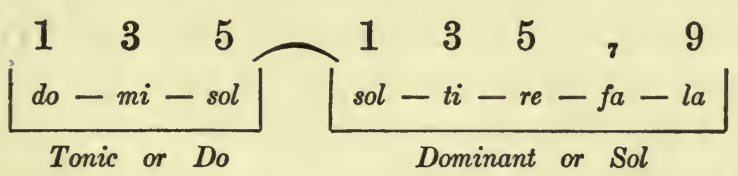

A harmony is named by its root, hence the harmony of the Tonic or Do, the harmony of the Dominant or Sol. The harmonic numbers indicate either root or relation to root. These numbers are large for major and small for minor intervals. This rule for marking major and minor intervals will henceforth be strictly adhered to. Our example contains but one minor interval, namely, $f a$, which is the minor seventh of 
its root. The above tones may be read as follows: Tonic-root, third, fifth; Dominant-root, third, fifth, seventh and ninth.

Every tone is a distinct harmonic percept and concept. A harmonic percept is our perception of the common report of a tone as root or third or fifth or seventh or ninth. A harmonic concept is our thought or conception of a tone in any one of these relations. Concepts are rooted in and spring from percepts just as percepts are rooted in and spring from feeling. Harmonic feeling is never wrong, but harmonic percepts may be wrong and cause wrong concepts. True knowledge is true perception of relations. False perception and consequent false conception is the danger to be averted. This danger is averted in the present study by the common reports of common feeling and perception. Since concepts are based on percepts, since the former are true if the latter are true, we will for the present fix our attention upon the latter.

The seven original tones present eight distinct harmonic relations, each of which is a harmonic percept, as follows: do is root, $m i$ is major third, sol is pure fifth, of the Tonic (harmony understood); $s o l$ is root, $t i$ is major third, $r e$ is pure fifth, $f a$ is minor seventh, $l a$ is major ninth, of the Dominant. Of these tones sol, the bond tone of the two harmonies, appears twice: first as fifth, then as root.

Some of these harmonic percepts are original, others are duplicates. A harmonic percept is original when it is the first of its kind: such are $d o$, the first root; $m i$, the first major third; sol, the first pure fifth; $f a$, the first minor seventh; la, the first major ninth. 
A harmonic percept is a duplicate when an original percept is repeated on another tone: such are sol as root, $t i$ as major third, $r e$ as pure fifth. This shows that the seven tones and eight harmonic relations of the two harmonic genera, consonance and dissonance, have introduced five original harmonic percepts into music. These five are now presented each with the tone that first produced it.

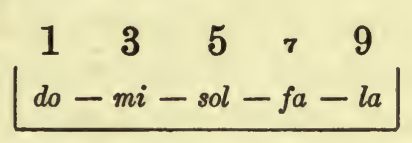

Three of these spring from the original consonance (Major Tonic), two from the original dissonance (Major Dominant). The expansion of harmony and tonality is due to the repetition of these harmonies and percepts on other tones, a subject to be treated in the chapter on potential harmony. The exact analysis of the above harmonic percepts now confronts us. These five percepts and the seven original tones are all included in the following simple folksong which we will analyze:-

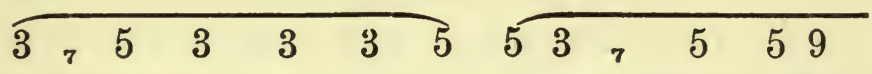

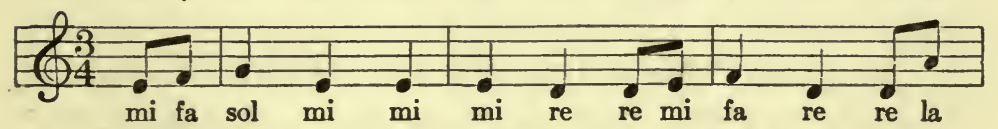

Tonic Dominant

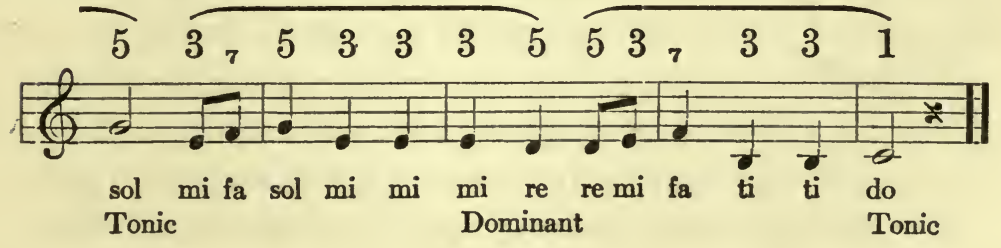


The reader with a trained ear will not stumble or hesitate over the numbers which mark the harmonic relation of each of the above tones; without pause or effort he at once recognizes $\mathrm{E}$ as $m i$ and major third of Tonic, F as f $a$ and minor seventh of Dominant, G as sol and pure fifth of Tonic, and so on. Through practice he has developed and transmuted common harmonic feeling into common harmonic perception, that is, true feeling of harmonic relations into true perception of harmonic relations, something that he once only felt into something that he now positively knows. The result is that he recognizes these relations automatically; he not only perceives them in the concrete as in the above melody, but he can think of them in the abstract since in his mind they have taken shape as ideas and concepts.

On the other hand, the reader whose ear is not trained has all this to learn. He may well ask: How am I to know that the first tone in this melody is a major third, that the second is a minor seventh, and so on? This analysis will at once answer this question and explain harmonic relations in one voice. In the succeeding questions and answers we will start at the bottom.

What proof is there that I share in common musicfeeling, in a word, that I am musical? It lies in the fact that you take pleasure in music, which in the absence of music-feeling would not be the case.

What proof is there that my feeling of tone-relation is true? It lies in the fact that you are able to follow and express (sing or hum) a melody since each tone in a melody simultaneously reports a definite relation 
in time (rhythm) and a definite relation in space (harmony) and this double report is the same in all of us. That you feel this double report, although you may not know what it is, is proved by your ability to follow and express a melody. Feeling of melody is feeling of united rhythm and harmony, melody being the composite of elements and the original vehicle of music.

What proof is there that each single tone in a melody is a harmony? It lies in the fact that each tone arises in the mind together with elementary tones called concomitants. This complex of a tone and its concomitants I have already named the harmonic thread of a tone. The harmonic thread of a tone is the specific harmonic form of a tone.

What causes the genesis in feeling of the specific harmonic thread or form of a tone? The proximate cause is the relation of that tone. This form-generating relation inheres in and is reported by melody in each of its tones and, as we have seen, this relation is at once relation in time (rhythm) and relation in space (harmony). Since this relation is asserted in melody it follows that if you feel the melody then do you feel the relation and, by implication, the harmonic thread or form of each tone in the melody. Your feeling of the harmonic thread of each tone in the above folksong is true.

What course am I to follow in order to learn to recognize and analyze these harmonic threads and so transmute what I feel into true perception and knowledge? Sing the first phrase of the above folksong over and over again for the purpose of making sure that you retain the feeling of the relation of the first 
tone to the other tones of the phrase. To retain the feeling of the relation is equivalent to retaining the feeling of the harmonic thread of their first tone, mi. Having made sure of this feeling, sing $m i$ and on the line of least resistance, drop on the thread of harmony from one component to another until you reach a tone which reports a stopping-point, a point of complete repose, a harmonic centre of gravity; for this tone is the unmistakable root or fundamental tone of the thread. You will find the harmonic thread to be as follows:-

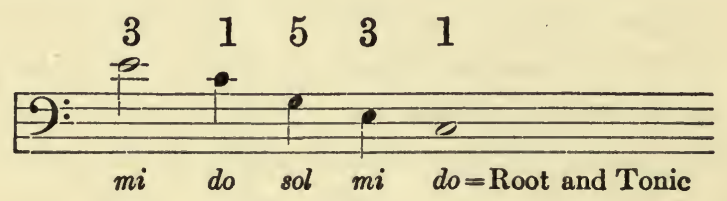

Having found the root, move back on the thread to the tone you started on and go down and up on the thread repeatedly as shown below:-

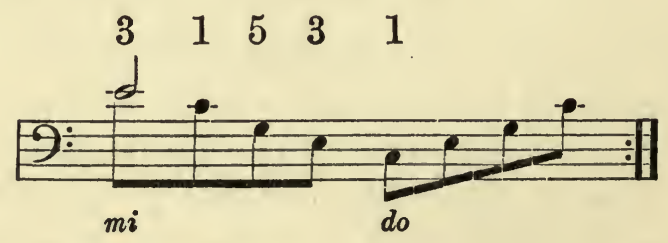

Once you recognize the root then the rest of the analysis is simple, namely, the number and names of components, the interval-relations of the components to the common root, the proving of the common root not alone by discovering that it is the most stable of all the components, but by further discovering that it is the only tone in the thread to which the other tones 
relate in the harmonic order of third and fifth in the case of this first tone and as third, fifth, seventh and ninth in the cases of other tones in this folksong. You will discover that in dropping on the thread you passed one root and followed the thread to the lower octave of that root, that when you pass a root you repeat the same series of tones in a lower octave. In fine, you have analyzed the harmonic thread of the first tone $(m i)$ and recognize this tone to be a large or major third because it lies two whole steps over its root.

As a prelude to proceeding with this analysis the last question and answer may be given in a briefer form. How in one voice am I to know that a tone is a root or third or fifth or seventh or ninth? By feeling its momentary relation and analyzing its harmonic thread.

Second tone fa, minor seventh. The harmonic thread of this tone has four components; its root is the Dominant. This thread is given at $a$ ) followed by an exercise at $b$ ).

a)

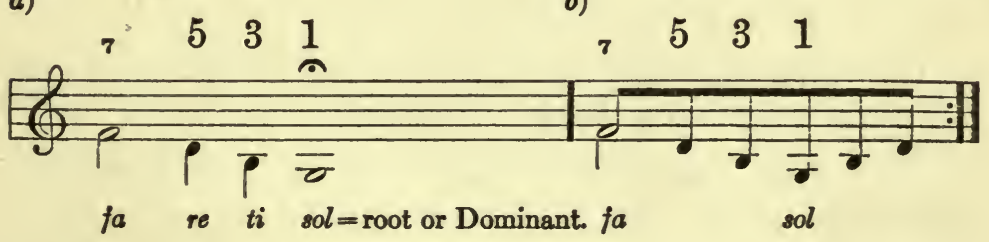

Third tone sol, pure fifth. Its analysis follows.

a)

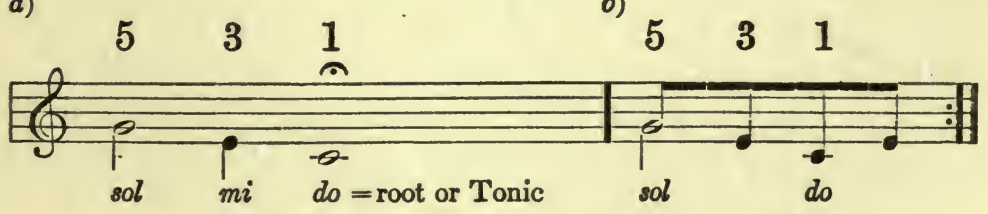


The next three tones are repetitions of the first, namely, $m i$, major third.

Seventh tone re, pure fifth of the Dominant. This time the Dominant-thread reports but three components.

a)

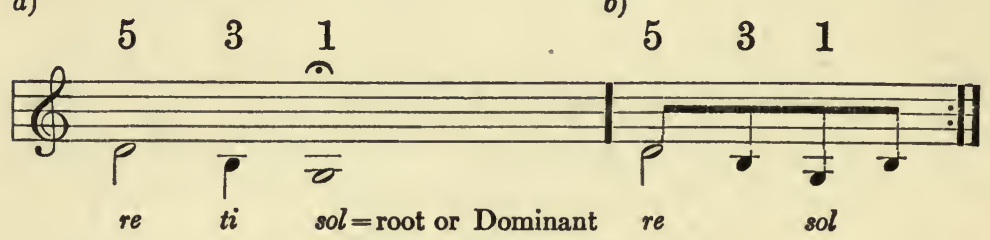

The next five tones are repetitions of percepts already analyzed.

Thirteenth tone la, major ninth of Dominant. This time the Dominant-thread reports five components.

a)

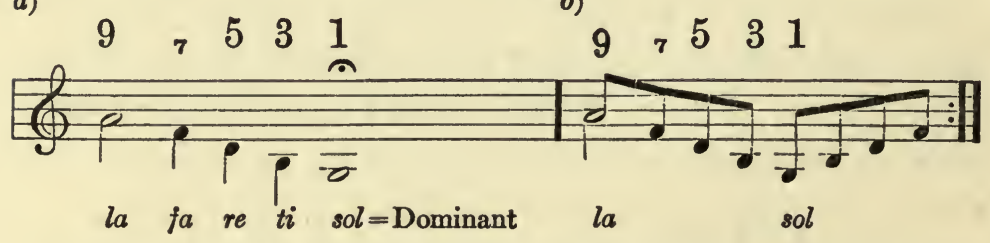

Excepting the last two all the remaining tones are repetitions of those already analyzed.

Last tone but one, $t i$, major third of Dominant. On $t i$ as on re the Dominant-thread reports three components.

a)
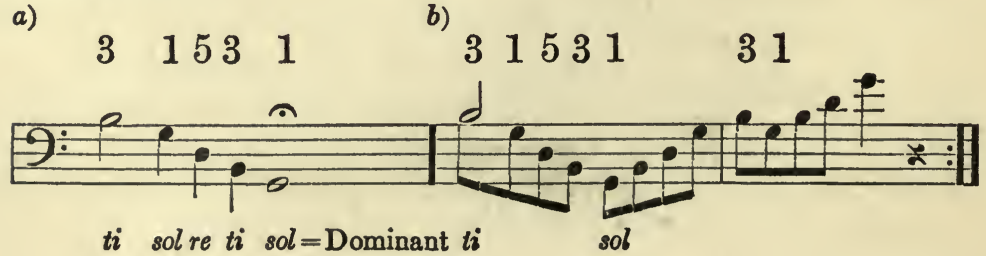
Last tone do, the Tonic, root of Tonic-harmony, the genus consonance and music's first regnant harmony.

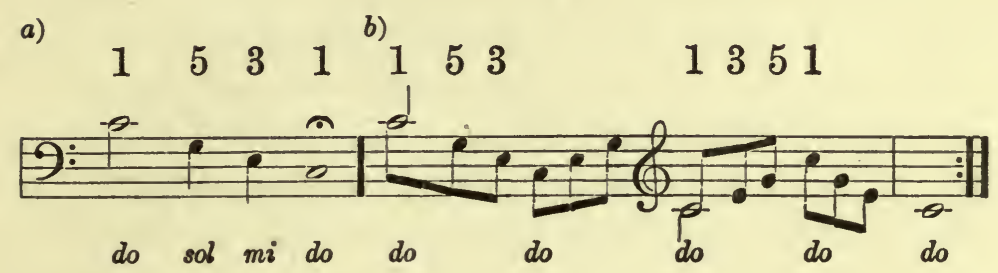

Here ends the analysis of the common report of the harmonic relation and form of each individual tone in this melody. However, the harmonic analysis is not yet complete. As we sing and think over this melody we observe in addition to the fact that each tone reports a harmony another fact, namely, that certain rhythmic groups of these tones relate to and report the predominance of a specific harmony, which I have already named the regnant harmony. Thus in each small phrase we observe a change from one regnant harmony to another, now the Tonic, now the Dominant, as marked in the example. Thus the first small phrase changes from Tonic to Dominant, the second from Dominant to Tonic, and so on. Regnant harmony being the special subject of the next chapter we need pause here only for a few observations. We note that these changes of harmony are instantaneous and recurrent; hence the implication of rhythm in causing these changes. So far I have accounted for the genesis of but one regnant harmony, the Tonic, since every conceivable succession of Tonic-components generates the Tonic-harmony 
and cannot possibly generate any other harmony. The answer in the next chapter to the question How did a second regnant harmony arise? becomes increasingly important. Sol, originally fifth of Tonic, could not appear as a root until the regnant Dominant-harmony had been generated. In passing let us observe that the Tonic-harmony, whether represented by do or $m i$ or sol, is always a three-tone thread. A review of the foregoing analysis will show on the other hand that the Dominant-harmony is a three-tone thread on $t i$ and $r e$, a four-tone thread on fa, a fivetone thread on la. From these threads of three, four and five tones are derived the chords composed of corresponding numbers of tones and known as the Tonic-triad, the Dominant-triad, the Dominantseventh chord and the chord of the major ninth, in all their forms and positions.

While the regnant Dominant appears in the above folksong the tone sol does not appear in it as a root. The following melody is selected because it presents sol as root. In fact, it presents the five original percepts, and the seven original tones in their eight relations to the Tonic and Dominant.

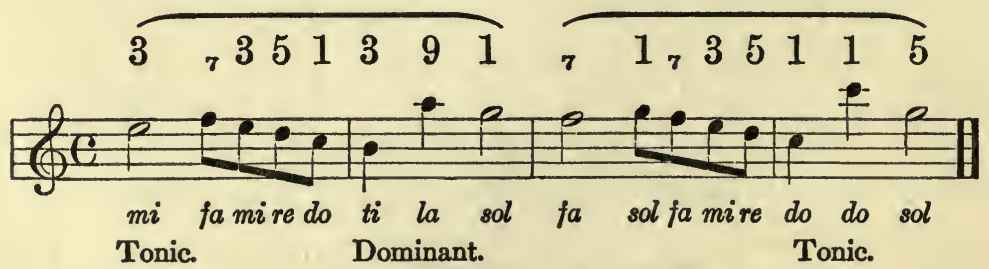

This analysis suffices to establish the following theses as scientific truths. 
1. Original harmony is harmony in one voice and the harmonic basis of music.

2. The original dissonance and consonance had their genesis in one voice, and their component tones are the seven original tones here identified as the seven diatonics of the Major mode.

3. Harmony in one voice asserts itself; each individual tone reports itself as root or third or fifth or seventh or ninth, and these reports are common and unalterable.

4. Rhythmic groups of tones generate and assert their relation to a particular subharmony; now it is one regnant harmony, now it changes to another regnant harmony. In one-voice music the regnant harmonies arise by natural selection, in multi-voice music they are due to personal selection. Regnant harmony determines the exact relation of each tone in a melody.

5. From the original dissonance and consonance are derived three fundamental forms of harmony, namely, the three-tone, four-tone and five-tone forms; five original harmonic percepts, namely, 1, 3, 5, 7,9 .

6. The mode-idea had its origin in the basic relation of cadence and repose, in which relation the original dissonance and consonance had their origin. From the first the mode has been harmonic and is based on the two harmonic genera of tones. The tones of the two genera being the seven Major diatonics it follows that the Major mode is the original mode.

7. Melody is the composite vehicle which has introduced one by one all these tones, percepts, forms and regnant harmonies of the Major mode.

The harmonic reports given in the above analyses 
cannot be changed, not by tempo, slow or fast; not by dynamics, loud or soft; not by interpretation, legato or staccato; they are what they are, not by man's will, but by the universal will and immutable laws inherent in tone-rhythmic relation. The prevalent chord-conception of harmony is responsible for the distinction between harmonic tones and melodic tones; the component tones of a "presiding chord" being called harmonic while the tones that lie over and under and play upon the chord-tones are called melodic. This distinction has lost its usefulness since it has been demonstrated that each individual tone, whether it belongs to the "presiding chord" or not, is harmonic. Were this not true there would be and could be neither tone-cadence nor tone-repose, neither dissonance nor consonance, no relation in the musical sense, in short, no music. The truth that every tone is harmonic is here based on the testimony of the inner ear which is the testimony of common feeling and perception. This truth is reported in all music, primitive and artistic, before Bach, of Bach, after Bach.

\section{On Symbols}

The symbols thus far employed are notes, syllables and harmonic numbers. To these we will add scalenumbers, for which purpose the seven original tones are now presented in the familiar form of the Major scale.

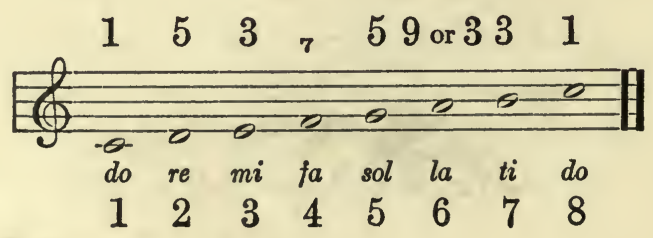


Here the syllables indicate the mode-tones; the notes, the pitch or key of the mode-tones; the upper row of numbers, the inherent harmonic relations; the lower row of numbers, the scale-order from the first to the eighth tone. Scale-numbers are outside, not inside numbers. Street-door numbers tell us nothing of what is going on inside of a house; no more do scalenumbers tell us what is going on inside of a tone; that is, they give us no intelligence whatever of the inherent harmonic relations of tones. To be sure the scalenumbers $1,3,5$ happen to correspond with the harmonic numbers over $d o, m i$ and sol, but the fact that we know that $r e, f a, l a$ and $t i$ are respectively the second, fourth, sixth and seventh tones of the scale by no means implies the slightest knowledge of the one thing we should know, namely, the inherent harmonic relations of the tones. We have seen that during the regnancy of the Tonic, $r e$ is $5, f a$ is $7, l a$ is $3, t i$ is 3 ; that during the regnancy of the Dominant, the relations of these tones are the same except in the case of $l a$, which is a ninth. There are no harmonic percepts answering to the scale-numbers 2,4 and 6 . The habit of orientation by means of scale-numbers is so fixed that when students begin the study of one-voice harmony they are very apt to confuse the scale-numbers with the harmonic numbers and vice versa. Scalenumbers serve a useful purpose, but that purpose should be defined. We will define all the above symbols and so avoid the confusion which would otherwise be inevitable.

1. A note with and without modifying sharp, flat or natural, is the sign and index of the relative pitch of a 
tone. This defines the note according to its position on the staff.

The metrical shape of a note is the sign and index of the relative length of the rhythmic period of a tone.

2. A syllable is the sign and index of the moderelation of a tone. By means of the syllables we are able to think and express the mode-relations without any connection with fixed pitch or key. But the terms mode-relation and key-relation become synonymous the moment the mode-relations are pitched or keyed in staff-notation. C Major means do-Major pitched or keyed on C, but Major always is do-Major whatever be the pitch or key of mode.

3. A harmonic number is the sign and index of the inherent harmonic relation of a tone.

4. A scale-number is the sign and index of the relative position of a tone in a scale. In the Roman form these numbers are employed as indices of the subharmonies, that is, of regnant harmonies. Thus, for example, the Tonic is marked I, the Dominant is marked V, the two roots being the first and fifth tones of the scale.

Of all these signs the harmonic numbers are the most important. Through the discovery of original harmony in one voice these harmonic numbers have gained a theoretic and practical value which hitherto they have not possessed. Their report in one voice is exact, synthetic and complete: exact, because their harmonic report is the common report of common feeling and perception; synthetic, because their exact report of inherent harmonic relation includes the feeling and idea of mode, key and interval; complete, 
because their exact and synthetic reports are indissolubly associated with rhythm, and therefore embody the complete intelligence of a tone's relation. This harmonic report of a tone's relation is therefore the essential and fundamental thing to observe, name and know.

\section{The Five Components of Harmony}

There are but five components of harmony, namely, root, third, fifth, seventh, ninth. The truth of this generalization is in no way impaired by the fact that there are numerous modified forms of these five. Some harmonies have three, some four, some five components, but none exceed the number of five. The ninth is the genetic limit of harmony. Common harmonic feeling and perception report and admit no harmonic components beyond the ninth. Root, third, fifth, seventh and ninth, being the only harmonic percepts, they are the only harmonic components. Chordtheories have admitted elevenths and thirteenths as components of chords and therefore as components of harmony. Such elevenths and thirteenths are purely theoretical concepts, which are as false as they are arbitrary since they have no foundation in and are confuted by common feeling and perception. On page 90 will be found two examples which present these elevenths and thirteenths in their true light as arbitrary computations of intervals from a given root which at $a$ ) is the Tonic and at $b$ ) is the Dominant.

The lower row of numbers in both examples indicates the arbitrary chord-intervals from 1 to 13 . The upper row of numbers in both examples is the true 
index of the common harmonic report of each tone in correlation with all the other tones. Compare the two sets of numbers. In $a$ ) the chord-intervals 7, 9, 11 and 13 are respectively $3,5,7$ and 9 , which are components of the Dominant. In $b$ ) the chord-intervals 11 and 13 are respectively 1 and 3 of the Tonic. The large notes in both examples show that both of these chords combine components of two harmonies; each contains two roots.

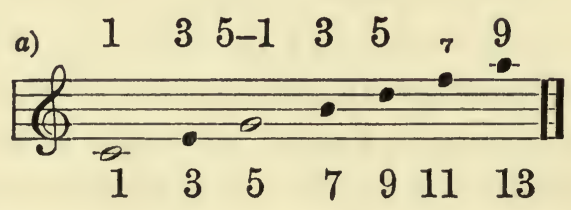

b)

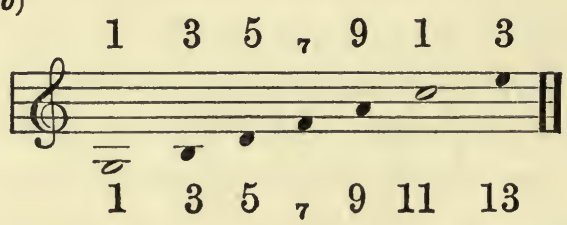

Chords formed by combining the component tones of one harmony I name simple chords; such, for example, are all the forms of the major triad. Chords, like those in the above examples, which are formed by combining the component tones of two or more harmonies, I name compound chords.

Tones which relate to but one root I name simple harmonics; such are 1, 3, 5 of the Tonic and 1, 3, 5, 7, 9 of the Dominant. Tones, like sol in example $a$ ), which simultaneously relate to two roots I name compound harmonics.

Simple and compound chords and harmonics are 
subjects to be treated later on. Meanwhile the above examples clearly point out the necessity for making careful distinctions between harmonic components which never exceed the number of five and chord-components which are not limited; between harmonic intervals and chord-intervals; between harmonic concepts, supported and verified by common feeling and perception, and chord-concepts, which the common reports prove to be false, and which therefore are arbitrary, misleading and untenable.

\section{The Five Original Cadences. Mode Defined}

The relation of cadence and repose is the basis of mode. The relation of tone-cadence and tonerepose originated in the relation of one harmony (dissonance) to another harmony (consonance). This inter-harmonic relation is mode-relation. The preceding account of the origin and nature of original dissonance and consonance in one voice is equivalent to an account of the origin and nature of the Major mode. The original mode is Major because the original consonance is major. The aggregate relations of the two harmonic genera may be called briefly the major consonance and its cadences.

Melody has brought forth two modes : first, the Major mode based on the major consonance and its cadences; second, the Minor mode based on the minor consonance and its cadences. The origin of the former has been explained; the origin of the latter is the subject of a later chapter. In mode-parlance what has just been called the major consonance and its cadences is the Major Tonic (-harmony) and its cadences. 
Three marks succinctly symbolize the mode-idea as follows:-

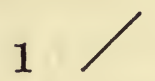

2

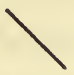

3

In the above order these marks signify rising cadence, falling cadence, repose. Join these marks and we form a simple sign for the Major mode, thus :-

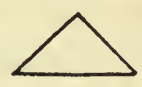

The Major Tonic and its cadences are the five original cadences of music. They are given below where each tone is numbered according to its genus-relation.

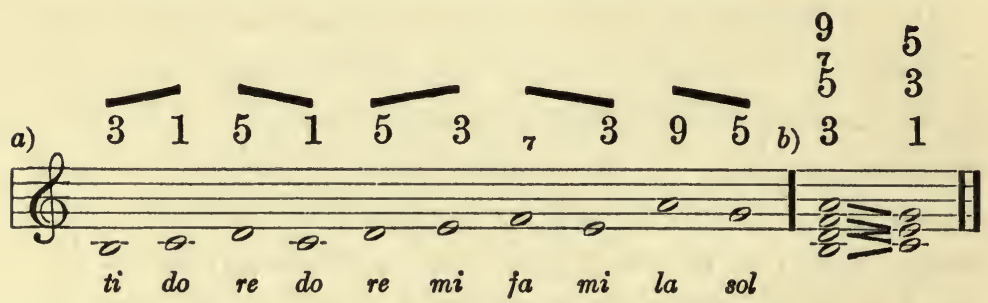

In $a$ ) the cadences are single, in $b$ ) they are combined in chords. Ti resolves in an upward half step, $f a$ in a downward half step: I therefore name ti the upleader, $f a$ the downleader. Of the original four cadence-tones re is the only one that reports both a rising and a falling cadence; in both of its cadences re resolves in a whole step. La reports its falling cadence by resolving in a downward whole step. Of these five original cadences two are rising, three are falling, two resolve in half steps, three in whole steps.

Although we may be able to hear these whole and 
half steps and able to name the two tones in each, although we may be able to perceive and name all intervals from primes to elevenths and able to define them as pure, major, minor, augmented and diminished, double-augmented and double-diminished, yet at the same time we may have no perception and may be completely ignorant of the one thing essential to our intelligent and true appreciation of a step and an interval, namely, the inherent harmony of each of the two tones that form a step and interval. For example. Besides hearing that the two tones in the first of the above cadences are $t i$ and $d o$ and that the step is a half step and an upward resolution, you should hear that you are stepping from the third of one harmony (Dominant) to the root of another harmony (Tonic). The perception of these harmonic and inter-harmonic relations is imperative. Far from inveighing against the customary study and practice of intervals, I consider the working out of intervals from each tone in the octave both a necessary discipline and an essential part of every student's mental equipment and technique. But students are warned to discriminate with care between interval-numbers which indicate the distance from one tone to another and harmonic numbers which indicate the harmonic relation of each individual tone to its root.

There being no melody apart from mode each tone in a melody is a mode-tone. There are three groups of mode-tones: 1. Diatonics. 2. Chromatics. 3. Enharmonics. We have seen that tone connotes harmonic form and harmonic relation, and that a specific form is due to a specific relation. There- 
fore these three groups of mode-tones are three groups of mode-relations. Both mode and tonality mean tone-relation, and at one time the two terms were synonymous. The evolutionary expansion of tonality consequent on the development of modern music has changed all this. While tonality comprehends all that is mode, mode does not comprehend all that is tonality. Definitions will explain. The mode is the sum of relations in one key. Tonality is the sum of relations in all keys. The mode is concerned with the interharmonic relations of one key, tonality with the interharmonic relations of all keys. Thus tonality is a general term and comprehends all that is mode. The evolution of the mode is therefore the first chapter in the evolution of tonality: the three groups of tones and relations are three evolutionary stages of tonality. The first stage culminated in the completion of the foundation-group of seven diatonics, which is the subject still before us. We have symbolized and named each of these tones by a syllable, a note in the key of $\mathrm{C}$, and a scale-number. Each is also known by a technical name which is added to the other names in this example.

Tonic Super- Mediant Sub- Dominant Sub- Subtonic Tonic tonic dominant mediant

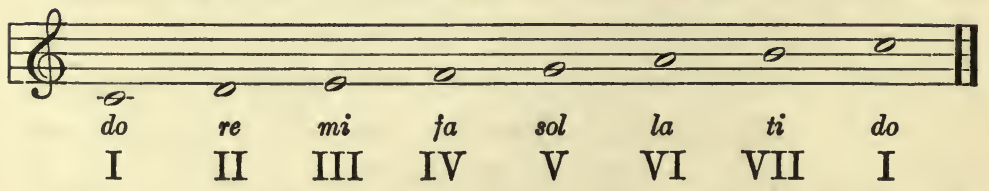

The unity of the mode-idea is exemplified by all these symbols except the notes which fix the pitch or key of mode on $\mathrm{C}$. 
Original harmonic forms and relations are the prototypes of all like forms and relations. Such prototypes are the major consonance, the four-tone and five-tone dissonance, the Major mode, the five original percepts $1,3,5,7,9$, the upleader $t i$, the downleader $f a$. We shall see that the evolutionary expansion of tonality and of the tone-system are due on the one hand to the multiplication of these prototypes, on the other hand to the production of new types which in their turn are multiplied. The multiplication of existing types will be explained by the psychological principle that all forms and relations in experience are potential in and pitchable ${ }^{1}$ on all tones in experience. The production of new types will be explained by the psychological principle of tone-genesis, the efficient accent. Meanwhile the relation of tonality and tonesystem requires definition. The tone-system is the index and scale of tones in use. The tones had their origin in relation, therefore, in tonality. Tonality and tone-system therefore stand in the relation of cause and consequence. The development of the latter was dependent on and concurrent with that of the former. The diatonic stage of tonality caused the diatonic division of the octave which resulted in the diatonic scalesystem. The chromatic stage of tonality caused the chromatic division of the octave which resulted in the chromatic scale-system. The enharmonic stage of tonality caused the enharmonic division of the octave which resulted in our modern enharmonic scale-system. This division of the octave is due to tonality, not to equal temperament as physicists believe. Tem-

${ }^{1}$ Reading uncertain. L. E. K. 
perament there is in musical instruments like the piano, but in music itself there is no temperament. A piano is tempered for the purpose of meeting psychological not physical requirements; to temper a piano is to shape physical means to psychological ends. Tonality is a question of psychology, not of physics. No two half steps, no two whole steps, no two intervals of any denomination, have exactly the same length. The cause lies in tonality, which is a web of harmonic threads. In evolution thread upon thread has been added to this web, so that at the present time the meshes of its thousand threads are so fine and delicate that they almost conceal the diatonic genus-threads with the result that some theorists have denied the existence of such a thing as mode or key. Two simple exercises will fix the two genus-threads which comprise the seven diatonics, in the mind of the student.

a)

b)

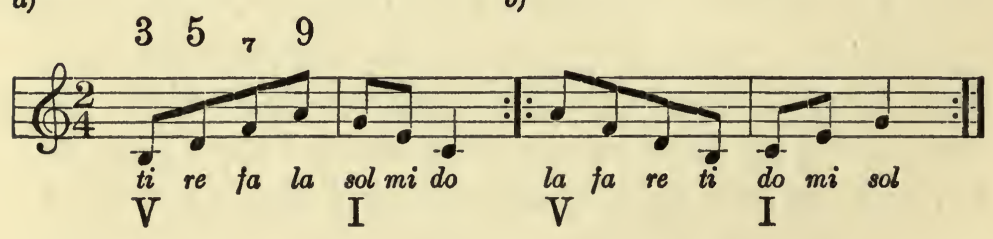

\section{Progression and Resolution.}

Steps from tone to tone are either progressions or resolutions. The step from a cadence-tone to a repose-tone is a resolution on the line of least resistance. Every step not a resolution is a progression. Every step being either the one or the other of the two the distinction between the two is very important. Since 
tones are either in cadence or repose we proceed from tone to tone in four ways as follows:-

1. From cadence to repose = resolution.

2. From repose to cadence $=$ progression.

3. From cadence to cadence $=$ progression.

4. From repose to repose = progression.

These four species of steps appear in the next example: cad. and rep. indicate respectively cadence-tone and repose-tone: the slurs indicate resolutions, and all the other steps are progressions.

$\begin{array}{ccccccccc}1 & 3 & 1 & 5 & 3 & 5 & 7 & 5 & 1 \\ d o & t i & d o & r e & m i & s o l & f a & r e & d o\end{array}$

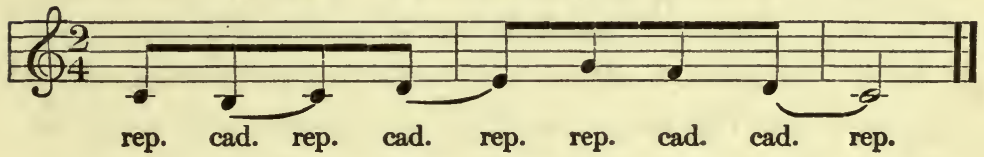

In the following ascending and descending scales each progression and resolution is marked pro. and res. respectively. There are two rising cadences or resolutions in ascending and three falling cadences or resolutions in descending. The step from $f a$ up to sol at N.B., although it proceeds from a cadence-tone
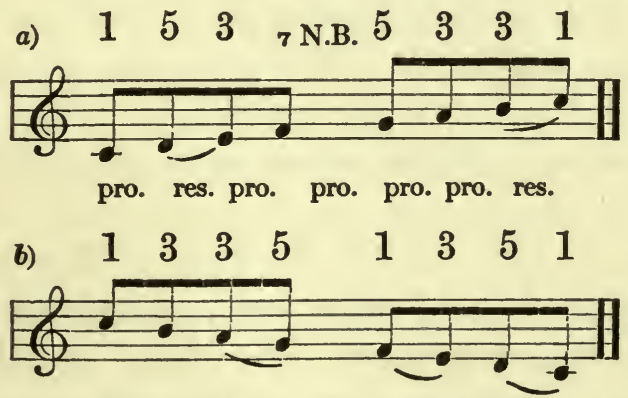

pro. pro. res. pro. res. pro. res. 
to a repose-tone, is a progression, because the cadence of $f a$ falls to $m i$ and does not rise to sol. All such evasions of the inherent cadence of a tone are classed as progressions.

The moment a series of tones is thought rhythmically it at once becomes melody and asserts its inherent regnant harmony, which in both of the above examples is the Tonic.

In a former writing [“The Septonate"] I misnamed progression by calling it a principle. Progression is neither a cause nor a principle. The same is equally true of resolution. Both progression and resolution are effects of causes inherent in the rhythmo-harmonic relation of the two tones forming a specific step.

From rhythm we have derived the basic relation of cadence and repose. In their application to tone the terms cadence and repose have thus far been used in exclusive connection with the four original cadencetones $(t i, r e, f a, l a)$ and the three repose-tones $(d o, m i$, $s o l$ ), in short, with the Major Tonic-harmony and its cadences. From this their original and restricted sense we are presently to use these terms in a wide and general sense as applying to tone-relation in general. Since every tone may appear in cadence or repose it follows that this basic relation derived from rhythm and then connected with specific tones will henceforth apply to tones and tone-relations in general.

\section{A First Music-Lesson}

The material to be presented is as follows:-

1. Rhythm: simple dual and triple. 2. Harmony: the Major Tonic and its five diatonic cadences. 
Method to proceed from generals to particulars, from perception to conception.

The purpose of a first lesson is to transmute a child's latent feeling of the inherent rhythm and harmony of melody into accurate observation. Present a simple diatonic melody and point out its rhythm and harmony in a general way, leaving particulars for the last part of lesson. Next present and explain material as follows:-

1. Rhythm: dual and triple forms: light and heavy accents: relation of these alternating accents to form, to keeping time and balance: no rhythm, no form: rhythm the foundation of form. Let the child express rhythm: beat it, walk it, talk it, as follows:-

Simple Dual Forms.

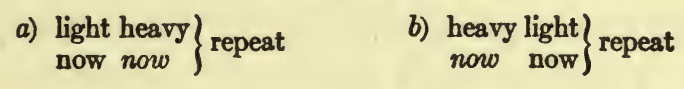

Simple Triple Forms.

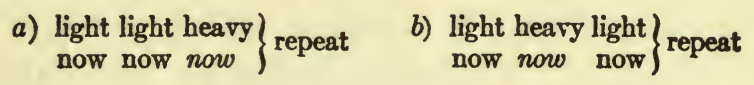

c) heavy light light now now now repeat

Select words whose relative accents correspond with all these forms.

2. Harmony: Let the student learn first the three repose-tones of the Tonic, their syllables and harmonic numbers; next, the four cadence-tones, their syllables and harmonic numbers; next the five diatonic cadences. Observe that the repose-tones and cadencetones each combine in a harmony and chord and resolve the cadence-chord into the repose-chord. 
This is the harmonic foundation, it is all in you. Observe and verify it in yourself and others. Hear it, feel it; name it, think it; sing it, play it; read it, write it, and, as a child of six once prompted me, "then know it."

3. Now return to the simple melody with which you started. Define its rhythm, name each of its tones by a syllable, point out each cadence-tone and repose-tone and give each its harmonic number indicating its harmonic relation.

For many years I have given this first lesson to students of all ages. If desirable the above material may be divided so as to occupy two or three lessons. To learn the lesson and learn it thoroughly is important; how long it takes to accomplish this is unimportant. Study music and be a musician. Music is the what; technique is the how. The latter equals zero if not based on the former. The musician has something to say; he has the right to speak and be heard; his technique is a means to an end; his art is music. On the other hand, the mere technician has nothing to say; he has no such right; his astounding technique amounts to an astounding facility in saying nothing; what should be a means becomes an end in itself; his art is mechanism; his expression is jejune jingle. It is never too late to learn a first musiclesson. 


\section{DISSONANCE AND CONSONANCE}

\section{Work for Students}

Work and write out the following material in all keys, namely, in C, G, D, A, E, B, F $\mathrm{A} b, \mathrm{D} b, \mathrm{G} b, \mathrm{C} b$.
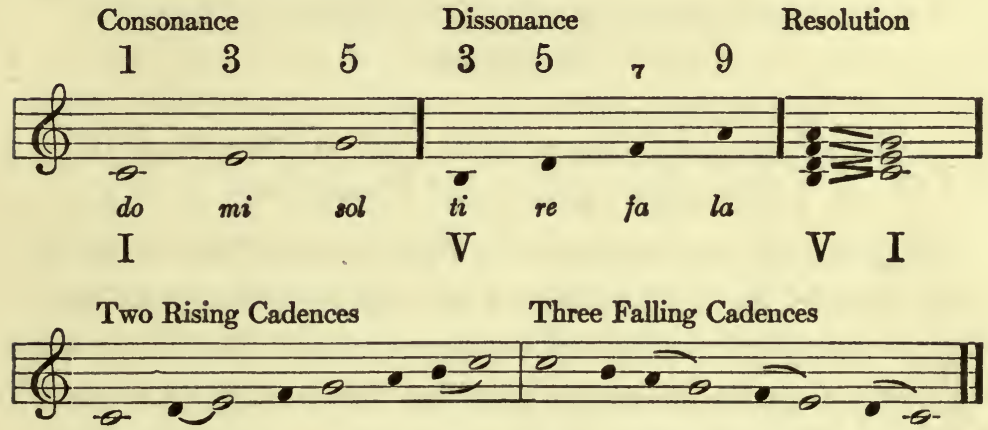

Additional work for students will be indicated from time to time as we proceed. 


\section{CHAPTER IV}

\section{THE EFFICIENT ACCENT AND REGNANT HARMONY OF MELODY}

\section{Regnant Harmony in One Voice and Its Principle of Genesis Explained}

IN preceding chapters we have traced the genesis of harmony back to music in one voice or homophony. In the chapters before us we are to trace the evolution of homophonic harmony in a sequence of cause and effect. Through the sudden transference of the harmonic basis of music from the chord to homophony, through the consequent lengthening of the age of harmony from a period of evolution extending over but a few centuries of chords to a period reaching back from the present to the first beginnings of music unknown ages ago, in short, through the discovery of original harmony in one voice and its common reports, the subject of homophony suddenly stands forth in a new light and gains a new theoretic and historic significance and prominence. In the common reports of homophonic harmony, the enumeration of which we have begun and will continue, we have found the long-sought key to common music-feeling and a common basis for testing truth. These reports have guided us in explaining and verifying the genesis of consonance and dissonance in one voice, and will as securely guide us in tracing the genesis of 
new homophonic harmonies. We have accounted for the genesis of the foundation-group of seven component tones and five harmonic percepts of the original consonance and dissonance, and I have named this original group the Major Tonic and its cadences. From this original group new forms of harmony introducing new tones and new harmonic percepts have been derived. How? Through rhythmic relation like their antecedents. The cause of the genesis of consonance and dissonance we discovered to be the rhythm-derived relation of cadence and repose. Rhythmic relation has produced all subsequent new forms of harmony. The psychology of this evolutionary process is next defined in terms applying to every stage in the development of homophony. Existing tones in existing relations generate and report only existing forms of harmony, while in new or changed relations they generate and report new forms of harmony. Next we will apply these principles to the foundation-group of tones. The seven original tones in their original relations in cadence and repose generate and report only the original forms of harmony in which they arose, while in new or changed relations they generate and report new forms of harmony introducing new tones and new harmonic percepts. The evolution of harmony is therefore the direct cause of the expansion of tonality and consequent expansion of the tone-system. Each developmental step in music was therefore dependent on and due to the evolution of harmony, and the three successive and interdependent stages of music, namely, homophony, polyphony and 
chords, are so many stages of harmonic evolution. Hence this logical conclusion. Root, trunk and overspreading boughs, all music from first to last is one growth of one psychological tree of tone-relations and forms of harmony. All tone-relations and forms of harmony in one voice, where did their genesis take place? In feeling, under the impulse of indwelling causes. In what form were they first embodied and expressed? In melody, the original voice and vehicle of tone-language, the indissoluble composite of relation and form in time (rhythm) and relation and form in space (harmony), the essence, heart and soul of music. All that is essential and potential in homophony is embodied in melody. Thus our study of homophony resolves itself into that of the common reports of our common feeling and perception of melody. Are we not all of us melodists? What is all primitive music but primitive melody, formal music but conventional melody, modern music but free melody? All along the line, are not all the great composers melodists? Are not their works immortal because their melodies are immortal?

This introduction to the several chapters before us may be concluded with a few observations which will focus our attention upon the special subject directly before us. One regnant harmony after another had its genesis in feeling and was embodied in and reported by melody. In a book published fourteen years ago ["The Septonate"] what I now call harmony in one voice I there named meloharmony, the inherent harmony of melody; what I now call regnant harmony $I$ there named ruling or governing 
harmony; what I now call the efficient accent was there named the rhythmo-harmonic accent or point.

1. The evolutionary sequence of homophonic harmonies is a sequence of regnant harmonies which melody brought forth one by one beginning with the regnant Major Tonic, the nucleus in relation to which the others arose. A regnant harmony asserts itself during every moment in melody. The regnant harmony of the moment selects and asserts itself, it determines the exact harmonic relation of each tone in melody and we all hear it in common. Therefore all melodies are based on regnant harmonies, the simplest on one such harmony (Major Tonic), the more complex on two or more such harmonies.

2. The efficient accent is the heavy recurring rhythmic accent of melody; it is the principle of harmonic genesis and development in homophony, and has generated one regnant harmony after another. The shortest melody consisting of two tones has but one efficient accent: the cuckoo-song is an example. Longer melodies are connected by a series of such accents. As a melody proceeds from one such accent to another one of two things happens: either the initial regnant harmony is maintained and repeated, or a new regnant harmony is generated. We are to study the causes in both cases. Two conditions were indispensable to the development of music beyond the stage of one regnant harmony, the Major Tonic. These were first, the lengthening of melody from one efficient accent to a series of such accents; second, the genesis of a second regnant harmony.

3. The component tones of the regnant harmony 
are named regnant tones. The tones lying over and under and cadencing up and down into the regnant tones are named bytones. Bytones are components of other harmonies named byharmonies. Regnant harmony, regnant tone; byharmony, bytone; let us bear these terms and their meanings in mind. The first regnant tones to appear in melody were $d o, m i$, sol, of the regnant Major Tonic: the first bytones to appear were the original cadence-tones $r e, l a, f a$ and $t i$, which as we have seen arose in relation to the Major Tonic-harmony. Of these embryonic melodies there are two types: first, those lowest in the order of development composed of regnant tones only and representing harmonic perception and harmonic relation in their incipiency and within their narrowest confines; second, those next in order of development, which introduce bytones along with the regnant tones, thus marking an advance in harmonic perception and relation. Melody based on one regnant harmony could advance no further; the second type of melody brings its first chapter of development to a conclusion, and this first chapter of melody corresponds with the first developmental chapter of harmony. From first to last the development of melody is dependent on that of harmony; melody could not advance another step until a second regnant harmony arose in relation to the first. When this step was taken a significant change was suddenly effected, for at one bound harmonic relation expanded from that of bytone to one regnant harmony to that of one regnant harmony to another regnant harmony; at one bound melody entered into a new region of inexhaust- 
ible fertility and initiated a new chapter in musicevolution, the end of which has not yet been reached. Let us be explicit on this point. Melody started with one regnant harmony as a nucleus, in relation to which it produced other regnant harmonies, in relation to which it produced still others, and so on ad infinitum, thus evolving an ever increasing psychological web of correlated threads of harmony. How then did melody recombine the seven original tones in new relations which generated one regnant harmony after another?

4. In every conceivable combination of the tones $d o, m i$, sol, melody reports the regnancy of the Major Tonic (I). In other words, a second regnant harmony is not latent or potential in this type of melody.

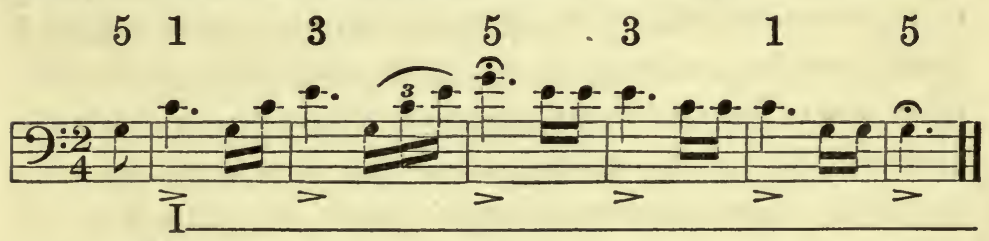

5. Melody first introduced bytones on its light rhythmic accents. In this their original relation the cadence-tones $r e, l a, f a$ and $t i$ do not disturb the regnancy of the Major Tonic and could not have generated a second regnant harmony. The example below presents $r e$ and $l a$, which are the first two bytones to appear in melody, re in cadence to do and mediating between do and mi, la in cadence to sol.

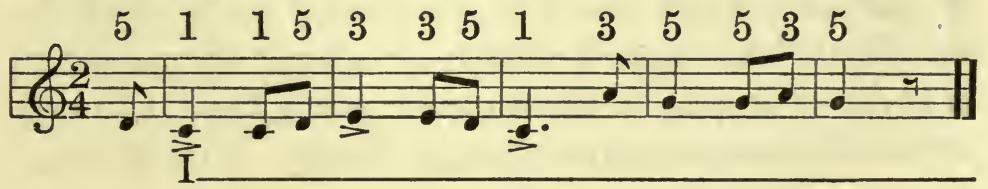


6. But at the moment when melody introduced $r e$ and $l a$ on its heavy rhythmic accents (efficient accents) the great transformation takes place. Suddenly $r e$ and $l a$ are transformed into regnant tones reporting regnant harmonies. The efficient accent on $r e$ generates the regnant Dominant-harmony (V): the efficient accent on la generates the regnant Subdominant-harmony (IV). These common harmonic reports of melody are next exemplified.

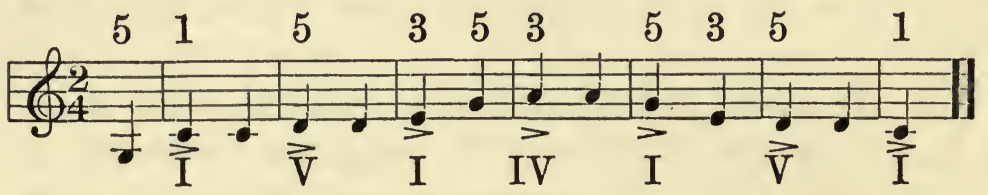

Each of the above efficient accents reports a change of regnant harmony; the mode relation of one regnant harmony to another is at once established in this pentatonic or five-tone stage of melody, and melody is enriched by the addition of two new regnant harmonies. The regnant Major Tonic, as we have seen, arose independently on an isolated tone. Not so with the regnant $\mathrm{V}$ and $\mathrm{IV}$, which arose in relation to and were dependent on the previously existing regnant $\mathbf{I}$. This dependence on and genesis in relation to antecedent harmonies distinguishes all other harmonies from the original regnant $I$, which has no antecedents. We observe further that while the regnant I entered into being by way of do its root, the regnant $\mathrm{V}$ was first represented and reported by $r e$ its fifth, the regnant IV by la its third. Such are the common reports of common feeling and perception, at once the simplest and surest test of truth. The efficient 
accent of melody has generated these first three regnant harmonies in the order $I, V, I V$, and the regnant harmony of melody arises of itself, asserts itself and is unalterable in one voice. We note that evolving melody in spinning the psychological web of correlated threads of harmony began with one thread, do, mi, sol of I; melody next added the bytones $r e$ and $l a$ on light rhythmic accents, re reporting $\mathrm{V}$ as byharmony, la reporting IV as byharmony; melody next introduced $r e$ and $l a$ on efficient accents and so produced the regnant $\mathrm{V}$ and IV. Thus far we have traced the genesis of harmony, and the addition of the regnant $\mathrm{V}$ and $\mathrm{IV}$ to $\mathrm{I}$ opens new channels of development and so many changes and possibilities in harmonic relation that it may be well to present the more noticeable points one by one.

7. The melodies in our last two examples are pentatonic, that is, composed. of the five tones $d o$, $r e, m i, s o l, l a$, which we have already identified as the pentatonic scale. Enough has been explained to show the archæologist that in his endeavor to establish the true chronological order of primitive melodies his conclusions are to be deduced not alone from the number of individual tones or the scale of a given melody, but from the inherent harmonic content and relations of that melody. The scale is not the thing of essential importance, but the inherent harmony is the important thing, the true guide and test. Melodies composed of the components of regnant I exclusively are earliest; melodies containing the bytone $r e$ are later, those containing the bytone $l a$ are still later; those containing the regnant $\mathrm{V}$ and IV 
are still later. The pentatonic stage of melody is evidenced in all primitive music in one of three ways: either these melodies precede or are approaching the pentatonic stage, or they have reached it or they have passed it. Not only was the pentatonic stage the natural product of the progressive development of music per se, but the entire development of the language and art of music up to the present time was dependent on the attainment and passage remote ages ago of the pentatonic stage of melody.

8. Certain tones like $d o, m i$, sol and others first appeared in melody in the relation of regnant tones (components of regnant harmonies). Certain tones like $r e, l a$ and others first appeared in the relation of bytones (components of byharmonies). We have seen how V and IV were transmuted from byharmonies to regnant harmonies. We are about to see how regnant $I$ is transmuted into a byharmony. The point to be noted here is this. Every such change of a tone's original relation to a new relation marks not alone the progress of melody consequent on the progressive development of its inherent potential harmony and harmonic relations, but it at once marks the progressive development of the harmonic sense, which is the proximate cause of the progress of melody and expansion of harmony, and which steadily though slowly led to the eventual discovery. or perception of harmony itself. The evolution of harmonic perception affords a striking example of the extreme slowness of the evolutionary processes of perception in general. Although from the first and through countless ages melody has asserted its inherent 
harmony, yet man's discovery or perception of harmony and its introduction in the form of chord date back but a few centuries. However, this great slowness is offset by what followed, for this discovery of harmony was magical in its effects, initiating as it did an era of development in music which for rapidity of progress and wealth of productivity has no parallel in psychology and history.

9. When we were dealing with but one regnant harmony and its bytones (Major Tonic and its cadences) the term repose applied exclusively to the original repose-harmony or major consonance and to the stable period of rhythm-repose in which this stable harmony arose. Then, too, the term cadence applied exclusively to the original cadence-harmony or dissonance and to the unstable and relative period of rhythm-cadence in which this unstable and relative harmony arose. But now that we have introduced three regnant harmonies all this is changed. Now and henceforth the terms cadence and repose become general and apply to rhythmic and harmonic forms and relations in general while the terms bytone and byharmony, regnant tone and regnant harmony become the specific and unmodifiable terms of analysis. Thus, for example, what we hitherto called the Major Tonic and its cadences we now specify as reg. I and its bytones. Presently we are to analyze reg. V and its bytones, reg. IV and its bytones. Here let us note the fact that every regnant harmony has its relative byharmonies.

In taking up the analysis of the broad relation of regnant harmony to regnant harmony let us bear in mind the following general truths: 1. Every tone 
reports a harmonic form and relation. 2. Every tone reports a consonance or a dissonance, is in cadence or repose, is a bytone or a regnant tone. 3. Every step from tone to tone, from harmony to harmony, is a progression or a resolution. 4. All these reports are common reports.

10. The regnant harmony of the moment is the repose and equilibrium of that moment. Whether the regnant harmony of the moment be I or V or IV or any other it is the repose and equilibrium of that moment. This is illustrated in our last example where the regnant harmonies appear in this order, $\mathrm{I}-\mathrm{V}-\mathrm{I}-\mathrm{IV}-\mathrm{I}-\mathrm{V}-\mathrm{I}$. Here we note the wider application of the term repose in the sense of the equilibrium of the moment.

11. The regnant harmony of one moment relates to the regnant harmony of the next moment. But the relation of a byharmony is confined to the single moment of one regnant harmony. See last example but one. The basic rhythmic links of a melody are its series of efficient accents, and the basic harmonic links of a melody are its series of regnant harmonies. Since the tones that fall on efficient accents generate and report the regnant harmonies, and since the moment from one such accent to another is that of one regnant harmony to another, it is clear that these rhythmic and harmonic links of melody are inseparably united and interdependent. The minute analysis of this relation of and movement from one regnant harmony to another now confronts us.

12. The steps from $I$ to $V$ and $I$ to IV are progressions; see below at $a$ ) and $c$ ). The steps 
from $V$ to $I$ and $I V$ to $I$ are resolutions; see below at $b$ ) and $d$ ). In these resolutions $\mathrm{V}$ and IV are in cadence to I. Here note the wider application of the term cadence in this connection with regnant harmony. Though the regnant harmony of the moment is the repose and equilibrium of the moment, we observe at $b$ ) and $d$ ) that it may be in cadence, that is, in unstable equilibrium.

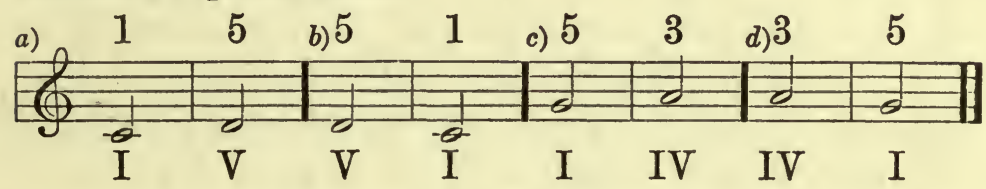

In the progression $\mathrm{I}-\mathrm{V}$ at $a$ ) re reports $\mathrm{V}$ as consonance with sol as concomitant 1 and $t i$ as concomitant 3. But in the resolution and cadence V-I at $b$ ) re reports $\mathrm{V}$ as dissonance, and in this cadencerelation all the original cadence-tones, namely, $t i, r e$, $f a$ and $l a$, assert themselves as components of the genus dissonance in that they each and all claim sol as their common root. Not until melody had produced regnant $\mathrm{V}$ in this cadence-relation was it possible for $l a$ to assert itself as 9. This genesis of regnant $\mathbf{V}$ in cadence belongs to melody's pentatonic stage and was generated by the efficient accent on re. During this stage sol which already existed as 5 of I could next be related as 1 of $\mathrm{V}$, and $l a$, which already existed as a bytone and as 3 of the byharmony IV, could next be related as 9 of $\mathrm{V}$. In short, during this stage melody became enriched by many new intervals resulting from the combinations of re, sol and $l a$ during the regnancy of $\mathrm{V}$ in cadence. Illustrations of some of these intervals follow. 

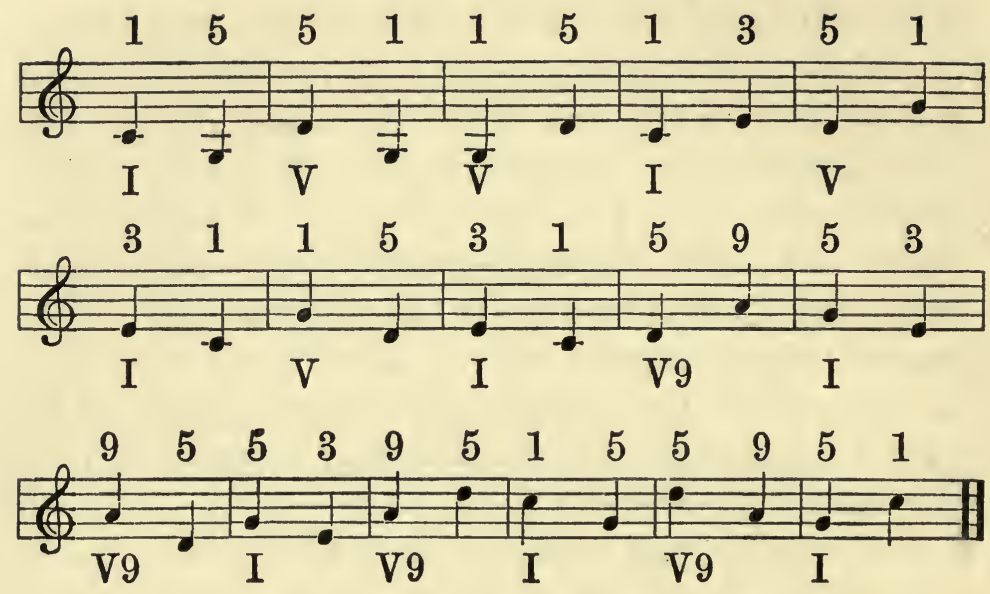

Next when the concomitants $t i$ as 3 of $\mathrm{V}$ and $f a$ as 7 of $\mathrm{V}$ were differentiated as individual tones the melody emerged from its pentatonic stage and was again enriched by many new intervals resulting from combinations of sol, re and $l a$ with $t i$ and fa during the regnancy of V. Some examples are given.
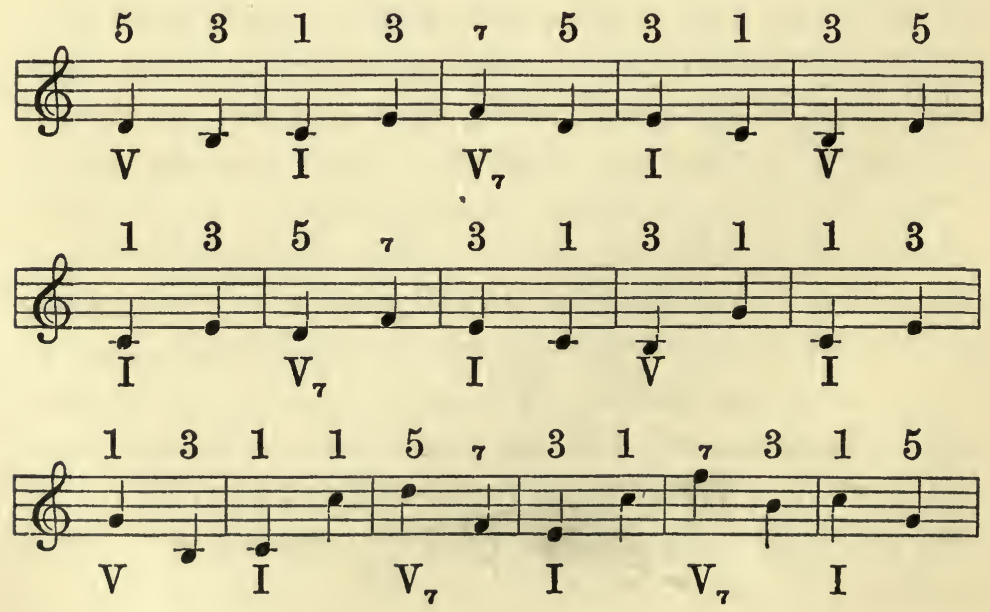


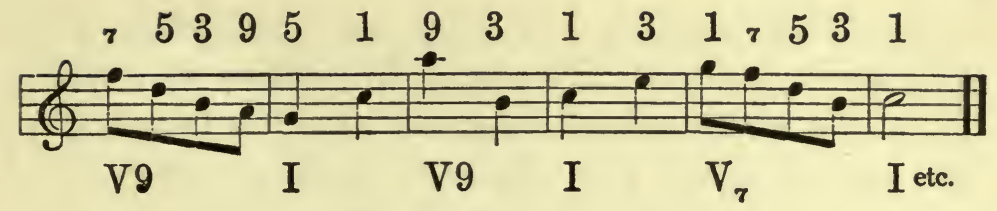

Here note the fact that regnant $\mathrm{V}$ is sometimes a consonance, sometimes a dissonance with four components as $\mathrm{V}_{7}$, sometimes a dissonance with five components as V9. Hence this general truth: The regnant harmony of the moment may be either a consonance or a dissonance.

Attention is again called to the first example of this paragraph. Both in the progression I-IV at $c$ ) and the resolution IV-I at $d$ ) regnant IV is reported a consonance by la. In both relations la reports do as concomitant 5 and $f a$ as concomitant 1 . Regnant IV again enriches melody with new intervals resulting from combinations of its components $f a, l a$ and $d o$. A few examples appear below.
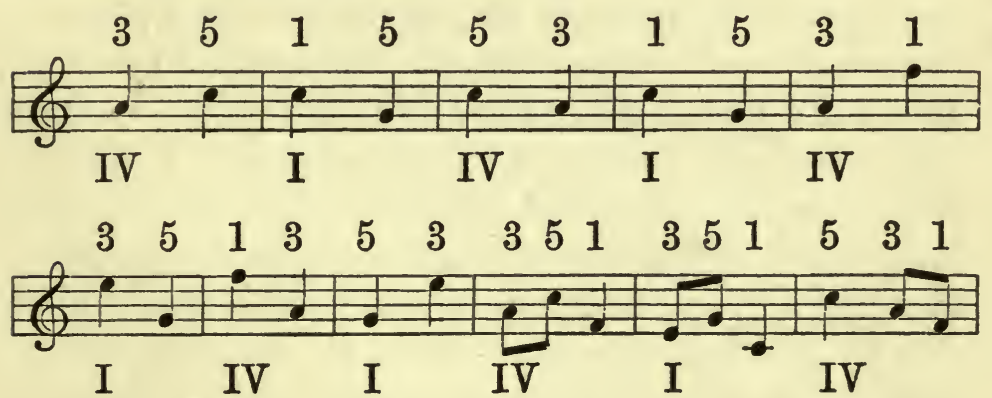

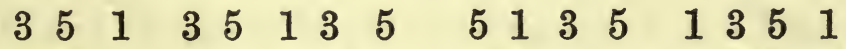

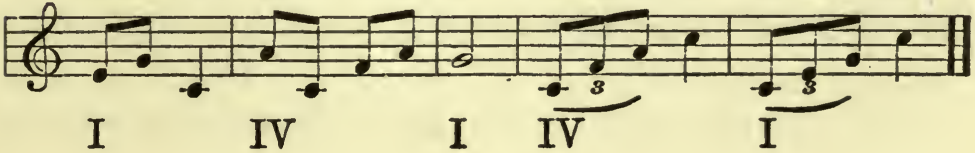


Here we observe that regnant IV, though it is a consonance, is in cadence to $I$. Hence this truth: Consonances as well as dissonances may be in cadence. Further analysis will extricate us from what here threatens to become a tangle of terms. This may be avoided by at once stating the following general truth which opens up and covers the whole subject of regnant harmony and its byharmony. Both byharmonies and regnant harmonies may be either consonances or dissonances : the former are always in cadence or unstable equilibrium, the latter may be either in repose (stable equilibrium) or in cadence (unstable equilibrium). Byharmony and dissonance, regnant harmony and consonance, these are not interchangeable terms. Confusion of these terms will result in complete confusion. Distinction between these terms will preserve complete clarity.

13. In the harmonic analysis of melody the series of questions to be answered are these: 1. What is the regnant harmony of the moment? Is its form a consonance or a dissonance? What are the regnant tones and their relations? 2. What are the bytones, their relations, the forms of harmony they represent? These leading analytical questions apply to all music since music the world over, past and present, primitive and modern, one-voice and multi-voice, is one in kind. These questions therefore apply to bird-melodies as well as human melodies, to oriental as well as occidental music, to Greek and Ecclesiastical melodies as well as to folksongs and dances, sonatas and symphonies.

14. Owing to the changes from one regnant 
harmony to another reported by the efficient accent of melody each of the seven diatonics appears now as a regnant tone, now as a bytone. Thus what is a regnant harmony at one moment is transmuted into a byharmony the next moment and the reverse. Our next example presents I with bytones, V with bytones and IV with bytones, and all these regnant harmonies and byharmonies are diatonic. A harmony is classed as diatonic when all its concomitants or components are diatonic.

\section{$\begin{array}{lllllllllllllll}1 & 3 & 1 & 3 & 1 & 3 & 1 & 5 & 1 & 5 & 1 & 5 & 3 & 5 & 3\end{array}$}

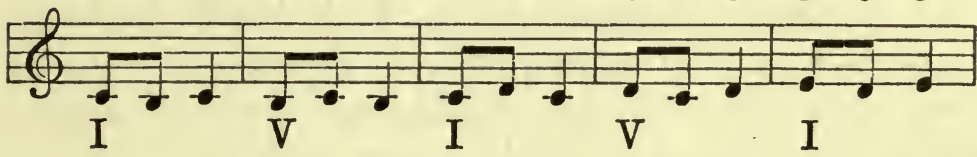

$\begin{array}{lllllllllllllll}5 & 3 & 5 & 3 & & 3 & 1 & 3 & 1 & 5 & & 5 & 1 & 5 & 1\end{array}$

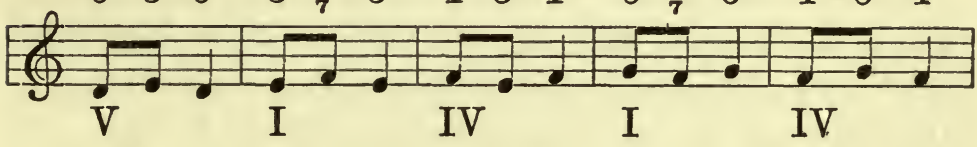

$\begin{array}{llllllllllllllll}5 & 3 & 5 & 3 & 5 & 3 & 3 & 9 & 3 & 3 & 3 & 3 & 3 & 1 & 3 & 1\end{array}$

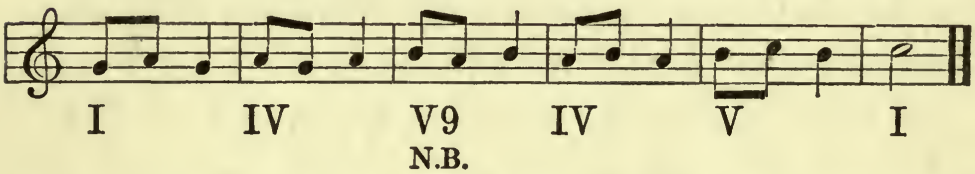

Except at N.B. all the above regnant harmonies are consonances. Except at N.B. the second tone in each measure is a bytone, but this second tone in every measure including N.B. is in cadence. With one exception all the byharmonies are consonances in cadence. The exception is reported by fa during the regnancy of $I$ when the byharmony is a fourtone dissonance as shown by the report of $f a$ as 7 . At 
N.B. the regnant harmony is V9 owing to the presence of $l a$ which is at once a regnant tone and in cadence and, strange to say, resolves into its own harmony. The ninth is the first harmonic component distinguished by these peculiarities, especially that of resolving into its own harmony, and la being the original ninth it was the first tone that appeared in this paradoxical relation. This characteristic instability of la as ninth during the regnancy of $\mathrm{V}$, caused by its position beyond the octave of its root, will be further illustrated as we proceed seriatim to analyze the diatonic bytones of each of the three regnant harmonies under consideration. Let us remember that at present we are dealing exclusively with diatonic harmonies as defined a moment ago.

$A$. The diatonic bytones of reg. I are $t i 3$, re 5 , $f a$ 7, la 3. During this regnancy these bytones persist each in the harmonic report just given. Even when playing upon the same regnant tone $f a$ and $l a$ persist in their respective reports as 7 and 3 as will be heard in the following fugue-subject of Bach here transcribed from C to C Major:-

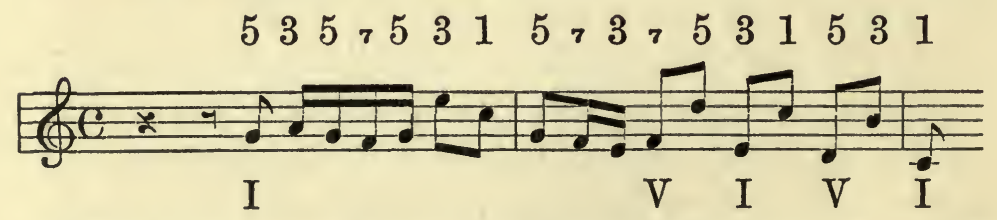

Previous examples present a sufficient number of illustrations of these bytones, and what still remains to be said of them will be found in the chapter on cadences.

$B$. During the regnancy of $\mathrm{V}$ there are but two diatonic bytones, namely, do 1 and $m i 3$ as follows:- 


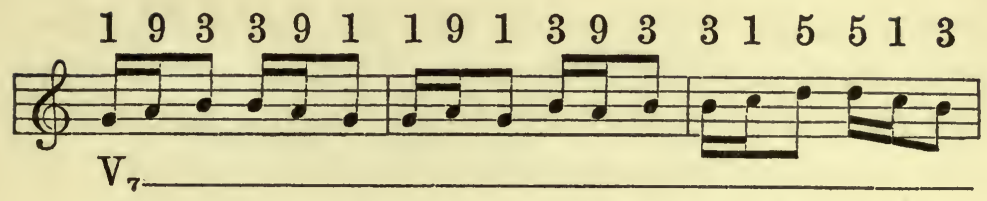

$\begin{array}{llllllllllllllllll}3 & 1 & 3 & 5 & 1 & 5 & 5 & 3 & 7 & 7 & 3 & 5 & 3 & 7 & 3 & 7 & 3 & 7\end{array}$

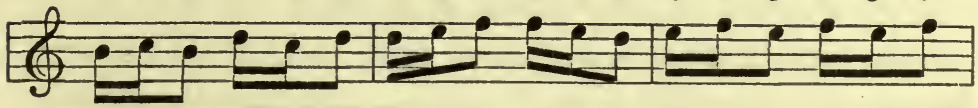

71991771717197539175931

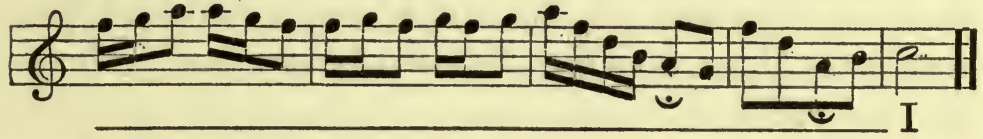

The bytone do plays on regnant $t i$ and $r e$, the bytone $m i$ plays on regnant $r e$ and $f a$. The cadences of regnant $l a$ to regnant sol and $t i$ appear in the first two measures and are emphasized through fermatas in the last two measures. These steps of $d o, m i$ and $l a$ are the only cadences in our example, all the other steps being progressions from one regnant tone to another.

C. Regnant IV has four diatonic bytones. They are $m i$ 3, sol 5, ti 3, re 5. Unless we generate the feeling of regnant IV we cannot perceive the true harmonic relations and reports of its bytones. In the subjoined example of the common reports of these bytones the feeling of IV is generated in the opening measures.

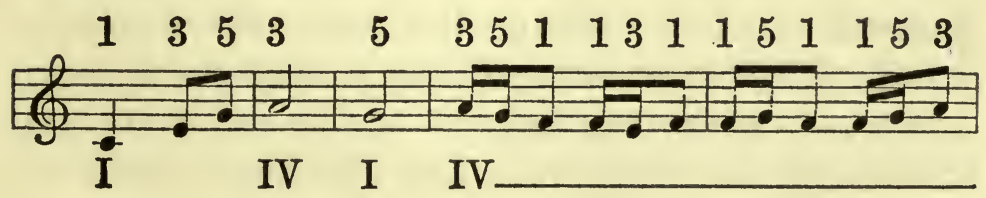




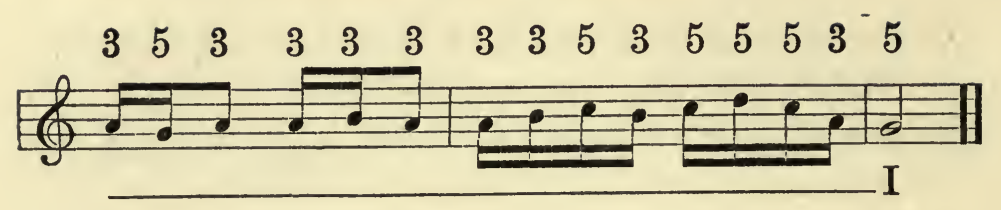

Noteworthy among these reports are the series of major thirds 3-3-3 (third last measure) and the series of pure fifths $5-5-5$ (second last measure). These reports have a bearing on certain important harmonic questions to be considered later on. We have now presented the diatonic bytones of each of the harmonies I, V and IV.

15. Certain changes in the rhythmic distribution of regnant tones and bytones mark concomitant changes from an earlier to a later stage of meloharmonic development, therefore of psychological development. Most of the examples thus far given illustrate the earlier of the two stages when regnant tones and bytones occupied the rhythmic periods in which they first arose, the former appearing on the heavy (efficient) periods of rhythm-repose, the latter on the light and unstable periods of rhythm-cadence. Rhythmic movements being characterized by regular alternations of light and heavy periods and accents, that is, by regular alternations of rhythm-cadence and rhythm-repose in obedience to the universal shaping principle of equilibrium, we may define this basic and universal relation of rhythmic cadence and repose as that of a rhythmic Dominant to a rhythmic Tonic, since the intoning of this relation caused the genesis of dissonance (V9) in rhythm-cadence and consonance (I) in rhythm-repose, therefore of the real 
Dominant and the real Tonic. The distribution of regnant tones and bytones illustrative of melodies belonging to the earlier of the two stages is as follows:-

Coincident rhythm-repose (heavy period and accent) and tone-repose (regnant tone).

Coincident rhythm-cadence (light period and accent) and tone-cadence (bytone).

The later of the two stages is illustrated by melodies in which regnant tones and bytones exchange their original rhythmic positions, the former occupying the cadence-periods, the latter occupying the reposeperiods of rhythm, as follows:-

Coincident rhythm-repose (heavy period and accent) and tone-cadence (bytone).

Coincident rhythm-cadence (light period and accent) and tone-repose (regnant tone).

This shifting of bytones from light to heavy rhythmic periods indicates a great advance in the development of melody consequent on that of the harmonic sense. Illustrations appear below.

$\begin{array}{llllllllllllllll}5 & 1 & 3 & 5 & 3 & 5 & 3 & 1 & 3 & 5 & 3 & 1 & 5 & 1 & 5 & 3\end{array}$
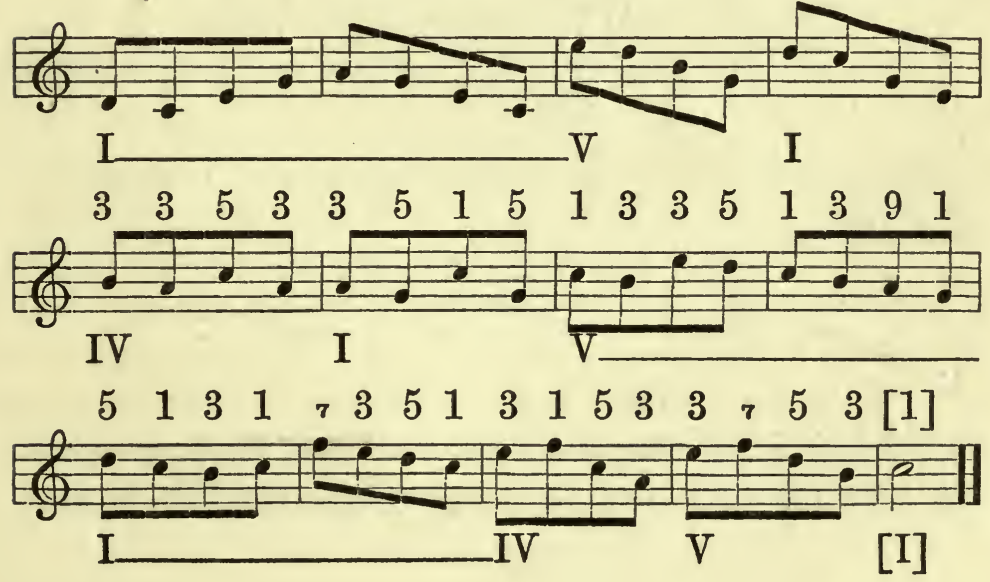
Further illustrations of diatonic bytones will appear in the chapter on cadences.

16. The truth that a tone's specific harmonic form is caused by its specific combined relation in time and space has been and will continue to be demonstrated. Thus far each of the seven diatonics (original tones) has appeared as a regnant tone and as a bytone, and has reported one of the five original harmonic percepts 1 or 3 or 5 or 7 or 9 . Thus far each of the seven has appeared in the following harmonic relations: do as 1 of $\mathrm{I}$ and as 5 of $\mathrm{IV}$; $m i$ as 3 of $\mathrm{I}$; sol as 5 of $\mathrm{I}$ and as $\mathbf{I}$ of $\mathrm{V}$; $t i$ as 3 of $\mathrm{V}$; $r e$ as 5 of $\mathrm{V}$; fa as 7 of $\mathrm{V}$ and 1 of IV; $l a$ as 9 of $\mathrm{V}$ and 3 of IV. This summary shows that four diatonics (do, sol, fa and $l a$ ) have appeared each in two harmonies, while the remaining three $(m i, r e, t i)$ have appeared only in one harmony. The former are bond-tones or connecting links between two harmonies. Of these sol is the first and the nexus between $I$ and $V, I$ and $V_{7}, I$ and V9 as follows:-

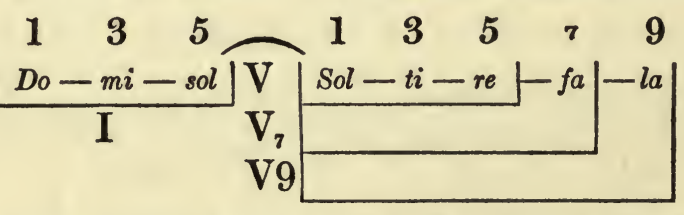

The next bond-tone is do, the nexus between I and IV.

$$
\underbrace{\left.\begin{array}{ccc}
1 & 3 & 5 \\
F a & -l a & -d o
\end{array}\right]\left[\begin{array}{ccc}
1 & 3 & 5 \\
D o & -m i & -8 o l
\end{array}\right]}_{\text {IV }}
$$

Sol, being the original bond-tone and first connecting link between two harmonies, was the first of the 
seven diatonics to undergo a change of relation, namely, from 5 to 1 . Next to follow was do, changing its relation from 1 to 5 . These bond-tones plainly indicate that the roots of the two harmonies which each connects lie a fifth apart. Thus $\mathrm{I}-\mathrm{V}$ connected by sol and I-IV connected by do are called fifthrelated harmonies. These fifth-related harmonies are not only the first of their kind, but are the first of any kind. This explains why fifth-related harmonies are nearest related harmonies, why fifth-related keys are nearest related keys. These fifth-relations also disclose the origin of the authentic closing-cadence $\mathrm{V}-\mathrm{I}$, of the plagal closing-cadence IV-I and of the fifthcycle of keys. In these diatonic-Major relations the bond-tones sol and $d o$ are in repose and stable, and this is true of all bond-tones of fifth-related harmonies. The case is otherwise with the bond-tones $f a$ and $l a$ which in all the relations thus far presented maintain their unstable character, which is explained by the fact that they belong to the genus dissonance. Whether as bytones to I or as regnant tones in V9 and IV or as bond-tones connecting V9-IV and IV-V9, both $f a$ and $l a$ manifest this unstable character, and they do not gain repose and stability until they appear in Minor as we shall see in the next chapter. Meanwhile I present them as connecting links between V9 and IV.

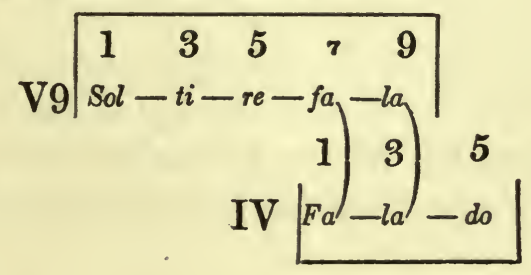


17. As defined on a previous page, a harmony is diatonic when all its components are diatonics. The test of the pure diatonic harmonies of melody, in fact of all the harmonic forms and relations of melody, lies in the common reports of original harmony in one voice. In one voice a diatonic in certain relations generates a thread of harmony in which all the concomitants are diatonics, while in certain other relations the same diatonic generates a thread of harmony among whose components there are chromatics and even enharmonics mingling with diatonics, as we shall see in the sequel. Here we are concerned with pure diatonic harmonies. I, V, $\mathrm{V}_{7}$, V9 and IV are diatonic harmonies and the only ones in the Major mode. All forms of harmony are consonances or dissonances. Each specific form of consonance and dissonance had its genesis on a specific tone in a specific relation, and each such original form is a prototype. Once generated and differentiated each prototype is reproduced and repeated on other tones also in specific relations. The harmonies thus far generated will serve as an illustration. I, V and IV are major consonances: $\mathrm{I}$ is the prototype of this specific form and it first arose on do $1 ; \mathrm{V}$ and IV are reproductions and replicates, the former arose on $r e 5$, the latter on la 3. Again, $\mathrm{V}_{7}$ and V9 are major dissonances, and both are prototypes of their respective forms of which all like forms are replicates. This concludes the summary of the diatonic harmonies of the Major mode. In the next chapter, the subject of which is the origin of the Minor harmony and mode, we shall encounter three other diatonic harmonies and 
new forms of consonance and dissonance, all of which are minor.

18. The operation of the principle of harmonic genesis and regnant harmony, the efficient accent, has now been exemplified. We shall resume these subjects later on, but before dismissing them here it may be well to pause and observe the operation of this principle with greater scrutiny. We have noted that alternating rhythm-periods make for rhythmic equilibrium, that alternating tone-rhythmic periods make for combined rhythmo-harmonic equilibrium, in short, that the connection between harmonic equilibrium and rhythmic equilibrium is indissoluble, and that rhythm has transmuted chaos of sound into perfect tone-equilibrium or harmony. The shortest rhythm contains two periods. The shortest melody contains two tones each occupying a rhythm period, one light, one heavy. Thus the combined form and equilibrium of composite rhythm and harmony is conditioned by recurrence of these alternating light and heavy periods. Let the following wave-lines indicate these alternating periods, first, in the order light-heavy; next, in the order heavylight, and let the repetition marks indicate recurrence.
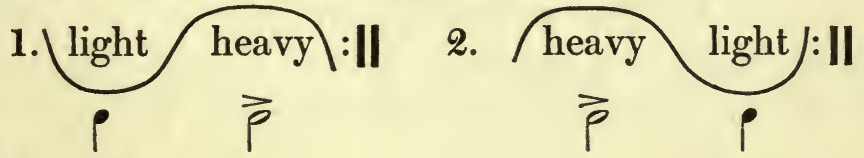

The notes indicate respectively short-long, longshort; the dynamic - indicates the efficient accent. Now sing each diatonic whole step and half step in accordance with these two forms of rhythm and note 
the operation of the efficient accent as it generates and reports the regnant harmony and determines which of the two tones is regnant and which is a bytone. The general result will be as follows: The tone that falls on the light and short accent is the bytone and component of the byharmony, while the tone that falls on the heavy and long accent (efficient accent) is the regnant tone reporting the regnant harmony of which it is a component. I first present the ascending steps.
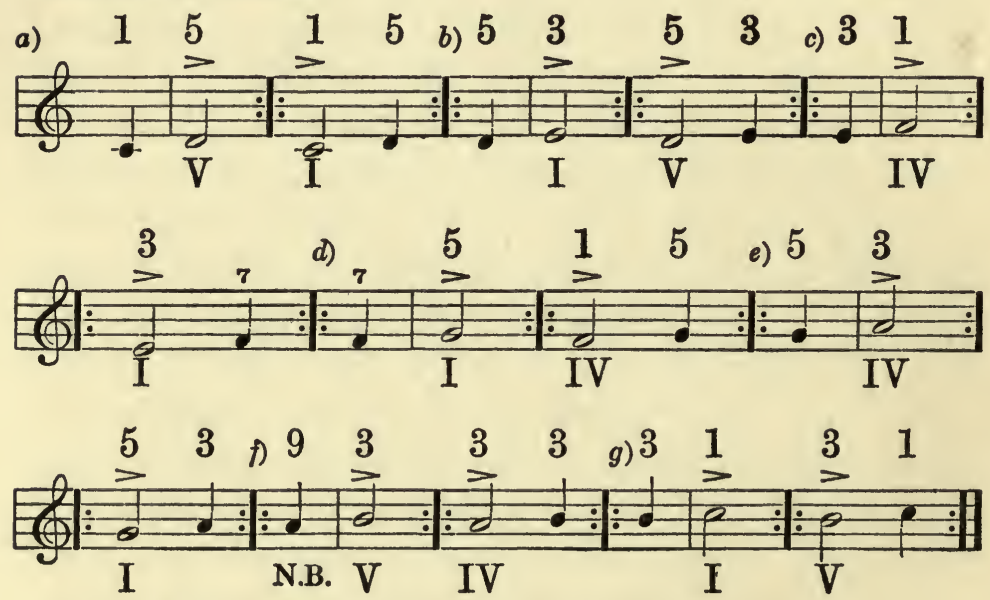

Next follow the descending steps.
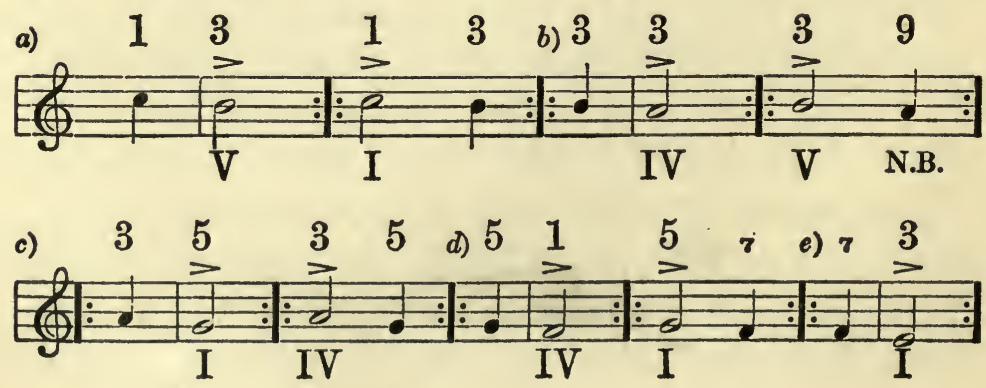


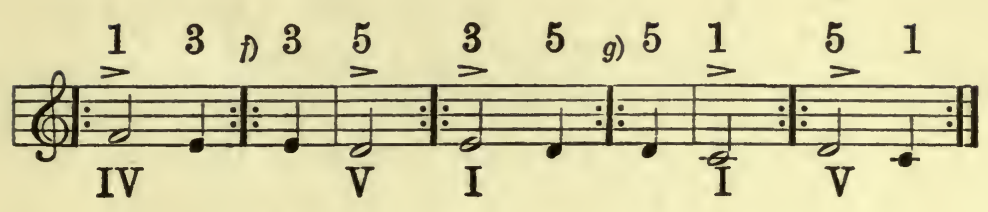

At N.B. in both above groups of examples we again encounter la 9 playing the part of a bytone during the regnancy of the harmony of which it is a component. Attention is called to the fact that except at N.B. the form of all the above regnant harmonies is that of a consonance. Here we observe the general truth that the efficient accent everywhere makes for the stable equilibrium of consonance except in cases like N.B. where specific relations of specific tones cause the regnant harmony to take the form of a dissonance. The above examples illustrate another series of facts. First, we observe that in certain relations a regnant consonance is generated by the efficient accent on a single component as indicated by the tones reporting I, V and IV; second, a regnant dissonance (see N.B.) is not generated unless at least two of its components occupy successive rhythm-periods. We will first take up the consonances I, V, IV. All the components of I possess this individual power to generate its regnancy, do by itself, $m i$ when preceded by IV or V, sol when preceded by IV, as shown below at $a$ ). Two components of $\mathrm{V}$ have this individual power; they are re and $t i$; see below at $b$ ). Two components of IV have this individual power, namely, $l a$ and $f a$; see below at $c$ ). 

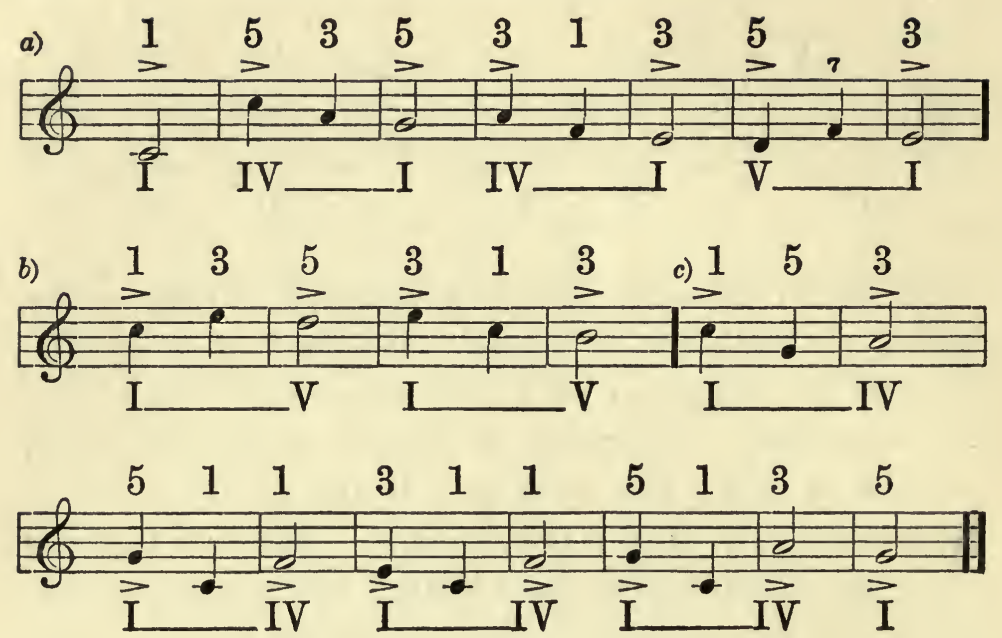

In its diatonic relations sol cannot report itself as 1 of $\mathrm{V}$ except in conjunction with another component of V. The same is true of do as 5 of IV. This explains why in their diatonic relations sol individually cannot generate regnant $\mathrm{V}$ and do individually cannot generate regnant IV.

The regnant dissonances $V_{7}$ and V9 next claim our attention. Both of these regnant dissonances require a succession of at least two components to generate them, and in generating regnant $\mathrm{V}_{7} f a$ must be one of the two, while in generating regnant V9 la must be one of the two. Examples of both are given below, regnant $\mathrm{V}_{7}$ at $a$ ), regnant $\mathrm{V} 9$ at $b$ ).

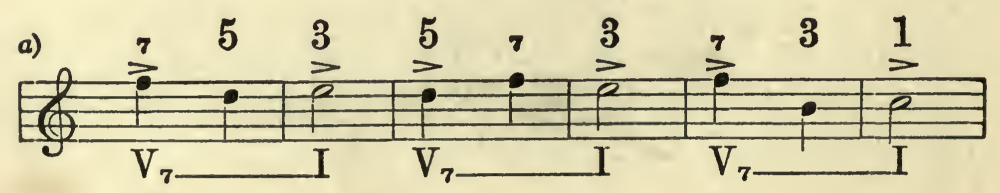



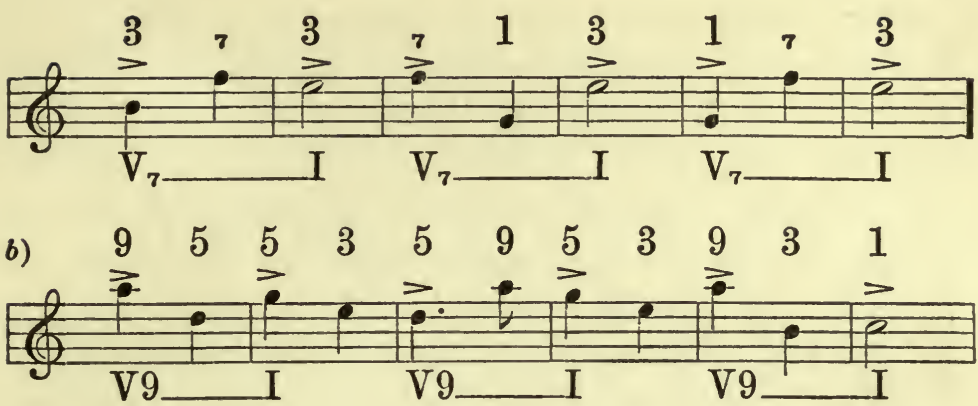

\section{$\begin{array}{llllllllllllll}3 & 9 & 5 & 1 & 7 & 5 & 9 & 1 & 3 & 3 & 5 & 9 & 3 & 1\end{array}$}

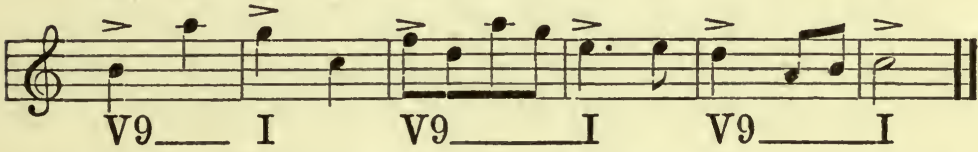

Alternating rhythmic periods are the elements of rhythmic form; a rhythmic form is therefore a succession of elements. Harmonic components are the elements of harmonic form; a harmonic form is therefore a concurrence of elements. Every such concurrence occupies a rhythm-period: thus when we relate one such concurrence to another we are moving from one rhythmic period to another, and this concurrence (harmony, form and relation in space) and succession (rhythm, form and relation in time) are indissolubly combined. It is therefore perfectly natural that regularly alternating rhythm-periods of cadence and repose should have caused corresponding concomitant alternations of regnant harmonies in cadence and repose, since both in rhythm and in harmony cadence is tend and repose is end of tend. One illustration will suffice.

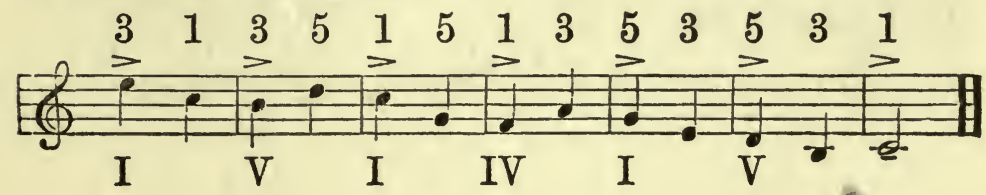


Such examples of concurrent alternations of rhythmic and harmonic cadence and repose manifest the direct influence of rhythm upon the harmonic structure of melody, while on the other hand the direct influence of harmony upon the rhythmic structure of melody is manifested in the lengthening of the rhythmic periods of alternating cadence and repose from beats to measures. These reciprocal influences of the two elements, now of rhythm on harmony, now of harmony on rhythm, the two always inseparably combined yet acting and reacting each upon the other in obedience to the inherent shaping principle of equilibrium, these are the chief shaping forces in the evolution of the musical phrase and thence of the larger forms of music. I will pause here a moment to point out how harmony may contract and expand the rhythmic form. In contractions secondary efficient accents appear within the limits of one measure (see below at a)) while in expansions the regnant harmonies may extend indefinitely and cause the rhythmic forms to be either perfectly regular (see b)) or irregular $($ see $c))$.
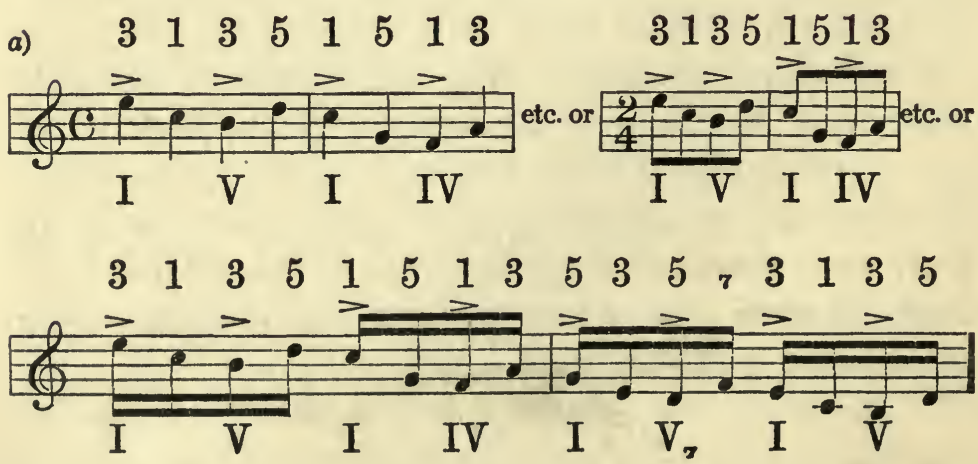

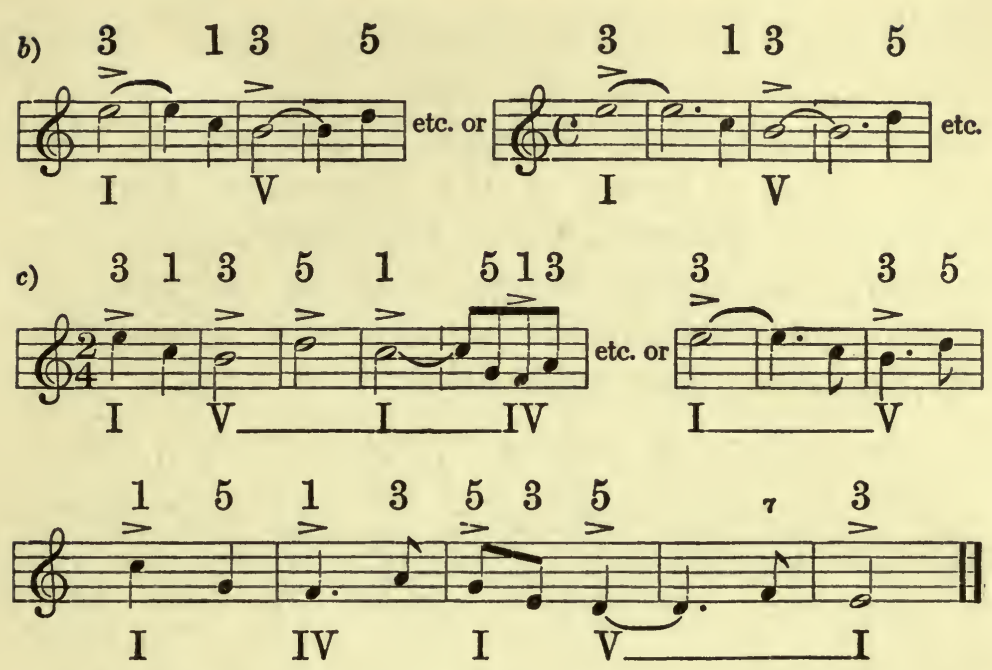

The next examples illustrate the prolongation of harmonic cadence in the progressions $\mathrm{V}-\mathrm{IV}$ and $\mathrm{IV}-\mathrm{V}$ at $a), \mathrm{IV}-\mathrm{V}_{7}$ at $b$ ).
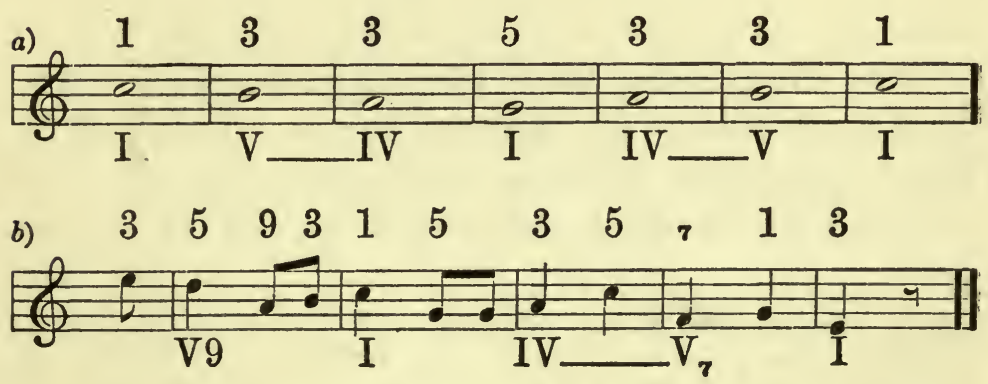

At a) as we move from ti 3 to la 3 and vice versa the concomitant harmonies report progressions in parallel fifths and octaves which though unseen are there and are heard. Such parallels are unavoidable.

A general survey of the foregoing analysis of regnant harmony and the efficient accent enables us 
to ask and answer a comprehensive question. Under what conditions does the change from one regnant harmony to another take place? This change takes place when a bytone of the momentary harmony falls on the efficient accent. The following examples present these bytone-changes on single diatonics, and a few chromatics are also introduced in anticipation of their subsequent explanation.
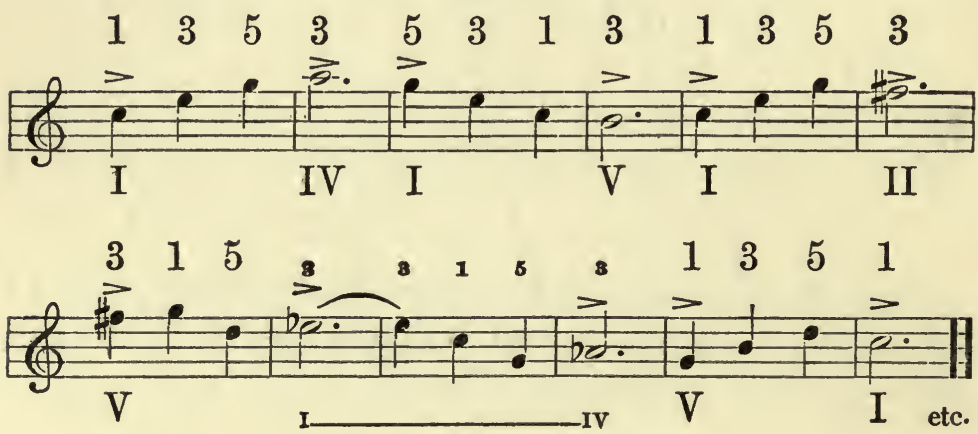

This change also takes place when certain single bond-tones fall on the efficient accent. The first of these bond-tone changes of regnant harmony is reported by the single diatonic sol as follows:-

$$
\begin{array}{lllllllllllllll}
3 & 7 & 5 & 9 & 1 & 5 & 3 & 7 & 5 & 5 & 7 & 5 & 9 & 1 & 5
\end{array}
$$

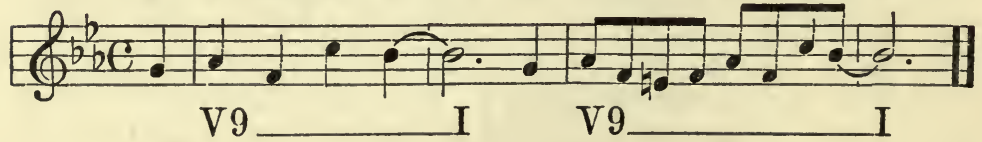

In this melody from Beethoven's $\mathrm{E}$ flat concerto the bond-tone sol instantaneously changes from 1 of $\mathrm{V}$ to 5 of I. In such bond-tone changes of regnant harmony two secondary causes coöperate with the 
efficient accent, first the tendency to resolve dissonance, next the regular alternation of harmonic cadence and repose, both of which I have already explained.

The foregoing analyses demonstrate that original harmony in one voice reports the exact number of components in a harmonic thread; three components in $I, V$ and $I V$, four in $V_{7}$, five in V9. They demonstrate that whenever and wherever it is potential in a relation the efficient accent makes for a regnant consonance, that is, for stable equilibrium. They demonstrate that the form of regnant harmony generated by the efficient accent, be it consonance or dissonance, is always a question of the momentary relation and is always the equilibrium of the moment, consonance being stable, dissonance being unstable or relative equilibrium.

39. Chords Derived from the Original Consonance and Dissonance in One Voice

From the prototype consonance I are derived the diatonic-Major triads I, V, IV known as the three primary chords.

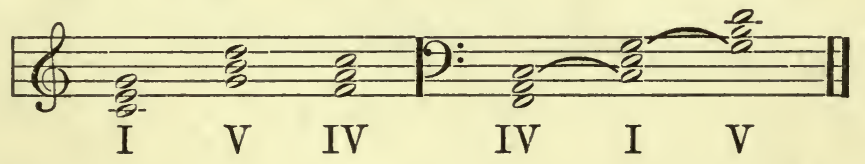

The common reports of original harmony in one voice for the first time demonstrate and prove the truth that these triads may be represented by single components as well as by any two or by all three. Every conceivable combination of two or three tones 
lies in these harmonic threads and may represent each of these triads. Of the many possible representations of the triad I, I present the following:-

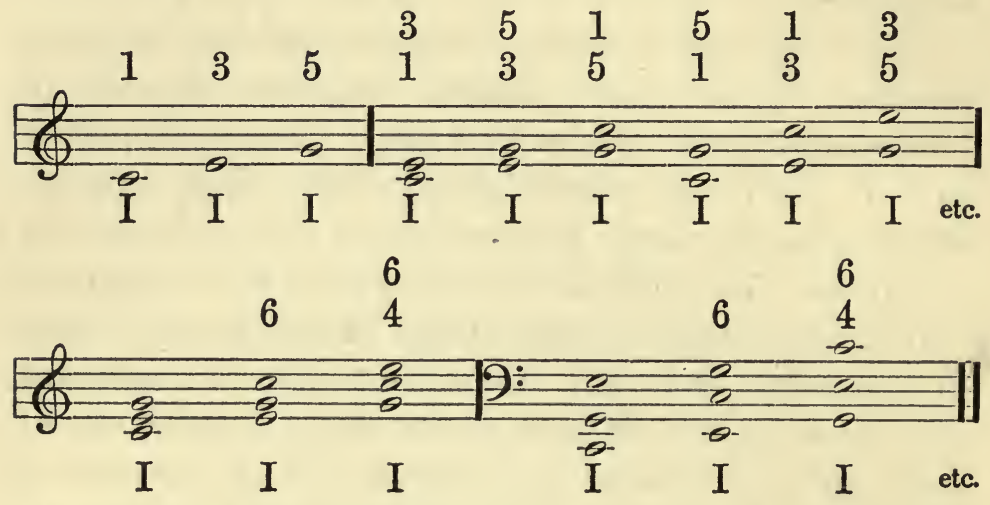

The triad V may be represented by the single components $r e 5$ and $t i 3$, the triad IV by the single components la 3 and $f a 1$. Both triads V and IV may appear in any of the above two-tone and threetone forms.

From the prototype dissonances in one voice, V9 and $V_{7}$, are derived the corresponding chords of the ninth and seventh, also the chord $\mathrm{VII}^{\circ}{ }^{\circ}$. Besides these, the dissonance V9 breaks up into three triads. All are given below in the order of their mention.

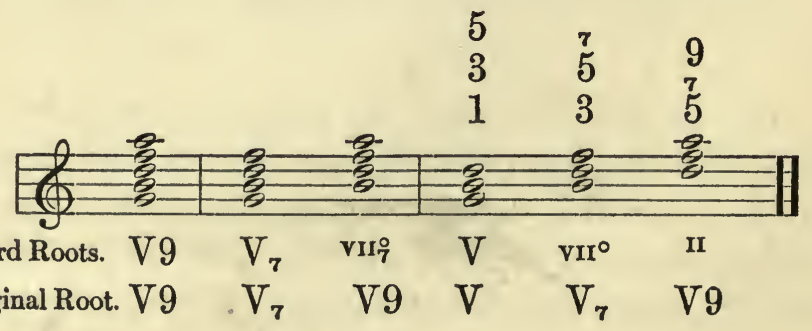


Like the harmonic report of a single tone so also that of a chord is determined by the relation in which it appears and varies as the relation varies. All the above chords in their diatonic-Major relations claim sol as their common harmonic root. Hence the above distinctions and discrepancies between chord-roots and original harmonic roots. Any tone may be taken as a chord-root. Thus a chord-root may be an original harmonic root as in $\mathrm{V} 9, \mathrm{~V}_{7}$ and $\mathrm{V}$, or it may be a harmonic third as $\mathrm{VII}^{\circ}{ }_{7}$ and $\mathrm{VII}^{\circ}$ or a harmonic fifth as II. The important fact to be observed here is that certain chord-forms of harmony are detached from their original harmonic roots. To regard the roots of the chords $\mathrm{VII}^{\circ}$, $\mathrm{VII}^{\circ}$ and II as harmonic roots and to symbolize them as 1 is to create the greatest possible confusion in the mind owing to the irreconcilable conflict and utter discord between a thing and its symbol, between what we really hear and feel and know to be true and what we are constrained arbitrarily to think and what we know to be false. Hence this truth: No given chord in a given relation is perfectly comprehended unless we subject it to the common reports of common harmonic feeling and perception. Hence the necessary distinction between harmonic analysis with true reports and chord-analysis with false reports. We shall meet all the above chords in transmuted relations when we take up the Minor mode. Here attention is called to the important chord $\mathrm{VII}^{\circ}{ }_{7}$, which is composed of the four original cadence-tones and which I name the Major-cadence-seventh-chord. In resolution its two lower tones rise, its two upper tones fall as below 
at $a$ ). Chords whose components simultaneously rise and fall have double cadences. Chords whose cadences rise only or fall only have single cadences. Below at $b$ ) and $c$ ) the double cadence of $\mathrm{VII}_{7}^{\circ}$ is separated into single cadences. At $b$ ) $s o l$ is added to the two lower tones of $\mathrm{VII}^{\circ}$, thus forming the triad $\mathrm{V}$ and becoming the bond-tone of the original rising chord-cadence V-I, the authentic ending. At $c$ ) $d o$ is added to the two upper tones of $\mathrm{VII}_{7}{ }_{7}$, thus forming the triad IV and becoming the bond-tone of the original falling cadence IV-I, the plagal ending.

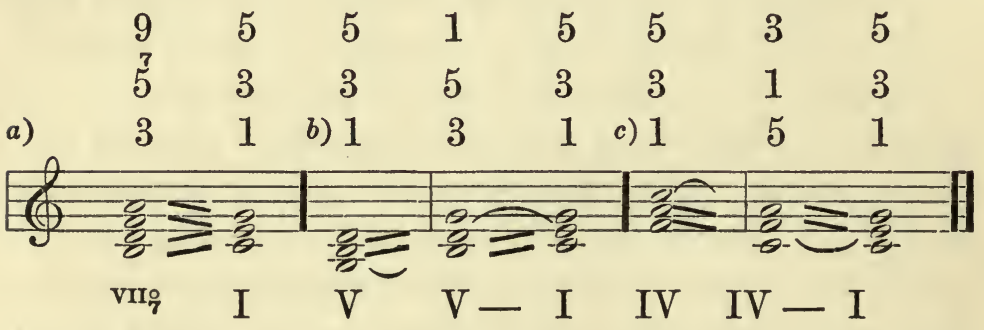

In this separation of the original cadence-tones in the triads $\mathrm{V}$ and $\mathrm{IV}$, re and $t i$ retain their original relations as 5 and 3 respectively while the relations of $l a$ and $f a$ are changed, la from 9 to 3, fa from 7 to 1 . Harmonic intervals are indicated by numbers specifying the exact relation of a tone to its harmonic root: such are the numbers over the above chords. Chord-intervals are computed from chordroots. Since any tone, that is, any component of a harmony may be a chord-root it follows that chordroots and chord-intervals are sometimes harmonic roots and harmonic intervals and sometimes not, 
wherefore no chord can be understood except through harmonic analysis. Above at $a$ ) the chord-intervals of $\mathrm{vII}_{7}^{\circ}$ are root, minor third, diminished fifth, minor seventh, while the harmonic intervals of the same tones are respectively major third, pure fifth, minor seventh, major ninth. These chord-intervals generate discord between feeling and thought while the harmonic numbers unite feeling and thought in complete concord: the former are arbitrary and false, the latter are self-asserted, unalterable and true. At $b$ ) and $c$ ) the chord-intervals and harmonic intervals agree, but this agreement becomes less and less frequent the further we penetrate into the domain of chords, and therefore the call for exact harmonic analysis will grow correspondingly more and more frequent.

Intervals are further to be distinguished under two heads: 1. Intervals of concurrence. 2. Intervals of succession. To the first belong the intervals formed by the concurring components of a tone's harmonic thread and of a chord. To the second belong all steps from one tone's harmonic thread to another and from one chord to another; in short, all steps in one voice and in combined voices. Here is an example in one voice:-

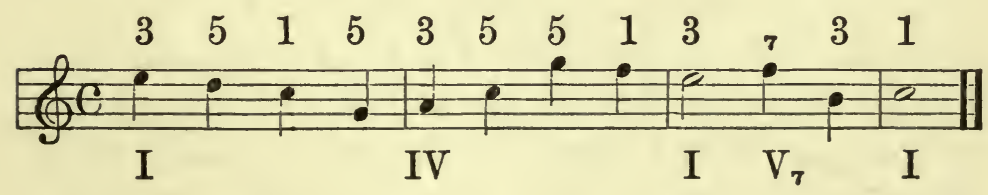

In moving from one of these tones to another the steps are major second, major second, pure fourth, major second, minor third, and so on. Thus we 
observe the above intervals in the ordinary sense of length of steps, to perceive and know which is to perceive and know very little since such intervalsteps give us no intelligence whatever of what is most essential, namely, the inherent harmony of each of the two tones in such a step. The essential thing to perceive and know is that in moving from the first to the second tone we are stepping from mi the third of one harmony to re the fifth of another harmony, for this includes the perception of the whole step or major second from $m i$ to $r e$ and the knowledge of the length of this step is but secondary and supplementary to that of the two harmonies. This is true of all steps in one voice, true likewise of the steps of each chordvoice as we move from chord to chord. Equally if not more important is the necessity to discriminate between the intervals formed by any two tones in a given chord and the harmonic report of each of the two tones. Two voices will suffice to illustrate this point as follows:-

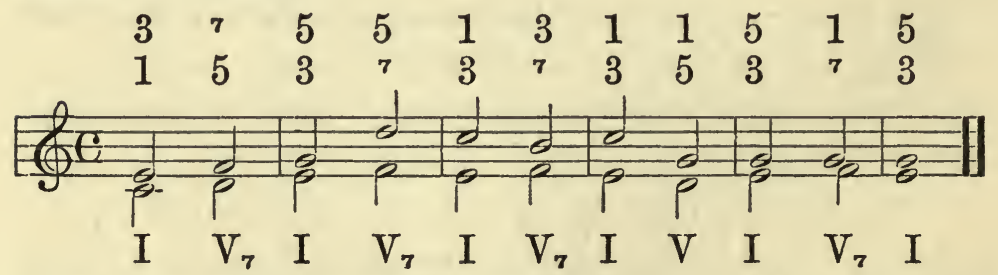

The intervals of these combinations or chords are as follows: major third, minor third, minor third, major sixth, minor sixth, augmented fourth, minor sixth, pure fourth, minor third, major second, minor third. With these intervals compare the superscribed harmonic reports and note that the first chord is the 
only one in which the interval-numbers and the harmonic report do not conflict. Numbers are used for so many and various purposes in music that we cannot wonder that students are so easily confused. Since the harmonic numbers alone accord with the common feeling and perception of relations they should bring some order out of this confusion. The term minor appears over and over again in the above description of intervals notwithstanding the fact that the entire example does not contain a single minor harmony, percept and concept. Why not like the Germans use the terms major and minor exclusively in connection with modes and harmonies? Why not, as they do, describe major intervals as great (gross), minor intervals as small (klein)? How much simpler, clearer, more sensible and practical to describe the above intervals thus: great third, small third, small third, great sixth, small sixth, and so on. This German custom will henceforth be adopted in these pages.

We have seen that one-voice harmony is self-assertive, that in one voice the harmonies are always complete, that is, single tones give rise to harmonic threads of three, four and five components. Chords are selective combinations of tones and may represent a harmony incompletely as well as completely: thus a triad may be represented by a combination of two or all three of its components; a seventh-chord by two, three or all four of its components; a ninth-chord by two, three, four or all five of its components. Briefly, onevoice harmony is assertive and its harmonic forms are complete; chord-forms are selective and may be 
complete or incomplete. A second voice always implies a first voice to which a second voice is added and this second or added voice is always selective. The original guide in the selection of one or more added voices is the concomitant harmony or harmonic thread of each tone in the first voice, and this first voice is always the dominating voice* or melody to which all added voices are subordinate. In short, the dominating voice is the melody the concomitant harmonies of which in every concrete case are this or that series as generated by the specific relations of its tones. When Wagner states that his melodies and their harmonies arise in his mind simultaneously he calls our attention to a great truth, namely, the indissoluble unity of melody and harmony. Had Wagner developed this idea theoretically his psychology would doubtless have led him to discover original self-assertive harmony in one voice. The influence of the dominating voice not alone on the selection of harmony, but also upon conception and expression, will be more fully dealt with in the chapters on polyphony and chords. The three one-voice harmonies $\mathrm{I}, \mathrm{V}_{7}$ and V9 have given us the complete triad, complete seventh-chord and complete ninth-chord. These. three are the prototypes of all like chords. From common feeling of harmony in one voice we have derived the principle of chord-building which is to superadd a third, fifth, seventh and ninth to a fundamental tone which is the chord-root. We have seen that I, V and IV are the only three-tone diatonic harmonies which assert themselves in one voice in Major. But in chord-building, triads, seventh-chords 
and ninth-chords may be and are produced on each of the seven diatonics and are incorporated in the Major mode. All these chords also appear in the Minor mode in completely changed relations and with completely transmuted harmonic reports of their components directly caused by the changed relations. In short, a given chord is one thing in Major and quite another thing in Minor, as we shall see. Meanwhile we here note that chords like one-voice harmonies fall into two divisions: consonances and dissonances. Each of these two divisions of chords subdivides into two varieties, namely, simple and compound chords. A simple chord is built of the components of one harmony: such are all the chords thus far derived and presented on a previous page. A compound chord is built of the components of two or more harmonies: this variety of chord will be explained in the proper place. In chorded music regnant harmony and byharmony become regnant chord and bychord. The subject of chords is resumed in the next chapter.

\section{The Tone-Region. Its Diatonic Scales}

Each of music's seven octaves repeats the same series or scale of tones, and forms the nucleus of a tone-region. The tones of all regions are connected by their harmonic threads, and the relative pitch of each tone is due to harmonic relation. The seven diatonics constitute the first group of tones that was discovered, expressed and exploited, and the causes and order of their genesis have been explained. The tone-region shows the natural juxtaposition of tones. 
Regnant I being the first harmony, do being the root of this harmony and the original meloharmonic point of repose which we call the Tonic, it follows that do is the original centre of the tone-region, as follows:-

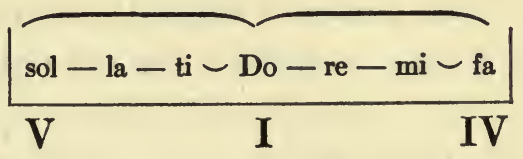

Here the seven diatonics form a scale of two conjunct tetrachords. The Tonic do is the common tone and common centre of the two. A tetrachord is a scale of four tones. The above dashes (-) and curves $(\smile)$ indicate respectively whole steps and half steps, and show that the two above tetrachords have the same form, namely, _ $\smile$. This scale of seven tones and conjunct tetrachords I have named the septonate.* The septonate is the nucleus of the tone-region. What evidence is there that do the Tonic is the original centre of the tone-region? The incontrovertible evidence is adduced from harmony briefly as follows:-

The cadence of $\mathrm{V}$ rises or resolves upward into $\mathrm{I}$; the cadence of IV resolves downward into I: ergo, I lies between V and IV. This septonal nucleus of the tone-region besides being the index of meloharmonic resolution is also the index of progression. For example, from V to IV progress upward, from IV to $\mathrm{V}$ progress downward. What is true of these harmonies is true of the corresponding chords. From the intuitive feeling of these one-voice self-assertive resolutions and progressions the rules for treating the corresponding chords in corresponding relations and 
for treating all other chords in similar relations in the same way have been derived by induction.

The diatonics form a scale of eight tones in which the same two tetrachords are disjunct. This scale proceeds from the Tonic-centre of one tone-region to the Tonic-centre of a contiguous region; in it the two Tonics form lower and upper terminals. This our familiar Major scale is as follows:-

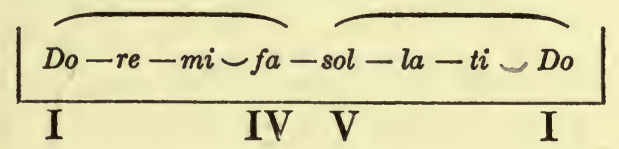

A consonant thread of harmony extends throughout the range of pitch and connects all its components in all regions. Of these threads $I$ is the genus and original, $\mathrm{V}$ and IV are relative. In the following illustration the arrows indicate the whole range of pitch.<smiles>[3H][Al]C[Al]([3H])I</smiles>

The thread of the dissonant genus V9 extends from one region into the next, and in each octave one such thread intersects another thus:-

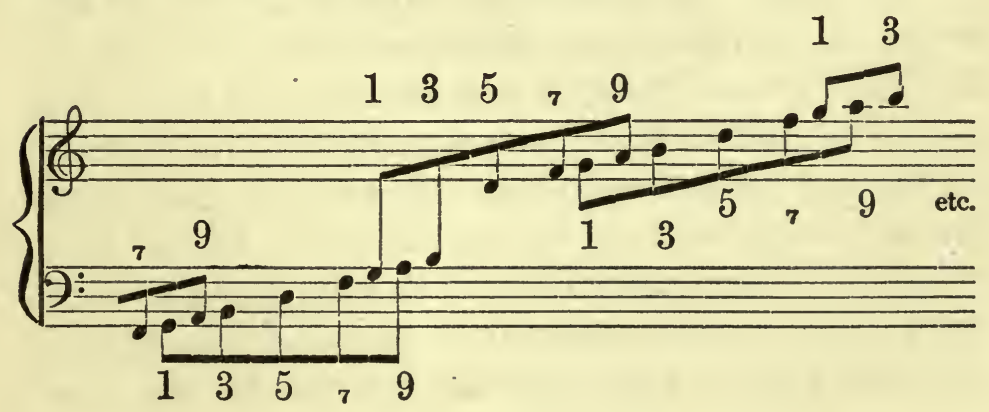


At each intersection four components of V9 form the tetrachord of three consecutive whole steps known as the tritonus, as follows:-

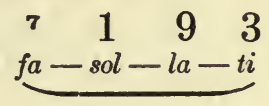

A few of the dissonant chords formed by combining these tones are next given in close and open positions.

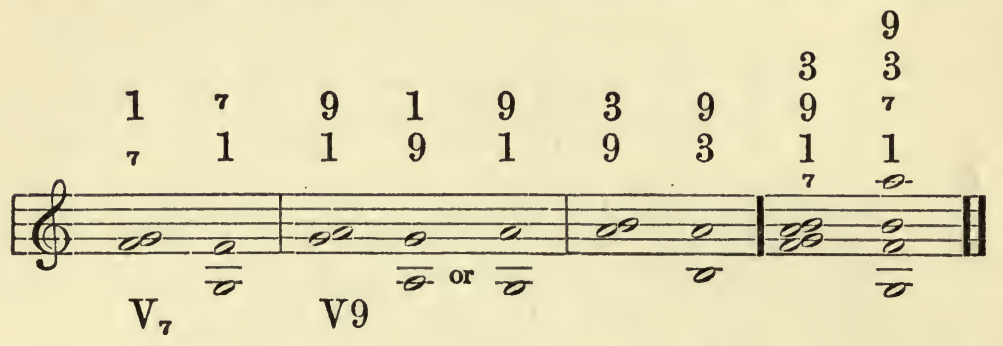

Here observe in passing that the tritonus is the only tetrachord whose four tones are components of one harmony and together form a simple chord of the dissonant type.

A septonate is named by its central tone: thus the above septonate is the Tonic-septonate. A diatonic scale of eight tones is named by its terminal: the above octonal scale is likewise a Tonic-scale. Each of the seven diatonics may appear as a septonal centre of two conjunct tetrachords and the octonal terminal of two disjunct tetrachords, and each such scale like that of the Tonic is named by its septonal centre and octonal terminal. Thus sol the Dominant, $f a$ the Subdominant, mi the Mediant, la the Submediant, $r e$ the Supertonic, $t i$ the Subtonic, each of these may be the septonal centre and the octonal terminal and, as these syllables and names imply, all 
these scales are related to the original scales of the Tonic. In these scales there are four forms of tetrachords as the subjoined groups of symbols of whole and half steps show.

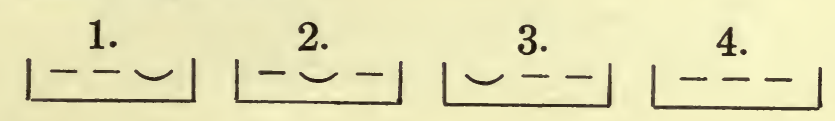

I here present the septonal conjunct forms of these scales.

$$
\begin{gathered}
\overparen{d o-r e-m i \smile F a-s o l-l a-t i} \\
\overparen{t i \smile d o-r e-M i \smile f a-s o l-l a} \\
\overparen{l a-t i \smile d o-R e-m i \smile f a-s o l} \\
\overparen{S o l-L a-T i \smile D o-R e-M i \smile F a} \\
\overparen{f a-s o l-l a-T i \smile d o-r e-m i} \\
\overparen{m i \smile f a-s o l-L a-t i \smile d o-r e} \\
\overparen{r e-m i \smile f a-S o l-l a-t i \smile d o}
\end{gathered}
$$

The above capitalized syllables of the central Tonic-septonate and those marking the centre of each individual septonate form a Greek cross which appositely suggests the Greek modes, which I next present in their octonal form of disjunct tetrachords.

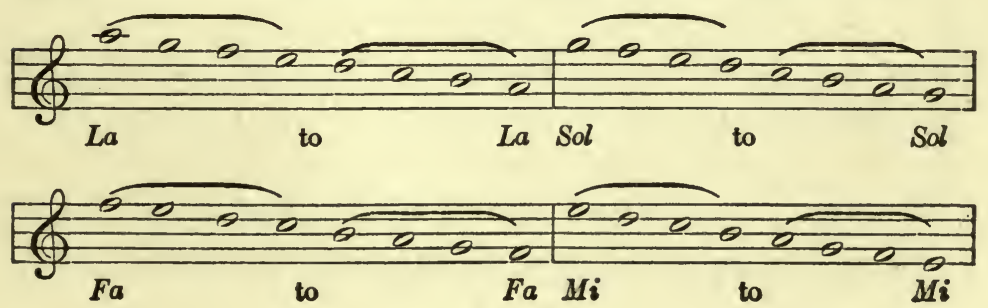



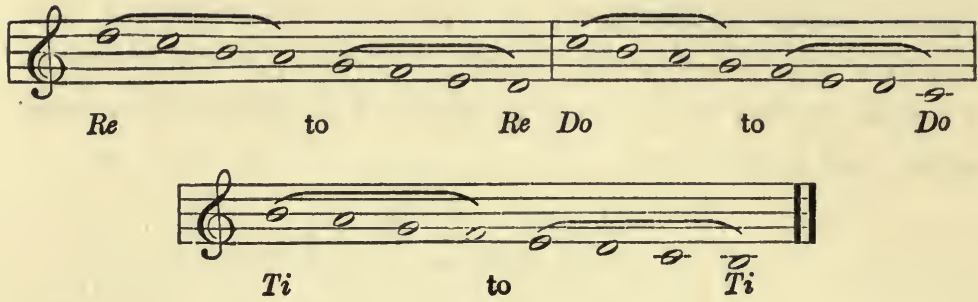

In three of these septonal and corresponding octonal scales the two tetrachords in each have the same form: in both Tonic-scales both tetrachords have this form, $-\smile \smile$ : in both Supertonic-scales they have this form, $-\smile-$ : in both Mediant-scales they have this form, $\smile--$. In each of the other septonal and octonal scales the forms of the two tetrachords differ, as the examples show. The appearance of these tetrachords in all music is most common. For illustrations the reader is referred to Bach's first "Invention" in two voices and the principal theme of Wagner's "Meistersinger." All the above tetrachords will be found in the following quotation from Beethoven's E flat Concerto:-

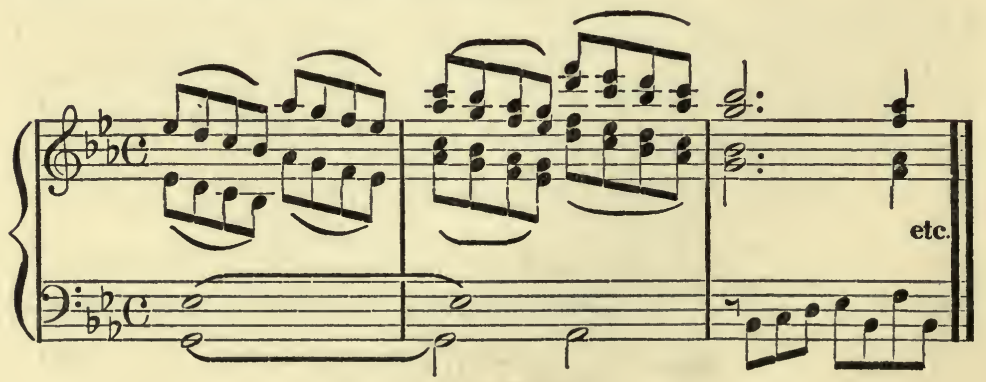

In his book on "The Music of Antiquity" Gevaert has extricated the Greek modes, their identity and 
names and their true connection with the churchmodes from a state of greatest confusion. My chief purpose in bringing forward these ancient modes at this juncture is to point out the fact that they all lie in and form part and parcel of our modern tonesystem. Thus far the attempts to harmonize the few extant specimens of Greek melodies in accordance with the arbitrary rules of chord-harmony appear not to have been successful or satisfactory. The same may be said of the harmonizations of Gregorian and Ambrosian melodies. Indeed, the consensus of opinion seems to be that the addition of chords distorts and destroys the inherent character, power and simple beauty of such melodies, and that they should therefore be left unharmonized. This disapproval of adding chords to such music, which originated in one voice, gains significance when we consider on the one hand that this disapproval springs directly from the common harmonic sense and is therefore a common report of common musicfeeling while on the other hand it is natural that no two investigators should agree on any one series of chords for a given melody. And why? Simply because chord-harmony is purely selective and always the expression of personal judgment and taste. But original harmony in one voice and its common reports place the subject of the music of antiquity and its harmonization on a new basis and in a new light. The Greeks had no multi-voice harmony, but they had one-voice harmony although they did not know it; they had no idea of harmony in our sense of chords, but they had the harmonic sense and applied 
the term harmonies to the tones composing their modes. Their possession of the common harmonic sense is proved by the fact that on one hand they perceived that certain tones tended to others (sense of dissonance), and on the other hand that a certain tone was final, the tone to stop on (sense of consonance). When Aristoxenus describes the sudden transition from the pitch of one tone to that of another as "the topical motion from the repose of one tone to that of another" he is unconsciously expressing his intuitive sense of one-voice harmony. His definition of rhythm would indeed be a credit to twentiethcentury text-books and encyclopædias.* If not his intuitive harmonic sense, what was it that caused Aristides, pupil of Aristotle, to make these queries, "Why is it that when I change the mese (middle tone) all the other tones are wrong; why when I change one of the other tones, that one alone is wrong?" Such evidence that the Greeks possessed the harmonic sense might be multiplied indefinitely. Books which shall embody the common reports of original harmony on Greek, ecclesiastical, in short, on all one-voice music, remain to be written, a life-work not for one, but for many. In another place analyses of several Greek melodies and Gregorian chants will be presented. Certain types of music are spoken of by historians and theorists as music without harmony and music without rhythm. As I have said and shall reiterate over and over again, melody without harmony and melody without rhythm never existed. The concomitant harmony of melody being selfassertive and its reports being common it follows 
that every melody ancient or modern is the messenger of common harmonic reports. The rhythm of ancient melodies may be traced in all cases where the melody is accompanied by a text, for the alternating syllabic accents of the text discover the heavy recurring accents which are at once the measure-accents and the efficient accents of regnant harmony. In harmonizing the melodies of antiquity the selection of chords should be made to conform with the concomitant harmonies which each such melody itself asserts. Harmonizations so selected would emphasize and enhance rather than distort and destroy the true nature, beauty and effect of such melodies, would strengthen rather than weaken them, and would circumvent the personal equation. Original harmony in one voice therefore not only empowers us to perceive the concomitant harmonies of a Greek melody and Gregorian chant, but empowers us to feel a Greek melody as the Greeks felt it, to feel a Gregorian chant as Gregory himself felt it.

\section{Musical Moments. Power and Originality of Music}

While thinking, expressing or listening to music as we proceed rhythmically from tone to tone, from moment to moment, the inner consciousness unites with, our whole being is merged in the flight of time itself; self-consciousness is annihilated, the spirit is liberated, our self-surrender is complete. During these musical moments we are dominated and swept onward by music's elemental forces and shaping principle; we are ever in the present, now-here, 
now-here. Now denotes time (rhythm), here denotes space (harmony): now-here connotes composite form and relation in time and space, the united harmonies of rhythm and tone, the musical moment. This complete obliteration from consciousness of all other ideas and mental processes, this enthralling concentration of the attending inner consciousness upon the musical moment, the ever present, is the secret of music's great, perhaps greatest, power. Whatever else this power may be, at bottom it is elemental, it inheres in the elements and principles of music, a field of investigation far from being exhausted, the only field free from speculation and open to scientific accuracy of observation. The true and the beautiful are rooted in, spring from and are shaped by these elements and principles, their power is primarily due to this elemental power, they are vague and mysterious in themselves yet nothing could be more real and potent. At least we know that our knowledge of the æsthetic power of music must ever remain limited to what we can learn from its elemental power. Alike spell-bound, liberated and uplifted by this great power of the musical moment are the producing composer, the reproducing artist and the contemplating listener. The psychology of the producing composer is eloquently set forth by Wagner in his essay on Beethoven. The musical moment of the artist and listener will be considered presently.

In the universe of one rhythm struggling for and maintaining one equilibrium or harmony each motion and moment are parts of a correlated and equili- 
brating whole. Each moment in the short space of a single human life is a rhythmic moment accentuating the individual struggle for physical, mental, social and spiritual equilibrium or harmony. When we consider that music is the direct language of equilibrium or harmony, and that it directly presents the universal message of all the arts, we can no longer regard its universal power as a mystery not to be penetrated and wholly insoluble. What choice or will has man to resist universal energy, rhythm and equilibrium, universal form and principle of form, all of which underlie, are blended and idealized in music? I have pronounced music to be the only universal and only purely spiritual language, but it is more; it is the language of liberty and freedom, it is a complete whole to which nothing can be added, from which nothing can be taken away. Can you add anything to or take anything from a tone, is not a tone complete in itself? Music's elemental power to absorb the whole attention and to annul all the ordinary conscious activities of thought and volition is due more to tone than to rhythm. Musical rhythm per se does not possess this power. Why? Because we are so pervaded with this law of motion that we spontaneously take up an initial rhythm, remember it, repeat it, and therefore anticipate it without conscious effort of attention, in a word, without knowing it. With tap of hand or foot we often unconsciously take up any pronounced rhythm in our environment and sharply mark the recurring accents to which we sometimes hum an improvised air. So fixed is the innate rhythmic habit of pre- 
serving the equilibrium from moment to moment, so keen the sense of keeping time or balance that our anticipation of the recurring periods of music is perfectly definite; because we feel what is coming we do not stop to think about it. This is why rhythm per se has not the power of concentrating the whole attention and does not necessarily even attract the attention. However, all this is changed when tone, the living and original voice of music, unites with rhythm; it is then that the elemental power asserts itself and holds the attention. Each tone in a musical series commands the entire attention; not one progression or resolution if unperceived that does not break the thread of connection, that does not mar our sense of the whole. Let the music be familiar or unfamiliar, in either case absolute attention upon each tone is a necessity; the momentary relation of each tone must be felt by the artist else he cannot express it, by the listener else he loses the connection. In unfamiliar music it is obvious that the listener cannot anticipate progressions or even resolutions, but even in familiar music where he does anticipate them, and where he anticipates whole phrases, sentences and paragraphs, nevertheless, he is compelled to rivet his attention upon each tone-moment, now-here, now-here. This rapt attention upon the musical moment is not the result of any conscious or voluntary effort, it is the direct effect of music's elemental power, the power of tone-rhythm. The artist expresses the musical moment as he feels it then and there. He has grouped the series of moments in a composition into motives, phrases, sentences, paragraphs; he has correlated and 
unified all these parts into a great whole: yet when he produces his work his consciousness is concentrated upon each tone-moment, now-here, now-here. It is precisely because the artist has conceived the whole in all its parts, precisely because he knows and anticipates each motive, phrase, sentence and paragraph, that he is able to concentrate his attention upon each moment, that he can express then and there what he feels then and there. Certainly the artist cannot express now when he is thinking of by and by. Observe your pupil who while playing on page 1 is disturbed by the consciousness of an approaching difficulty on page 2. It is plain that the thought of by and by is effectually musicidal to the momentary expression of now. In each tone of a melody there is a balance of the united harmonies of time (rhythm) and space (tone) to be perceived, which if unperceived then and there are lost forever. Common music-feeling in which this union of harmonies originated, whence it emanates, to which it alone appeals and is directed, is therefore at once the originator, the transmitter and receiver of the rhythmo-harmonic voice of music, melody. The psychology of music's elemental power presents another chapter, the subject of which is the operation of the law of gravitation in the domain of feeling and thought. Light rhythm-periods tend and resolve into heavy rhythm-periods, which are rhythmic centres of gravity; dissonances tend and resolve into consonances, which are harmonic centres of gravity: in both, this tendency to resolve is attraction into equilibrium. Having thus roughly explained music's elemental 
power as concentrated in the musical moment we will next briefly consider music's originality and unique position as an art.

Tone has just been described as a complete whole to which nothing can be added, from which nothing can be taken away. Tone is unique, therefore original; there is nothing like it or comparable to it in the entire realm of expression in which it has but - one rival, speech. But the spoken word describes, defines, voices something not itself and is a means to an end, while tone directly voices itself, only itself, and is at once both means and end. Again, the spoken word has a specific meaning, a meaning put into it, while tone has a universal meaning, a meaning not put in but inherent, which is harmony. Tone is directly presentative; tone-language presents itself and nothing else; it does not and cannot represent or misrepresent, nor can it be represented in artificial substances or forms. Music is idea in tones, no more, no less. Tone-rhythm embodies and presents the music-idea, nothing else. When we contemplate music we contemplate the reality, the thing itself, music. A statue or portrait of a man is a statue or a portrait, but not the reality, the thing itself, a man. Tone-rhythm is substance and form in one. Substance and form of what? Of the music-idea, which is melody, the composite of rhythm and harmony. Unlike the substances which the other arts change from their original form into something else, into a building, a statue, a painting, the substance of music permanently preserves its original form, is immutable, cannot be shaped into anything 
but music. The subject of music or the music-idea is always melody, the substance and form of music is always tone-rhythm, therefore in music the subject and the substance are not only always united, but neither exists independently of the other, the two cannot be sundered. Great and greatest music requires no fuller titles than Melody in A, Sonata in B, Symphony in C. This perfect union and inseparability of subject, substance and form in the music-idea or melody which directly presents itself and which cannot present something not itself, at once points out the originality of music, its unique position as an art and distinguishes music from the other arts. I have just defined music as idea in tone. More widespread than one might suppose is the narrow view which limits the idea to that which can be expressed in words. Were this true the inner psychical world of ideas would be deprived of much besides music. An idea is that which conveys complete sense to the mind no matter what its peculiar form or vehicle may be, no matter what sense or combination of senses it appeals to. The mind's wealth of ideas is limited only by the number of forms or vehicles in which to embody and express ideas, and no one form of idea has a perfect equivalent in any other form. There is no equivalent in words for an idea in tones and vice versa. A beautiful melody is a perfect idea in tones just as a beautiful poem is a perfect idea in words. Each is perfect of its kind, the one no more so than the other, perfection being absolute and not relative. We may compare the psychology of the two ideas and their relative power, not their truth and beauty, for 
the true and the beautiful are ever perfect. How vain, hopeless, even absurd is the seeking of equivalent ideas in words for ideas in tones.

The language of tones alone completely voices and harmonizes the composite inner experience; it is the inner world of harmony governed by the same laws as the outer world which it mirrors, it is therefore a whole; universal harmony is its essential message, universal harmonization of mankind is its essential purpose and function. The composite inner experience with its infinitesimal number of elements is summed up in the momentary mood (Stimmung), and the most we can say of the ever changing mood is that it is now brighter, now darker, or now lighter, now heavier; that it varies in the individual and is not the same in any two individuals. Music attunes the momentary mood of one, of all; here lies its power, the power of the musical moment. All the other arts share in the universal message and purpose, but no one or combination of them so pervade the inner life, exert so great a power or occupy so unique a position in the art-hierarchy as does music. In the drama we note that the other arts merge into, aid and strengthen each other in accomplishing the essential purpose of the drama which first of all is pure illusion. But music being a whole and complete in itself does not and cannot merge with, be aided and strengthened by the other arts. The drama is illusion, music is reality; the drama represents, music presents. Drama and music are therefore antitheses, each is most potent by itself, each antagonizes and disturbs the other when the two are associated, as in the music-drama. For 
these reasons in the main the music-drama is a work of hybrid not of pure art. Whenever and wherever music presents itself it attracts and dominates the attention. In all its associations with other arts music refuses to play a second part and never does. The composers of songs, cantatas and operas are great and greatest only when and where their music is great and greatest. Music-contemplation is disturbed in the opera by the presence of scene and action, in the cantata by the implied scene and action which the imagination must supply. Words expressive of pure sentiment alone blend harmoniously with music, and when distinctly rendered do not disturb music-contemplation, wherefore as a work of art the song is purer than either cantata or opera. Such hybrid art-creations, while they are justifiable, exert immense power and may even be called great, nevertheless as works of art they are not pure. As a matter of course absolute music is the most pure and potent music. Pure enjoyment in music-contemplation is grounded and dependent on anticipation, that is, on familiarity with a composition. The greater this familiarity the greater our enjoyment, the keener our anticipation of each musical moment; it is then that we yield ourselves completely to the power of the musical moment. The unfamiliar conduces to another species of enjoyment during which the mind maintains the attitude of interrogation as what next? but this is not the true mental attitude of complete receptivity and pure enjoyment. Every public performance demonstrates that the familiar is most enjoyed, wherefore two thirds of a programme should be made up of familiar com- 
positions. Great music and the great scenes of nature affect us similarly. Both stir us to the core and pervade us with the sense of infinity. In the contemplation of either we enjoy, absorb and are benefited, each according to individual capacity and receptivity, just so much, no more, no less.

Owing to its peculiar elemental power, its completeness in and by itself, the universality of its message and function, the indissoluble unity of its subject, substance and form in melody, it is futile to compare music with the other arts. Architecture is often chosen for this purpose of comparison because like music it is a presentative art, and certain analogies are traced in its static rhythms and harmonies and the mobile rhythms and harmonies of music. "Architecture is frozen music," is a frequent quotation. If there must be comparisons let them be sought in the myriad recorded and mobile rhythms and harmonies of nature and not in the other arts, whose subjects are too specific and definite and fix the attention upon the same single idea or group of ideas, thus directing thought and feeling into the same definite channels. There is however a broad common ground which music shares with all the arts. Each art, music included, has its peculiar form or vehicle of expression in which each in its own way embodies human thought and feeling. All art is self-expression, and every artwork springs from the imagination. But the building, statue, painting which we behold are finished performances; each stands before us in its entirety; each has been produced once for all time; each time we look at it we behold the same performance; each such 
work may be contemplated at leisure; we may observe its points in any order we please and may discuss them with a companion without disturbing the moments of contemplation. None of these particulars apply to music. The composer's original and finished creation is a book of symbols comparable with the plans and specifications of the architect. True the musician may read the book and hear the music in the way that Carlyle preferred to see plays, "in the theatre under my hat." But the music-work to be contemplated by the listener must be performed, not reproduced, but actually and audibly produced; each and every hearing involves a fresh and independent production. No artist, no conductor can exactly duplicate a previous production; each is new, individual. A music-work is produced then and there and contemplated then and there on the spot; now it begins, now it is ended and ended forever, it has passed into eternity along with the moments during which it held artist and listener united by its magical spell, a mere evanescing memory to look back upon and talk about. Not only are the moments of production and contemplation concurrent, not only do they begin and end together, but they concentrate the attention of both artist and listener upon one and the same idea; their duration is prescribed and limited; there is no looking backward until the final harmony has ceased to vibrate. Artist, it is difficult to determine which is the greatest, your responsibility, your power, or your privilege. Your responsibility is great, standing as you do between the masters whose creations it is your power and privilege to recreate and your 
fellow man to whom you interpret these creations. Your responsibility to the master-genius is twofold: first of all, because the message of music is universal; next, because the universal message embodied in great music is the quintessence of an integral portion of its creator's inner life, of his experience of universal experience, for which he demands a corresponding integral portion of your inner life and experience, life for life, heart-beat for heart-beat, a whole for a whole, and all this for each and every performance. Your responsibility is not lessened in that your performance is not handed down to posterity like a building, statue and painting for deliberate contemplation and for critical essay and assay. Yours is but a moment, a unique moment in infinite time; yours is a unique power and privilege exerted at the musical moment when your heart-beat is merged with the heart-beat of hundreds, even thousands of your fellow men in one harmonious rhythm, "im Ganzen, Guten, Schoenen." Worthy are those who do not shirk the responsibility, who do not abuse the power and the privilege.

42. Subrhythm and Rhythm-Expansion. Music's Classic Form

The term period here used only in connection with rhythm applies to rhythm-waves of every form and length. There are beat-periods, subbeat-periods, measure-periods, periods of two and four measures, of three and six, of eight and twelve measures, and so on. A beat-period may be divided and subdivided into shorter and shorter waves or periods; a measure- 
period may be expanded into longer and longer waves or periods and the form of a wave or period may be regular or irregular while every form is reducible into the elementary rhythm-numbers 2 and 3 . Equilibrium, the shaping principle, requires a wave of one length to be followed and balanced by another wave of the same length. A long period or great wave is a balanced composite of successively shorter and shorter balanced periods or waves whose relative lengths and intensities are equal divisions and subdivisions of the whole, the balance of each being relative to that of all the others in the balanced whole in accordance with the inherent principle of form. Among all these waves or periods there is one which is at once the characteristic and fundamental rhythm inherent in and reported by every phrase of melody. This foundation-period, the predominating and characteristic pulse of music-thought and feeling I name the subrhythm. The symbol of the subrhythm is the measure. When two-pulse the subrhythm is written in dual measure; when three-pulse, in triple measure. The subrhythm is the thing itself, the basic rhythmidea, while the measure is only its symbol. Since the names of things and those of their symbols are not interchangeable, and since we possess no term for what is here designated as subrhythm, I do not hesitate to add this term to our overstocked nomenclature. Periods shorter than the subrhythm play upon the subrhythm, they present the play of rhythm upon rhythm. Periods longer than the subrhythm are expansions of the subrhythm first into phrases, next into groups of phrases, next into groups of groups of 
phrases. In the following illustration the forms of all the periods are dual.

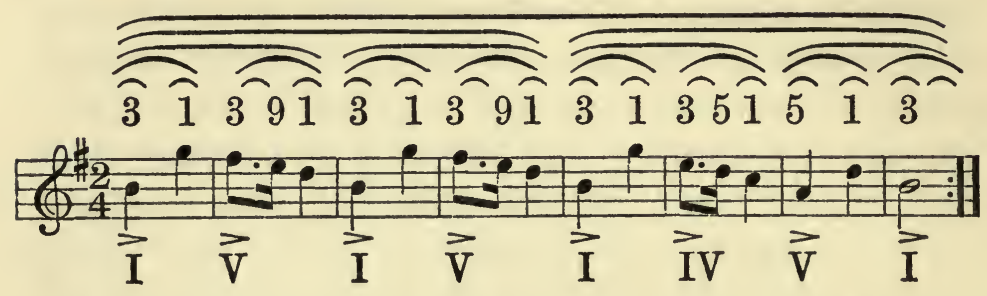

In their relative order from shorter to longer the above wave-lines indicate respectively beat-periods, measure-periods (subrhythm), two-measure periods, four-measure periods, lastly the whole or eight-measure period. Just as each shorter period is balanced by another of the same length, just so the larger eightmeasure period requires another eight-measure period in order to effect a balance. Thus the repetition of the eight-measure period produces a still greater wave or period of sixteen measures. The possibilities of rhythmic expansion are alone limited by the perceptive and conceptive faculties. Although our example presents the simplest form of rhythm it suffices to illustrate the subrhythm and its expansion. On the line of least resistance the repetition of an initial subrhythm is spontaneous; however, it is an error to speak of repetition as a principle of form, since it but superficially describes the operation of the actual principle, equilibrium. The regular alternations and repetitions of periods long and short are plainly due to the cardinal shaping principle, equilibrium, which is the vera causa of balanced motion and rhythmic unity.

Appearing in the above example are the numbers 
2, 4, 8 and 16, namely, groups of two beats, and of 2, 4, 8 and 16 measures. All these numbers reappear in the potential divisions and subdivisions of one or both of the subrhythmic periods or beats as follows:-

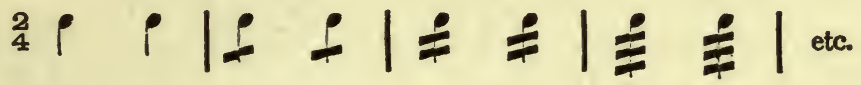

Thus we observe on one hand the expansion, on the other the division and subdivision of the subrhythm, the latter being illustrative of what I have just called the play of rhythm upon the subrhythm. This play of rhythmic thought upon the subrhythmic periods is further illustrated by the following list of rhythms potential in a single period of the subrhythm.

1. $\rho$

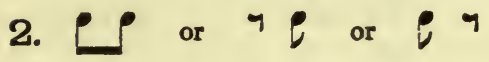

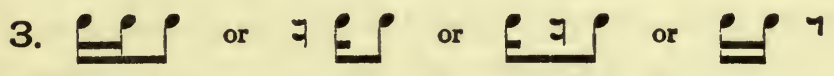

4. $\varphi \rho$ or $\varphi q$ or 9

5. $P$ or 7 if or 4

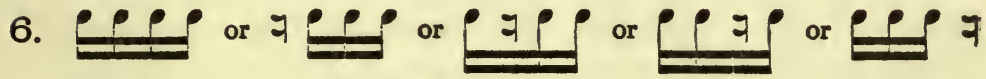

7. $P$ or $F=$

8. $f \rho$ or $E \rho$ or $¥ \ell^{\circ}$ or $¥ \ell \mp$

Students after working out this list resulting from the division of a quarter-note will find it profitable to work out other lists headed by notes of other denominations, as $0, P, \ell$. Each of the four result- 
ing lists will present the same series of rhythms and each individual rhythm will appear in another set of symbols thus:-

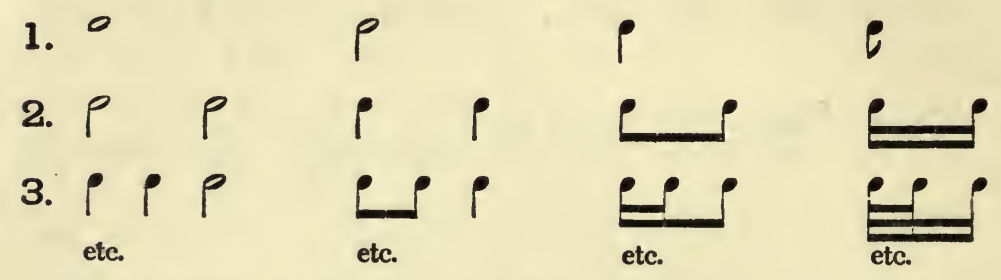

This work may be supplemented by four other lists in which the unit is divided into three parts as follows:-

1. 0 .

2. $\rho$. $p \rho$

3. $\rho \rho \rho p$

etc.
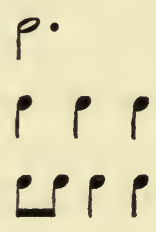

etc.
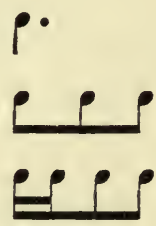

etc. e.

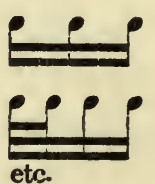

Such rhythmic work will cultivate alertness of observation and is stimulating to the imagination. How to pursue and apply such work will readily suggest itself to teacher and student.

In its diversity of rhythmic forms, its play of rhythm upon rhythm, its inexhaustible combinations, mixtures and groupings of the most diverse rhythms, music has only one rival, nature. Although from the view-point of evolution mensural music is but a thing of yesterday, although our historians speak of much of the ante-metrical music as music without rhythm, nevertheless when we consider that all motion is rhythm, and that all form is rhythmic form shaped by equilibrium, it follows that rhythm- 
less music is inconceivable and never existed. That it never did exist, and that tone and rhythm have never been separated in music, has been demonstrated and proved in precedent chapters of this book by the truth that the original form and relation of tone, namely, consonance and dissonance in one voice, had their genesis in the stable and unstable equilibrating periods of rhythm. This indissoluble union of rhythm and tone took place not by any voluntary effort of man, but under the impulse of inherent laws. The high degree of rhythmic complexity attained in primitive music is a familiar fact of history. The rhythm of primitive chants and songs unaccompanied by instruments was emphasized by words or gestures or both together, and when accompanied by instruments the rhythmic emphasis was further intensified by drum, pipe and string. In all this musical exercise, the results of which must have been very crude in its early stages, common feeling of rhythmic sound was its common guide, while pleasure in and love of rhythmic sound were its common stimuli. Moreover, this exercise in its early stages was marked by an instinctive and unconscious obedience to inherent and unwritten laws, not so difficult to be sure as conscious obedience to written laws. The effect of this pleasure-gratifying and unconscious law-abiding exercise of the music-sense was the slow dawning and developing of that keen and accurate perception which is the source of all our knowledge of music, the evolution of perception being the road upon which all knowledge has been gained. This pleasure-gratifying and law-abiding 
exercise in rhythmic sound on the road to true perception is traceable throughout music's development. The story of the development of pure instrumental music is not long in telling. The primitive woodsman beat upon a hollow tree-trunk and the sound pleased him; the primitive shepherd blew into a reed and the sound pleased him; the primitive warrior twanged his bowstring and the sound pleased him. Because the sound pleased woodsman, shepherd and warrior they kept on beating, blowing and twanging, man has kept on beating, blowing and twanging ever since, does so to-day, and promises to do so in the future. In the hollow tree-trunk the primeval woodsman discovered the principle of the drum, in the reed the shepherd that of the wind-instrument, in the bowstring the warrior that of the stringed instrument. All sorts of drums, pipes and stringed instruments in all sorts of shapes were fashioned out of all sorts of materials favoring the principle of each class. Steadily advancing perception, selection, craft and art gradually employed and combined the best materials, discovered and produced new materials, modified and improved shapes, added new principles such as stroke of bow and blow of hammer on string, improved and perfected many old instruments, discarded many others and invented new ones. And all this was accomplished under the impulse of steadily evolving music-feeling and music-art in fulfilment of inherent laws and principles. Result: the modern orchestra with its choirs of perfected instruments, the great organ, the pianoforte and their respective literatures.

The basic group-numbers of rhythms being 2 and 3 , 
it follows that theforms of music-rhythms are as diverse as are the regular and irregular combinations of these elementary group-numbers, first in the subrhythm, next in the potential subdivisions and expansions of all the potential subrhythms, which is to say that the diversity of music-rhythms is limitless. The classification of music-rhythms is roughly outlined under the four following heads:

I. Simple groups of 2. Simple groups of 3.

II. Compound groups of 2. Compound groups of 3.

III. Mixed groups of 2 and 3, as 5, 7, 10, 11, etc. IV. Simultaneous groups of 2 and 3, and of their compounds and mixtures.

The forms of I and II are regular; those of III and IV irregular. It is possible, though rare, that the subrhythmic periods and all the shorter and longer periods resulting from the division and expansion of the subrhythm may be regular throughout. But what should be emphasized here is the fact that while a subrhythm may be regular its shorter and longer periods may present many irregular forms, and conversely, while the subrhythm may be irregular its shorter and longer periods may present many regular forms. This great variety of potential subrhythmic forms, the limitless possibilities of their division and expansion, the commingling and concurrence of regular and irregular forms, the infinite possibilities in multi-voice music of the interplay of rhythms, not only of one rhythm on another but of rhythms upon rhythms, all this plainly intimates the inexhaustible wealth of music-rhythm. 
The subrhythm, the written form of which is the measure, is named by the number and length of its periods, therefore by its measure or metre. The subrhythmic period is a beat of the measure. The measure of subrhythms may be simple dual or triple, compound dual or triple, mixed dual or mixed triple, that is to say, the measure may contain 2 or 3 or 4 or 5 or 6 or 7 beats. The measure of five beats is mixed dual because 5 is divisible into two parts, namely, $2+3$ or $3+2$. The measure of 7 beats is mixed triple because 7 is divisible into three parts, namely, $3+2+2,2+3+2$, or $2+2+3$. The length of a subrhythmic period is named by that of the beat of a measure and may be a $d$ or $f$ or $f$ or $f$; it may also be a d. $d$. , $d$ or $\delta$. Hence the various indices of the measure of subrhythms as ${ }_{2}^{2}, \frac{3}{2}, \underset{4}{2},{ }_{4}^{3}$, and so on. The above dotted notes are suggested as measure units and may be marked in the measureindex by a corresponding dot after the number indicating the unit as ${ }_{2}^{2}$. instead of ${ }_{4}^{6}, \frac{2}{4}$. instead of ${ }_{8}^{8}, 3$. instead of ${ }_{4}^{9}, \frac{3}{4}$. instead of ${ }_{8}^{8}, 4$. instead of $\frac{12}{8}$, etc. All this but suggests the possibilities of diverse subrhythmic forms, while those of the subdivisions and expansions of those subrhythms must needs be left to the suggestion and imagination of readers and composers.

Music has another resource for variety of rhythms in another mode of division peculiar to itself. I allude to the division of a unit into three parts or triplets as

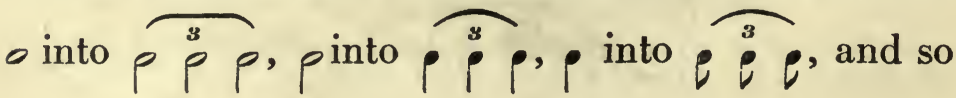


on. There are yet other resources arising in the play of the imagination upon the subrhythm; for example, the play of a 3 on a subrhythmic 2 , of a 5 and 6 on a subrhythmic 4, and so on, not to mention the possibilities of new forms arising by subdivision and expansion of these play-rhythms.
a) $\stackrel{2}{4} \rho \mid \widetilde{\rho^{3} \rho}$

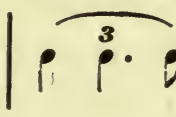
$\overbrace{i}^{3} p$
etc.

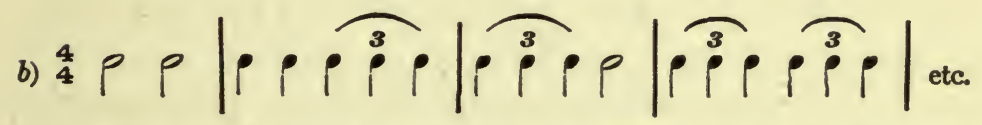

Also the play of 2, 4 and 5 on a subrhythmic 3, not to mention possible subdivisions and expansions, as follows:-

${ }_{4}^{3} \rho \cdot\left|\overparen{\rho^{2} \rho}\right| \overparen{\rho p^{4} p}\left|\overparen{\rho p_{p}^{5} p}\right|$ etc.

Next, an example (Chopin Op. 42) where the melody sings a 2 to the subrhythmic 3 , the former dividing the accompanying figure into $2 \times 3$, the latter dividing it into $3 \times 2$, as follows:-

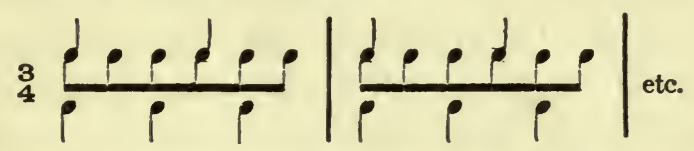

Next, an example (Schumann "Des Abends") where the melody sings 3 to the subrhythmic $2(a)$ ) and later continues the same thing in syncopation as at $b$ ).

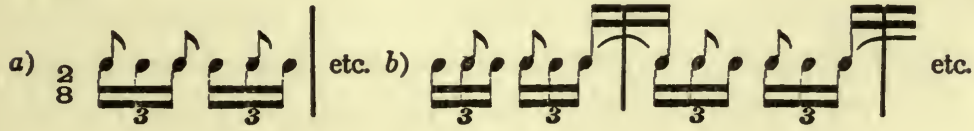


Our next example illustrates two concurrent melodies, the subrhythm of one of which is ${ }_{8}^{6}$ or ${ }_{4 .}^{2}$, while that of the other is ${ }_{4}^{3}$.

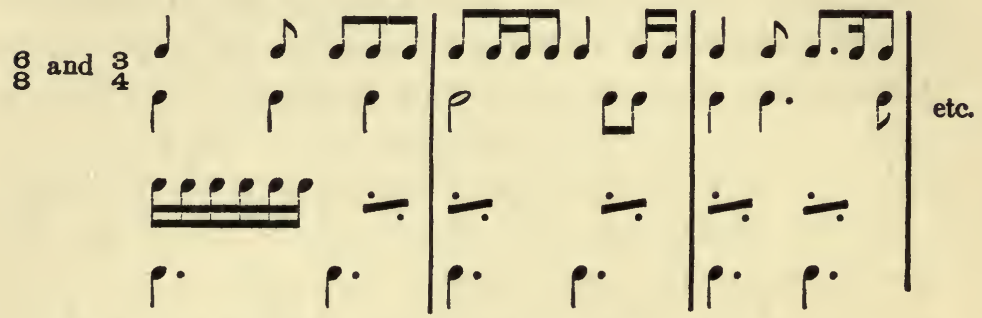

To sum up: Below are the five forms of elementary periods.

TwOS

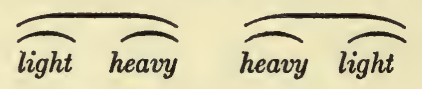

THREES
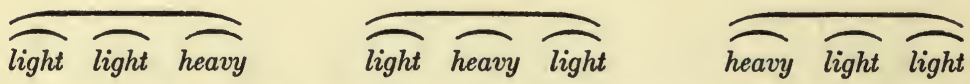

Any of these forms may be the subrhythmic period of, may appear in the smaller and larger periods of the subrhythmic divisions and expansions. In any period the above forms may be simple, compound or mixed. In simultaneous rhythms the possible concurrences of twos and threes, their compounds and mixtures are simply endless. A single larger period of simultaneous rhythms may combine the greatest variety of regular and irregular forms. No single musicwork is so rich in variety of rhythms as Bach's "Welltempered Clavichord." Mozart and Beethoven, the former notably in the subdivisions of the subrhythm, the latter in both the subdivision and expansion of the 
subrhythm, present a great diversity of forms. More complex rhythms of the classes III and IV appear in profusion in the works of Berlioz, Liszt and Wagner, of Chopin, Schumann and Brahms, of Tschaikowsky, Strauss and others. Music's structural development has followed the natural law by which forms proceed from simple to complex, from regular to irregular, from homogeneity to heterogeneity. Music-rhythms are boundless as thought, imagination and expression; they are however the shapes of music-thought itself and are not to be viewed and treated as moulds into which composers shape music-thoughts as caterers shape cakes and ices. Music-thought and imagination shape tone-rhythm and necessarily obey and fulfil the law of being inherent in tone-rhythm. Melody, the composite of the two elements rhythm and harmony, the flower of music and the essential form of the music-muse, has undergone great structural changes and will undergo other changes as the evolving music-muse may require. Greatly as old and modern melodies differ in structure yet they all obey and fulfil the shaping principle of tone-rhythm and they are all based upon a common structural unit, namely, the phrase. The phrase appears everywhere, in bird-song, in folk-song, in the melodies of all composers. Differences in structure lie first of all in the form and next in the treatment of the phrase. The phrase as presented by self-developed melody in a state of nature is one thing while the phrase as developed in the creations of music-art is quite another matter, although both are links in a chain of continuous evolution. In fulfil- 
ment of the shaping principle of equilibrium the first great end and aim in melody's self-development was perfect symmetry, and this meant perfect simplicity of form. In a state of nature and under conditions of complete freedom to bud and blossom into perfect form in conformity with the laws of its being, melody attained this end and aim in the folk-dance and folk-song in which it directly and spontaneously voiced the soul of the people. This perfect form of ideal beauty attained by melody in a state of nature is nothing short of wonderful. In melody's structural development its two elements rhythm and harmony have acted and reacted upon each other and have played an equipollent part. The simple symmetrical melody arose under the predominating influence of rhythm at a time when harmony was little developed and the chord unknown. On the other hand, the more complex structures of modern melodies have arisen under the predominating influence of melody's rapidly developing element of harmony. But nothing could be wider of the truth than the view that in modern music melody has been supplanted and superseded by harmony. Melody being the raison d'être of harmony could not be supplanted by one of its elements. I repeat: no melody, no harmony; no melody, no idea; no melody, no music. From first to last music is melody and all composers are melodists.

In fulfilment of the shaping principle of equilibrium short and simple tone-rhythms expanded into symmetrical phrases, and these phrases then expanded into the symmetrical folk-melody. This regular expansion of the subrhythm into larger and 
larger symmetrical periods lay in the rhythmic nature of things. Melody in a state of nature could develop no further and was ripe for greater things, was ready to enter the realm of fine art, "the paradise and playground of the human spirit." Melody did enter into this domain of constructive thought and imagination and the classic form of music took root. Regular symmetries in smaller parts and wholes naturally led to regular symmetries in larger parts and wholes. Hence the classic sonata and symphony, in creating which the old masters simply felt, obeyed and fulfilled the shaping principles of tone-rhythmic thought, leaving it to others to define these principles. Genius was their guide and law, art and its universal message was their absorbing end and aim. Nothing could have been more natural than these regular symmetries and the prominence of the group-numbers 2 and 4 both in the germinal melodies and larger structures. Are not nature's most obvious rhythms dual and regular, has not nature produced bipeds and quadrupeds in fulfilment of equilibrium, do we not walk on two feet and group our steps in twos and fours? True our modern composers have profited by nature's further teaching that there are countless irregular symmetries both in minute forms and in large aggregates and masses, all of which are pervaded and ruled by harmony. But regular symmetries which in music correspond with perfect simplicity of form had to come first and did come through the influence of rhythm, while through the influence of harmony have appeared those irregular symmetries in the phrases, melodies and larger structures of modern music which have been so 
unjustly condemned as unsymmetrical because they do not square with the regular symmetries of the classic form. However, such criticisms as well as the conception of the classic forms as conventions and models to be strictly adhered to have their origin in the minds of analyst and theorist, who necessarily follow "limping" in the wake of genius. In a previous chapter a distinction was drawn between rhythmic time and mathematical time or clock-time: the former has the group-pulse or accent which the latter lacks. The same distinction holds between rhythmic and mathematical symmetry. The regular symmetries of the classic form are rhythmic, not mathematical, and therefore the classic sonata and symphony are not to be likened to the geometrical patterns of French gardens and the regular squares of a modern city. Symmetry in music, be it regular or irregular, is always rhythmic. When we consider that rhythm pervades body and soul and that we spontaneously express the group-pulse or accent in our ordinary bodily movements and speech, it is strange, to say the least, that so large a proportion of performers seem not to know what the rhythmic group-pulse is and in their performances so often remind us of clock-time.

The folk-melody is the bloom of ages upon ages of evolution, and its perfect form of ideal beauty is one of the countless wonders of nature. The thought and imagination which developed this free-born melody into the perfect rhythmic balance and unity of the classic form, and which is so simple and naive in Haydn, so pure and balanced in Mozart, so great and potent in Bach and Beethoven, constitute the 
record of music's first great wave of development as an art. The classic form is not only to be regarded as the necessary culmination of a wave of psychical development, but is an ideal and spiritual achievement, an eternal glory, which no extravagance of language can overestimate. In it, all that has followed is rooted, for music-art is a continuous evolution, the old and the new being one in kind and links of one chain. In music, as in all the arts, the classic constitutes the firm rock of its school, it is the basic school of musicculture for composers, performers and listeners. Composers and performers thus schooled are quickly detected. "Learning to know the best that has been thought, said and done," this, Matthew Arnold tells us, is culture. For music-culture we should therefore turn first of all to the old masters whose works clearly reveal the fundamental principles of tone-art. We may then turn to the modern masters not for the purpose of learning as some think how they have violated laws, but to continue our culture. Genius enforces, does not violate, laws. Its ideal and spiritual content, the potency and universality of its message, not its specific form, constitute its justification and greatness before the tribunal of beauty, the art-deity. This message and greatness like beauty itself are mysteries, yet in the presence of a great work of art they are realities: the beauty of the work is unmistakable, es packt. 


\section{CHAPTER V}

ORIGIN AND NATURE OF MINOR

\section{Origin of the Minor Consonance}

WiTh the subject before us we resume our study of the evolution of harmony in one voice, which is the self-asserting harmony of melody. Music began with one voice, that is, with melody, wherefore origins are to be sought in one voice or melody. Our study is centred in melody, our facts are the common harmonic reports of melody, our test of truth is common feeling and perception of the self-reports of melody. This confirmed by common experience and observation is the truth of our theses, namely, that melody is the indissoluble composite of rhythm and harmony and not an element; that melody apart from mode, that mode apart from harmony do not and never did exist; that in one voice the harmonic reports of melody are common reports and are not mutable except through arbitrary personal selection; that the efficient accent on an isolated tone always generates the major consonance, in other words, that the natural harmony of a tone is major. Independently the last thesis suffices to establish the priority of the major consonance and mode. But overwhelming and conclusive evidence of the priority of major is furnished by bird-songs and primitive melodies most of which are in major while the proportion of those 
in minor is exceedingly small. The major mode arose when the major consonance arose; the minor mode arose when the minor consonance arose: the question of the origin of the mode therefore resolves itself into that of the origin of the consonance with which it sprang into being and in which it is rooted. How melody brought forth major has been fully explained. How melody brought forth minor is the study confronting us.

An isolated tone never generates and reports the minor consonance. It is true that on an isolated tone we may think and hear the minor chord as we may any one of a hundred other chords, but in so doing we think and hear what we select, not what a tone itself asserts and reports. Now in this our study of one voice or melody everything hinges upon our power to discriminate between the self-report of a tone and personal selection. The former alone is free from bias and has value; the latter is all bias and valueless. Whether discrimination between the two be easy or difficult, in no way affects the truth of our thesis that an isolated tone never reports the minor consonance, nor does it affect any of our data and theses.

In evolution a new something springs from a previously existing something. Since major came before minor it follows that minor sprang from elements previously existing in major. We have explained how melody began by intoning the rhythmic relation of cadence and repose and thus brought forth the major consonance and its cadences, that is, the major mode. Hence our thesis: the form of harmony is 
due to relation. Later we demonstrated that certain changes in relation generate new forms of harmony. Hence our thesis: new forms of harmony spring from previously existing tones in new or transmuted relations. This thesis points out the solution of the centuries-old puzzle as to the origin and nature of the minor consonance and mode. It required at least two tones and a specific relation potential in those two tones to generate the minor consonance in feeling and perception. The two tones in which that specific relation was potential previously existed in major. What are the two tones, what the specific relation? The tones are $d o$ and $l a$, the relation is a small third. The downward step do to $l a$ with the efficient accent on la generates the harmonic thread of the minor consonance as follows:-

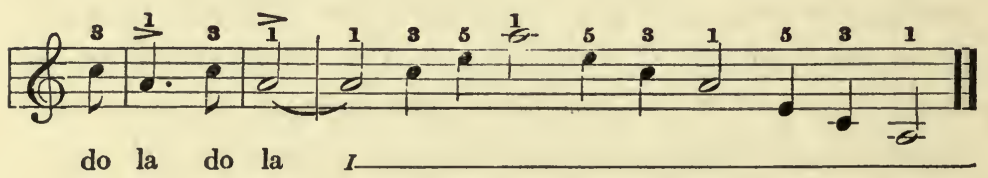

This I claim to be the origin of the minor consonance and mode in one voice. Our example illustrates the self-assertion of the minor consonance and demonstrates that this specific form of harmony springs from the repose or stable equilibrium inherent in the specific relation of the small third formed by do and la. Apart from two tones in the above relation of a small third the minor consonance cannot be felt, heard, thought or expressed, and therefore could not have been generated and asserted by melody. On the other hand, apart from this consonance which we 
all recognize and therefore relate as the minor Tonicharmony it is impossible to feel, perceive or conceive the minor mode.

In one voice, specific relations of specific tones give rise to and report specific forms of stable and unstable harmonies, that is, of consonances and dissonances. Just what these specific relations, tones and forms of harmony are we learn from our common feeling and perception of the self-reports of melody. In observing and verifying the common reports in one voice we stand on common intellectual ground, for when that which we think, fully and faithfully interprets the common feeling and percept then only shall we agree as to the facts or common reports. I repeat: our concepts in one voice are false when they conflict, and true when they completely accord with our common feeling and percept, that is, with the common report of melody. Now the small third is the only relation that gives rise to and reports the minor consonance. I next present three theses based upon common reports.

1. Any isolated combination of two tones in the relation of a small third generates and reports the minor consonance which we all involuntarily recognize and relate as the minor Tonic-harmony.

2. An isolated major consonance invariably reports its root to be $d o$, its third to be $m i$, its fifth to be $s o l$.

3. An isolated minor consonance invariably reports its root to be $l a$, its third to be $d o$, its fifth to be $m i$.

The three components of the major consonance are major harmonic percepts which I mark with larger numbers. The three components of the minor con- 
sonance are minor harmonic percepts which $\mathrm{I}$ indicate by smaller numbers. Both consonances and their symbols are given below for comparison and correlation.$$
\begin{array}{lll}
1 & 3 & 5
\end{array}
$$
1. Major Tonic-harmony: $\mathrm{do}-\mathrm{mi}-\mathrm{sol}$

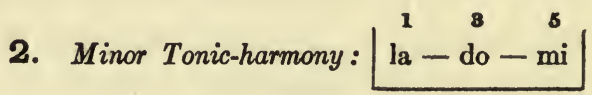

Upon the priority of major we base our thesis that minor has been derived from elements previously existing in major. Thus major supplied the original tones named diatonics which in minor reappear in new and transmuted relations. Note do and $l a$ in the above example. Do, the major Tonic and the original root (1), of the genus consonance, reappears in minor as small third (3) of the minor consonance. $L a$, the original ninth (9) of the genus dissonance, in which it is the highest tone, reappears in minor as the original minor Tonic and root (1) of the original minor consonance. Thus again, major supplied the original forms of consonance and dissonance, each of which assumes a new and transmuted form in minor. Our example presents the original and transmuted forms of consonance. Thus again, major supplied the basic relations of rising cadence, falling cadence and repose which characterize and underlie tone-relation in general and mode-relation in particular and which in minor are directly imitated. Minor is therefore not only derived but is purely imitative; it is derived from material provided by the prototype major, and it imitates the relations of cadence and repose ori- 
ginally derived from rhythm and first intoned by melody in the prototype major mode. Here we note in passing that imitation is not alone a principle of music-structure as demonstrated in round-song, antiphonal chant, sequence, canon and fugue, but, what is even more important, imitation is a principle of harmonic genesis closely allied to that of potential harmony, the subject of a later chapter. Again referring to our example we note that $d o$ is the original major Tonic, that $d o$-major is the original major mode; next, that $l a$ is the original minor Tonic, that $l a$-minor is the original minor mode and corresponds with what is known as relative minor. The almost universal adoption of relative minor as the true minor amounts to a tacit acknowledgment of the priority of major, and presents but one of thousands of cases in which our great thinkers draw their conclusions from facts reported by common feeling and perception. In all books on music, be they historic, biographical, æsthetic, theoretic or didactic, we everywhere find the direct appeal to music-feeling for every hidden and ultimate truth. It is safe to say that every truth that came to stay in the books came by way and sanction of music-feeling. The conflict between an abstract theory and concrete feeling waxes strong in every case where the two are irreconcilable owing to the unconquerable protest and revolt of music-feeling. One of a number of cases in point is the ZarlinoRiemann theory of pendant minor with harmonic roots in air upon which we will later on present the common harmonic self-reports of one voice or melody. The concept of minor as la minor (relative minor) 
completely harmonizes with our common feeling and percept of minor, and its validity is demonstrated and confirmed by the self-reports of melody.

Reverting to our theses on page $\mathbf{1 7 9}$ it may be asked, why fix upon the specific tones do and $l a$ for the origin of minor? Among previously extant diatonics are there no other combinations of two tones in which the requisite relation of a small third is potential? Ages upon ages before there was any conscious perception of harmony, melody had brought forth both the major mode and minor mode in one voice. In connection with this early formative period of melody when feeling of harmony was in its incipient stages of development we could not confidently speak of specific tones or of specific relations generating specific forms of harmony, in short, we could not answer the above questions, were it not for harmony in one voice, its definite self-reports and its demonstrable principles. Admittedly the refined harmonic sense of to-day is connected with, rooted in, and the evolutionary product of, the harmonic sense of the entire past, or briefly, of yesterday, and it follows that the harmonic percepts of to-day spring from the harmonic feelings of yesterday, that the common self-reports of melody so clearly perceived to-day are the same which yesterday were but dimly felt. Thus harmony in one voice is the connecting link between the harmony of the present and that of the entire past, and by means of its self-reports we can trace the genesis of tone upon tone, relation upon relation, harmonic form upon harmonic form; and because these self-reports are common and apply to all music in one voice it matters little whether our illustra- 
tions are drawn from modern or primitive melodies, or whether we devise them as we proceed, so long as they are in one voice and exemplify the special case under consideration. We may now answer the above questions beginning with the second. Yes, there are three other combinations of diatonics which frequently appear in primitive melodies in the relation of small thirds. One is sol down to $m i$, which like do to $l a$ dates back as far as the pentatonic period, and which insistently reports the major Tonic-harmony (I), sol asserting itself as 5, $m i$ as 3 . Later on when the downleader $f a$ and the upleader $t i$ had made their appearance, melody introduced two other combinations, namely, fa down to $r e$, re down to $t i$. During the anteminor stage of music when melody had evolved but a scant web of harmonic threads and had generated at most three regnant harmonies, namely, I, V and IV, not one of these combinations in small thirds could have generated the minor consonance. Why not? Simply and obviously because these original harmonies of melody necessarily and always appear in correlation, as demonstrated by primitive melodies of birds and men. Because of this necessary correlation the combinations fa to $r e$ and $r e$ to $t i$ insistently report the major Dominant-harmony (V), fa asserting itself as $7, r e$ as $5, t i$ as 3 . Indeed, the original relations of original tones are so deeply rooted in harmonic feeling that even to-day we cannot change them except through deliberate reflection and a voluntary effort of selection which in every such case results in a modulation. Needless to say it would be the height of absurdity to accuse man of such refined intellectual 
powers of abstraction at a time when his melodies were the simple, naïve and spontaneous intonations of concrete feelings. Of these primitive melodies and of the beautiful folk-melodies and of the immortal melodies of our masters two things are equally true: not one was ever produced through deliberate reflection, and no one can tell whence they came. Of all the seven diatonics do and $l a$ are the only two tones through which melody could have brought forth the minor consonance, and this paragraph may be concluded by restating our thesis.

Any isolated combination of two tones in the relation of a small third generates in feeling the minor consonance, and in every such case the two specific tones are $d o$ and $l a$.

\section{Original and Duplicate Forms of Harmony}

Each specific form of harmony in one voice arose on a specific tone in a specific relation: every such form being the first of its kind is classed as the original, and every repetition of such an original on other tones is classed as a duplicate.

In the whole realm of harmony there are but two forms of consonances, the major form with its distinctive and characteristic large third (3), the minor form with its distinctive and characteristic small third ( 3 ). Of the two consonances the major form is the prototype, the minor form is the derived and modified type. Their distinctive thirds at once mark the structural difference between the two forms and the individuality and essential character of each. The major Tonicharmony based on do is the original major form: the 
minor Tonic-harmony based on la is the original minor form. In evolution these forms are repeated on other tones, and all such repetitions for lack of a better name are here called duplicates. Duplicates of the major form on $\mathrm{V}$ and IV have already been presented and explained and others will follow. Duplicates of the minor form will appear presently.

Roman numbers are employed for the double purpose of indicating the root and the specific form of a harmony; in larger type they indicate major, in smaller type, minor harmonies. I shall strictly adhere to this universal custom save in one particular, namely, the numbers indicating minor harmonies will be printed in italics for reasons which will become obvious as we proceed.

\section{Origin in One Voice of the Minor Form of Dissonance. Original Cadences of the Minor Mode}

In minor the diatonics owing to their reappearance in new and transmuted relations undergo a redistribution and regrouping. The prototype modal relations of cadence and repose in precedent major are directly imitated in minor, and these imitative relations constitute the vera causa of the genesis of the minor forms of consonance and dissonance which are the counterparts in minor of the two major prototypes. For the group of tones and relations which we have named the regnant major Tonic and its cadences there is a corresponding minor group, the regnant minor Tonic and its cadences; for each specific tone and relation in the precedent major group there is a corresponding tone 
and relation in the derived and imitative minor group. In short, everything in major has its parallel and counterpart in minor. Major provided the material by means of which melody produced minor, and minor in its turn has added new material. Just as in major so in minor, the cadence-tones arose over and under and tend up and down into the regnant Tonic-harmony. Because of these corresponding tones, relations and harmonies in the two modes, parallel examples in major and minor will be given in all cases where they will add to the clearness of our exposition. Our first example presents a pentatonic melody, in which note the common harmonic self-reports and corresponding tones, relations and harmonies in the two modes. The pitch of these and other examples is chosen for convenience of presentation and should be thought an octave lower.
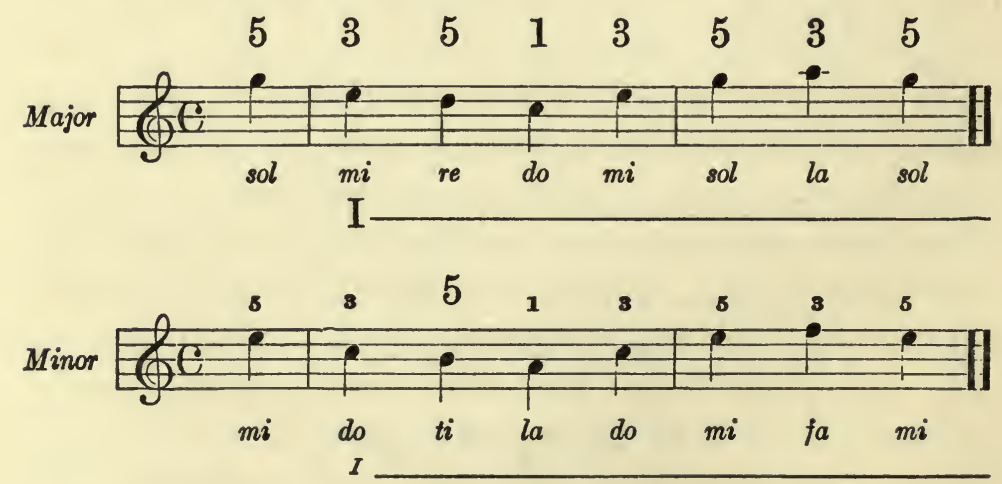

Carefully compare these parallel examples. The syllables and harmonic numbers show the new and transmuted relations of the diatonics in minor. Observe that each mode is represented by the three com- 
ponents of the Tonic-harmony, by one component of its Dominant, by one component of its Subdominant. Observe the parallel regnant harmonies, $I$ in minor, the counterpart of $I$ in major. Tone upon tone compare the corresponding tones and harmonic percepts of the two modes as follows: $m i s$ in minor is the counterpart of sol 5 in major, do 3 of mi 3, ti 5 of re 5, la 1 of do 1 , and so on. The essentially imitative character and nature of the minor mode is plainly manifest not only in the whole meloharmonic phrase, but in each tone and interval, each progression and cadence, each harmonic percept. Observe the parallel falling cadences: ti 5 to $l a 1$ in minor corresponds with re 5 to do 1 in major, fa 3 to $m i s$ in minor with la 3 to sol 5 in major. Observe that the cadence-tone $t i 5$ in minor reports its concomitant third to be a large third and a chromatic, namely, si (g) in our example), and that this chromatic is the minor upleader which corresponds with the major upleader $t i 3$. Observe in the falling cadence $f a$ to $m i$ ( $f$ to e) in minor how unnatural it would be to substitute for f. These observations will have an important bearing on the sequel.

The major Dominant (V) was first announced and represented in melody by its fifth $r e$ and first appeared in cadence, that is, as a byharmony. The same is true (see above example) of the corresponding minor Dominant $(V)$ which was first announced and represented by its fifth $t i$ (counterpart in minor of the major ro) and likewise first appeared in cadence as a byharmony. Again, the major Subdominant (IV) was first reported by its third la, the parallel minor Subdominant (as in example) by its third fa. Thus the 
part played by re and $l a$ in major is repeated in minor by its corresponding tones $t i$ and $f a$. Thus, as we have seen, the efficient accent on $r e$ generated the regnant Dominant (V) in major; likewise the efficient accent on $t i$ generated the regnant Dominant $(V)$ in minor. Again, the efficient accent on $l a$ caused the genesis of the regnant Subdominant (IV) in major, on $f a$ the corresponding regnant Subdominant $(I V)$ in minor. In the parallel examples below compare these corresponding regnant harmonies and note the harmonic reports upon their genesis as just explained.
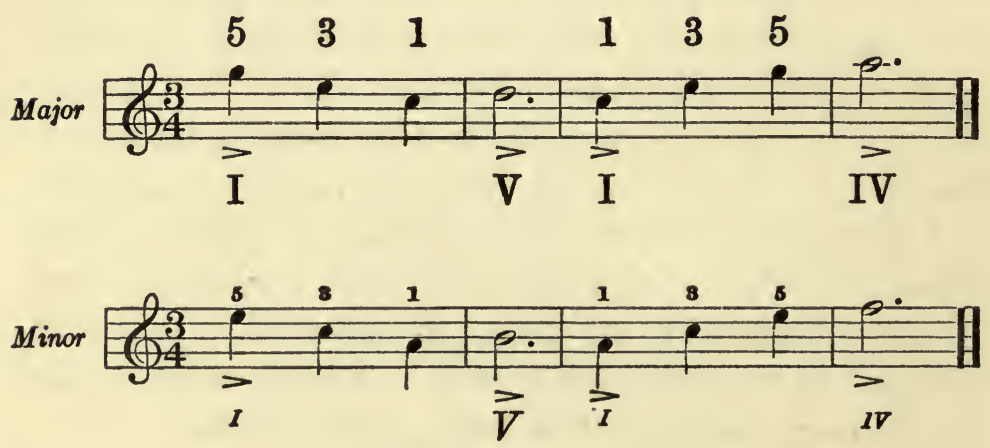

Our next consideration is the minor form of dissonance and how it arose. The entire harmonic thread (comprising five components) of the genus dissonance (prototype major form) was and is latent in the major cadence-tone re. Likewise the entire harmonic thread (comprising five components) of the derived and transmuted form of dissonance in minor was and is latent in the corresponding minor cadencetone $t i$. Compare the two in the following example:- 

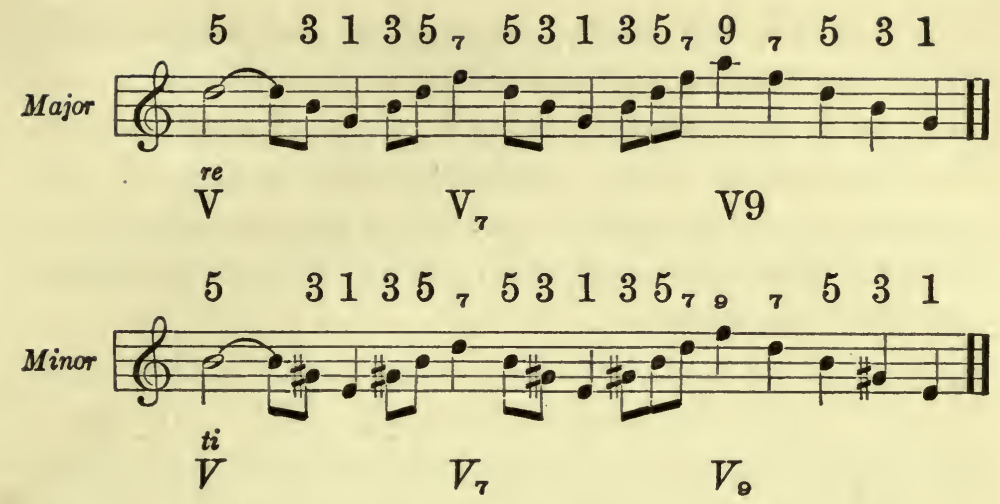

The two forms are again presented in syllables and harmonic numbers for further observations.

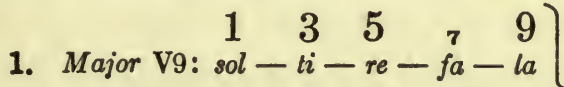
2. Minor $\left.V_{9}: \begin{array}{cccc}1 & 3 & 5 & 7 \\ m i & -t i-r e-f a\end{array}\right\}$

Compare corresponding tones and harmonic percepts as follows: $s o l$ is root of major Dominant, $m i$ is root of minor Dominant, and so on. Observe that the two dissonances differ only in their ninths, all the other intervals being the same; the ninth in major is large and was first reported by $l a$, the ninth in minor is small and was first reported by fa. The distinctive individuality of each of the two types of consonances is due to its characteristic third, 3 in major, $\mathbf{s}$ in minor, while that of each of the two original types of dissonances is due to its characteristic ninth, 9 in major, $\bullet$ in minor. Both types of dissonances confirm the truth of our thesis that the ninth is the highest harmonic component of a harmonic root and therefore the genetic limit of harmony. 
Sol is the bond-tone connecting the cadence and repose groups of harmony V9-I in major, appearing first as 5 of $\mathrm{I}$, thereafter as $\mathbf{1}$ of $\mathrm{V}$. Likewise $m i$ is the bond-tone of the corresponding groups of harmonies $V_{\theta}-I$ in minor and likewise $m i$ appeared as $s$ of $I$ before appearing as 1 of $V$. Both bond-tones are next presented.
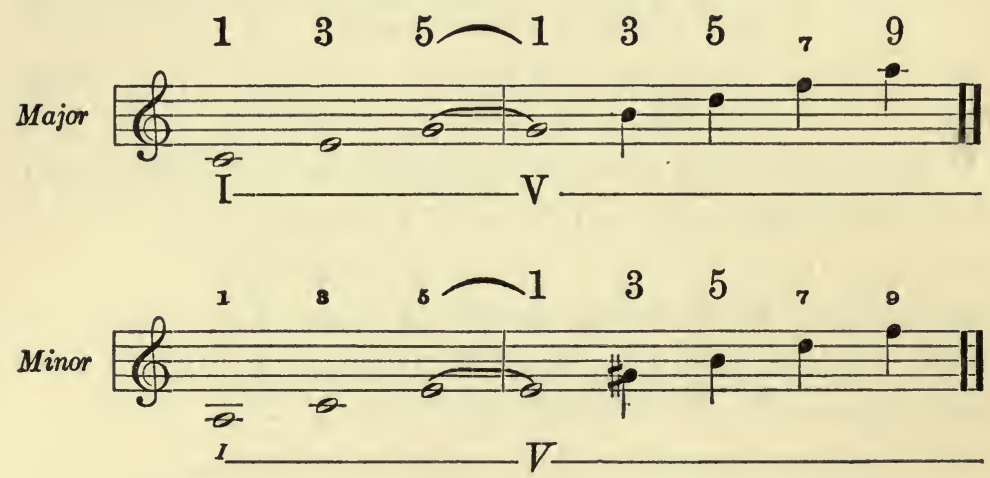

Just as the major dissonance arose in relation to the major consonance just so the minor dissonance arose in relation to the minor consonance. The remaining four components of the two dissonances are cadencetones which lie directly over and under, and which tend and resolve up and down into the components or repose-tones of the two consonances. Of the four in major all are diatonics and had their genesis in relation to the major consonance. Of the four in minor three are previously existing diatonics in transmuted relations while one (si, the chromatic) is a newly derived tone the genesis of which we have just explained. The four in minor directly imitate the 
four in major. Compare below the four cadencetones and three repose-tones in each of the two modes.

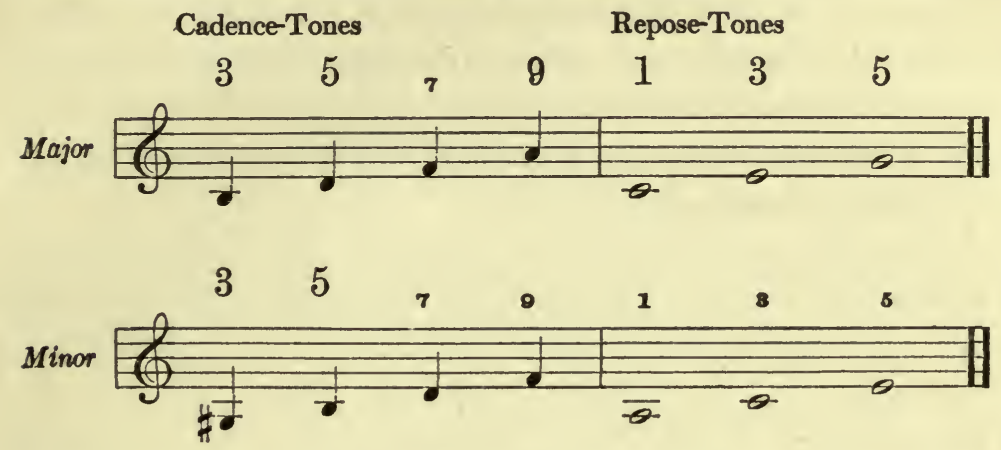

In this relation the four cadence-tones present an aggregate of five cadences in each mode since $t i$ in minor resolves both up and down like its prototype $r e$ in major. Each cadence in minor imitates and is the counterpart of its corresponding cadence in major. Compare the five parallel cadences below.
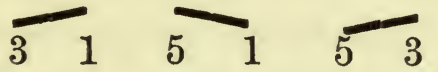

1. Major: ti do re do re mi
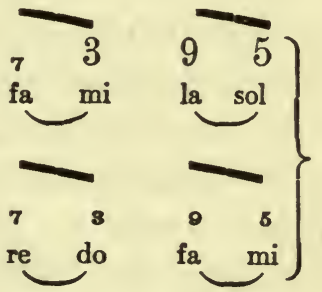

The resolutions of these cadences are next presented in the form of chords as follows:-

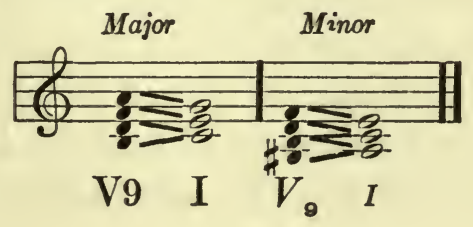


The addition of a terminal Tonic to each of the above groups of four cadence-tones and three reposetones completes the scales known as diatonic major and relative minor. They are presented below both ascending and descending for the purpose of exhibiting their parallel progressions and resolutions or cadences, the latter marked by slurs.
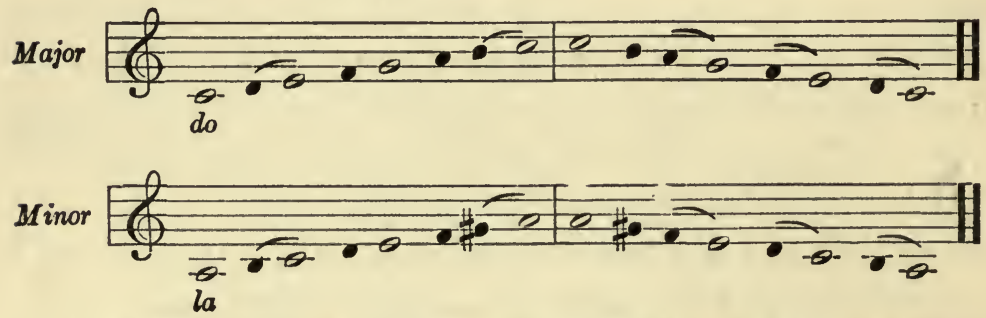

In all the preceding illustrations of parallel cadences we note how each cadence in minor has arisen by imitating its major prototype. Thus the upleader si 3 in minor corresponds with the upleader $t i 3$ in major, the downleader $r e \mathrm{r}$ in minor with the downleader $f a r$ in major, the double cadence of $t i 5$ with that of its prototype $r e 5$, the cadence of $f a$ e with that of its prototype la 9. In short, each tone and relation in major is offset by a corresponding tone and relation in minor. Hence the close relationship of major and minor. Each mode has its own specific form of consonance and specific form of dissonance at its foundation, and let us remember that in one voice, melody generated all these forms in obedience to the inherent and uniform laws of causation which we have already defined.

The above minor group of tones is as noteworthy for the absence of sol, the only diatonic which does 
not appear, as it is for the presence of the newly generated tone si. As regards si, which arose as a concomitant in the harmonic thread generated by $t i 5$, we pause here to observe first, that chromatics first arose as concomitants and were generated by diatonics in transmuted or new relations; next, that all newly generated tones like si pass through three consecutive stages of psychological evolution which mark the progressive development of melody. Indeed, with the exception of the components of one harmony, all tones have passed through these three evolutionary stages. The one exception is the major Tonic-harmony which was at once a regnant harmony and the first harmony generated by melody and whose components do 1, mi 3, sol 5 therefore made their first appearance in melody as regnant tones. The three consecutive psychological stages are as follows:-

First Stage: in which a tone had its genesis as an elementary harmonic or concomitant in a thread of harmony generated by a previously existing tone in a new relation. This is a tone's lowest or elementary stage.

Second Stage: in which a tone has been differentiated and has appeared in melody as a bytone, that is, in the relation of cadence on a light rhythm-period. In this stage a tone has become an individual constituent of melody and of the tone-system. This stage may be called briefly the bytone stage.

Third Stage: in which a tone has appeared in melody as a regnant tone. In this stage a tone first appears on light rhythm-periods after or between other co-harmonics of the regnant harmony, but does 
not attain its highest development in one voice until it appears on the efficient accent (heavy rhythmperiod), when it generates the regnant harmony of the moment. This highest stage of a tone in one voice or homophony is named briefly, the regnant stage.

These three stages apply exclusively to music in one voice or homophony. Next let us follow si 3 in minor and its major prototype $t i 3$ through these three stages. Our parallel examples illustrate their lowest stage as concomitants. In minor, si is present as concomitant 3 in the harmony generated by $t i 5$; in major, $t i$ is present as concomitant 3 in the harmony of re 5. See below at the places marked by an asterisk.

Minor
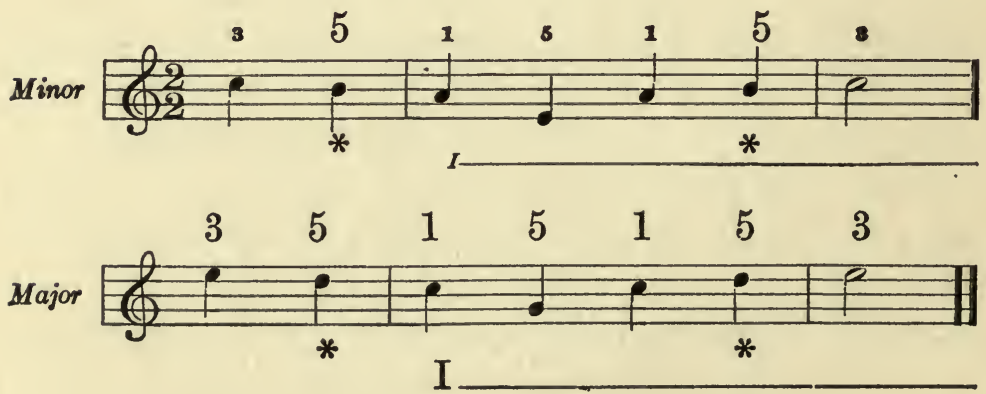

Next the two tones appear as bytones in their second stage.

Minor

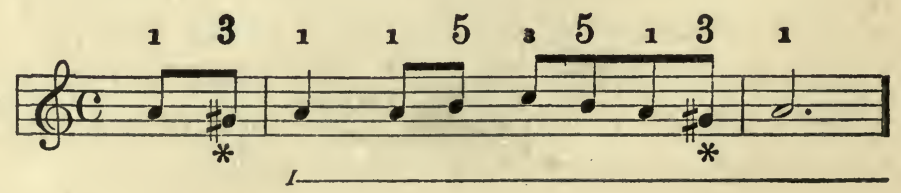




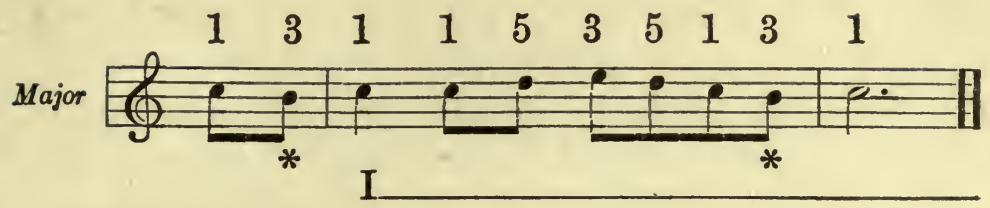

Next in their third and regnant stage.
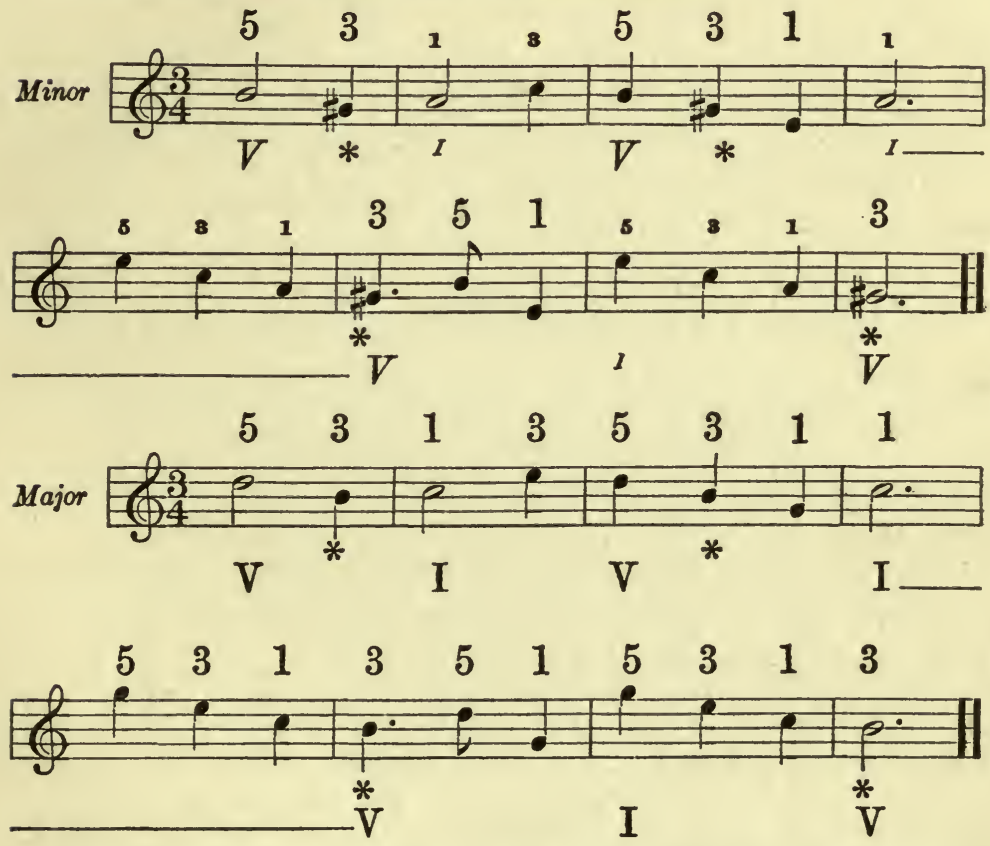

Everywhere in all the above and previous examples the common harmonic self-reports demonstrate the fundamental implication of rhythm, therefore the operation of the shaping principle of equilibrium, in short, the uniform laws of psychological causation in homophony.

The absence of the diatonic sol in the minor group of seven tones thus far presented raises this question: 
Does sol ever appear as a constituent tone of the minor mode and if so, how? Presently we shall see that sol does appear in minor melodies, and plays a most significant part in the minor mode. The succeeding parallel examples present all seven tones of both modes in all their tonic and dominant relations.

\section{$\begin{array}{lllllllllll}3 & 9 & 1 & 7 & 3 & 5 & 1 & 5 & 3 & 1 & 5\end{array}$}

Major

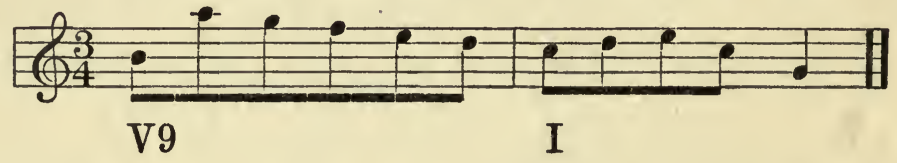

Minor

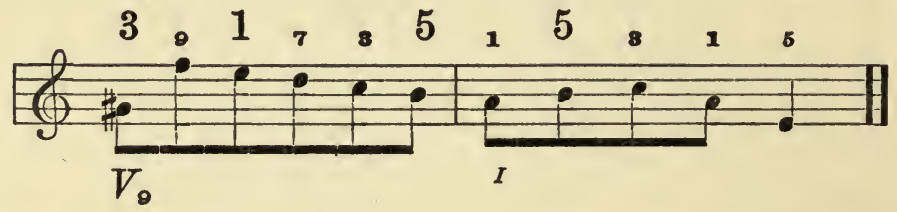

- These seven tones of the minor group appear in all their tonic and dominant relations in each of the following fugue-themes of Bach.

1.
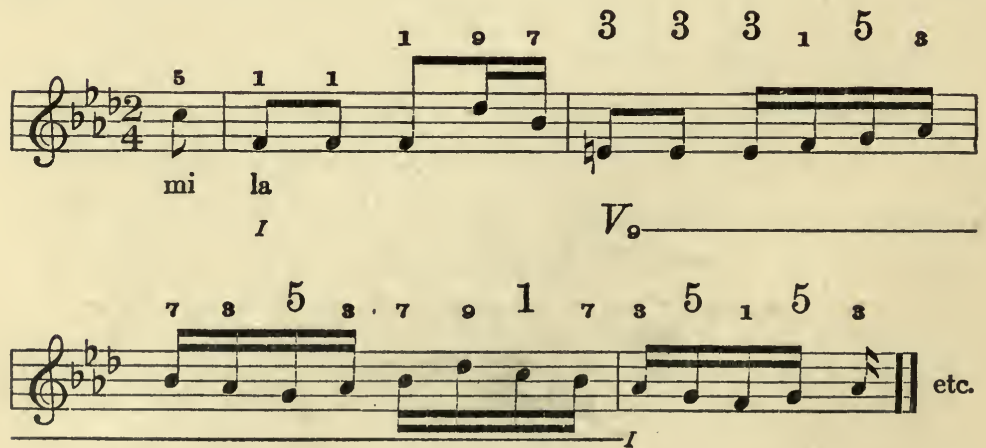
2.

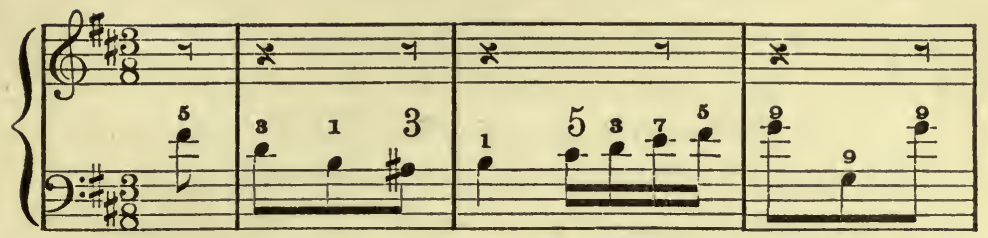

mi $\quad \underset{I}{d} \quad$ la $\quad$ si

$V_{\circ}$
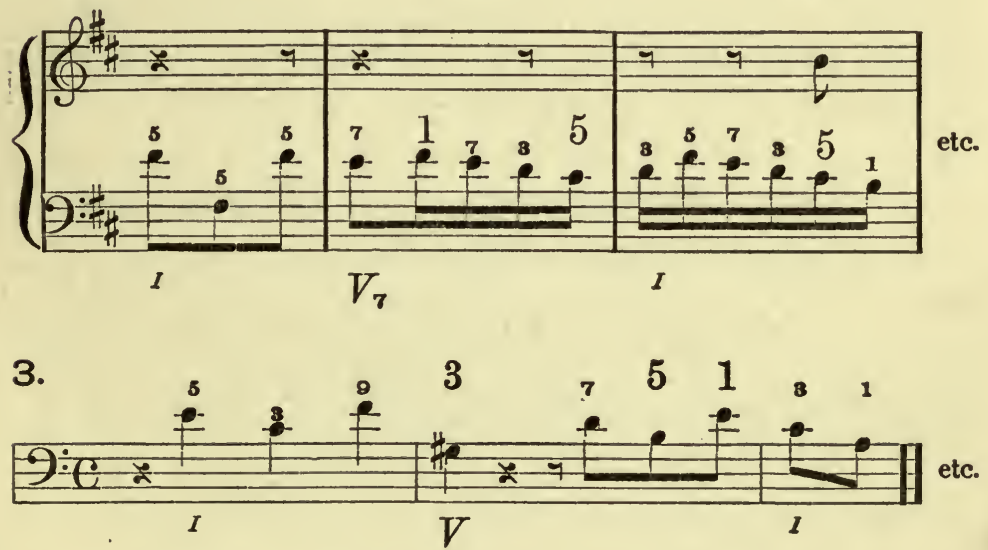

The study of Bach more than that of any other one master quickens our perception of meloharmony and its common self-reports and teaches us to appreciate the essential and fundamental importance of meloharmonic discrimination to an intelligent interpretation and expression not alone of polyphonic music, but of all music. In the study of the rhythms and harmonies first of one melody and next of combined melodies we gradually realize that there are principles of expression inherent in music itself and therefore in common feeling of music. What these principles are is considered in a later chapter. That 
Bach had a profound and vivid sense of these inherent principles and expected as much from his interpreters may be inferred from the fact that he left us his monumental pianowork "The Well-tempered Clavichord" without a single mark of expression.

We have explained the origin in one voice of the minor form of dissonance, have defined its five components and their correlations. We have accounted for seven tones of the minor group and have encountered these seven tones in the following nine minor relations: $l a$ as 1 of $I, d o$ as $\mathrm{s}$ of $I, m i$ as $s$ of $I$ and 1 of $V$, si as 3 of $V$, $t i$ as 5 of $V$, re as 7 of $V$, fa as $\bullet$ of $V$ and $s$ of $I V$. All these tones and relations appear in the subjoined fugue-theme of Bach.

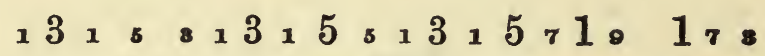

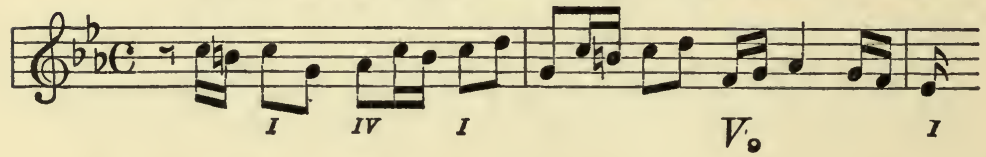

46. Three Regnant Minor Harmonies and Their Bytones and Cadences

Having explained the subject of regnant harmony in the preceding chapter we may proceed without needless repetitions to study the bytones and cadences of the minor tonic, dominant and subdominant harmonies. In a given melody the leading question is: What is the regnant harmony or series of regnant harmonies? Every tone in a melody relates to a regnant harmony, and if a component, is classed a regnant tone, if not, a bytone. Such are the essential points to be borne in mind. 
1. Regnant Minor Tonic. Its regnant tones are $l a, d o, m i$, its bytones are $s i, t i, r e, f a$. In future examples each bytone is marked by a star. During the regnancy of this harmony, si, $t i$ and $r e$ report themselves respectively as 3,5 and 7 of $V$, while $f a$ reports itself as $\mathbf{s}$ of $I V$. See below and compare with the parallel major example.
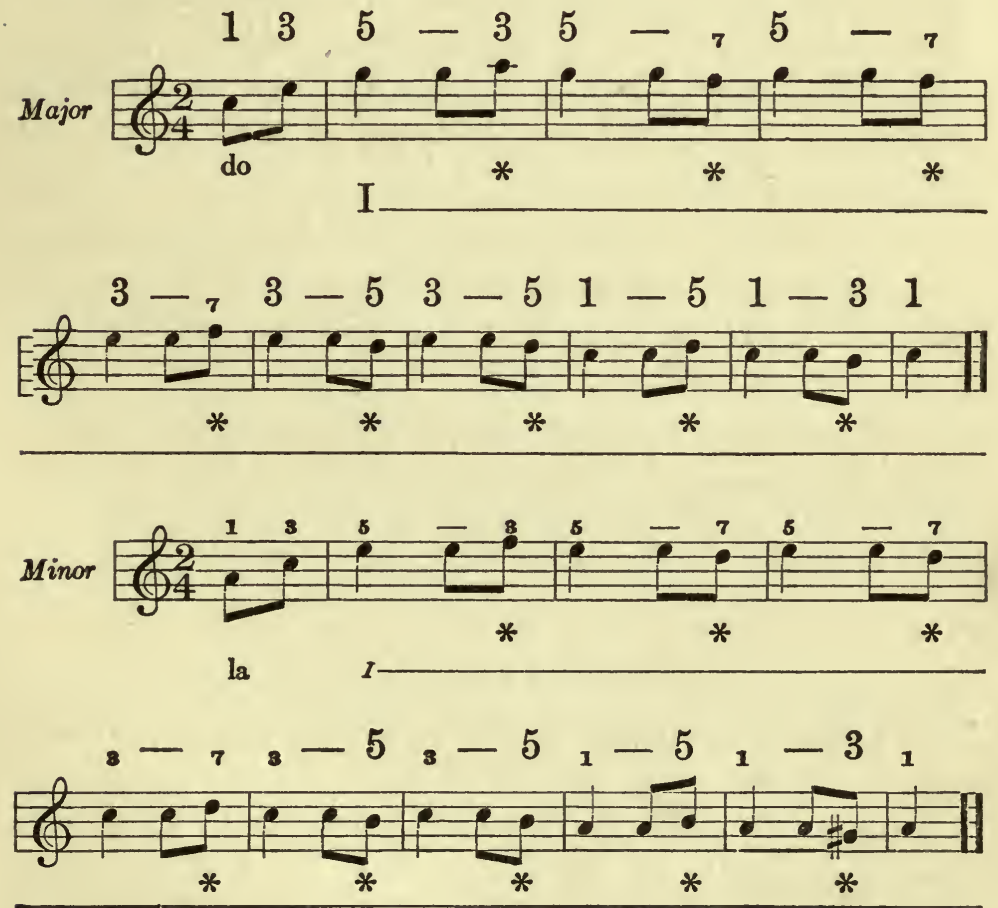

While there are other bytones to this regnant our examples are strictly confined to the tone-material thus far accounted for. This material includes the diatonic sol and evokes the question: Does sol ever appear as a bytone to this regnant? Our questions 
are addressed not to abstract theory, but to concrete melody and its governing principles. Melody could and did, can and does introduce sol in this relation as shown below. Sol arises on the line of least resistance in the descending tetrachord which starts on the octave and terminates on the fifth of the regnant minor tonic. See last two measures [but one]. Comparison with the parallel example in major again recalls our attention to the imitative nature of minor and shows that each harmonic percept and step in minor are the direct counterparts of their respective major prototypes.

$\begin{array}{lllllllllll}1 & 3 & 5 & 3 & 5 & 3 & 5 & 3 & 3 & 5 & 3\end{array}$

Major

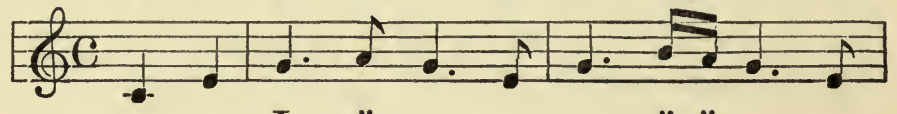

I *

* *

$\begin{array}{lllllllllllllll}5 & 1 & 3 & 3 & 5 & 3 & 5 & 1 & 3 & 3 & 5 & 7 & 3 & 5 & 1\end{array}$

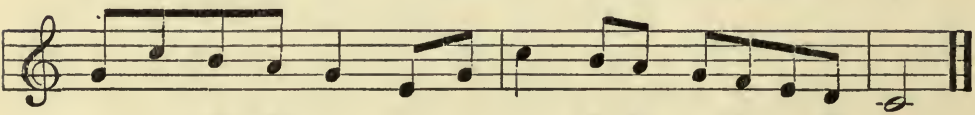

* *

* * * *

Minor
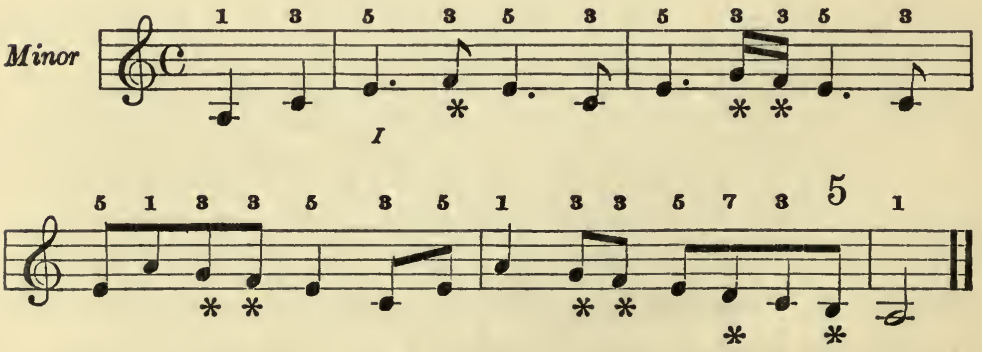

In the minor example sol appears in the last three measures [but one], and reports itself as small third of the dominant, thus demonstrating that the minor domi- 
nant in this instance assumes the form of a minor consonance, the index of which is $V$. The data to be observed in this connection are first, that $V$ is a pure diatonic harmony since all its components are diatonics; next, that $V$ arises spontaneously in one voice; next, that the minor dominant $V$ is a chromatic harmony owing to its large third $s i$, which is a chromatic. Presently we shall see that the diatonic minor dominant $(V)$ asserts itself in one voice as a regnant harmony. Further observations are these: The asterisks in our examples show a series of two bytones, the first resolving into the second, the second resolving into a repose-tone of the regnant $I$. Bytones which resolve into the regnant harmony are classed as bytones of the first degree: bytones of the second degree resolve into those of the first degree. We shall meet with bytones of the third degree which resolve into those of the second. In the descending tetrachord from $l a 1$ down to $m i$ s we recognize the upper half of the descending melodic minor scale as follows:-

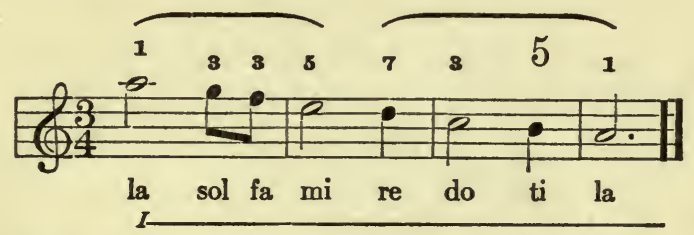

All the above tones are diatonics, yet the scalemelody is not diatonic. Why not? Simply because all the harmonies are not diatonic. To be diatonic all the components of a harmony must be diatonics. This is the case with all the tones of the first of the above two tetrachords, which is pure diatonic minor. Not so 
in the second tetrachord, in which the harmonies both of $r e \tau$ and $t i 5$ report the presence of the chromatic si (g开) as a concomitant and component 3, for which reason they are classed as chromatic harmonies. These common harmonic reports in one voice therefore plainly and conclusively demonstrate and prove that even though a melody be entirely composed of diatonics, yet that melody may not be diatonic. The test as to whether a melody is or is not diatonic lies in its concomitant harmony, which in one voice asserts and reports itself, and this test and new view-point will greatly modify the facts and conclusions which in the past have been recorded by music-archæologists in their studies of homophony. But is there such a thing as a pure diatonic minor melody? Such a melody might easily be conceived and represented by selecting diatonic chords as an accompaniment, but this would be but an arbitrary conception void of any archæological value. On the other hand, if such a melody is conceivable in one voice and itself generates and reports only diatonic harmonies which we all perceive in common, then indeed would we gain a fact of considerable value to music-archæology and psychology. The common self-reports in the next illustration answer our question in the affirmative, and conclusively demonstrate that such melodies do arise in one voice, and from this we may infer that they may have arisen in the remote homophonic past.

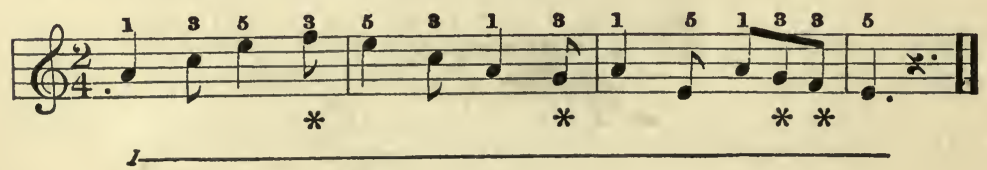


This is a pure minor melody, each tone reports a diatonic harmony, each harmony is a minor consonance. In the first measure the bytone fa reports itself 3 of $I V$, in the second measure $s o l$ reports itself $s$ of $V$, in the third measure both bytones make the same reports. Thus through sol the minor dominant assumes the form of a minor consonance. Thanks to selfasserting harmony in one voice we are able to affirm that there is such a thing as pure diatonic minor which is the perfect counterpart of pure diatonic major. The subject of pure minor melodies will again be reverted to when we shall study sol in other relations.

Does melody ever ascend on the upper half of the descending melodic minor scale? Yes, there are many examples, especially in modern music. We cite one from Liszt, Rhapsody II.

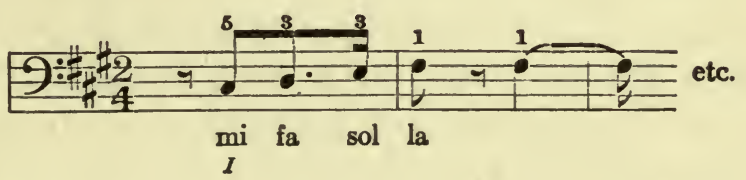

The ascending upper half or tetrachord of the melodic minor scale has been derived through imitation from the same tetrachord of the major scale, thus introducing another chromatic, namely, $f i$ (f in $\mathbf{A}$ minor) as follows:-

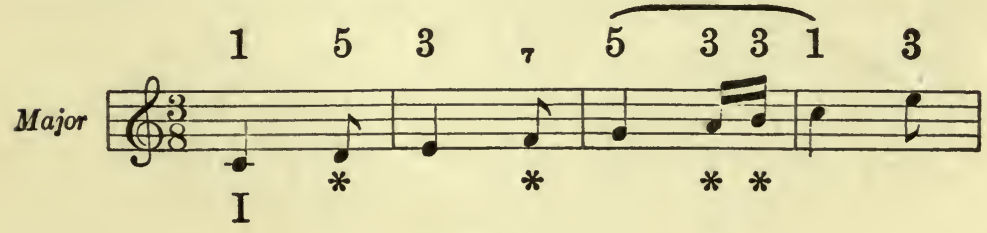




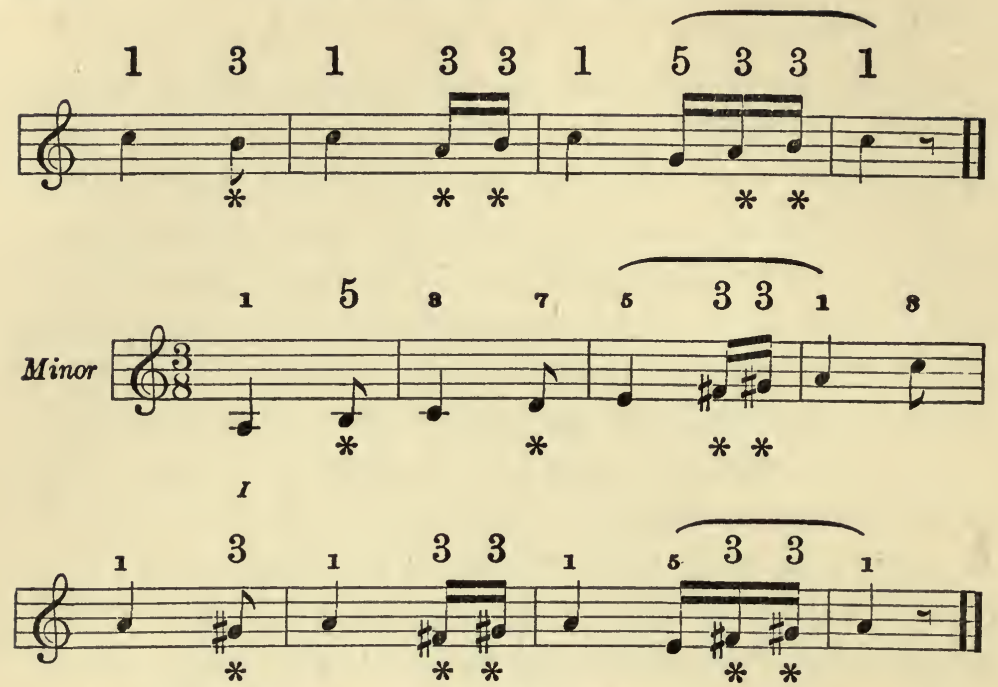

Here the chromatic $f i$ ( $f(f)$ arises as a bytone to regnant $I$; it is a bytone of the second degree and resolves into si, a bytone of the first degree; its report of 3 announces the subdominant in the form of a major consonance. Our examples show that the minor dominant in one voice assumes the forms of both consonances, the major form through si 3 , the minor form through sol 3. See below.

$$
\frac{\mid \begin{array}{ccc}
1 & 3 & 5 \\
\mathrm{mi}-\mathrm{si}-\mathrm{ti}
\end{array}}{V}
$$

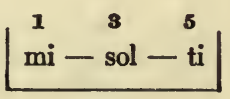

[V]

Next we note that in one voice the minor subdominant assumes both forms, the minor through $f a \mathrm{~s}$, the major through $f i 3$.

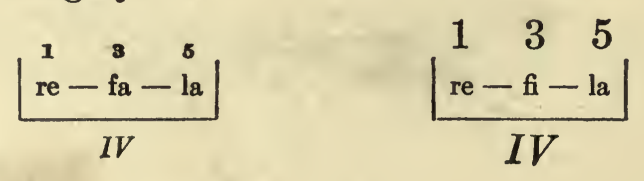


We have met all these forms as byharmonies to regnant $I$ and are presently to see how they arise as regnants. All these harmonies are nearest related to the minor tonic, and arose at an early period of melody's exploitation of the minor mode in one voice; and since they assume both the major and minor forms and appear both as diatonic and chromatic harmonies, they plainly reveal the mixed or hybrid composition of the minor mode, and add further conclusive testimony to the derived and imitative nature of minor. Our examples and analyses clearly point out that there is but one source of light and truth on homophonic problems, that there is but one true and responsible reporter on those fundamental homophonic harmonies in which all harmonies are rooted, the one and only reporter into whose testimony the personal equation cannot enter. This one source, this one reporter is melody, the composite of rhythm and harmony, the free, untrammeled and universal rhythmo-harmonic voice of music. The growth of the scale of tones from its incomplete to its complete diatonic form, thence to its chromatic form and thence to its present enharmonic form, means the gradual growth of the tonesystem from its first beginnings up to the present time. However, the efficient cause of all this growth is rhythmo-harmonic melody. Under the guidance and government of its inherent laws of development melody discovered and exploited tone upon tone, relation upon relation, harmony upon harmony, thus gradually expanding the scale and system of tones and keys. Beginning by intoning the relation of cadence and repose and generating consonance and dissonance, 
melody has continued to cadence and repose on this tone, on that tone, on any tone in the ever widening tone-realm, the difference between to-day and yesterday being a difference in the extent of the tone-realm, a difference between simpler and more complex melodies. Like yesterday, so to-day melody reports now a consonance, now a dissonance, no more, no less.

2. Regnant Minor Dominant. Like its major prototype this regnant has three forms: a three-tone form $V$, a four-tone form $V_{7}$, a five-tone form $V_{\theta}$. This harmony was first reported in melody by its fifth $t i$. The concomitants of $t i 5$ are $m i 1$ and si 3 . The efficient accent on $t i$ or $s i$ generates regnant $V$ thus:-

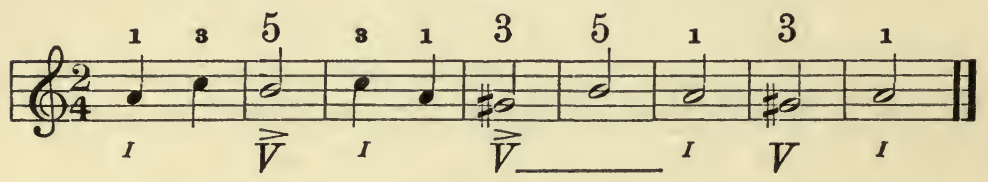

Through its accession of this regnant, melody was enriched first by all the possible steps from one component to another, next by the bytones and cadences playing upon its components. The former are too obvious and require no illustration. As to the latter we will first consider the bytones of regnant $V$. Regnant $V$ has but two diatonic bytones, namely, $l a$ and $d o$, which cadence into the third (si) and fifth ( $t i)$ of this regnant. See below and compare with parallel example in major.

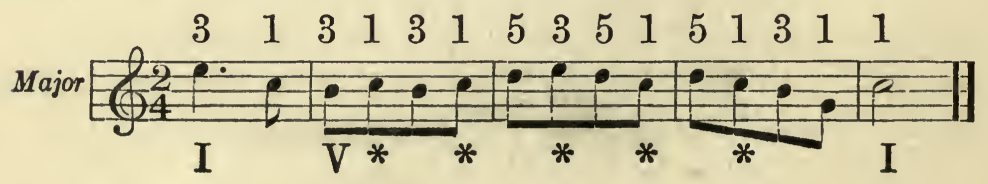




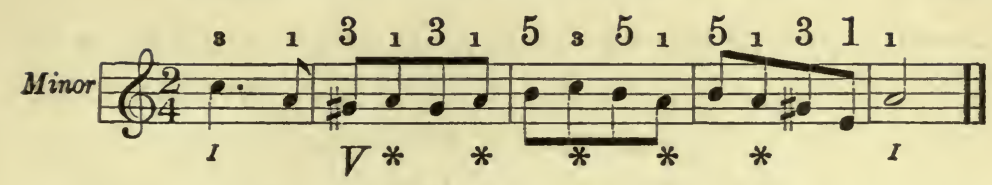

There are no diatonic bytones to the root $(m i)$ of this regnant. $R e$ and $f a$, which lie respectively under and over this root, are not bytones of the regnant dominant; they are components and regnant tones. During the regnancy of the dominant, re reports itself as $\mathrm{r}$ and gives rise to the four-tone form $V_{7}$ while $f a$ reports itself as $\bullet$ giving rise to the five-tone form $V_{\ominus}$. See below and compare with corresponding tones and relations in major.
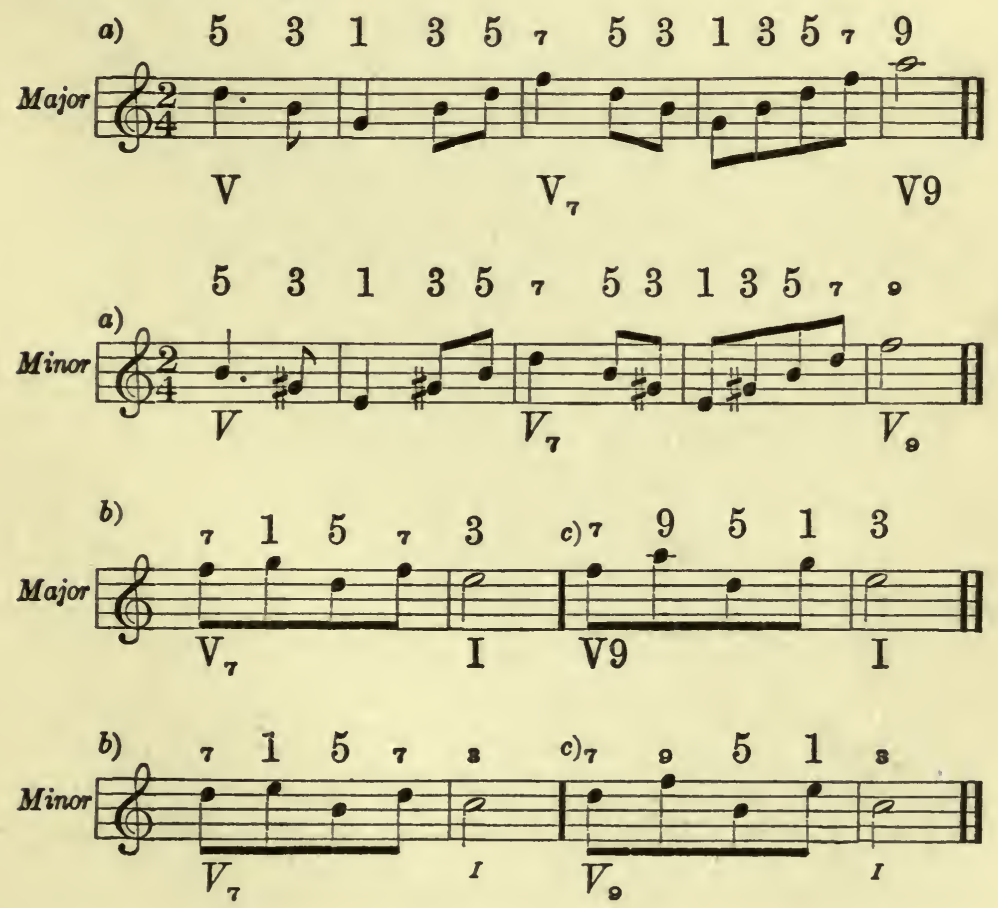
The seventh (re) of $V_{7}$ has but one diatonic bytone, which lies under it and is $d o$. The diatonic lying over $r e r$ is $m i$ the regnant root. See below and compare with parallel major.
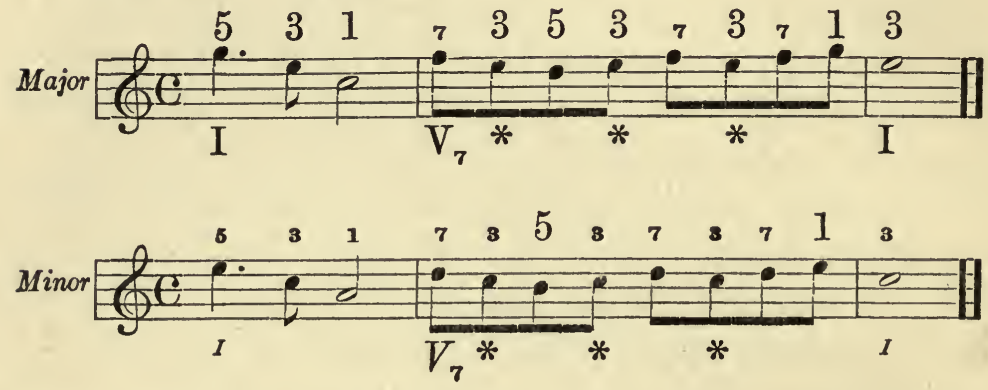

Next let us study the ninth $(f a)$ of $V_{\theta}$. In the first place this small ninth like its prototype la 9 in major, cadences into the regnant harmony of which it is a component. In other words, the regnant tone $f a$ o resolves into its co-harmonic the regnant tone $m i$, as shown below. Again compare with example in major.
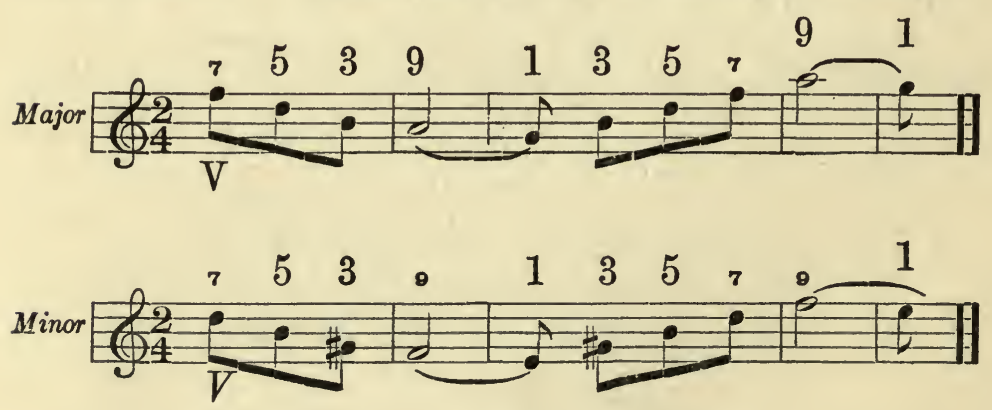

During the regnancy of the dominant, melody also resolves the ninth upward into the upleader, which is the third of that harmony. Compare the next parallel illustrations. This rising cadence is keenly felt in 
stepping from the large ninth to the upleader (la to ti in major, $f i$ to si in minor as at $b$ ) in the minor example below), but is not perceptible in stepping from thesmall ninth $f a$ to the upleader $s i$ as at $a$ ) in the minor example.
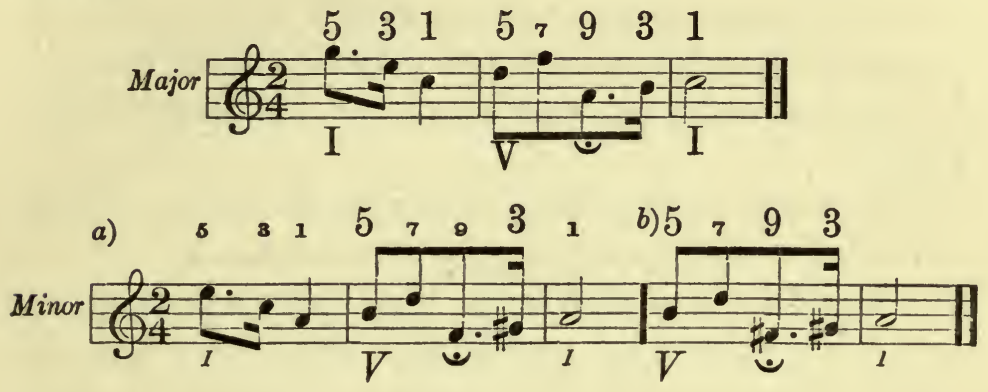

At $a$ ) in the above minor example, $f a$ and the other components of regnant $V$ are the counterparts in minor of the corresponding components of regnant $\mathrm{V}$ in the major example. But at $b$ ) in the minor example the melody during the regnancy of $V$ exactly imitates and duplicates the steps of the major melody in the corresponding measure thus introducing the chromatic $f(f \neq)$, which reports itself as large ninth and a component of the regnant harmony, thereby causing the regnant minor dominant to assume the original major form of dissonance. This inherent tendency of both the large and small ninths to resolve each into the harmony of which it is a component has led some music-theorists to class the ninth as a bytone to the chord of the dominant. But here we are not dealing with chords, we are dealing with the antecedents of chords, with harmony in one voice the common self-reports of which for the first time enable 
us to discriminate positively between regnant tones and bytones, and they clearly and conclusively demonstrate in the case of the two ninths that a tone may be at once a regnant tone and in cadence to its own harmony. A regnant tone is not a bytone, a bytone is not a regnant tone: by carefully and strictly adhering to the necessary distinction between the two we shall avoid what else would be inextricable confusion.

Are there any diatonic bytones to either of the two ninths during the regnancy of either of the two dominants? No, the tones thus far accounted for which lie over and under the ninth are, like the ninth, components of the regnant dominant in both modes. The tone under the ninth is the root, the tone over the ninth is the third of the dominant, during the regnancy of which both tones are of course regnant tones. We are now to see that the ninth is not the only cadencing regnant tone as shown at N.B. in the next parallel examples, in which the melody cadences from the regnant third to the regnant ninth.
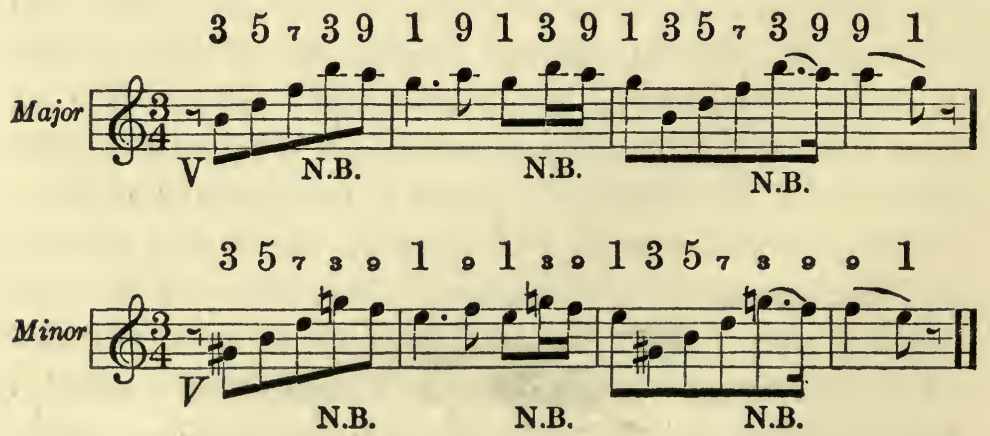
The diatonic sol at each N.B. in the above minor melody calls for a series of observations. Through sol in the above relation, original harmony in one voice discloses a curious and interesting fact which throws a strong and clear light upon consequent complex chord-formations so numerous in modern music. The above minor melody is the exact counterpart in minor of the parallel melody in major, and sol arises in the minor melody on the line of least resistance. Previously we met sol as small third but as a bytone to regnant $I$. Now we meet sol again as a small third, but this time as a regnant tone and, what is more, as a regnant tone in cadence. Observe that the cadence-tend of sol in this relation is much stronger than that of the parallel tone $t i$ in the major melody. And why? Because of the presence of the large third si in the concomitant harmony of sol. That is to say, this sol 3 reports si 3 in its concomitant harmony, it means that we feel and hear the small third and the large third of the same root simultaneously. Hence the stronger cadence-tend of $\mathrm{sol}_{3}$ to $f a$ o than that of the parallel major ti 3 to la 9 . Hence the important fact reported by harmony in one voice that there are harmonies containing double thirds, that is, two thirds of one root. Hence the inference that there may be other double harmonics as double fifths and the like, an inference to be verified later. From this important fact adduced from and verified by harmony in one voice we naturally draw the logical conclusion that chords may be compounded of double harmonics, that is, of double thirds and the like. Such chords may be named double chords. 
They are a true reality, since modern music has introduced them frequently. I present a double chord containing double thirds, choosing for my subject $\mathrm{sol}_{\mathrm{s}}$ in the above relation, which tone and relation are responsible for the genesis of this double harmony and consequent double chord.

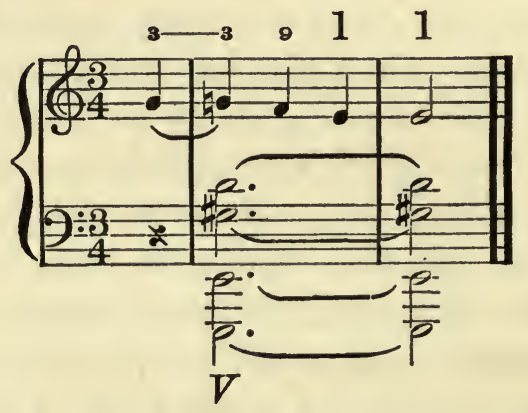

This cadence of $\mathrm{sol}_{3}$ into $\mathrm{fa}_{2}$ during the regnancy of $V$ is often found in the melodies of Chopin. Here is a familiar example from the prelude in $\mathbf{E}$ minor.

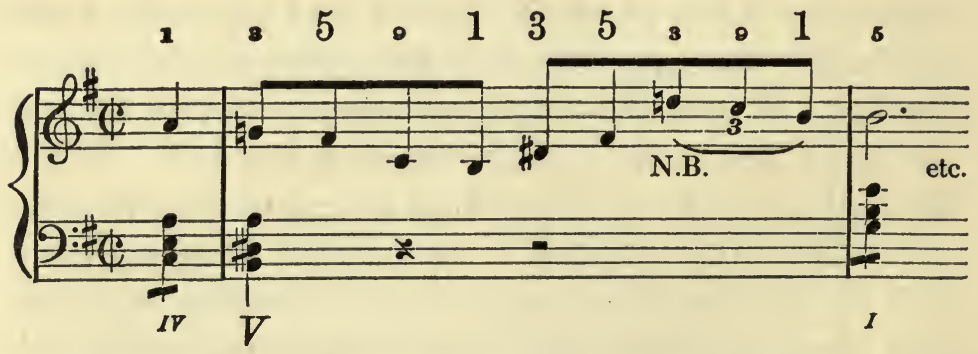

Such excerpts from compositions might be multiplied indefinitely. For my last illustration of sol in this relation $I$ give the principal theme of the allegro of Beethoven's sonata op. 111. Although this opening theme presents sol a but once, it is given in its entirety, it being so fine an example of harmony in 
one voice, a form of writing in which Beethoven so frequently expressed himself.

$$
\begin{array}{llllllllllll} 
& 5 & 3 & 1 & 8 & 3 & 5 & 3 & 3 & 1 & &
\end{array}
$$

$9: \frac{b}{b b} c^{4}$

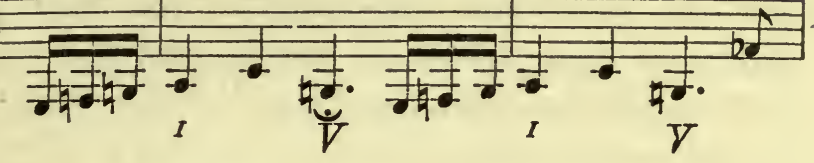

$1785873510173537351 \% 38$

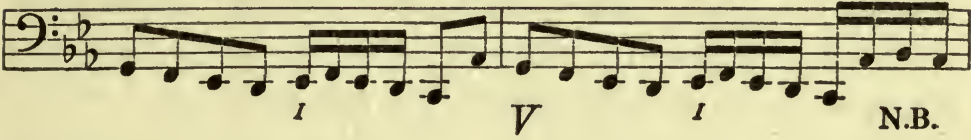

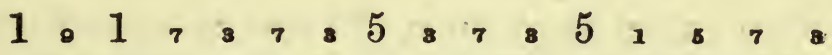

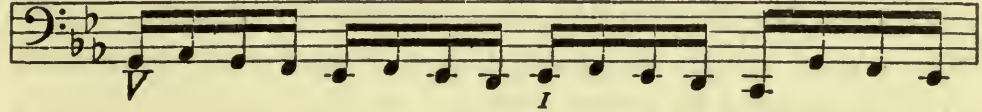

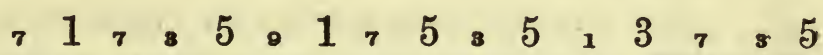

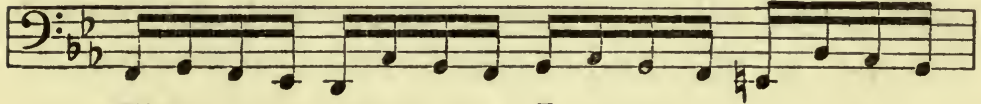
V

I

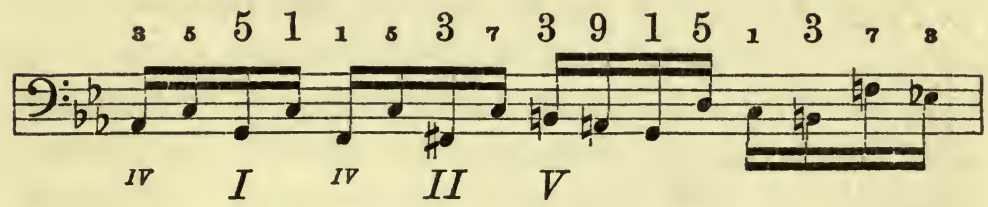

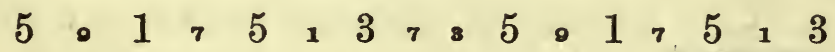

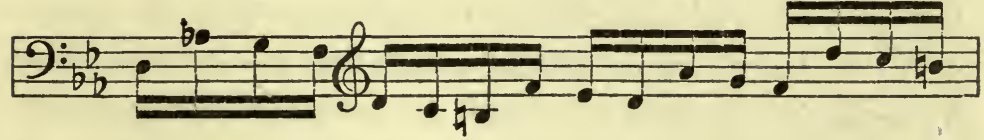

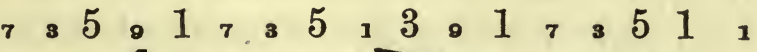

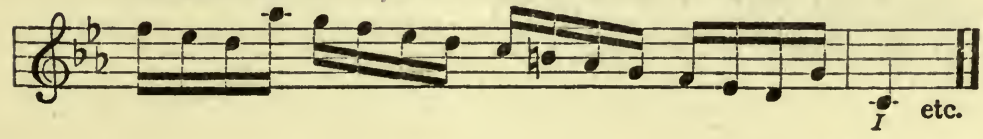


The above harmonic numbers indicate the selfreport of each tone and speak for themselves. This theme presents certain regnant harmonies which hitherto have not appeared in our examples, and comment upon which at this juncture of our exposition would be premature and is therefore deferred. In connection with the above example we call attention to this law. Relation of tones and harmonies is always forward. Rhythm-relation being forward all relation is forward. Observe the triplet in each of the two motives with which the theme opens. This premeasural triplet relates forward and therefore relates to and plays upon the regnant tonic-harmony. Observe $f a(a b)$ at the end of the third and fourth measures: it likewise relates forward and therefore reports itself $\bullet$ of $V$.

One more remark remains to be made regarding sol $\mathrm{s}$ as a cadencing regnant tone. It is an original product of the minor mode and is distinctively a minor harmonic percept. We have seen how melody evolved the minor mode out of tone-material and relations previously extant in major, thus generating the new and individual minor forms of consonance and dissonance by imitating the cadence and repose relations of the prototype major mode. Through the same process of imitation, melody has reversed the process by reproducing and imitating in major many of the melodic steps and harmonic forms which first arose in minor. Just as melody adopted the major tetrachord in minor (below at a)) just so melody adopted two minor tetrachords in major, as at $b$ ) and $c$ ). 
a)

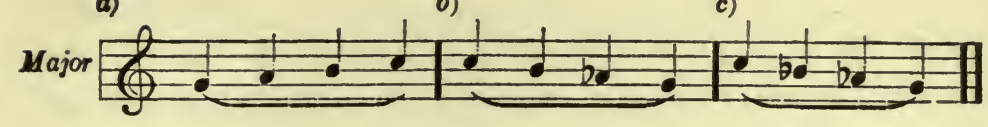

a) b) c)

Minor

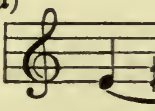

This introduction by melody of the products of one mode into the other at once exhibits the union in melody of perfect freedom with perfect adherence to law and order, but in modern music has assumed such proportions and created such an apparent modal muddle that each of the two modes seems well-nigh to have lost its identity. The modal identity is however always asserted and reported by the modal major or minor tonic-consonances. This self-report so obvious and definite in simple homophonic melodies is less obvious but not less definite in the complex melodies of polyphony and chorded music with their intricate chromatic harmonies and manifold modulations. As we progress in tracing the evolution of melody and the consequent concurrent evolution of tonality and of the tone-system, it will become increasingly clear that our conceptions of mode, tonality and scale or system require considerable modification. In order to maintain our clearness of view as we gradually enter into these apparent complexities we will continue to focus our attention upon melody, the voice which has gradually discovered and exploited the wide realm of tones as represented by the enharmonic scale with its boundless potential relations and harmonies, our only source and reporter 
of truth. I repeat, melody, perfectly free because perfectly self-governed, may repose or cadence here, there, anywhere in the tone-realm. Melody exercised this freedom yesterday in a narrow, exercises it to-day in a wide realm of tones.

One more form of the regnant minor dominant remains to be presented. This form is a minor consonance generated by melody through the diatonic sol. We have met this consonance, due to the report of sol as small third, in the paragraph on the minor tonic, where sol appeared as a bytone. In the following mclody $\mathrm{sol}_{\mathbf{z}}$ is a regnant tone and announces the regnant minor dominant in the form of a minor consonance.
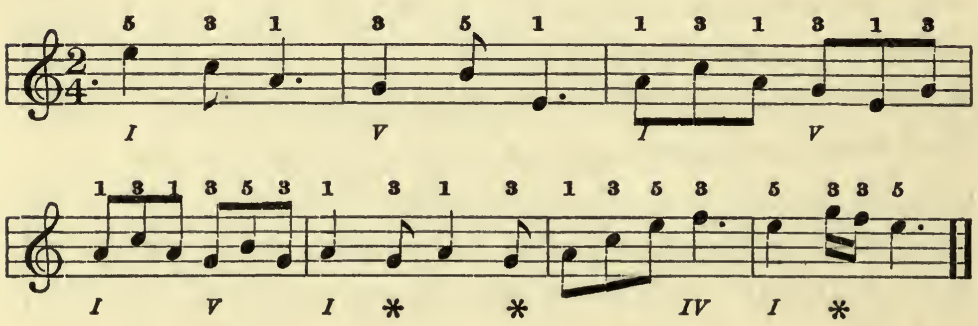

Here sol is reports regnant $v$ in the second, third and fourth measures and appears as a bytone in the fifth and last measures. This melody reports three diatonic harmonies, namely, $I, V$ and $I V$; all of its tones and their concomitant harmonics are diatonics, all its harmonic percepts are minor, in short, this example presents a pure diatonic minor melody. This proof by the above harmonic self-reports that a pure minor melody is not only conceivable and self-assertive in one voice, but is an absolute reality, 
confirms our thesis that melody and not a scale is the real object of study and source of true knowledge regarding music. No conceivable rhythmic arrangement in one voice of the scale of diatonics from la to la will generate and report exclusively diatonic harmonies and minor consonances. To be sure this is easily effected with chords arbitrarily selected for the purpose, but such selective representation of harmony is no test.

The form of a minor consonance cannot be generated by the other two components, namely, the root (mi) and the fifth ( $t i)$, save when both or either of the two is associated in the same rhythmic period with sol 3. This is shown in our next example from the fifth measure onward. $T i$ alone (see second measure) or $t i$ supported by $m i$ (see third measure) always announces the minor dominant in the form of the major consonance.
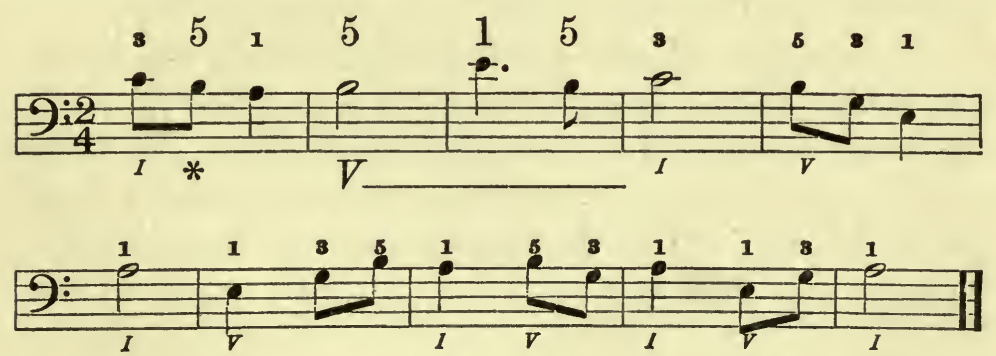

The mixed or hybrid nature of the harmonies generated by the diatonics of the minor mode is next exemplified, and may suggest the rich and varied harmonic potentiality of the minor mode to the tone-muse of young composers. 

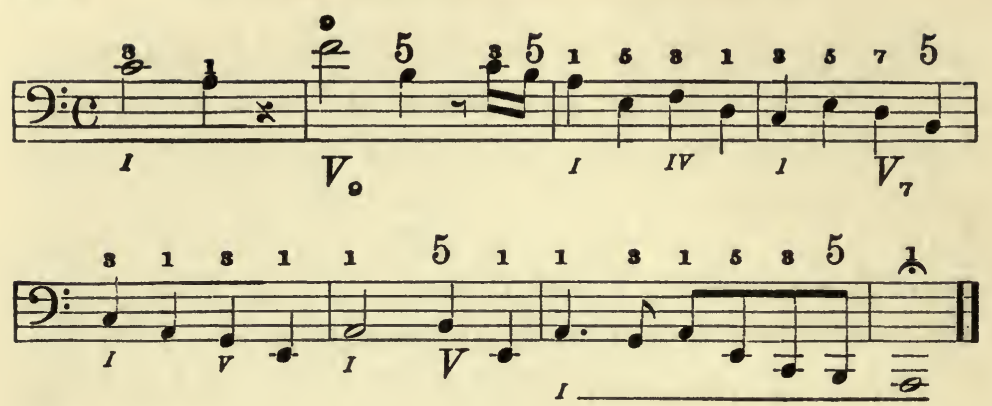

During the regnancy of $v$, sol the generator of this harmony has one diatonic bytone, namely, $l a$, as follows:

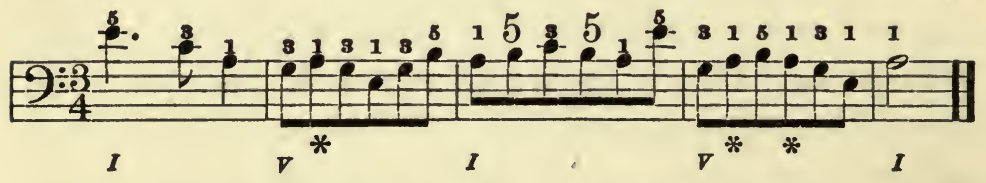

The summary of the forms of the regnant minor dominant which we have thus far generated and explained is as follows: $V_{\imath}, V 9, V_{7}, V, V$.

3. Regnant Minor Subdominant. Like its major prototype this regnant was first generated and announced in melody by its third which is $f a$. The efficient accent on $f a$ and also on $r e$ when supported by $f a$ generates this regnant minor consonance and diatonic harmony as follows: -

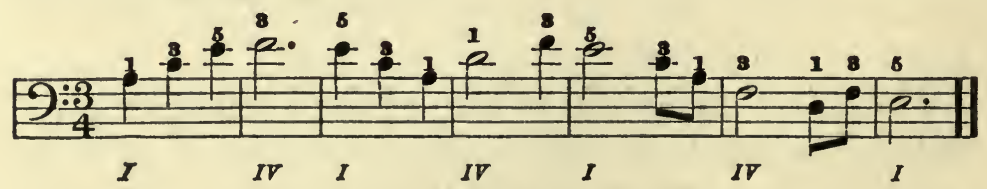

Our present tone-material contains five bytones to this regnant. Four of these bytones are diatonics, 
namely, do, mi, sol, $t i$. The other bytone is the chromatic si. The next example includes all of them and indicates the harmonic self-report of each in this specific relation.
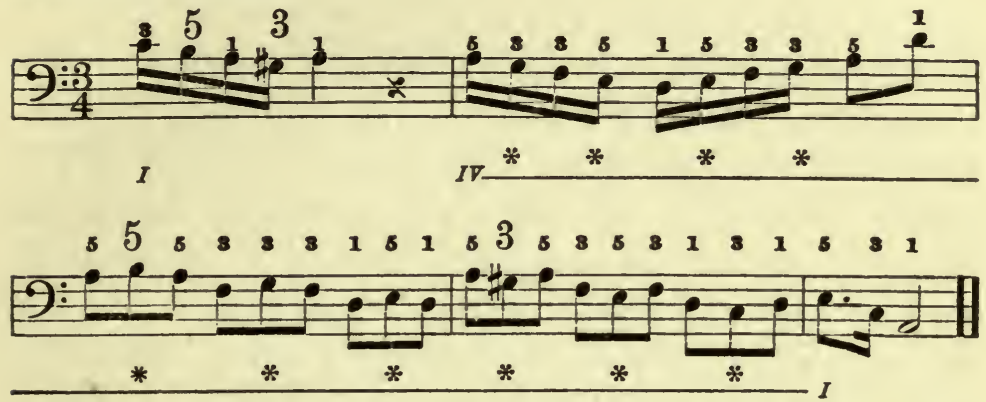

The efficient accent on $f(\mathrm{f} \neq$ in A minor) causes the regnant minor subdominant to assume the form of a major consonance. Owing to the chromatic $f\left(f\left(\frac{f}{t}\right)\right.$ this regnant $I V$ is classed as a chromatic harmony which, as the next example shows, enters most naturally after regnant $I$ and is most naturally succeeded by regnant $V$ or regnant $I V$.
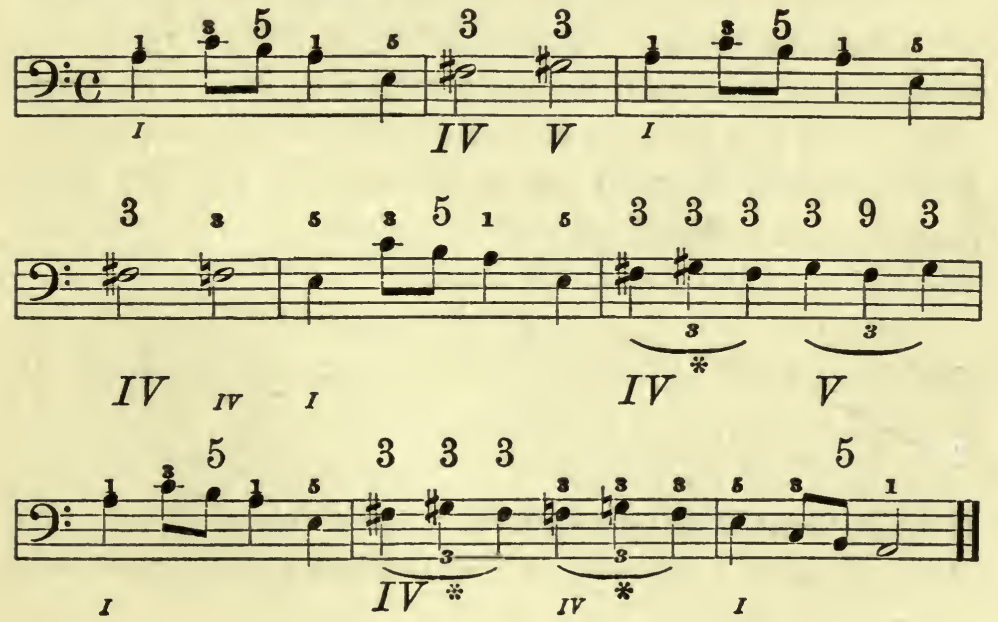
Here we note that regnant $I V$ enters after $I$ and is succeeded twice by $V$ and twice by $I V$. A bytone to regnant $I V$, namely, si (g is marked by an asterisk. Our present tone-material contains other bytones to this major form of the subdominant, and even though all these bytones are diatonics they all have a modulatory tendency, that is, they shift the key-centre and change the mode from minor to major. We have demonstrated that even though a melody be composed entirely of diatonics it may contain and report chromatic harmonies, and we are presently to show how diatonics among themselves may effect and definitely report modulations. Meanwhile, let us observe that the fact that a melody contains only diatonics by no means proves a melody to be diatonic. To the eye such melodies on paper appear to be diatonic and have been thus erroneously judged and classified. Thanks to common harmonic reports in one voice such errors are no longer possible. The statement that music is heard, not seen, ought to be supererogatory. An Indian chief after háving invited a group of men to squat with him in his wigwam proceeded to ask what was the vocation of each guest. Fixing his eyes upon one who was pointed out as a musician the chief placed a finger on his ear and winked. That much he knew.

We have now presented the regnant harmonies of the minor tonic, dominant and subdominant, and have studied the bytones and cadences of each. The relations and combinations of regnant harmonies among themselves, their progressions and resolutions (cadences), were analyzed in the preceding chapter where 
we treated the regnant harmonies in major. Those in minor being very similar in their relations and successions, we need not pause here to consider them individually since their relations and connections are exemplified in our illustrations of minor melodies. To summarize. The tone-material which has thus far appeared in our minor melodies aggregates nine tones, namely, the seven diatonics and the two chromatics si and $f i$ (g and $\mathrm{f} \frac{\mathrm{f}}{\mathrm{f}}$ in $\mathrm{A}$ minor). Our next example introduces all of these tones.
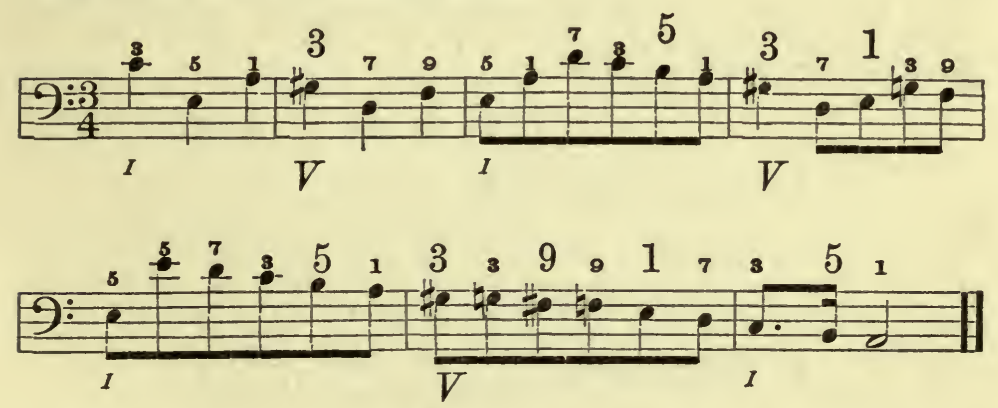

Next we summarize the forms of harmonies thus far reported by our melodies in minor.

1. Minor consonances: $I, I V, V, I$ is the original, $I V$ and $V$ are duplicates.

2. Major consonances: $V, I V$. Both are duplicates of the original I or major tonic.

3. Four-tone dissonances: $V_{7}$, which is a duplicate of the major prototype $\mathrm{V}_{7}$.

4. Five-tone dissonances: $V_{\theta}, V 9$. The latter is a duplicate of the original major V9.

All the above forms resolve themselves into two which had their origin in the minor mode and which are distinctively minor, namely, the minor form of 
consonance, that based on la being the original; the minor form of dissonance, that based on $m i$ being the original.

47. Harmonic Percepts of Minor Origin

The minor forms of consonance and dissonance comprise five harmonic percepts which correspond to the five major percepts derived from the major forms of consonance and dissonance. Both groups are given below for comparison, and each harmonic percept is indicated over the tone on which melody first generated and reported it.
$\begin{array}{lll}1 & 3 & 5\end{array}$
79

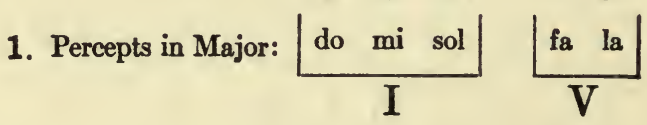
2. Percepts in Minor: $\frac{\left|\begin{array}{lll}1 & 8 & 5 \\ \text { la } & \text { do } & \text { mi }\end{array}\right|}{I} \frac{\left|\begin{array}{ll}7 & 0 \\ \text { re } & \text { fa }\end{array}\right|}{V}$

Among these percepts we observe one duplicate, the small seventh, which originated in major on $f a$ and which was reproduced in minor on re. Thus only four of these percepts had their origin in minor and are therefore distinctively minor harmonic percepts. They are:-

$$
\left|\begin{array}{cccc}
1 & 8 & 5 & 0 \\
l a & \text { do } & m i & f a
\end{array}\right|
$$

The whole number of harmonic percepts thus far generated by melody and explained is nine, as follows:

$$
1,1 ; 3,3 ; 5,8 ; 7 ; 9 \text {, } 9 .
$$


The meaning and use of these numbers we have defined. Over the notes of a melody they are read thus: large root, small root; large third, small third; large fifth, small fifth; small seventh; large ninth, small ninth.

The self-reports of melodies in minor like those in major confirm the truth of our theses, namely, that in one voice each tone is felt, heard and expressed in cadence or repose as root or third or fifth or seventh or ninth; that specific relations generate specific forms of harmony, and that the two are linked as cause and effect; that no form of harmony contains more than five components. These nine percepts derived from the major and minor forms of consonance and dissonance, and which are the harmonic products of homophonic melody far back in the ages, constitute the connecting link between homophony on one hand and polyphonic and chorded music on the other, and therefore the harmonic basis of all music. However simple the one or complex the other, one thing is always true of and reported by all one-voice music and all multi-voice music. It is this. Now the regnant harmony is a consonance, now it is a dissonance, one or the other. This was so in the yesterday, is so in the to-day, and, we may assume, will be so in the to-morrow of music's evolution. Homophonic melody produced the only two forms of consonances in music and the two original major and minor forms of dissonances. All the above nine harmonic percepts are therefore distinctively homophonic products. As we shall see, homophonic melody may have continued to produce even other harmonic percepts of the dis- 
sonant order, to which belong all the myriad new harmonic percepts and forms which are distinctively the products of polyphonic and chorded music. All the new harmonic percepts derived from multi-voice music are inseparably linked to and rooted in the above nine and, as we shall find, are either combinations, compounds or modifications of the nine. Hence the importance of the nine. In pursuing this study of melody's evolution of harmony which we trace in its common self-reports two things should be borne in mind: first, the harmonic percept, important because it comprises a complete harmonic thread; next, the regnant harmony, important because it determines the exact relations of tones.

\section{A Tone's Harmonic Pedigree}

Observe that each of the above nine percepts arose on a specific tone; next, that these percepts are reproduced on other tones; next, that certain percepts when thus reproduced on certain tones generate new tones in the concomitant harmony. For example, sol was the first large fifth, namely, 5 of $I$ in major. When this large fifth was reproduced on $t i$ in minor a new tone, the chromatic si, was generated in the concomitant harmony, in which it reported itself as large third. This fact, in conjunction with the thesis that all the nine percepts are potential in all tones and with the rhythmo-harmonic laws of causation which we have set forth, throws light upon the processes by which melody gradually expanded the tone-system and tonality and evolved so much out of so little. But the fact that a harmonic percept originated on a specific tone 
and thereafter was reproduced on other tones points to the interesting inference that each tone has a harmonic pedigree. By this I mean that melody first introduced a tone in a specific relation, and next proceeded to introduce that tone in another relation and then in another, and so on. Such a sequence of relations would trace the tone's harmonic evolution or line of descent. Aside from its immediate interest and value to psychology, the harmonic pedigree if ascertained would enable the archæologist to determine approximately the chronological order and relative ages of primitive melodies. To be explicit. What is a specific tone's line of descent or harmonic pedigree? It is that tone's evolutionary sequence of harmonic relations. Where is this evolutionary sequence to be traced? In melody, where it was produced. All harmonic percepts being potential in all tones, melody has carried each tone through a sequence of percepts. To illustrate all this we will here present the harmonic pedigrees of the seven original tones (diatonics) so far as ascertained at this juncture of our study.

1. Do first arose as $\mathbf{I}$ of $I$ in major, then appeared as 5 of $I V$ in major, then as 3 of $I$ in minor. So far as already ascertained the pedigree of $d o$ is briefly $1,5,3$.

2. Sol first arose as 5 of $I$ in major, next appeared as 1 of $\mathrm{V}$ in major, then as $s$ of $V$ in minor. This pedigree of $s o l$ is briefly $5,1,3$.

3. $M i$ first arose as 3 of $I$ in major, next appeared as $s$ of $I, 1$ of $V$ and 1 of $V$ in minor. This pedigree is briefly $3,5,1, x$.

4. $R e$ began as 5 of $\mathrm{V}$ in major, next appeared as 7 
of $V$ in minor, then as $x$ of $I V$ and 1 of $I V$ in minor. This pedigree is $5,7,1,1$.

5. $L a$ began as 3 of IV in major, next appeared as 9 of $\mathrm{V}$ in major, then as 1 of $I, 5$ of $I V$ and 5 of $I V$ in minor. This pedigree is $3,9,1,5,5$.

6. $F a$ began as 7 of $\mathrm{V}$ in major, next appeared as 1 of IV in major, then as 3 of $I V$ and $\odot$ of $V$ in minor. This harmonic pedigree is $7,1,8,8$.

7. $T i$ began as 3 of $\mathrm{V}$ in major, next appeared as 5 of $V$ and $s$ of $V$ in minor. This pedigree is $3,5, s$.

In these pedigrees we observe that of the nine percepts thus far accounted for $d o$ has reported three and has still to appear as 1, 3, 8, 7, 9, ,; sol has reported three and has still to appear as $1,3,5,7,9$, 9 ; $m i$ has reported four and has still to appear as 3, 5, 7, 9, 9; $r e$ has reported four and has still to appear as 3, 3, 5, 9, ๑; la has reported five and still has to appear as 1, s, 7, ,; fa has reported four and has still to appear as , 3, 5, s, 9; ti has reported three and has still to appear as 1, 1, 3, 7, 9, .. Of all these relations still remaining to be reported by diatonics both the relations and the harmonies are either chromatic or enharmonic. The above pedigrees of seven tones present an aggregate of twenty-six harmonic relations each of which is distinct and individual. Thus we observe that the multiplication of harmonic relations is very rapid while that of harmonic percepts is very slow. This is true not only of homophony, but of multi-voice music as well. Further back the ZarlinoRiemann theory of pendant minor was alluded to as an example of irreconcilable conflict between musicthinking and music-feeling. This conflict becomes 
evident when we subject the foundation of the theory to the test of harmonic self-reports in one voice, a test which we are now prepared to apply having just summed up the original harmonic percepts of homophonic melody and having finished our explanations of the origins both of major and minor. The theory in question is based on acoustics, and postulates that the minor chord springs from a descending acoustic series of undertones generated by a root on the top just as the major chord springs from the ascending acoustic series of overtones generated by a root at the bottom, that the minor chord is the exact inverse of the major chord in that the relative intervals and ratios of vibration in both acoustic series are identical, as shown below by the familiar acoustic numbers $1 ; 2 ; 3 ; 4 ; 5 ; 6 ; 8$;. Thus at $b$ ) the minor chord is as $4 ; 5 ; 6 ; 8$; going down, and the major is the same going up. In short, minor is inverted major.

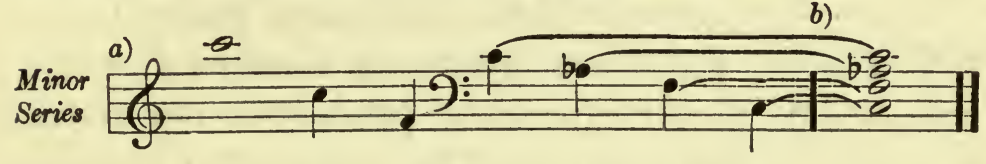

$1 ; 2 ; 3 ; 4 ; 5 ; 6 ; 8$;

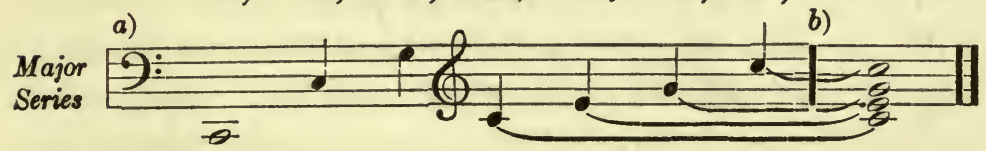

It is assumed that $\mathrm{C}$ is the root of both the major and minor triads at $b$ ). In other words, the supposed C-minor triad hangs suspended from its aerial root $\mathrm{C}$ just as the C-major triad rests upon its groundroot $C$. The inverted acoustic series forming the above minor triad is a purely arbitrary conception, 
since the existence of such a series of undertones has never been demonstrated, nor has it ever been heard by the musical ear. It cannot be gainsaid that from a mathematical point of view this hypothetical series of undertones is both charming and fascinating, since to the eye its explanation of the minor chord appears both logical and satisfactory. This probably explains why the theory has won so many adherents. But musical hearing, feeling and perception refuse thus to be deceived. The common harmonic self-report of the minor triad at $b$ ) is this: $\mathbf{F}$ is the root, $\mathbf{A} b$ the third, $\mathrm{C}$ the fifth. The triad is $\mathrm{F}$-minor, not $\mathrm{C}$-minor. One might as well try to invert one's self and walk on the ceiling as try to perceive $\mathrm{C}$ as the root of this triad. The test of harmonic self-reports on the above hypothetical minor series is as follows: 1 ; or $\mathrm{C}=5$. 2; or $\mathrm{C}=$ s. 3 ; or $\mathrm{F}=1 . \quad 4$; or $\mathrm{C}=\mathrm{s} . \quad 5$; or $\mathrm{A} b=\mathrm{s}$. 6 ; or $\mathrm{F}=1$. 8 ; or $\mathrm{C}=5$.

Next I present the Zarlino-Riemann minor scale, the tones of which are arbitrarily conceived as the components of three pendant primary minor triads supposed to hang suspended from the aerial roots $\mathrm{C}$, $\mathrm{F}$ and $\mathrm{G}$. Below compare this pendant minor scale with the ascending major scale and observe the perfect correspondence of the whole and half steps. Just as in the case of the triad so also here in the case of the scales the minor is the exact inverse of the major.

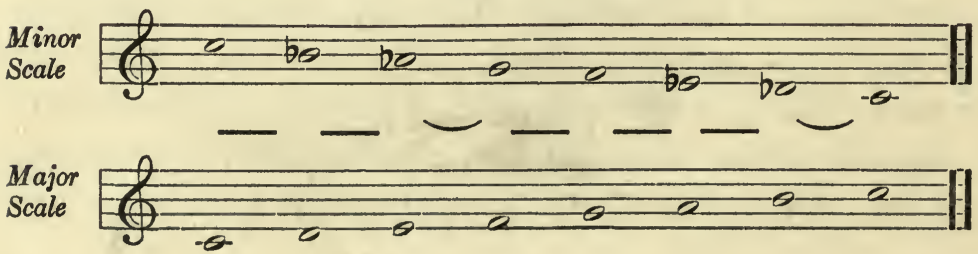


The test of harmonic self-reports in one voice when applied to this hypothetical minor scale at once discloses the fact that the scale is major, not minor. In whatever rhythm we may ascend or descend on this scale the resultant melody will always report itself as major, each individual tone will report a major harmonic percept, in short, we feel and perceive in common that this scale starts and ends on $m i$, the large third of the major tonic-harmony upon which it is based. Our next example presents the scale in its descending form, each tone is named by a syllable, each harmonic percept is marked by its specific number.

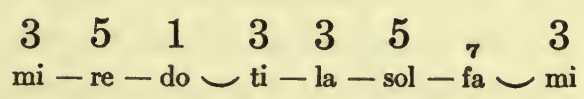

Not only is this Zarlino-Riemann scale major, but it is also identical with the ancient Dorian scale of the Greeks. In the terms of our notation the tonic of this scale is $A b$ and not $C$; the basic harmony of the scale is that of $A b$-major and not the supposititious pendant minor chord of $\mathrm{C}$.

On the line of least resistance, upon which homophonic harmonies assert themselves, this scale absolutely refuses to report the minor mode. However, there are two ways in which in one voice this scale may be induced to report itself as minor. First, by a prelude in which we establish the feeling of the minor consonance as below at $a$ ); next, by arbitrarily conceiving the scale as minor. In the first case the minor harmonic percepts owing to the prelude arise on the homophonic line of least resistance, while in the second case they are premeditated and therefore selective. 
In both cases the result as to harmonic reports is the same and as follows:-

Prelude

Scale

a)

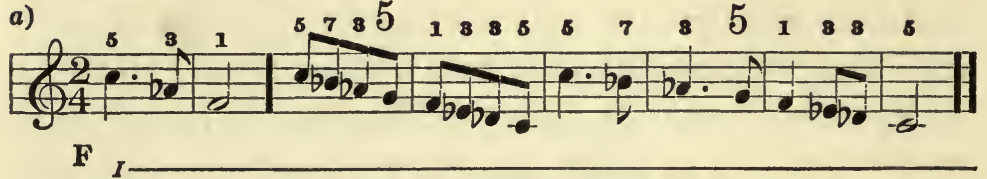

Now that we have transmuted the scale from major to minor thereby demonstrating that it may report itself as minor in homophonic melody or one voice, this question arises: Does this scale of minor harmonic percepts in any way support the theory of pendant minor? The above common harmonic self-reports based on common harmonic feeling and perception answer in the negative. These self-reports plainly testify as follows: the scale, now minor, starts and ends on $m i(\mathrm{C})$, which is the fifth of the minor tonic-harmony based on la $(\mathrm{F})$; its tonic or point of complete repose is $\mathrm{F}$ and not $\mathrm{C}$; its tonic-harmony is erect F-minor and not pendant C-minor. Homophonic harmony and its common self-reports being subjects new to music-theory the same is necessarily true of the facts here adduced as well as of the conclusions to which they point. In conclusion it remains to be said that besides being an acoustic theory of harmony based on an acoustic hypothesis, the Zarlino-Riemann theory is specifically a chord-theory. Having demonstrated in preceding chapters of this book that chordharmony is selective harmony it is difficult to see how the chord-theories of harmony could possibly have escaped the bias of personal selection and therefore of the personal equation. 
49. Chords Derived from the Minor Forms of Consonance and Dissonance in One Voice

From the original minor form of consonance $I$ is derived the original minor triad $I$. All other minor triads like $I V$ and $V$ are duplicates. Below are the triads $I, I V, V$.

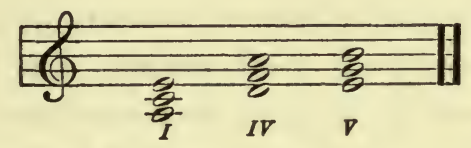

Like its major prototype the minor form of dissonance presents six chords, namely, the small ninthchord $V_{9}$, the two seventh-chords $V_{7}$ and $V I I^{\circ}{ }_{7}$, the three triads $V, V I I^{\circ}, I I^{\circ}$, as follows:-

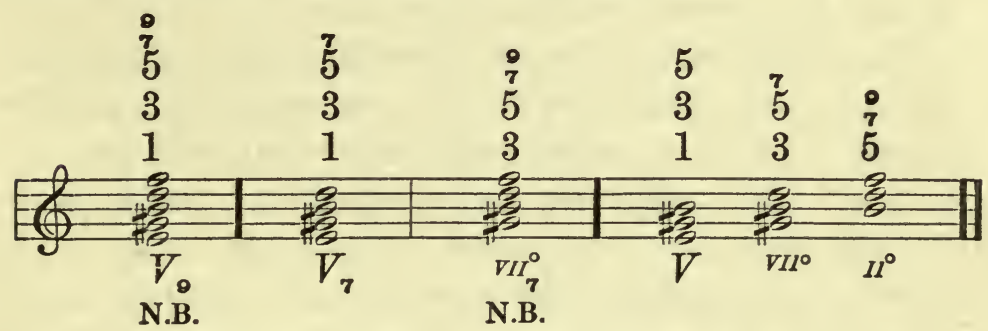

Of all these chords only two forms are of minor origin. They are the small ninth-chord $V_{8}$ and the diminished seventh-chord $V I I^{\circ}$, both marked N.B. in our example. Each of these forms is the first of its kind, all like forms being duplicates of these originals. The remaining four chords are duplicates of forms which originated in major and have been presented in § 39. The first, second and fourth of the above chords are based on the harmonic root $m i$, the third 
and fifth omit the harmonic root, the sixth omits both the harmonic root and third. The superposed harmonic numbers show that $m i$ is the harmonic root of all of the six chords. In $\S 39$ we pointed out and explained by means of the harmonic selfreports of homophony the necessary distinctions between harmonic roots and chord-roots, between harmonic intervals and chord-intervals and by the same means demonstrated that chords are often incompletely represented by one or two components, sometimes appearing detached from their harmonic roots, sometimes from their harmonic roots and thirds, sometimes even from their chord-roots. These distinctions and facts being exemplified in the above groups of chords and having previously been explained it is enough here to call attention to them.

By comparing the above minor group of consonant and dissonant chords with the corresponding major group in $\S 39$ the reader will observe that two chords identical both as to form and component tones appear in both groups. They are: II in major and $I V$ in minor; vII ${ }^{\circ}$ in major and $I I^{\circ}$ in minor. Despite their identity in form and component tones these triads make one report in major and a very different report in minor, as shown below.

$$
\begin{aligned}
& \begin{array}{llllll}
5 & 7 & 9 & 3 & 5 & 7
\end{array} \\
& \text { 1. Major: } \frac{|\mathrm{re}-\mathrm{fa}-\mathrm{la}|}{\mathrm{II}} \frac{|\mathrm{ti}-\mathrm{re}-\mathrm{fa}|}{\mathrm{VII}^{\circ}} \\
& \text { 2. Minor: } \frac{|\mathrm{r}-\mathrm{fa}-\mathrm{la}|}{I V} \frac{|\mathrm{t}-\mathrm{re}-\mathrm{fa}|}{I I^{\circ}}
\end{aligned}
$$


Obviously this difference in harmonic report is caused by difference in relation. Just as in homophony the self-report of a specific tone varies as its relation varies just so in multi-voice music the selfreports of certain specific chords vary as their relations vary. No words can therefore overstate the importance of relation, it is everything. Have we not demonstrated in the genesis and evolution of harmony that harmonic form to relation is as effect to cause? We have demonstrated that homophonic melody by means of relation has produced the original forms of harmony and the original tones of the tone-system. Let us be explicit on this question of form and relation. The two are inseparable in concrete music. So long as we are contemplating and investigating tones or chords in relation so long only are we contemplating and investigating concrete music. But the moment we leave out relation we leave out music and are then contemplating and investigating only the mere material of music. Thus abstracted from relation, a specific tone is simply a constituent of the tone-system distinguishable from the other constituents as they from it by relative pitch. A specific chord thus abstracted from relation is simply one of the innumerable chords of music's chord-material distinguishable from other chords as they from it by difference in structure. Briefly, a tone or a chord out of relation is out of music. The physical, physiological and psychological views, analyses and theories of music's raw material, that is, of tones and chords out of their distinctively musical relations, have not discovered a single truth about music, have added nothing to our 
intelligence and appreciation of music, and are utterly valueless to music-theory and music-education. Music itself presents its own peculiar forms and relations, in short, its own peculiar problems to the investigator. However, in his quest for truth the investigator is in reality seeking he knows not what unless he equip himself with the first essential requisite to music-research, namely, with an adequate knowledge of what the peculiar forms, relations and problems of music are. After all, the great leading question is: What is music? And the answer to this question has to be worked out independently by musicians. Music $i s$, and it is futile for physicists to tell us that music is all wrong and should be otherwise.

The harmonic reports of the chords thus far derived plainly show that a chord-root may be a harmonic root or third or fifth; that a chord-third may be a harmonic third or fifth or seventh; that a chordfifth may be a harmonic fifth or seventh or ninth: in short, that the self-report of a chord is determined by its relation and is ascertained by harmonic analysis as here set forth. No one, for example, hears the component tones of the diminished seventh-chord $\left(\mathrm{VII}^{\circ}{ }_{7}\right.$ in minor) as root, small third, diminished fifth and diminished seventh: we all hear them as 3, 5, 7, ๑. All other chords not based on harmonic roots furnish similar examples. Chords are therefore more than mere combinations of tones differing in structure. Each component tone in a chord reports a harmonic percept. Therefore correctly defined, a chord is at once a combination of tones and a combination of harmonic percepts. Homophony produced the origi- 
nal tones and the original harmonic percepts; in polyphony and chorded music these tones and percepts have been combined in well-nigh every conceivable way.

In parallel examples I next present the major and minor subtonic-seventh-chords. Each of these chords is composed of the four cadence-tones of the mode in which it arose. At $a$ ) the chords present double cadences, that is, simultaneously rising and falling cadences. At $b$ ) and $c$ ) the cadence-tones are separated and the cadences become single, that is, at $b$ ) they rise, at $c$ ) they fall.
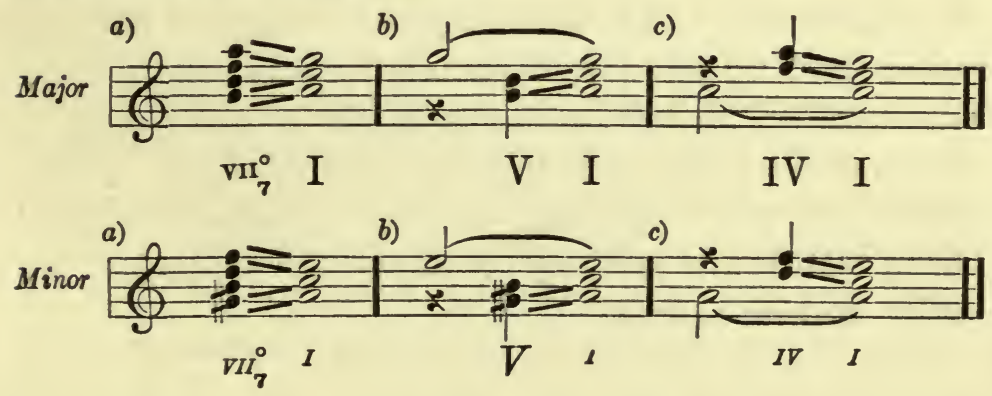

At $b$ ) the bond-tones sol in major and $m i$ in minor combine with the two rising cadence-tones thus forming the major and minor dominant-triads. At $c$ ) the bond-tones do in major and la in minor combine with the two falling cadence-tones thus forming the major and minor subdominant-triads. The resolutions at b) present the authentic ending, at $c$ ) the plagal ending. The next example illustrates these single cadences and two endings in pure diatonic minor, all the triads being minor and composed of diatonics. 


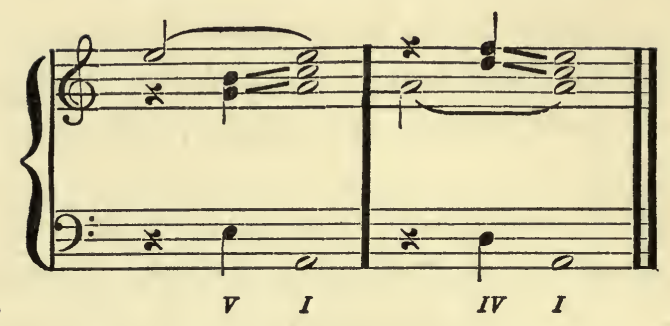

The above example may call forth this question: Are not the above triads $I, V$ and $I V$ identical with the secondary triads of the major mode known respectively as VI, III and II? The question is premature at this juncture, but may be answered provisionally in the affirmative. As chords they are identical both in major and minor, but their relations in major and minor differ. Their relations in the above example are in minor, and each triad is a combination of the minor harmonic percepts $\mathbf{1 - 3} \longrightarrow \mathbf{3}$. Concisely stated, triads which are primary in minor are secondary in major and vice versa. 


\section{CHAPTER VI}

CHORDS IN THE LIGHT OF THEIR ORIGIN

50. Description and Summary of Chords Thus Far Derived

Aт present our list of triads aggregates five in major and six in minor as follows:-

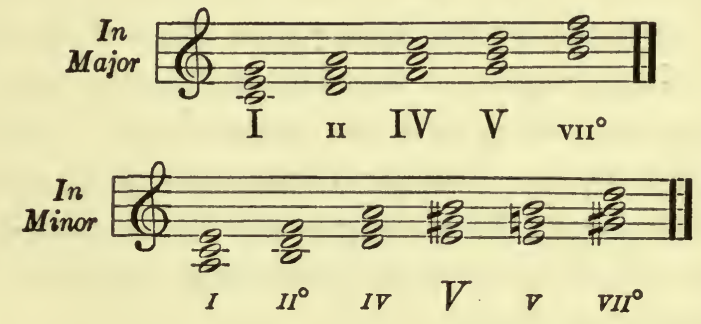

This summary presents only three distinct types of triads, the major, the minor, the diminished. The originals of the three types are respectively I in major, $I$ in minor, vII $^{\circ}$ in major. All other triad-types are either modifications of the three originals or compound chords.

The structure of a triad is described when we name the exact interval relations of its third and fifth. We describe the major triad as root, large third, pure fifth: the minor triad as root, small third, pure fifth: the diminished triad as root, small third, diminished fifth. When we describe the structure of chord-types we treat each type as chord-material and compute the intervals of components from the chord-root without considering whether or not the chord-root is a har- 
monic root. But in the harmonic analysis of a concrete case we first name the type of a specific chord and then proceed to describe the chord's specific relation which gives us the harmonic report we are in search of.

There are three triad-positions. In its first position, the triad is named the ground-triad, the chordroot being its lowest tone. In its second position with the chord-third as lowest tone, the triad is named the sixth-chord and may also be called the terceform. In its third position with the chord-fifth as lowest tone, the triad is named the fourth-sixth chord and may also be called the quint-form. The positions of triads are further distinguished as close and open: close when the components are in closest proximity, as below at $a$ ), open when the components are spread apart as at $b$ ).

a) Close

b) Open

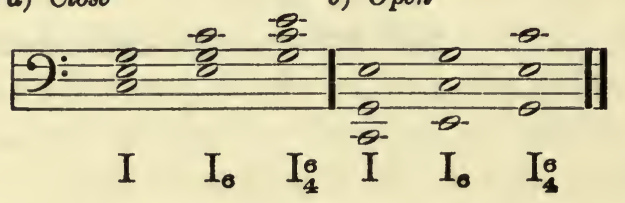

As everybody knows, all thorough-bass numbers like 6 and ${ }_{4}^{6}$ in our example indicate intervals as computed from the lowest tone or bass.

Seventh-Chords. We have thus far presented four, two in major, two in minor. They are:-

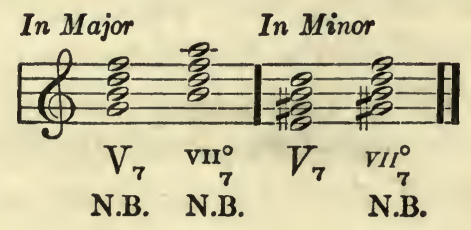


This summary presents three types, each marked N.B. Each of these types is the original; the chordroot of the first is the major dominant, that of the second is the major upleader, that of the third is the minor upleader. Every type of chord should have a name in terms descriptive of its structure like the three triad-types just considered. Since any chord-type may appear on any tone in any key it would simplify analysis were we able to refer to each specific type by its structural name before proceeding to report on its specific relation in any special concrete case. The first of the above types of seventh-chords is known as the dominant-seventh-chord, the second as the major subtonic seventh-chord, the third as the minor subtonic seventh-chord andalso as the diminished seventhchord. All these names except the last are relationnames. The first type is also known as the primary and also as the main (Haupt) seventh-chord, and these names also describe relation instead of structure. Before proceeding to give each of the above seventhchords its structural name we will first explain how the form of such a chord is described. A seventhchord is a combination of a triad and a superadded seventh. Its description requires two terms, the first defining the triad, the second defining the seventh. The two terms joined by a hyphen will give the exact structural name of the specific type. The first of the three types (N.B. in our example) comprises a major triad and a small seventh; the structural name of this type is therefore the major-small seventh-chord; the first of the hyphened words describes the triad, the second describes the seventh. Accordingly the sec- 
ond type (second N.B. in example) is named the diminished-small seventh-chord. The third type (last N.B. in example) is named the diminished-diminished seventh-chord, or briefly, the diminished seventhchord. All other types of seventh-chords are either modifications of these or compound chords.

Next we exemplify the four positions or forms of a seventh-chord. They are: 1. the ground-form with chord-root as lowest tone; 2 . the terce-form with chord-third as lowest tone; 3 . the quint-form with chord-fifth as lowest tone; 4. the sept-form with chord-seventh as lowest tone. The four are known respectively as the ground-seventh-chord, chord of the fifth-sixth, chord of the third-fourth, chord of the second. All appear below in close and open positions.

Close

Open

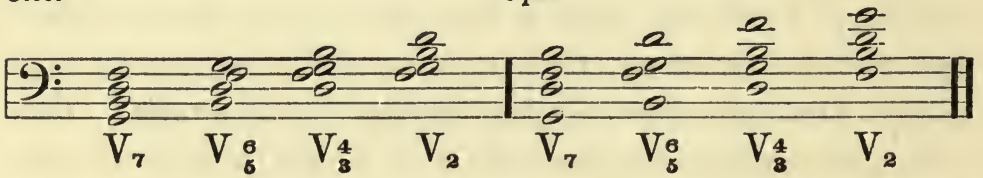

Ninth-Chords. We have thus far derived two, the large ninth-chord in major, the small ninth-chord in minor: both are based on the dominant, and each is the original of its peculiar type.

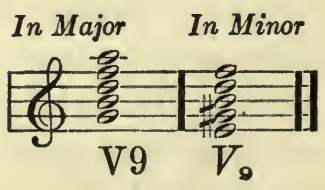

The description of a ninth-chord requires three terms, one for the basic triad, one for the superadded 
seventh, one for the superadded ninth. Thus the large ninth-chord is described as major-small-large, the small ninth-chord as major-small-small.

Owing to the fact that the chord of the ninth extends beyond one octave the customary inversion-idea cannot be applied to this chord. In truth the idea though universally practiced cannot logically apply to any chord, since the inversion of a chord, like that of a tone, is simply an impossibility. A triad has three positions close and open, a seventh-chord has four positions close and open, and each individual position is an individual form distinguished from other positions and forms by its lowest tone or bass. Thus the ninth-chord falls in line with the triad and seventhchord. Having five components the ninth-chord may appear in five positions close and open. They are presented in the next example. The first position is the ground-form with chord-root as bass and is marked $\theta$; the second with chord-third as bass is the terce-form and is marked ${ }_{3}^{\circ}$; the third with chordfifth as bass is the quint-form, marked ${ }_{5}^{9}$; the fourth with chord-seventh as bass is the sept-form, marked ${ }_{7}^{9}$; the fifth with chord-ninth as bass is the none-form, marked $\stackrel{9}{\circ}$.

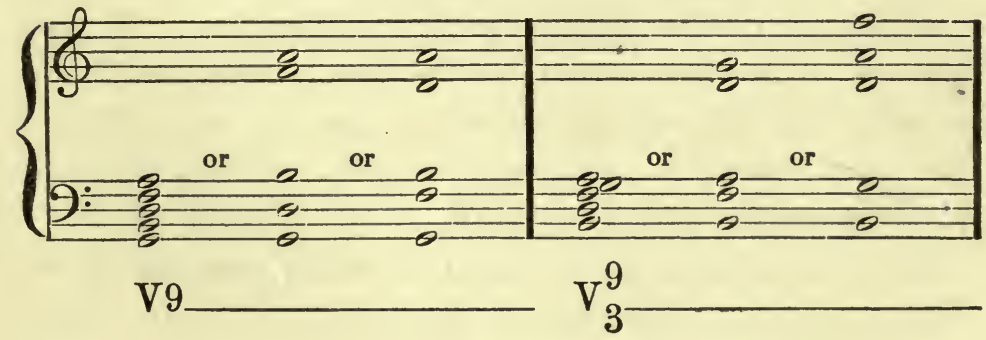




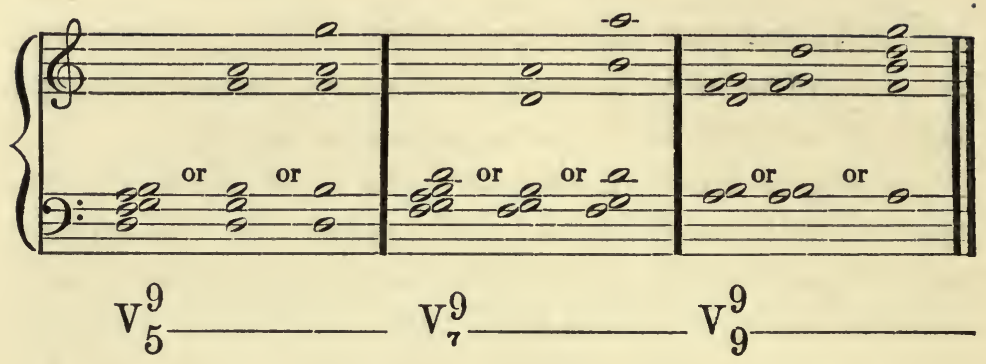

The open positions after the close position of each of the above forms are easily multiplied by conceiving other combinations of the five chord-components. When viewed as abstract material, the close positions of the above forms from the second onward strike both ear and eye as amorphous and repulsive. But in the concrete when each component reports a clear and definite harmonic percept these chords at once gain a definite shape and suggest many conjunctions with other chords, some preceding, others succeeding them. For the time being we are summarizing and describing the structure of chords the origin of which we have explained in previous chapters. On the other hand, the treatment of chords in concrete music is the special subject of another part of this work. But a word in the latter connection may be said here. As harmonies we have seen that the large and small ninth-chords appear sometimes with the root, at other times without the root. With the harmonic root the two above types are classed as ninthchords; without the harmonic root the resultant chords are classed as seventh-chords. By omitting the harmonic root in the above example all the chords would become seventh-chords. 
I next present the two original types of ninthchords in a series of ground-forms very commonly employed, especially in instrumental music. It will be observed in these illustrations that while the chordroot is retained throughout, the upper four tones appear successively in four positions first close, then open.

\section{Large Ninth-Chord}

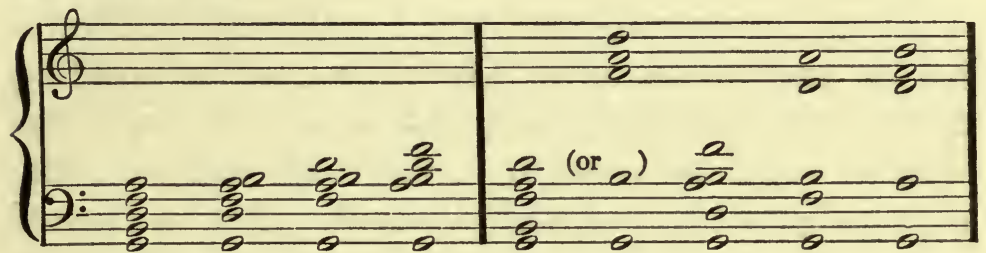

$\mathrm{V} 9$

Small Ninth-Chord

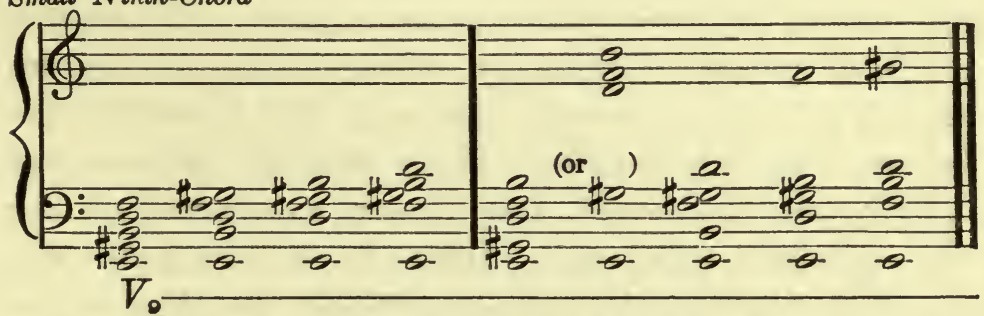

All other types of ninth-chords are either modifications of the original two or compound chords.

51. Simple and Compound Chords Defined

1. A simple chord is a combination of components of a single harmony.

2. A compound chord is a combination of components of two or more harmonies.

In the above summary all the chords are simple and all the types there presented are types of simple chords. Their sole guide having been harmonic feeling and 
perception, the first builders of chords worked inductively and were not troubled by laws of acoustics. Moritz Hauptmann* tells us that treatises on harmony usually open with a learned chapter on acoustics the half-truths in which have little if any influence on the chapters that follow. The truth is that the commonly adopted rules for building chords were formulated in accordance with the dictates of harmonic feeling and perception. The rules are: for building triads, superadd third and fifth to root; for seventhchords, superadd seventh to triad; for ninth-chords, superadd seventh and ninth to triad. The validity of these rules as applied to simple chords has been confirmed by the three-tone, four-tone and five-tone threads of original harmony in one voice. This principle of chord-building by superadding third upon third has been extended beyond the ninth to the eleventh and thirteenth. The resultant chords, all of which are compound, are known as chords of the eleventh and thirteenth. The above rules apply exclusively to simple chords. Their application to chords in general is a purely arbitrary procedure and has caused much gratuitous confusion in heads and books. For when our intellectual or conceptual report on a specific chord in a specific relation does not agree with and is in truth utterly refuted by our concrete perception of that chord's harmonic report, how can we help feeling confused! Theories that present such conceptions are certainly false. Viewed in the abstract a chord is musically dead; we have done with it when we describe its structure and classify it. Viewed in the concrete a chord is alive, each of its 
components is alive with its harmonic self-report, for the chord is musically related. We are here concerned with chords that are alive. We have seen that in concrete music, harmonies may be completely and incompletely represented by chords; completely when the chord presents all the harmonic components, incompletely when certain components are omitted. Whatever their number, when the components of a chord report a common root then the chord is simple, and when they report two or more roots then the chord is compound. The largest number of chords in use are compound. The subject of compound chords belongs to Part II of this work, but a few examples at this juncture will suffice to show what they are. To the two definitions of chords at the opening of this section we now add a third which is general.

3. Chords are selective combinations of two or three or four or five or more individual tones. They are classed under the following heads: I. Consonant or Dissonant. II. Simple or Compound. In the following parallel examples in major and minor all the combinations marked by asterisks, with the exception of the second, are compound chords. In these compound biads ${ }^{1}$ (two-tone-chords) the two tones are components of different harmonies; one reports one root, the other another root.

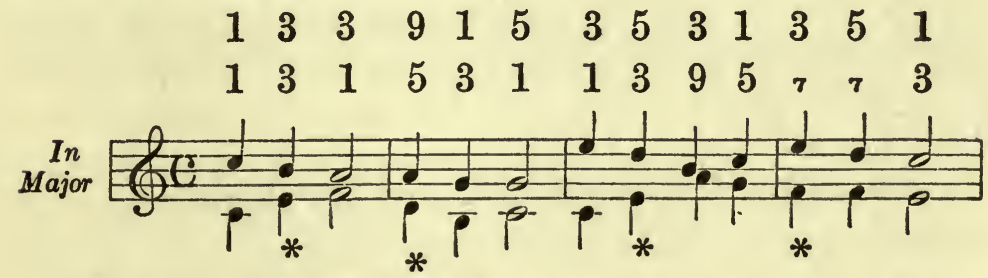

1 The writer coined the word biad by analogy with triad and tetrad. L. E. K. 
$\begin{array}{lllllllllllll}5 & 1 & 3 & 1 & 3 & 3 & 5 & 5 & 5 & 3 & 3 & 9 & 1\end{array}$ $\begin{array}{llllllllllllll}5 & 5 & 1 & 1 & 1 & 1 & 3 & 3 & 3 & 1 & 7 & 7 & 7\end{array}$

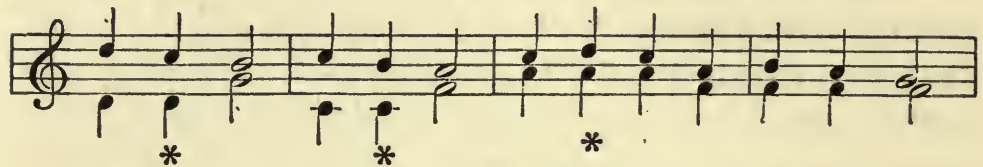

$\begin{array}{lllllllllllll}3 & 3 & 1 & 5 & 3 & 3 & 3 & 3 & 5 & 7 & 3 & 5 & 3\end{array}$

$\begin{array}{llllllllllllll}3 & 5 & 1 & 1 & 1 & 3 & 5 & 1 & 3 & 3 & 1 & 1 & 3 & 1\end{array}$
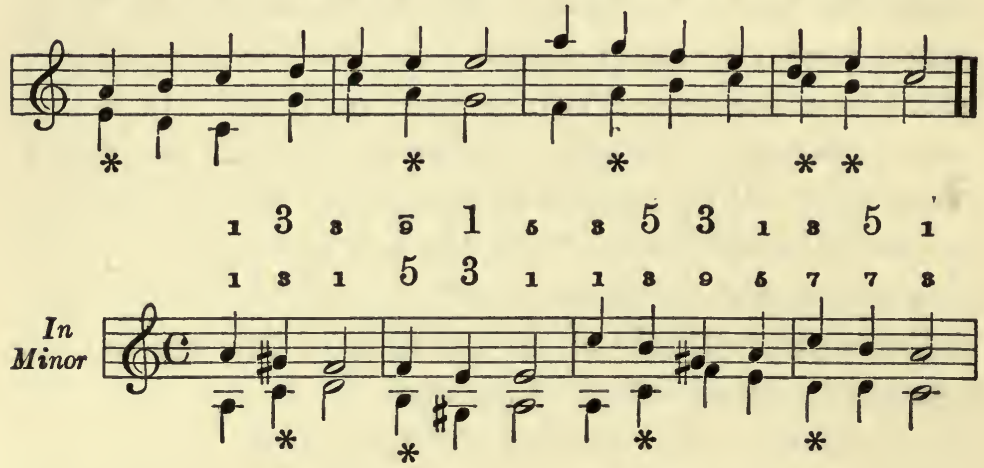

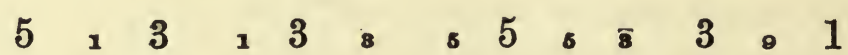

$\begin{array}{lllllllllllll}5 & 5 & 1 & 1 & 1 & 1 & 8 & 8 & 8 & 1 & 7 & 7 & 7\end{array}$

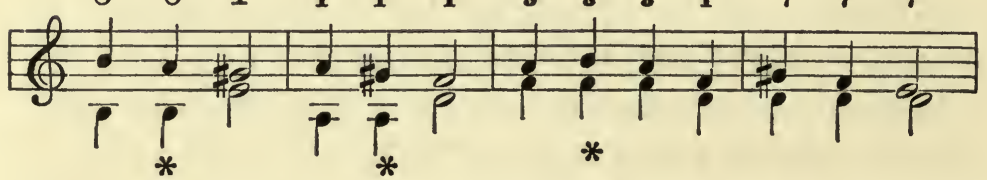

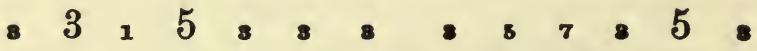

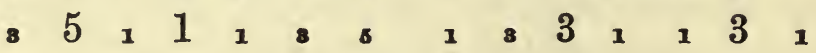

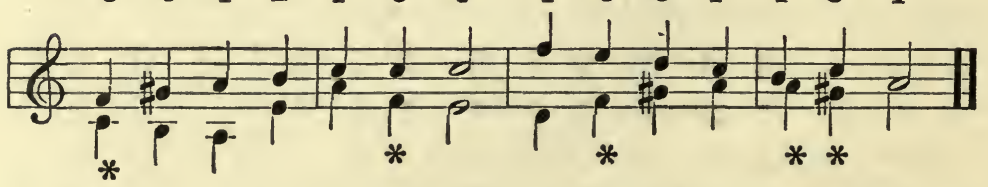

The above superposed percept-numbers, large and small, register our common perception of the concrete harmonic self-report of each tone in each biad and 
therefore of each biad's harmonic relation. Relation, being the immediate cause of a tone's and chord's specific self-report, is first of all a question of mode: Is the mode major or is it minor? This becomes plain when we compare the corresponding relations and consequent self-reports in these parallel examples. The two examples present a number of the same biads, but the reader will observe that the same biad makes one report in major and quite another report in minor. In addition to the question of mode one of three other questions enters into this self-report-determining relation of every tone or chord. The three questions are: Whither? Whence? Whence and whither? The first pertains to an initial tone or chord, whose selfreports are influenced by what follows. The second pertains to a terminal tone or chord whose selfreports are influenced by what precedes. The third pertains to an intermediate tone or chord whose selfreports are influenced both by what precedes and follows. By concretely thinking and carefully comparing these two examples of biads the reader will appreciate the influences of this whither, whence and whence-whither of relation. One more remark. All biads are incomplete forms either of triads or seventh-chords or ninth-chords. In a series of paragraphs, each devoted to a measure of the above parallel examples, we will now take up the explanation of the biads marked by asterisks, first explaining the biad in major and then the corresponding biad in minor.

First Measure. This biad (with asterisk) simultaneously reports 3 of $\mathrm{I}$ and 3 of $\mathrm{V}$, is therefore a 
compound chord and represents the major medianttriad the symbol of which is III. The corresponding biad in minor is a compound of $s$ of $I$ and 3 of $V$ and represents the minor mediant-triad known by the symbol $M K$. Thus the major mediant-triad is a compound of the harmonies I and V: the minor medianttriad is a compound of the harmonies $I$ and $V$. I next present the full triads with harmonic report of each component.

1. Major Mediant-Triad:

$$
\begin{aligned}
& \begin{array}{rrr}
3 & 5-1 & 3 \\
\mathrm{mi} & - \text { sol }-\mathrm{ti}
\end{array} \text { marked III. } \\
& \begin{array}{lll}
\mathbf{E} & \mathbf{G} & \mathbf{B} \\
\hline
\end{array}
\end{aligned}
$$

2. Minor Mediant-Triad:

$$
\begin{array}{ccc}
\text { s } & \text { s-1 } & 3 \\
\text { do- } & \text { mi } & - \text { si } \\
\text { C } & \text { E } & \text { G\# }
\end{array} \mid \text { marked } M X .
$$

The three tones in these triads are known as the chord-root, chord-third, chord-fifth respectively. The middle tone (chord-third) in each of the triads simultaneously reports itself as a component of two harmonies. A tone presenting such a double report is named a double harmonic. Every compound chord contains at least one double harmonic. Primary chords are simple: secondary chords, like those above, are compound. Therefore secondary chords are compounds of primary or simple chords. Before and after the simple chords of which they are compounds, the two above triads appear in third-relations and are heard as compound in accordance with the above analysis. They are given below in these third-relations and are marked N.B. 


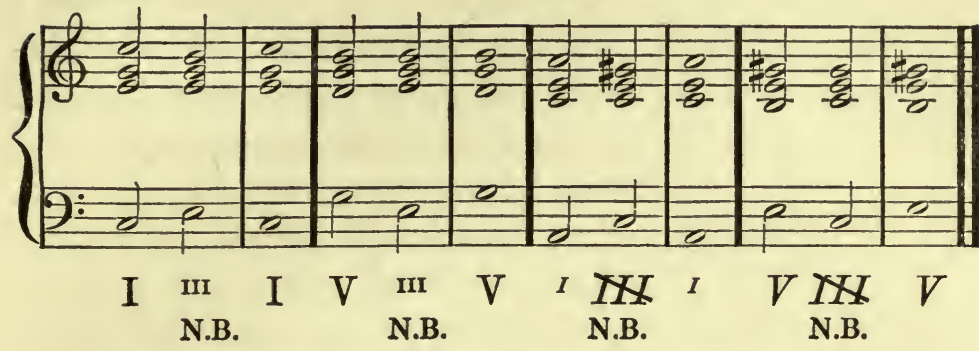

In short, these triads are heard as compound in all relations excepting fifth-relations, in which case they are heard as simple chords, that is, chords whose components all report a common root. The structural description of the two triads is as follows: the major mediant (III) is a minor triad its chord-intervals being root, small third, pure fifth; the minor mediant ( $I X I)$ is an augmented triad its chord-intervals being root, large third, augmented fifth. This type of augmented triad is supposed by Richter and others to have arisen in minor on the third degree of the scale. This would mean that our example presents the original augmented chord. We shall see that this is not so, since the harmonic percept of the augmented fifth first arose in homophony on the major dominant, and we shall further see that the augmented triad of the major dominant is a simple chord.

Since the above mediant-triads are compounds of the tonic and dominant harmonies of their respective modes it follows that there are other secondary triads, namely, those which are compounds of tonic and subdominant and those which are compounds of dominant and subdominant. These are the submedianttriads vI in major and $V I$ in minor, and the super- 
tonic-triads II in major and $I I^{\circ}$ in minor. Thus in each mode there are three primary and three secondary triads. We first present the harmonic analysis of the major and minor submediant-triads.

$$
\begin{aligned}
& \left.\begin{array}{ccc}
3 & 5-1 & 3 \\
l a-d o-m i
\end{array}\right\}=\text { VI. } \\
& \text { 1. Major: }\left|\begin{array}{ccc}
l a-d o-m i \\
\mathbf{A} & \mathbf{C} & \mathbf{E}
\end{array}\right|=\text { VI. } \\
& \text { 2. Minor: }\left[\begin{array}{ccc}
\mathbf{3} & \mathbf{5 - 1} & \mathbf{3} \\
\mathbf{F} & \mathbf{A} & \mathbf{C}
\end{array} \mid=V I\right. \text {. }
\end{aligned}
$$

It is only in certain relations that these triads make the above self-reports. They do so when they appear as bychords on light rhythm-periods each before and after the primary triads of which they are compounds. See below:-
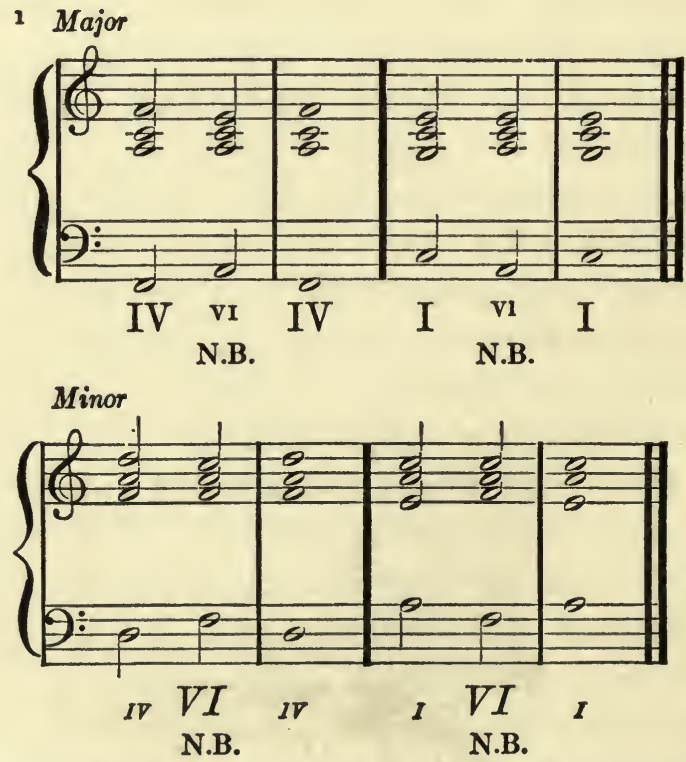

1 This example and those on pp. 251 and 252 , not found in the MS., were supplied by Miss Luise Haessler. L. E. K. 
In most other relations these secondaries are heard as simple chords. Surprising and noteworthy are the facts first, that the triad vi is at once a minor triad and a compound of two primary major triads; second, that the triad VI is at once a major triad and a compound of two primary minor triads. The two asteriskbiads in the ninth and tenth measures of our parallel examples represent the triads in question and report them as compound.

Next follows the analysis of the supertonic triads II in major and $I I^{\circ}$ in minor.

$$
\begin{aligned}
& \text { 1. Major: } \left.\begin{array}{rrr}
5 & 7-1 & 9-3 \\
r e & -f a & -l a \\
\mathbf{D} & \mathbf{F} & \mathbf{A}
\end{array}\right] \\
& \text { 2. Minor: } \begin{array}{rrr}
\mathbf{5} & \mathbf{7 -} & \mathbf{0 - 8} \\
t i-r e & -f a \\
\mathbf{B} & \mathbf{D} & \mathbf{F}
\end{array} \mid
\end{aligned}
$$

These compounds of $\mathrm{V}$ and $\mathrm{IV}$ in major, $V$ and $I V$ in minor, make the above self-reports as bychords in connection with their respective modal subdominanttriads as follows:-

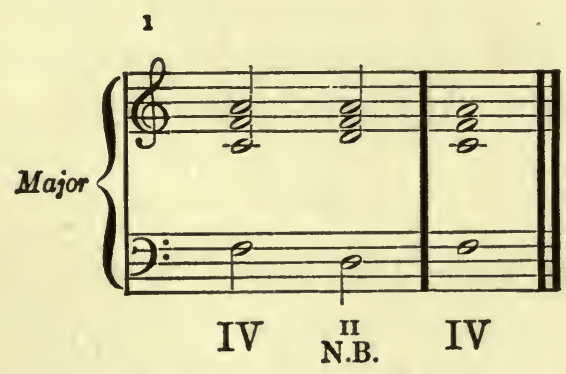

2 See footnote, p. 250. 


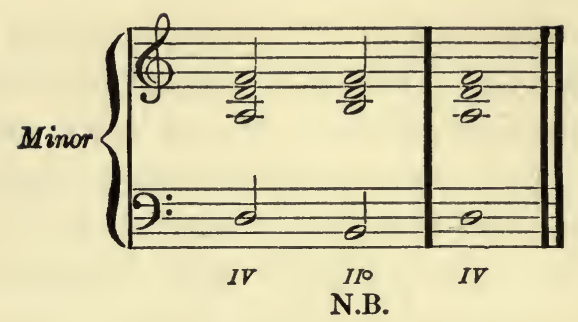

The asterisk-biads in the seventh measure, page 246, represent these supertonic-triads and are heard as compound. Before the dominant these triads are heard as simple chords.
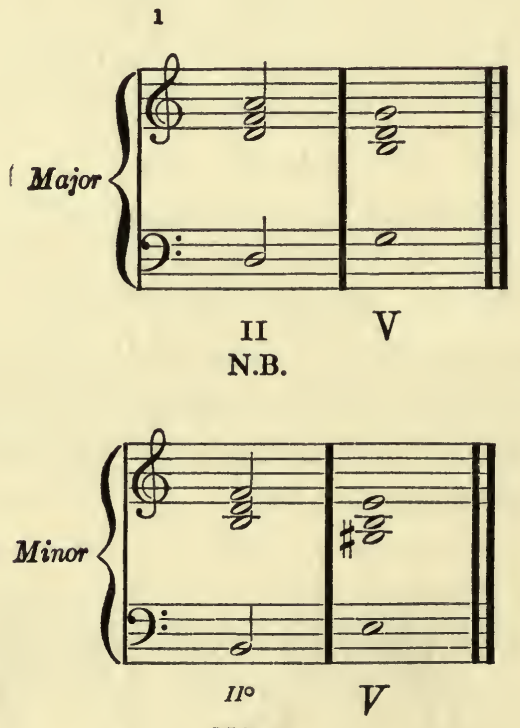

N.B.

The books agree that this downward progression from II to $\mathrm{V}$ and from $I I^{\circ}$ to $V$ is most natural and correct, but do not satisfactorily explain why. The

${ }^{1}$ See footnote, p. 250. 
supertonic-triad is based on the fifth of the dominant and therefore lies over it. Besides this, the fifth of the supertonic-triad is the original ninth of the dominant and its natural tendency is downward. Hence these natural progressions.

Second Measure. The supertonic-triads as simple chords and as just described are represented by the asterisk-biads in this measure which precede the dominant. Their analysis in this relation is as follows: II $=5,7,9 ; I I^{\circ}=5,7$, 8 .

Third Measure. This biad is a compound of I and $\mathrm{V}$, and represents the secondary seventh-chord of the major mediant III $_{7}$. The corresponding biad in minor, a compound of $I$ and $V$, represents the corresponding chord $M X 7$ in minor. Below are the full harmonic reports on these chords.

$$
\begin{aligned}
& \text { 1. Major: } \left.\begin{array}{cccc}
3 & 5-1 & 3 & 5 \\
\text { E } & - \text { sol } & - \text { ti } & - \text { re } \\
\text { B } & \text { B } & \text { D }
\end{array}\right\}=\mathrm{III}_{r} \text {. }
\end{aligned}
$$

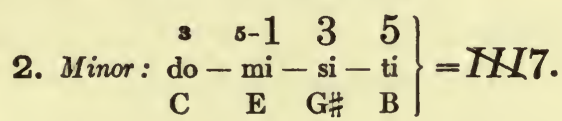

The remaining secondary seventh-chords (excepting those of the major and minor subtonics which we have already analyzed and found to be simple chords) are compounds of primary harmonies. They are those of the two tonics $\mathrm{I}_{7}$ and $I 7$; those of the two subdominants $I V_{7}$ and $I V_{7}$; those of the two submediants $\mathrm{VI}_{7}$ and $V I 7$; those of the two supertonics $\mathrm{II}_{7}$ and $I I^{\circ}{ }_{7}$. These chords are next analyzed in the order of their mention. $I_{7}$ is a compound of the primaries $I$ and V; $I \gamma$ is a compound of $I$ and $V$, as follows:- 


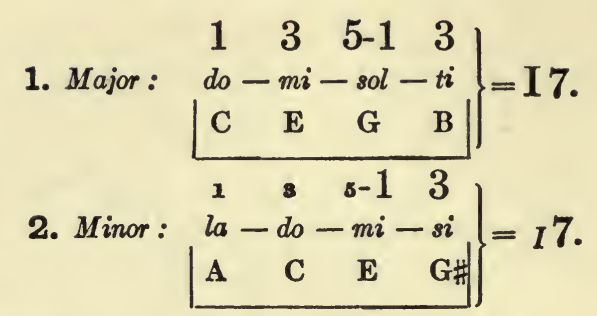

Next follow the major subdominant seventh-chord which is a compound of I and IV and the corresponding chord in minor which is a compound of $I$ and $I V$.

$$
\begin{aligned}
& \text { 1: Major: } \left.\begin{array}{cccc}
1 & 3 & 5-1 & 3 \\
f a & -l a & -d o & -m i \\
\mathbf{F} & \mathbf{A} & \mathbf{C} & \mathbf{E}
\end{array}\right]=\operatorname{IV} 7 . \\
& \text { 2. Minor: } \begin{array}{rrrr}
\mathbf{1} & \mathbf{8} & \mathbf{5 - 1} & \mathbf{3} \\
r e & f a & -l a & -d o \\
\mathbf{D} & \mathbf{F} & \mathbf{A} & \mathbf{C}
\end{array} \mid=I V_{\mathbf{7}} \text {. }
\end{aligned}
$$

1 The submediant seventh-chord in major is a compound of IV and I; in minor it is a compound of $I V$ and $I$, as follows: -

$$
\begin{aligned}
& \text { 1. Major: } \begin{array}{cccc}
3 & 5-1 & 3 & 5 \\
l a & -d o & -m i & -s o l \\
\mathbf{A} & \mathbf{C} & \mathbf{E} & \mathbf{G}
\end{array} \mid=\mathrm{VI}_{\mathbf{7}} \text {. }
\end{aligned}
$$

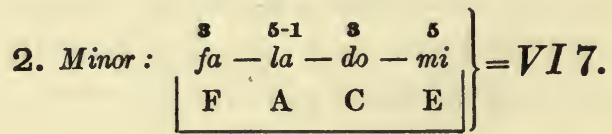

The supertonic seventh-chord in major is a compound of $\mathrm{V}$ and IV, while in minor it is a compound of $V$ and $I V$, as follows:-

${ }^{1}$ This paragraph omitted in MS. was supplied by Miss Luise Haessler. L. E. K. 


$$
\begin{aligned}
& \text { 1. Major: } \left.\begin{array}{cccc}
5 & 7-1 & 9-3 & 5 \\
r e-f a & -l a & -d o \\
\mathbf{D} & \mathbf{F} & \mathbf{A} & \mathbf{C}
\end{array}\right\}=\mathrm{II}_{\imath} \text {. } \\
& \text { 2. Minor: } \begin{array}{cccc}
5 & 7.1 & 0-3 & 5 \\
t i-r e & -f a & -l a \\
\text { B } & \text { D } & \text { F } & \text { A }
\end{array} \mid=I I_{7}^{\circ} \text {. }
\end{aligned}
$$

While in certain relations there are variations in the reports of these secondary seventh-chords they nevertheless always report themselves as compound. These compound triads and seventh chords call forth many observations which however belong to Part II on chords. My purpose here is fulfilled by introducing the subject of compound chords, by showing that they really exist and what they are. Interested readers will observe the differences in major and minor of the self-reports of certain chords which are identical in both modes.

Fourth Measure. The asterisk-biad is a compound of I and V differing from the compounds thus far considered. The regnant harmony is that of the dominant and is represented by its seventh in the lower tone and therefore the upper tone is a bytone. In short, this is a compound of regnant tone and bytone, examples of which are very common. All this is true of the corresponding biad in minor.

Fifth Measure. The parallel asterisk-biads present similar compounds of regnant tone and bytone.

Sixth Measure. These compound biads represent the major and minor tonic-seventh-chords which we analyzed a moment ago.

Seventh Measure. These parallel biads represent 
the major and minor supertonic-triads in relations in which they are heard as compound chords. They were analyzed in the paragraph on the first measure.

Eighth Measure. Compare this second biad with the last biad in the preceding measure and observe how the self-report of a specific combination may vary even in the same mode. Also compare the same biads in minor.

Ninth and Tenth Measures. Both measures present the same biad in different positions. This biad represents the submediant-triad in a relation in which it reports itself a compound chord. The same applies to the corresponding biads in minor. The analysis of these submediant triads has already been given.

Eleventh Measure. These parallel compound biads represent respectively the major and minor submediant-seventh-chords which were analyzed on a previous page.

Last Measure. Both of these biads are based on the regnant dominant, and are therefore compounds of a regnant tone and a bytone. In the first biad the bytone is below, in the second it is above. The same is true of the corresponding biads in minor. This concludes the analysis of the parallel examples on pages 245-246.

The only secondary triads and seventh-chords not included in the above analyses are those of the major and minor subtonics, which are simple chords, since the components of each report a common root. It may also be stated here that all secondary ninthchords are compounds either of two or of three primary harmonies. In another chapter we shall con- 
sider the conclusions to be drawn from the facts adduced from these analyses.

Our tone-material thus far accounted for admits of a brief presentation of two other groups of compound chord-structures both of which are very common and have proved puzzling and difficult to account for and explain by means of the arbitrary principle of superadded thirds, a principle which in no way applies to them. The first of these groups of chords are compounds of repose-tones and cadence-tones, that is, of stable and unstable tones. The second group comprises chords with superfix-tones, infix-tones and subfix-tones, that is to say, chords with a tone added above, between or below. Our next parallel examples present compound chords of the first group.
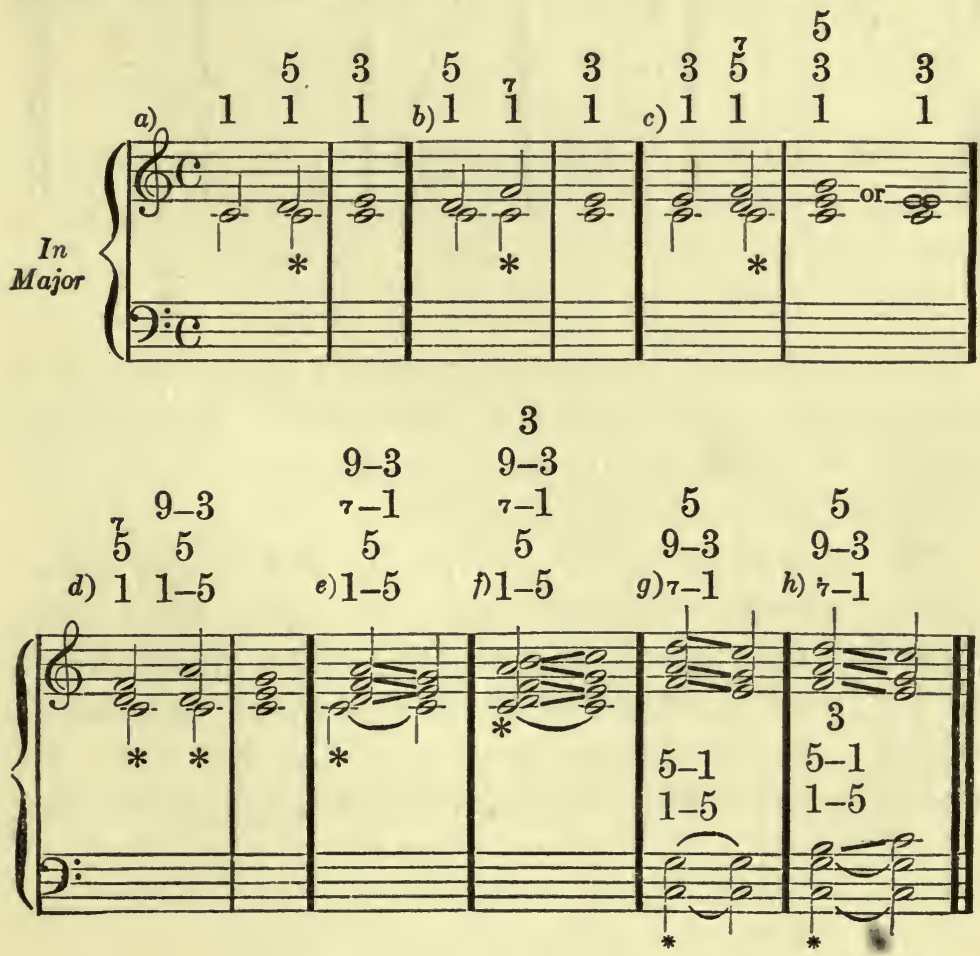

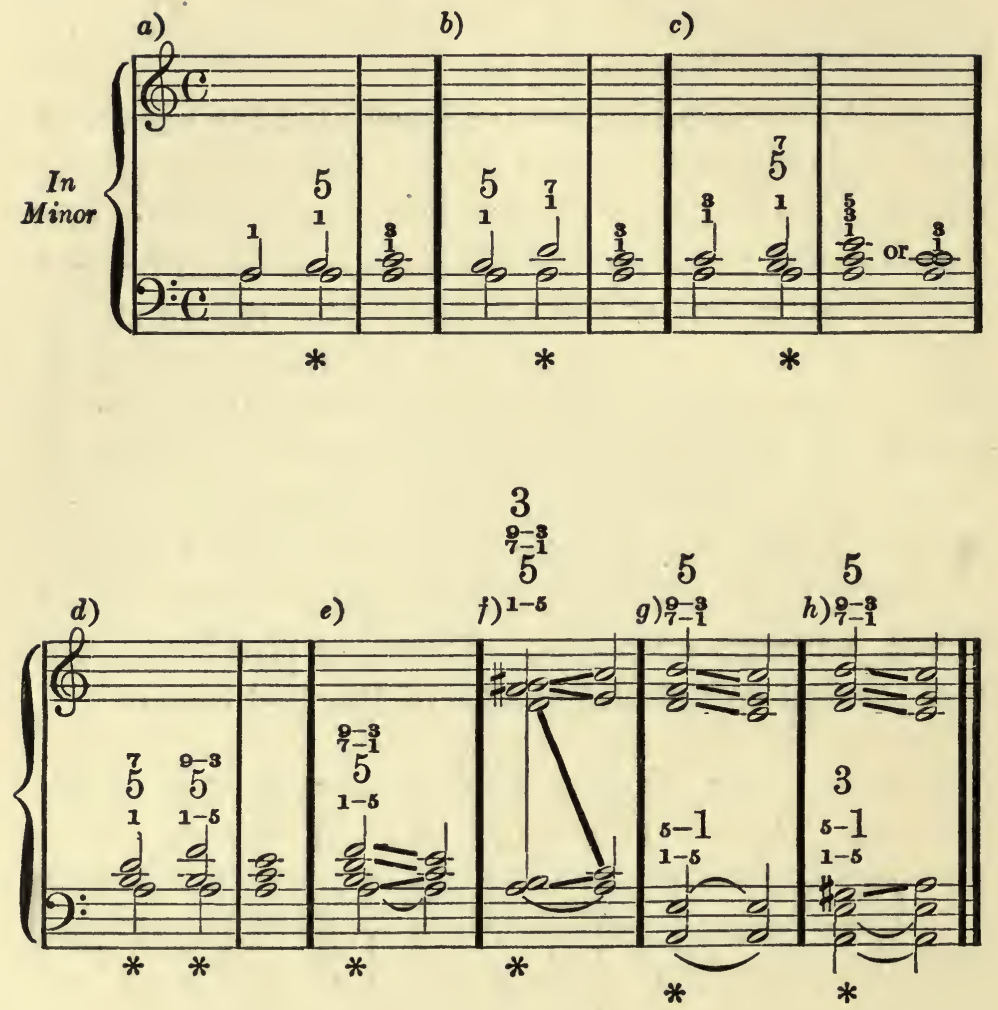

All the above combinations marked by asterisks are compounds either of the two primaries $\mathrm{I}-\mathrm{V}$ in major and $I-V$ in minor, or of the three primaries $\mathrm{I}-\mathrm{V}-\mathrm{IV}$ in major and $I-V-I V$ in minor.

The chords in $a), b), c), d), e$ ) and f) are compounds of one stable tone plus one, two, three and four unstable tones respectively. The stable tone do 1 (C) is the chord-root of each of these compound chords. Why? First, because being the tone to which the other tones are added and being stable it is 
the principal tone in each chord; second, because it is the harmonic root of the chord into which each of these compound chords resolves. The chords in $g$ ) and $h$ ) are compounds of two stable tones plus three and four unstable tones respectively. Both of these stable tones do (C) and sol ( $\mathrm{G})$ are harmonic roots, but for the reasons just given do (C) is the chord-root of these compounds. The harmonic root $f a(\mathrm{~F})$ which appears in these chords is in every case an unstable tone. The chord-root of these compounds may appear below, between or above the other chordcomponents, but the ground-form or fundamental position of these and like chords is that form or position in which the chord-root is lowest tone or bass. In all cases the structure of these chords is described in accordance with the ground-form and in the interval-terminology of thorough bass. On the other hand, the harmonic reports of these chords are determined by the concrete relations in which they appear. While this species of compound chord may arise on any tone their occurrence is most frequent on the major and minor tonics and dominants. There are so many types of this species of chord that we now present only a few others and defer their harmonic analysis owing to the fact that they introduce harmonic percepts not yet accounted for.

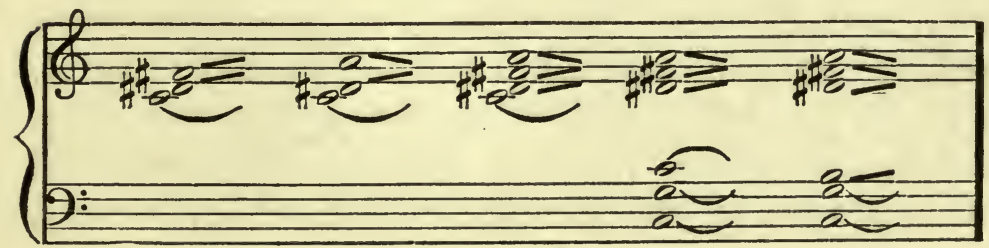



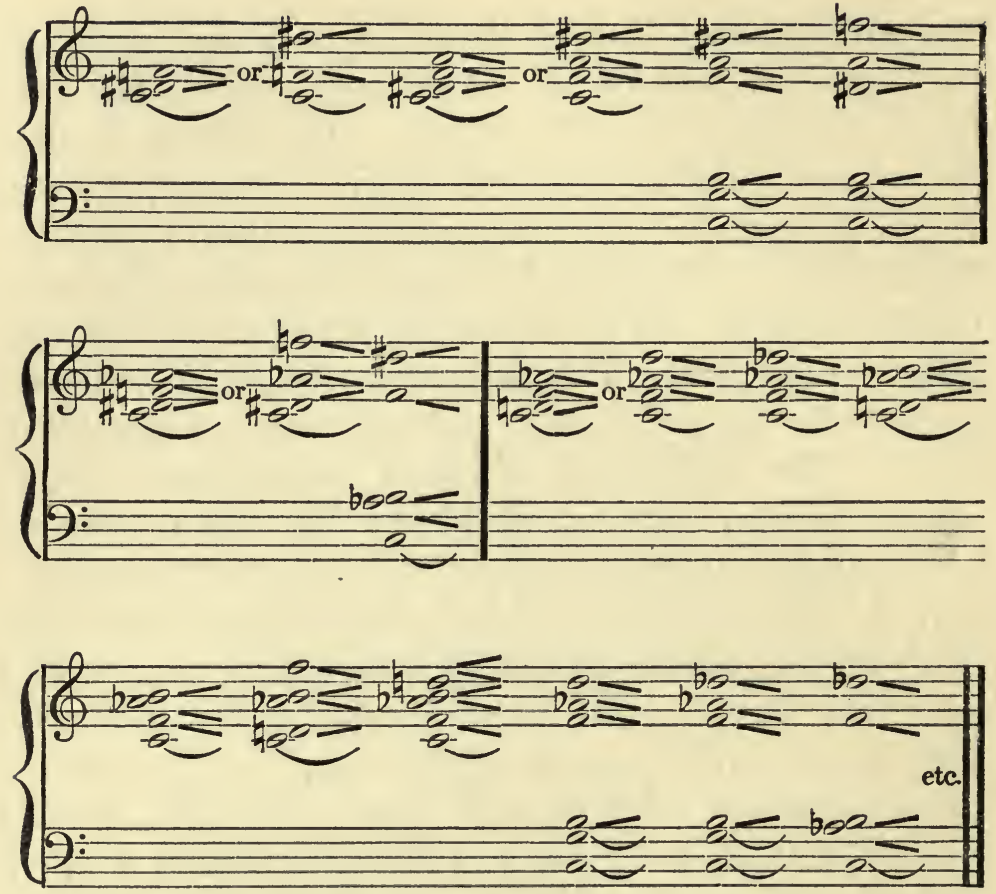

The above ties for stable tones, and cadence-marks for unstable tones plainly indicate the resolutions of these compound chords into the major tonic-harmony. To the eye the first three chords appear to be nothing but fourth positions of the diminished seventh-chord based on the chord-root $\mathrm{D} \#$ in which case the chords would be simple. Not so to the ear. In all these chords $d o(\mathrm{C})$ is stable and reports itself as harmonic root, that is, as 1 . The attempt to think do in these compounds as a small ninth and as unstable, in short, as anything but 1 and stable, results in a voluntary intellectual strain which is wholly unsupported and contradicted by the common reports of feeling and 
perception. As to number and variety there is no limit to compound chord-structures of this group, since they include every imaginable combination of one or two or three stable tones plus from one to four distinct unstable tones in forms in which each compound tone appears but once and in other forms in which components are doubled and even trebled. Moreover, these compound chords may be conceived on any tone and in endless relations. In fine, these chords are distinct structures because each may be a regnant harmony in which relation the components of each are regnant tones. The fact that as regnant harmonies each of these compound chords may be elaborated with its bytones may prove suggestive to composers in that it points to a wealth of new melodic, harmonic and polyphonic possibilities as well as to many as yet unthought and unpenned ornamental figures and passages. The study and elaboration of these compound chords as well as of others about to be presented may serve as a stimulus to the composer's thought and imagination.

Attention is next directed to what on a previous page was called a second group of compound chords. The description of these chords is roughly as follows: Each of these structures has a triad for its nucleus and to this triad one tone is added either above or below. The tone when added above is a supersixth of the chord-root and the resultant combination is named a supersixth-chord. The tone when added below is a subsecond of the chord-root and the resultant chord is named a subsecond-chord. To understand these or any other chords they must be conceived in the con- 
crete as regnant harmonies the self-reports of which are perfectly distinct. The distinctive peculiarity of these compounds is simply this: The added tone does not disturb the identity and predominance of the triad. Conversely, the triad preserves its identity, regnancy and predominance after the tone is added. For example: after superadding A to the C-major tonic-triad the triad still retains its identity, regnancy and predominance and we hear the new combination as the major tonic-triad plus the added tone. True, the resultant chord is a new and distinct idea and unity, and the added tone adds something new to the selfreports of the triad-components, thus creating the compound chord, nevertheless the truth of our thesis persists, the triad does not lose its identity and predominance. The nucleus-triad of a supersixth or subsecond chord may be major or minor or augmented or diminished, and every type of these chords may be found on any tone in any key. This conveys some idea of their limitless number. Below in parallel examples are supersixth-chords based on the triads of the major and minor tonics, dominants and subdominants in $a), b$ ) and $c$ ) respectively. These chords are marked by adding the symbols +6 to the bassnumber, pitch-modifying signs being added when necessary.

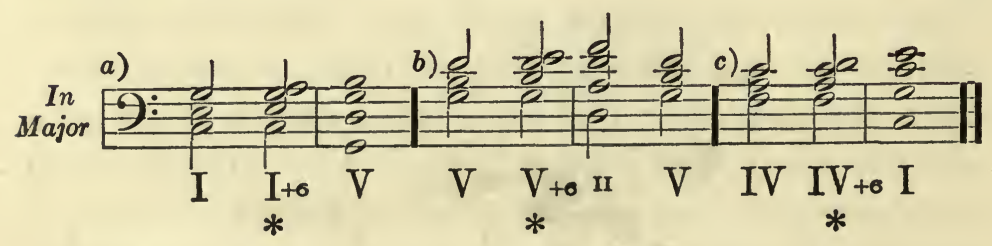




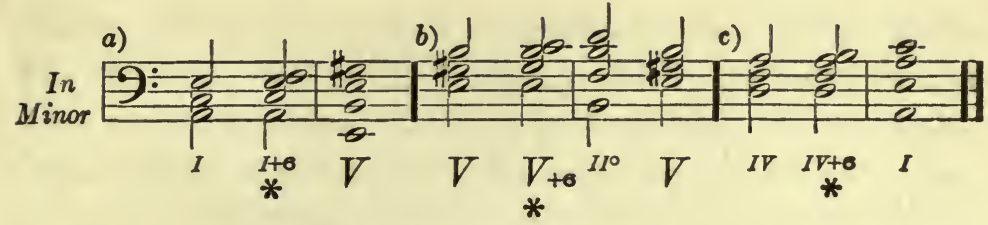

While the added tone in each above supersixthchord does not disturb the identity and regnancy of the nucleus-triad it does affect the two lower tones of the nucleus-triad in that it transmutes them from simple to compound harmonics. In fact, the added tone and these two lower tones of the nucleus-triad combine in and represent another, a second triad in each such chord. Hence this definition: A supersixth-chord is a complex of two triads one of which predominates and is the nucleus. How do we know which of the two triads is the nucleus? This is reported by the regnant harmony. We will analyze the first of these chords marked $I+6$ in $a$ ). This chord is a complex of I (C-major triad) and vi (A-minor triad). Of these two triads the former is at once nucleus, tonic, primary and simple, while the latter is at once submediant, secondary and compound, a compound as already shown of the harmonies I and IV. Thus $\mathrm{I}+6$ is a complex of the triads $\mathrm{I}-\mathrm{VI}$ and a compound of the harmonies I-IV. A compound chord however complex is a distinct idea and unit; it differs from every other chord of the same and other species though its structure may be similar; it is felt, heard and thought as a single idea, which is the direct product of its specific combination. This will appear as we proceed to analyze the other supersixth-chords of our example. In $a$ ) the chord $I+6$ is a complex of 
the triads $I-V I$ and a compound of the harmonies $I-I V$. In b) $\mathrm{V}+6$ (major) is a complex of the triads V-III and a compound of the harmonies V-I, while $V+6$ (minor) is a complex of the triads $V-\Pi H$ and a compound of the harmonies $V-I$. In $c$ ) $\mathrm{IV}+6$ (major) is a complex of the triads IV-II and a compound of the harmonies IV-V against which $I V+6$ (minor) is a complex of the triads $I V-I I^{\circ}$ and a compound of the harmonies $I V-V$. Our analysis suffices to show the exact structure of these chords and suggests their natural relations to other chords which we shall consider in Part II.

Rameau first conceived and presented the supersixth-chord which he found on the major subdominant-triad (as above in $c$ )) and of which he explained that the added tone did not change the triad. But all the other supersixth-chords in our example are formed in the same way, are for the most part in the same common use, are equally distinct ideas, the harmonic report of each being equally distinct and definite; in short, they are actualities not to be overlooked and commanding general recognition.

The fact that each of the above chords is a complex of two triads in which one of the two triads is nucleus and predominates, naturally suggests this question: Does the other triad in each of these complexes ever assert itself as nucleus and predominant? Yes, it does. By what test is this to be verified and known? By the immutable report of regnant harmony. All this is conclusively demonstrated in the next group of parallel examples in which the asterisked chords follow each other in the same order as those in the pre- 
ceding group of examples. One by one in their given order let the reader compare the corresponding asterisk-chords in both groups of examples. He will observe that each of the corresponding chords in both groups is a combination of the same tones, a complex of the same triads, a compound of the same harmonies. But nevertheless each chord in the group of examples below is an entirely different, new and distinct structure and idea. The structure is as follows. Each of the asterisked chords below is formed by subadding a second to a triad and is named a subsecond-chord. The symbols +2 mark the subsecond-chord.
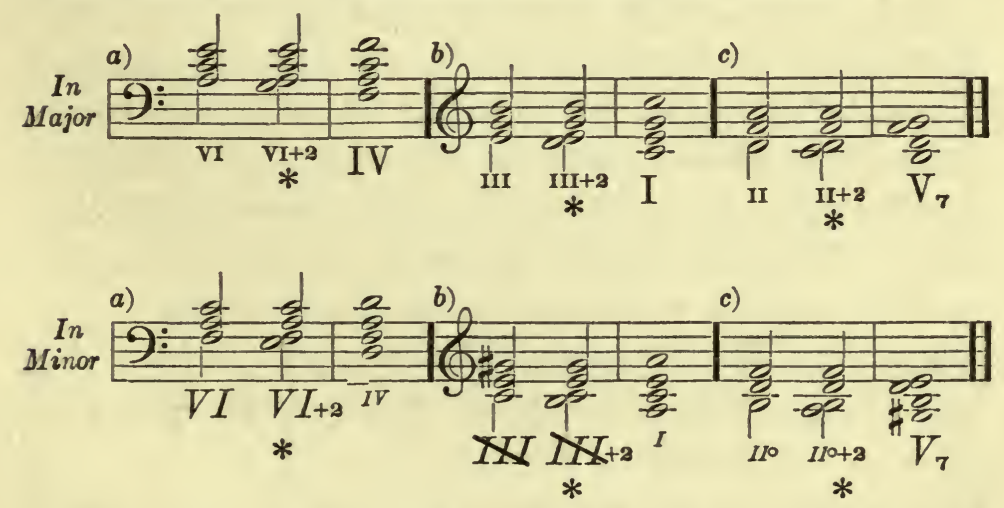

The concrete idea of each of the above subsecondchords is explained in the terms of harmonic analysis as follows: In $a$ ) the chord $\mathrm{VI}+2$ (major) is a complex of the two triads vI-I, vi predominating, and a compound of the harmonies I-IV: against this $V I+2$ (minor) is a complex of the triads $V I-I, V I$ predominating, and a compound of the harmonies $I-I V$. In $b$ ) III +2 is a complex of the triads III-V, III predominating, and a compound of the 
harmonies $\mathrm{I}-\mathrm{V}$, against which $K I+2$ (minor) is a complex of the triads $X X-V, \Psi X$ predominating, and a compound of the harmonies $I-V$. In $c$ ) the chord II + 2 (major) is a complex of the triads II-IV, II predominating, and a compound of the harmonies V-IV, against which $I I^{\circ}+2$ (minor) is a complex of the triads $I I^{\circ}-I V, I I^{\circ}$ predominating, and a compound of the harmonies $V-I V$.

Analysts do not agree on the chord in the opening measures of Beethoven's Sonata Op. 31 No. 3. This chord is $\mathrm{II}+2$ in its ${ }_{5}^{6}$ position, the one above in $c$ ), as shown in our next illustration. Most of these chords appear both in major and minor, their harmonic reports varying as their relations are changed. Thus, for example, the chord vI +2 (above in major) appears in minor where it becomes $I+2$. This is exemplified below in the opening measures of Beethoven's Sonata Op. 27 No. 2.

Op. 31. No. 3.

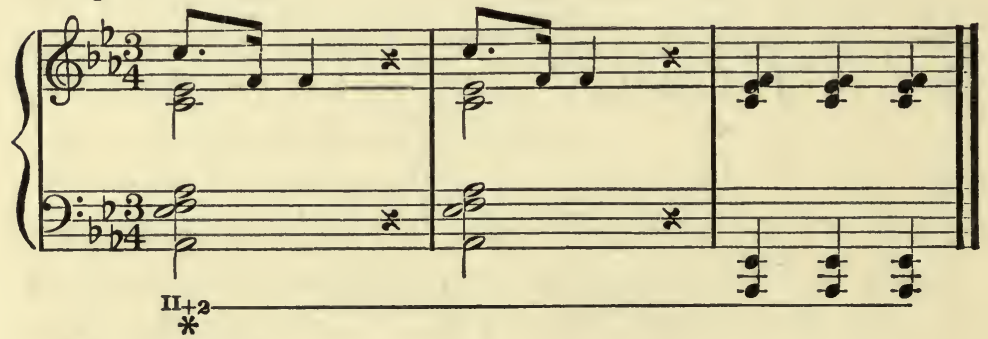

Op. 27. No. 2.

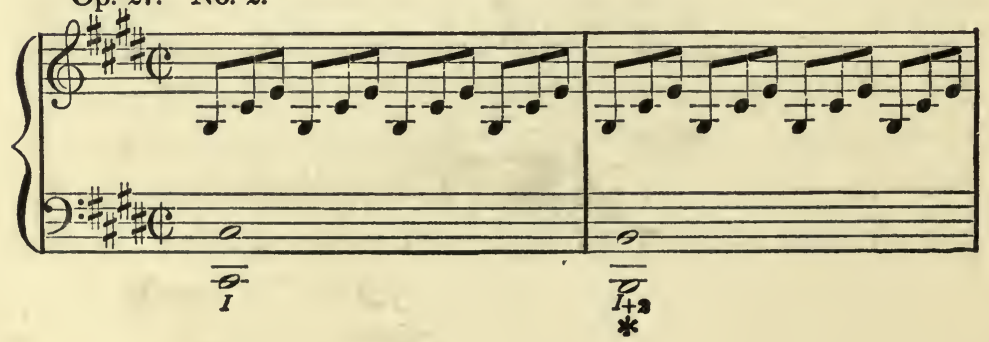


CHORDS IN THE LIGHT OF THEIR ORIGIN 267

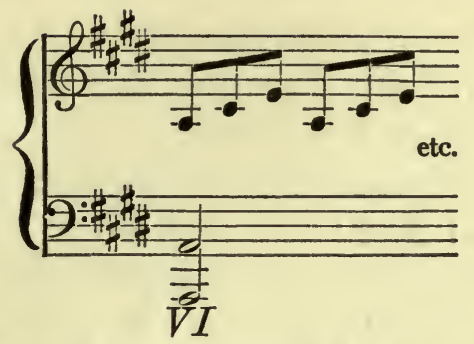

The thorough-bass mark of the ground-form or first position of a supersixth-chord is ${ }_{5}^{6}$, of that of a subsecond-chord is 2. These chords being combinations of four tones naturally have four positions both in close and open voicing. Since a combination of the same four tones is now a supersixth-chord and now a subsecond-chord, now reports itself in major, now in minor, since each such chord may appear in one of four positions either in close or open voicing, how is it possible to tell which is which? Always by the report of regnant harmony, which is absolute. The chords $I+6$ in major and $I+2$ in minor are combinations of the same four tones and will serve to illustrate all these points. Both are presented below,
a) In Major
b) In Minor

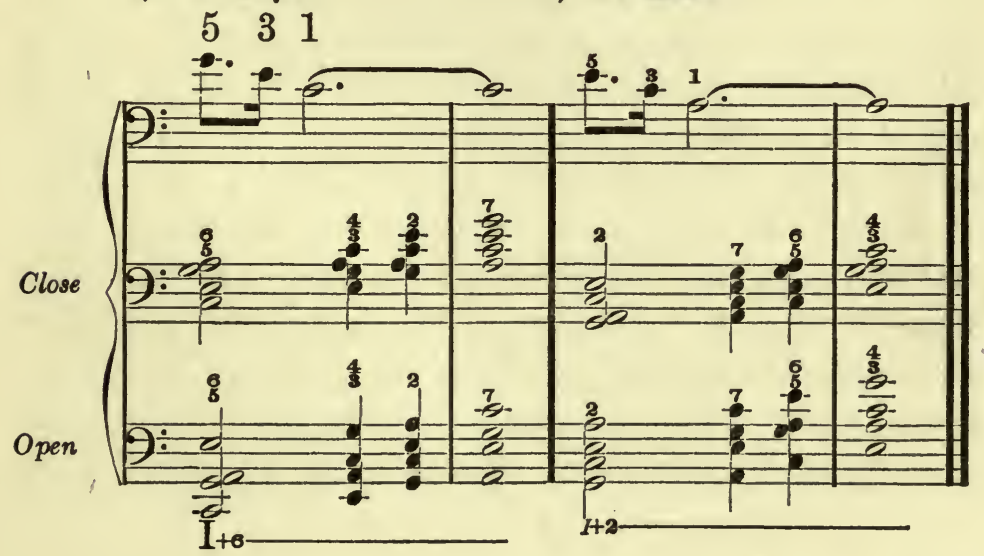


each in four positions in close and open voicing together with its peculiar thorough bass numbers.

In $a$ ) the regnant harmony of melody and chord report the major-tonic-triad as nucleus and predominant, $\mathrm{C}(d o)$ as chord-root and A $(l a)$ as added tone. In $b$ ) the same sources report the minor tonic-triad as nucleus and predominant, A (la) as chord-root, $\mathrm{Gr}(\mathrm{sol})$ as added tone. To the eye the chords in $a$ ) and $b$ ) appear to present the same structures and ideas: to the ear, as the above analysis shows, they present entirely distinct structures and ideas. In $a$ ) we all hear a major triad plus a supersixth; in $b$ ) we all hear a minor triad plus a subsecond. If music is what we hear rather than what we see then supersixthchords and subsecond-chords are positive realities and facts of common concrete experience which are recorded in every music-score and confirmed in every musical mind. But, it will be asked, are not the above chords as well as all the other supersixth and subsecond chords thus far presented simply secondary seventh-chords? Yes and no. Yes, in the sense that they are commonly known and classed as such. Emphatically no, in the sense that their structure is the same as that of the actual harmonic seventh-chords $\mathrm{V}_{7}$ in major and $V_{7}$ in minor. Once more, closely observe the above two chords $I+6$ and $I+2$. Does either of the two contain a harmonic seventh? No: in certain positions both chords present a seventh, but this seventh is a chord-seventh, that is, an arbitrary thorough-bass seventh computed from an arbitrary chord-root; it is not a harmonic seventh, as the following analysis proves. Above in $a$ ) the chord $\mathrm{I}+6$ 
reports the components of its nucleus-triad to be $1,3,5$ of $I$ and reports its added tone to be 3 of IV, while in $b$ ) the chord $I+2$ reports the components of its nucleus-triad to be $1,3,5$ of $I$ and reports its added tone to be 5 of $I I I$. Thus neither of the two chords contains and reports a harmonic seventh. Hence this obvious question: Should chords without harmonic sevenths be known and classed as seventh-chords? Thorough-bass answers yes; harmony answers no. That is to say, from the view-point of thorough-bass the above chords are seventh-chords, from the viewpoint of harmony they are not. If we distinguish between the two view-points, both of which are necessary, there need be no difficulty or confusion. In fact, the prevalent thorough-bass system and its terminology are indispensable to the theory and practice of harmony; not only is their utility unquestionable, but they have become fixed habits. The adoption of a simple and exact term from the German will, I think, remove the whole difficulty. To explain: For triad the German says Dreiklang, for seventh-chord the German says not only Septimenaccord, but also Vierklang. Vierklang is the term in question. According as we may prefer its Latin or Greek derivation the English equivalent of Vierklang is quadrad or tetrad. I suggest the adoption of the term tetrad as the classname of all chords of four components. Tetrads may be subdivided into as many distinct groups as there are distinct structures. Thus seventh-chords would form one group, supersixth-chords would form another group, subsecond-chords still another, and so on. Such a classification would not only conform both 
with harmony and thorough-bass and render the two reciprocally explanatory, but it would enable us to say truly that certain tetrads are seventh-chords, certain other tetrads are supersixth-chords, and so forth. This would deliver us from that unnecessary and harassing evil of trying to force all chords to fit into one of a few arbitrary and conventional thoroughbass patterns. The truth is that music resembles nature in that its species and varieties of distinct structures are countless and limitless. Everywhere in nature there is music, everywhere in music there is nature.

In the next parallel examples the same four tones combine in forming a subsecond-chord in $a$ ) and a supersixth-chord in $b$ ). The subsecond-chord in $c$ ) and the supersixth-chord in $d$ ) are likewise combinations of the same four tones. These chords are marked by asterisks and their forms are explained by the accompanying symbols. Minuter analysis is unnecessary here since each chord is a complex of triads and compound of harmonies similar to those previously presented and analyzed.
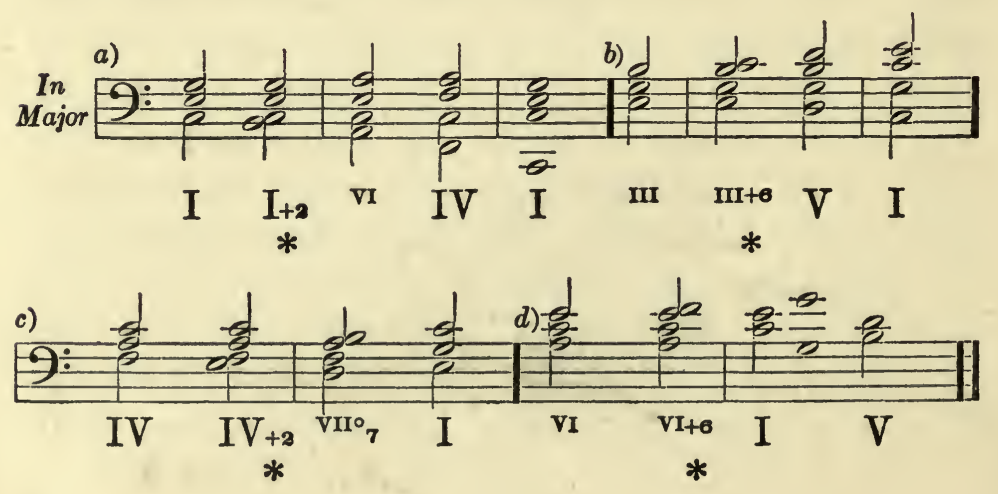
CHORDS IN THE LIGHT OF THEIR ORIGIN 271
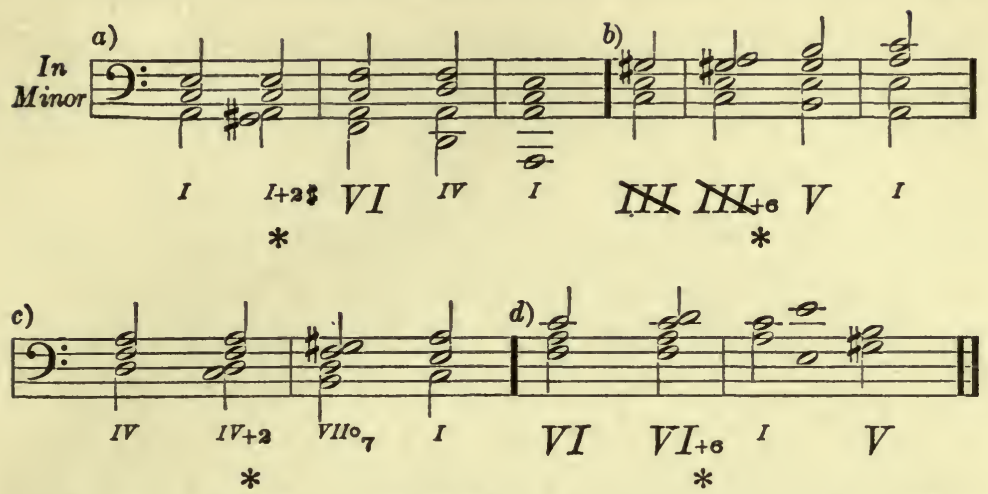

In the chords marked by asterisks the next collection of parallel examples presents supersixth-chords in each of which the added tone is either a chromatic or an enharmonic. Most of these chords are familiar and are known in current text-books by other names. In structure and idea they present and report themselves as tetrads of the supersixth-group, of which there are as many varieties as there are distinct structures. The possible connections of these chords being wellnigh boundless only a few examples are given, and owing to the fact that we have not yet explained the genesis of these chromatic and enharmonic harmonies which these chords represent, their further analysis is deferred.
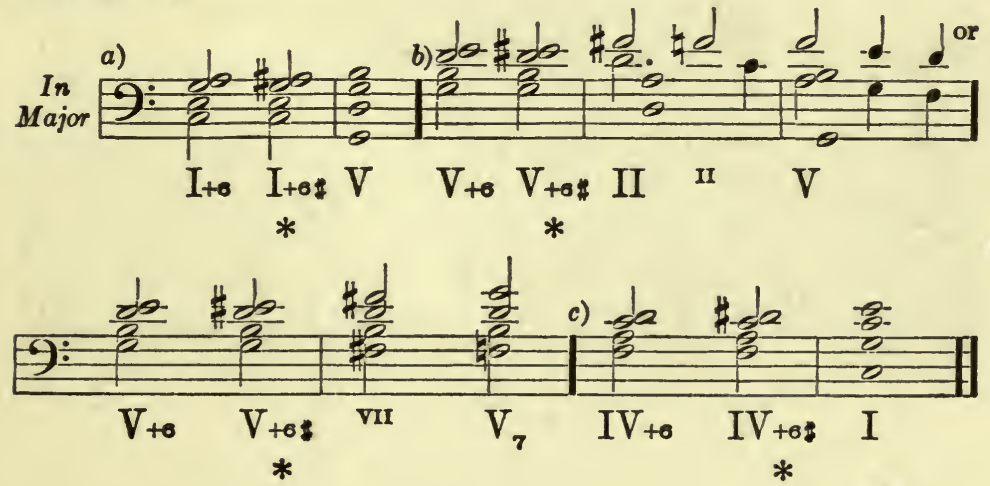

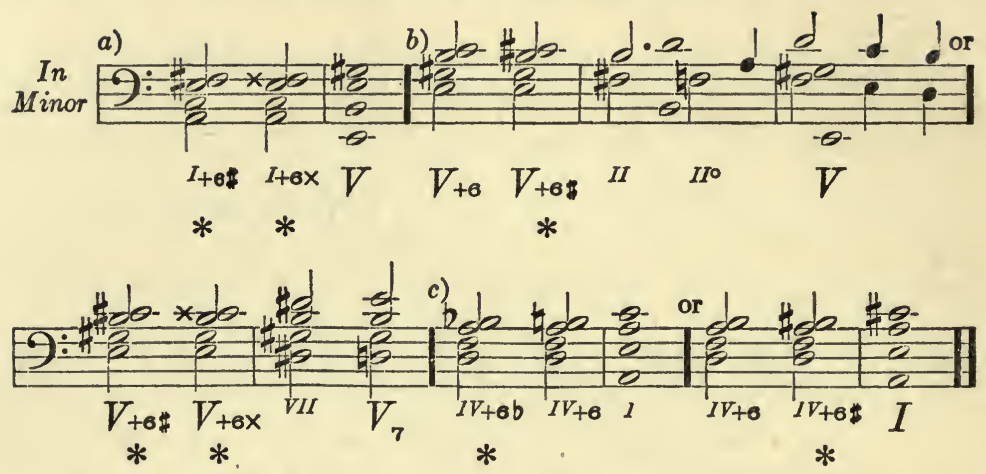

The compound tetrad having been introduced and explained, the subject is here dropped. Of several other distinct species of compound chords I will point out but one more with which the present provisional exposition of this wide and fertile field of inquiry may be brought to a conclusion. The harmonic analysis of the peculiar and distinct chord-structures now confronting us and marked by asterisks in the next group of examples is omitted save in one important particular, namely: the harmonic root of each such chord is indicated by a capital letter. Thus the harmonic root of the asterisked chords in $a$ ) is $\mathrm{G}$, in $b$ ) is $\mathrm{C}$, and so on. The key being $\mathrm{C}$ major the harmonic root $\mathrm{G}$ in $a$ ) is the dominant, $\mathrm{C}$ in $b$ ) is the tonic, and so on. These harmonic roots are reported by the regnant harmony in each instance.

a) 1 .

2.

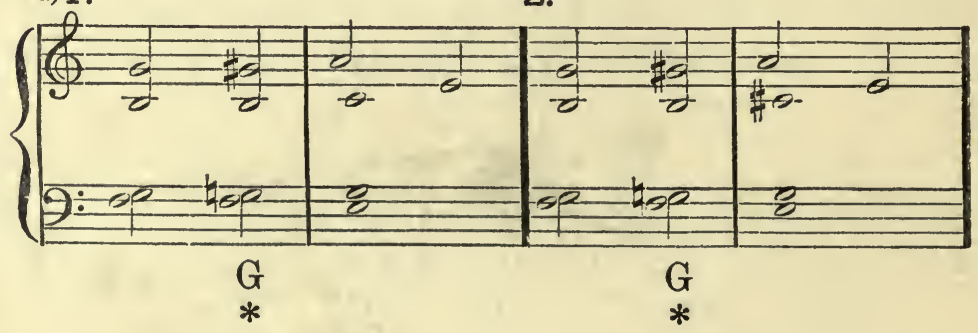


CHORDS IN THE LIGHT OF THEIR ORIGIN 273
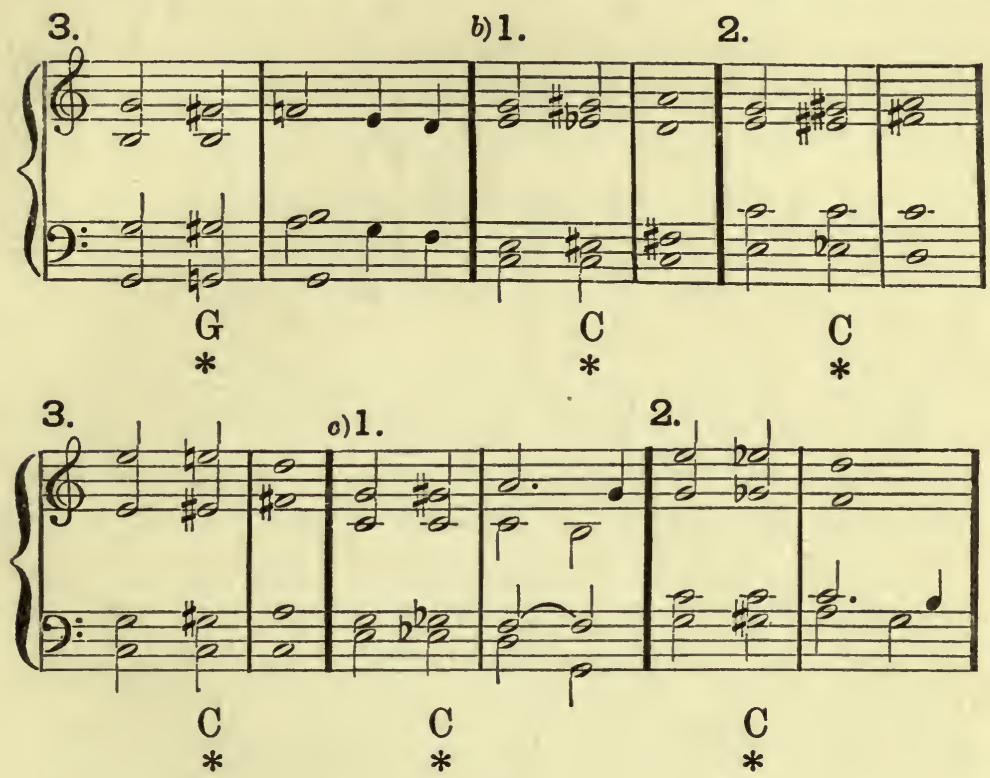

3.

4.
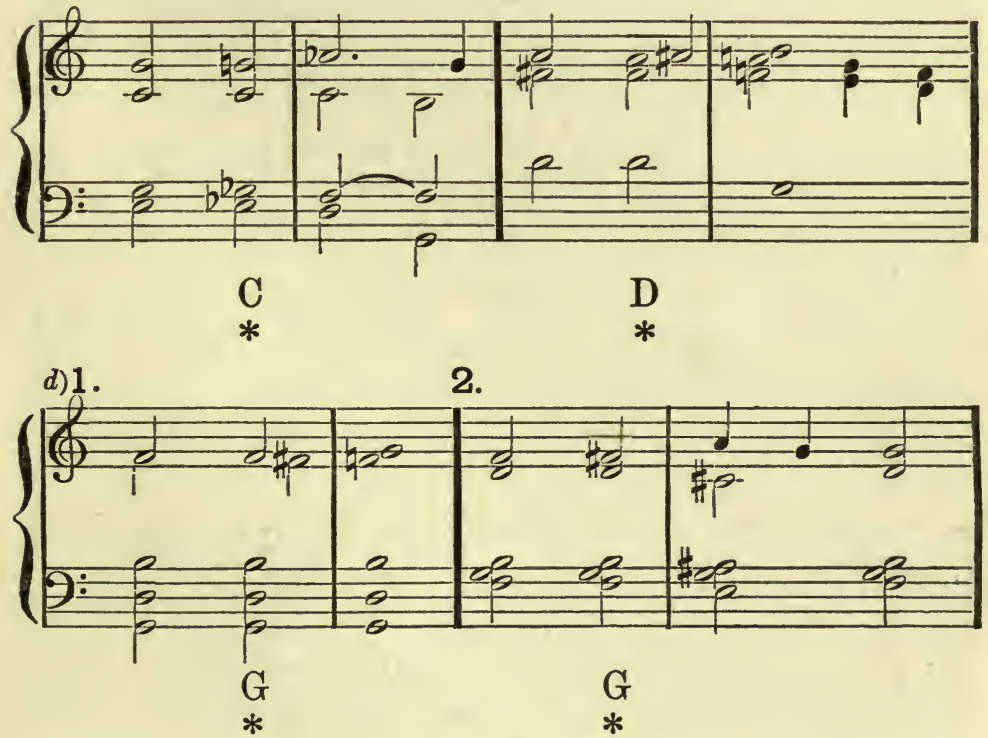


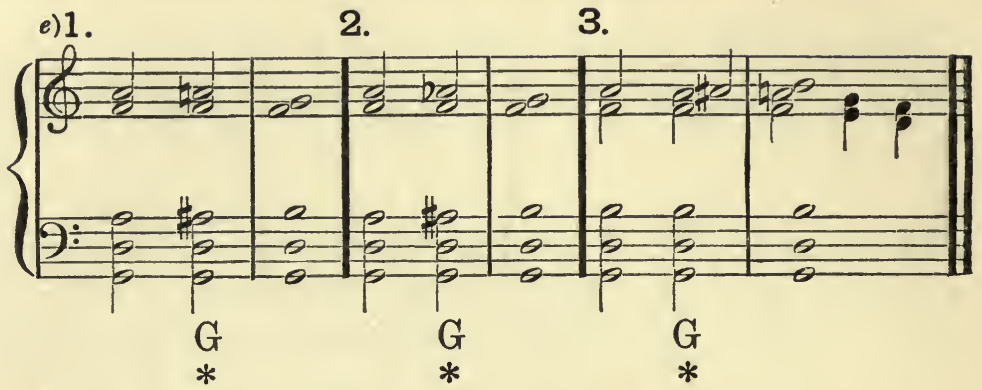

Each of these chords is a regnant harmony, each component of each chord is therefore a regnant tone and reports a harmonic percept. For the present this ends our harmonic analysis of these structures because each reports certain harmonic percepts which will not be explained and ascertained until we reach the chapter on chromatic and enharmonic harmony. Our present description of these chords will therefore be superficial because confined to the abstract interval-terms of thorough-bass but will nevertheless suffice for their introduction. The peculiarity common to all these compound chords and rendering them distinct from all others is this: Each contains two distinct components answering at once to the same letter-name and to the same interval-denomination as chord-root, chord-third and so forth. Observe the asterisked chord in a) 1 and 2: it contains a G and a $\mathrm{G} \not$ : $\mathrm{G}$ is the chord-root, $\mathrm{G} \neq$ is the chord-root sharped: apparently the chord has two roots: harmonically of course this is not the case: regnant harmony reports that $G$ is the chord-root and that $\mathrm{G} \neq$ is an added tone. The asterisked chord in $b$ ) 1 and 2 contains $\mathrm{E} b$ and $\mathrm{E}$ in 3 contains $\mathrm{E}$ and $\mathrm{E} \neq$ : thus each of these chords contains two distinct chord-thirds of the root C. The 
asterisked chord in c) 1 and 2 contains Gb and G that in 3 contains $\mathrm{G}$ and $\mathrm{G} b$, that in 4 contains $\mathrm{A}$ and $A$ : each contains two distinct chord-fifths of a common chord-root. Likewise each of the asterisked chords in $d$ ) contains two distinct chord-sevenths of the same root, in $e$ ) two distinct chord-ninths of the same root. Now it may be objected that all these structures are nothing but passing chords. Yes, but they are chords all the same, each is regnant, each is a combination of harmonic percepts and subject to harmonic analysis. Next it may be objected that the above notation of these chords is arbitrary and incorrect, that in the asterisked chord in $a$ ), for example, we might substitute $A \dot{b}$ for $\mathrm{G} \neq$ and then the chord would simply be the small ninth-chord of the dominant, marked $V_{8}$. I reply that $A b$ in this chord would be absolutely false and misleading for two patent reasons. First, because $\mathrm{Ab}$ is a chromatic downleader with a downward tend whereas the regnant harmony reports a chromatic upleader with an uptend: hence G . Second, because the step from At. in this chord to A in the next chord reports a progression whereas the relative and regnant harmony report this specific step to be a rising cadence and resolution: hence again, $\mathrm{G}$. On its logical side no one will gainsay that the symbols of notation to be accurate should be selected in conformity with the harmonic idea to be conveyed, and that this should be insisted on even at the cost of certain old and time-honored traditions and conventions, the preservation of which is the function of history but whose usefulness in practice no longer exists. Certainly our 20th-century notation of 
the classics should discard the many inaccuracies of the 17th- and 18th-century notation. At best our notation has its limitations; still its symbols are adequate for a more accurate presentation of the harmonic idea. Editors have done much in this direction, but editions still contain many harmonic errors. How are these errors discovered? By the common immutable self-reports of regnant harmony. Correct harmonic notation is a question of conformity with these common self-reports. I will stop here for but one illustration and quote the subjoined measure from the Adagio-theme of Beethoven's E flat piano-concerto, the error in which was corrected by von Bülow in the Cotta-edition, but still occurs in other editions. At N.B. in $a$ ) the melody distinctly and unmistakably reports itself as the large third of $\mathrm{D}$, that is, as $\mathrm{F} \times$ : see correction at N.B. in $b$ ). Instead of $\mathbf{F} \times$ Beethoven wrote $\mathrm{G}$, which is a diminished fourth, and $\mathrm{G}$ reappears in every repetition of the melody throughout the Adagio: see in Peters' edition. It is impossible to hear this specific tone in this specific relation as a diminished fourth, nor could Beethoven so have heard or conceived it. The common self-report as large third is immutable and therefore the notation $\mathrm{G}$ is misleading and false while that of $\mathrm{F} \times$ is logical and

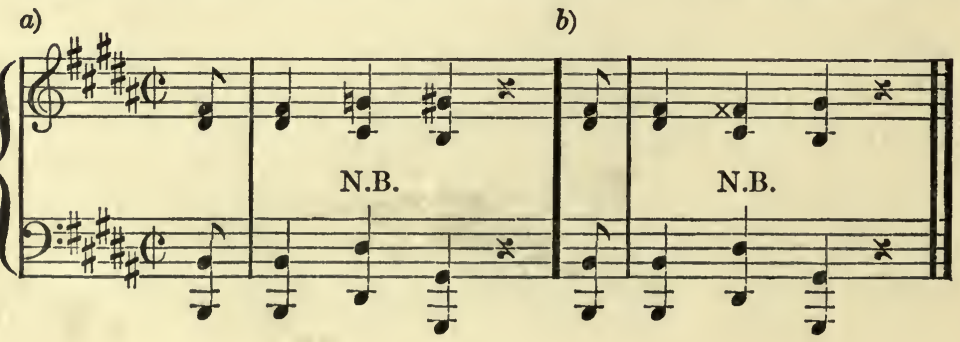


true. To the speller and performer of notes such errors are not troublesome: it is otherwise with the reader and interpreter of $i d e a s$.

52. Melody the Original Reporter of Harmony, Therefore the Natural Preceptor and Guide in the First Studies in Chords

The thread of this exposition is here temporarily dropped in order to inquire into the most simple and direct way of insuring from the outset the student's musical understanding and mastery of the chordmaterial taken up from lesson to lesson. The groundforms of the three primary triads I, V, IV constitute the material of the usual first lesson. It is customary, after explaining this material and giving rules for its treatment, to embody it in a group of exercises each consisting in a series of fundamental basses. The student then fills in the chords, in doing which he carefully ties the bond-tones and avoids the impermissible consecutive fifths and octaves. This lesson is followed by others, each adding more material, more rules plus exceptions to or modifications of previous rules, more exercises in the bass, more performances by the student, and so the work proceeds. It is well known that in performing these tasks most students do not exercise their natural musical faculties in the slightest degree, they see but do not hear what they write, their observance of rules, their performances are purely mechanical. Such unprofitable results point directly to some radical defect in teaching, to some psychological error in our pedagogy. 
How account for this defect, what is its cause? The majority of those composing the rank and file of students are only moderately endowed with musical gifts, yet each student sets out with a deep love of music and that love is the certain proof that he possesses innate musical faculties, the activity and healthy growth of which it is the function of efficient pedagogy to stimulate and direct. The defect, its cause, indeed the source of the whole difficulty lie in the universally adopted form in which the work is presented to the student, namely, in the exercises in fundamental basses, in short, in the fundamental basses. To be sure, the fundamental tone is the only true viewpoint of chord-material as such in the light of its structure, since each structure rests and is built upon its root or fundamental. This being true it would seem that the only natural and logical form of first exercises for students is that of a series of fundamentals as is the prevailing custom. So it would seem, but it is not true. Our pedagogy has failed adequately to discriminate between two essentially distinct viewpoints of chord-material; first, that of the chord as a structure and mere material; second, that of the chord as applied in the living stream of connected rhythmoharmonic feeling and thought. The first of these viewpoints is that of the fundamental tone. The second, as the above heading and all thus far said in these pages imply, is melody. Melody is the student's first consciousness of music, in melody he recognizes both the object and the proximate cause of his love of music, to him melody is from the outset something real, tangible, comprehensible, the one thing he 
feels, can follow and express because of his innate sense of the relations of its tones and of the natural form and sequence of its phrases, the one thing he knows and delights in, the one thing which to him is music. From all this the student is cut off by an exercise in fundamentals at the sight of which his musical faculties not being stirred are as dead. The student's intellectual grasp of the rhythmo-harmonic form and content of a simple melody should be the first end and aim of a teacher. How this is done has been shown in preceding chapters. Tell him that each tone in melody conveys two definite and simultaneous reports to his perceptions, a rhythmic report and a harmonic report. Associate these reports with correct symbols and the student's feeling and thought are connected for all time. The resultant intellectual grasp of these reports is the certain awakener of his musical faculties and intelligence with which at the crucial moment his face will not fail to light up. Melody, the original reporter and raison d'etre of harmony, the universal voice and form of the inner music-consciousness, is the student's natural key to the what, how and why of chords. Melody is the direct reporter of fundamentals and chords. Fundamentals and chords are not reporters of melody though they may suggest them. The common practice of conceiving different melodies to a given bass belongs to a later stage in study. Thus to begin the study of chords is to reverse the natural order.

Below are examples of first exercises embodying the primary triads. It is a psychological error to suppose that any beginner however gifted possesses the con- 
ceptive power to grasp the four-voice music-thought embodied in these given basses. The impossible being demanded, the student's performance is necessarily mechanical and musically dead since his musical faculties are not called into requisition. How many beginners are there who even so much as hear the given bass itself! Even those who do, what musical sense can they make of it, what harmonic connection do they perceive in these series of bass-tones? None whatever. Does not the untrained and natural basssinger feel and find his tones in relation to something else which he grasps and remembers as a whole, namely, to a melody? When there is no one present to sing the melody what does this natural bass do, does he sing the bass-part? No, he sings the melody. Thus cut off from melody, from music-thought by these basses, the student's only intellectual refuge lies in the prescribed rules for connecting chords which more often tell him what not to do rather than what to do. Even though he performs his task correctly he has gained nothing musically, and the educational purpose is not attained.

1.

2. 8

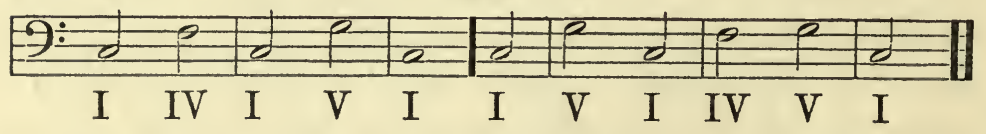

The same material, in short, the same exercises are next presented in the form of melody, of music-thought itself.

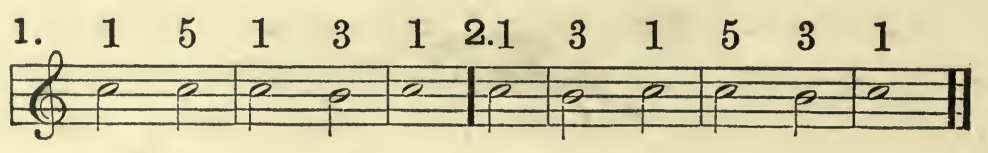




\section{CHORDS IN THE LIGHT OF THEIR ORIGIN 281}

These melodies and their harmonic index plainly set the student's task before him, and give him the key to the whole musical rationale of the situation. Melody being the one simple and real fact in the beginner's inner consciousness and experience of music, it follows that the given melody is the one thing that his musical faculties can seize upon and be stirred by, the one thing that lies within his intellectual grasp and appreciation, the one thing he appreciates and remembers as a whole and in relation to which it is easy for him to add something else since it explains the musical what, how and why of the addition. The beginner feels and can follow the inherent relations connecting the tones of the given melody, he readily learns to hear the concomitant voices reported by the melody, since those voices but complete the sense of the melody. Thus as he adds voice upon voice the student duly learns to appreciate the concurrences and correlations of all the four voices, in fine, he knows what he is about and attains the educational purpose of the exercises. Below is the desired result of his performance, valuable if worked out from a given melody, valueless if worked out from a given bass.

1.

2.

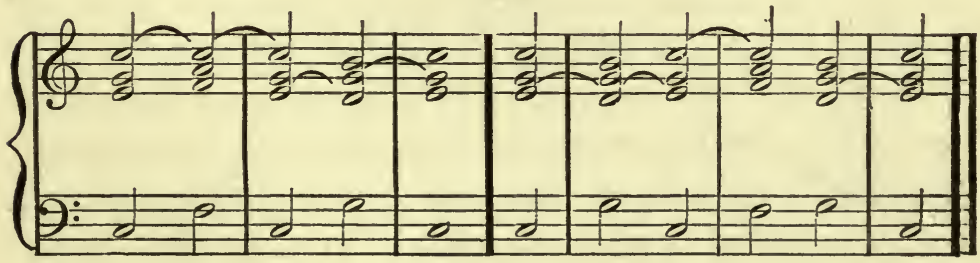

The corresponding material in minor is embodied 
in the following given basses at $a$ ), given melodies at $b)$, and performances at $c$ ).

1.

a)

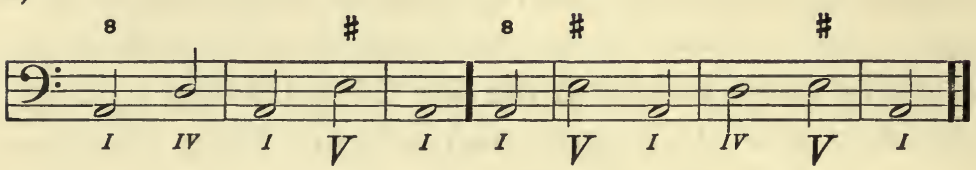

1.

2.

b)

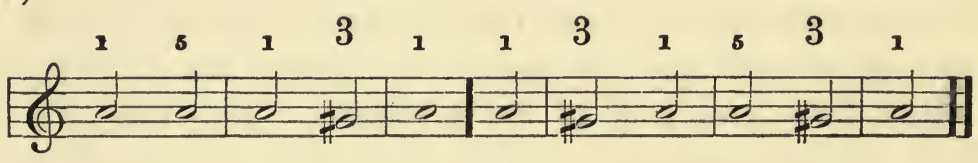

1.

2.

c)

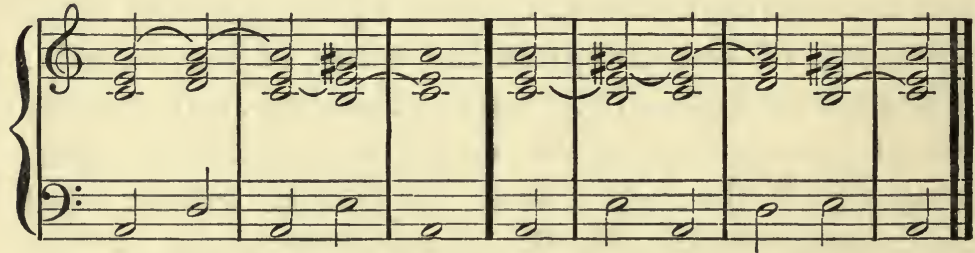

It will be observed that the above exercises are the exact counterparts in minor of those just presented in major. This comparative study and treatment of corresponding material in major and minor by means of such parallel exercises in given melodies is commended for its usefulness to students.

Exercises in the given bass, owing to their arbitrary prescription of the order and arrangement of material, completely cut off the student from that independence of thought and judgment in the use and selection of chord-material which is so essential to its mastery. Not so with exercises in given melodies, for these may 
be presented with and without harmonic prescriptions. For illustration we will take the first of the above parallel exercises in major and minor. Present these melodies without harmonic numbers and ask the student for their harmonic self-reports. He will respond with the following:-

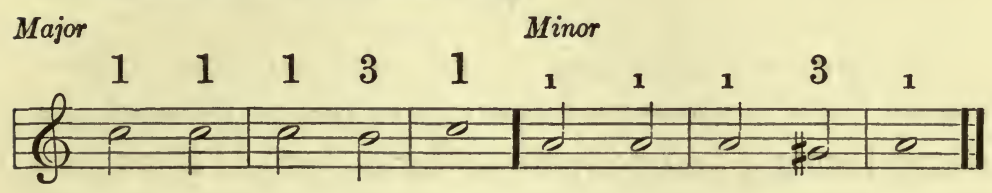

Setting out with a distinct perception of these common harmonic reports asserted by the melody itself the student has a great advantage for he is thus enabled to distinguish between such self-reports of natural harmony and the personally selected reports of selected harmony. In short, he learns what is the difference between self-reported harmony and personally selected harmony, between reports perceived and reports conceived, all of which he cannot learn from a given bass. Now change the harmonic numbers of these parallel exercises as follows and ask the student which harmonies are self-reported and which are selected.

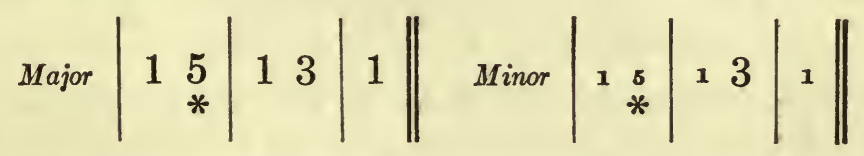

The student will answer: the second harmony in both exercises is selected, all the others are selfreported. Next ask the student to conceive other harmonizations of the same melodies restricting himself of course to the ground forms of the primary 
triads. He will readily think out the following connections of harmonies:-
a) Major: $\left|\begin{array}{ll|ll|l||}1 & 1 & 5 & 3 & 1\end{array}\right|$
Minor: $\left|\begin{array}{ll|ll|l|l|}1 & 1 & 5 & 3 & 1\end{array}\right|$
b) Major: $\left|\begin{array}{ll|ll|l||}5 & 1 & 5 & 3 & 1\end{array}\right|$
Minor: $\left|\begin{array}{ll|ll|l|l|}5 & 1 & 5 & 3 & 1\end{array}\right|$

The student is to work out all these exercises in four voices both in close and open harmony. Present the chord-forms 6 and ${ }_{4}^{6}$ : require the student to introduce them in these same exercises placing the thoroughbass numbers under the notes of the melody. He will easily produce the following conceptions:-

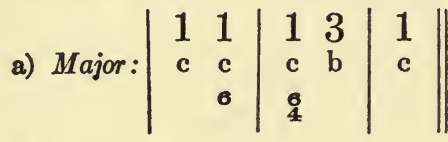
Minor: $\left|\begin{array}{ll||ll|l}1 & 1 & 1 & 3 & 1 \\ \text { a } & \mathrm{a} & \mathrm{a} & \mathrm{g} \# & \mathrm{a} \\ & \mathrm{b} & \mathrm{b} & & \end{array}\right|$
b) Major: $\left|\begin{array}{ll|ll|l||}1 & 5 & 1 & 3 & 1 \\ \text { c } & \text { c } & \text { c } & \text { b } & \text { c } \\ & & 8 & & \end{array}\right|$
Minor: $\mid$\begin{tabular}{cc||cc|c}
1 & 5 & 1 & 3 & 1 \\
a & $\mathrm{a}$ & $\mathrm{a}$ & $\mathrm{g}$ & $\mathrm{a}$ \\
& & $\mathrm{a}$ & &
\end{tabular}

When the secondary triads are introduced the student will soon find the right place for the submediant in the same melodies as follows: See asterisks.

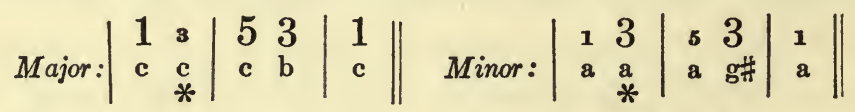

These illustrations suffice to show the practical value of our harmonic numbers as here applied to melody, the natural and all-potential harmonic voice of music. Both when they indicate harmonic selfreports or percepts and when they indicate selective harmonic reports or concepts, they directly explain and interpret the true meaning of harmony to the 
student's musical understanding. In fulfilment of an inherent law, melody evolved the chord. Nature has bountifully endowed the student with a keen sense of that inner law and of that concomitant harmony always reported by and inseparable from melody. The genesis and development of harmony being due to melody it lies in the nature of things that the study of harmony is the study of the harmony of melody, in a word, of meloharmony.

At the outset the student's inner consciousness and experience of music assumes but one tangible and graspable form, melody. Nature's gift to the student is an inborn appreciation of melody, the power to follow and remember a melody as a connected whole and therefore the power to turn it over and over in his mind as he selects this or that series of chords and musically reflects upon this or that way of leading the voices. Given a melody to harmonize, the student sets out with the one thing he can mentally grasp; he perfectly comprehends the subject of his work and therefore also its object. Having a tangible subject he has a tangible object; his melody is his preceptor and guide in his choice of harmonies, explains to him why now a root or fifth or third is doubled, why a bondtone is now tied and now not tied, why an upleader is sometimes not resolved but led downward and why the downleader is often treated in a like manner; in short, he thinks and hears everything in relation to and from that melody, which is the key to the whole situation. Harmonic numbers over a given melody appeal to the student's musical intelligence and reason. Roman numbers under a given bass do not. The 
principles of music are inherent in and assert themselves in a melody. This cannot be affirmed of a given bass except when the melody is presented in the bass. Thus guided through melody to a clear perception of the operation of these rhythmo-harmonic principles, the student is prepared to appreciate that rules apply to specific cases and not to all cases.

Teachers will find no difficulty in preparing working-material for students in the form of given melodies in which the usual chord-material is progressively introduced. Besides presenting melodies with and without harmonic numbers it will be found useful to require students to conceive a few melodies of their own which shall embody the material of each lesson. It is also suggested that the work should introduce a greater variety of rhythmic forms than is usual. Exercises in the earlier stages should include the two forms of dual subrhythm or measure, light-heavy, heavy-light and the three forms of triple subrhythm or measure, light-light-heavy, light-heavy-light, heavy-light-light. In later stages, compound and even mixed subrhythms should be introduced. In preceding chapters I explained the original and inseparable correlations of rhythm (form and relation in time) and harmony (form and relation in space) of rhythmic accents and harmonic forms. These correlations obtain in selective harmony as well as in selfreported harmony, and it follows that the study of rhythm is as essential as that of harmony. A series of harmonies occupies a series of rhythm-periods; the former cannot be understood apart from the latter. Its rhythm is the foundation of a music-concept or 
melody. A familiar melody is recognized when its rhythm is tapped by the fingers. Melody is intoned rhythm. Change its rhythm and you produce another, a different melody out of the same series of tones. It is unscientific and untrue to speak of such a changed melody as the same melody in another rhythm. In forming his concept of a melody let the student begin at the bottom by exaggerating the emphasis of its rhythm. Then let him intone the rhythm. The exaggerated emphasis will then plainly report the concomitant harmonies in his mind and guide him to a satisfactory result in his selective harmonization of the melody.

There are other advantages of exercises in given melody which do not exist in those of the given bass. I will stop here to point out only one. It is this. Given melodies may be presented in every voice, not only in the soprano, but in the bass, tenor and alto as well. In all these voices the student will comprehend the melody equally well, and such exercises in each of the four voices may be presented from the start. It may be objected that such exercises will infringe upon the exclusive and erudite domain of simple counterpoint. Yes, but why not? After all, is that domain either so exclusive or so erudite as tradition would have it appear? In all forms of counterpoint does not each tone in each voice report a root or third or fifth or seventh or ninth, a consonance or a dissonance? After all is said of the basic importance of its rhythm, is not all counterpoint a question of harmony, of regnant harmony and byharmony, of regnant tone and bytone? The study of counterpoint as an evolutionary 
chapter in history is one thing; the study of counterpoint as an art to be mastered or a necessary part of music education is quite another thing. This art of acquiring independence in the use and selection of materia musica in the simpler contrapuntal forms should not be put off until the student has worked his way through an entire textbook on chords. The conventional cantus firmus is but a melody, and everything that is to be added to the melody lies in it and grows out of it. The sooner such work is begun the better. Let A, B, C indicate the order of conceptive work dealing with a cantus. A: think the rhythm with exaggerated emphasis. B: intone the rhythm. $\mathrm{C}$ : harmonize the intoned rhythm. Such a concept is synthetic and complete since B is inseparably associated with $\mathrm{A}$, and $\mathrm{C}$ with both $\mathrm{B}$ and $\mathrm{A}$. Now that we have discovered in one voice both the origin of harmony and the fundamental principles of music, now that we can positively affirm that melody is not an element but an indissoluble composite of rhythm and harmony reporting in one voice now a consonance and now a dissonance and that music had its genesis in this composite voice of united rhythm and harmony, now that we are able to view and study the material of music in the light of its origin and can trace its development since we can learn from the harmonic self-reports of homophonic melodies what nature has done and from selective harmony what art has done in the evolution of both rhythmic and harmonic material: it follows by implication that the entire rhythmoharmonic materia musica both as applied in art and in textbooks stands forth in a wholly new light. A 
young child may now gain as perfect an intellectual grasp of the rhythmo-harmonic form and content of a melody as that of his teacher. Each step in such analysis renders clearer and deeper the child's musical appreciation, since it directly reports and causes the child to realize the purely musical content of a melody. The child sets out with a purely sensory perception and appreciation of melody: through rhythmo-harmonic analysis this perception and appreciation are elevated from that lowest domain of mere sensation to the higher and alone dignified domain of the intellect. Thus a little musical savage is at once metamorphosed into a little intelligent musician. From $A$ to $Z$ the study of music is the study of the rhythm and harmony of melody. Thus from the start our youngest students may not alone really study but may really study music itself, may begin and continue with the study of melody, its rhythm and its harmony. Young students may learn to appreciate and perform their little pieces by Bach, Mozart and Beethoven with the same adequate intelligence and consummate art with which mature artists produce the more complex works of these masters, in short, so far as he goes the student may be an intelligent musician and a true artist. Theory and practice may be united from the start, their separation is a thing of the past. The intellectual appreciation and enjoyment of music may in consequence spread far and wide and need no longer be regarded as an exclusive possession of the enlightened few. Than music no art is more accessible and democratic, therefore less esoteric. 



\section{BIRD SONGS}





\section{BIRD SONGS}
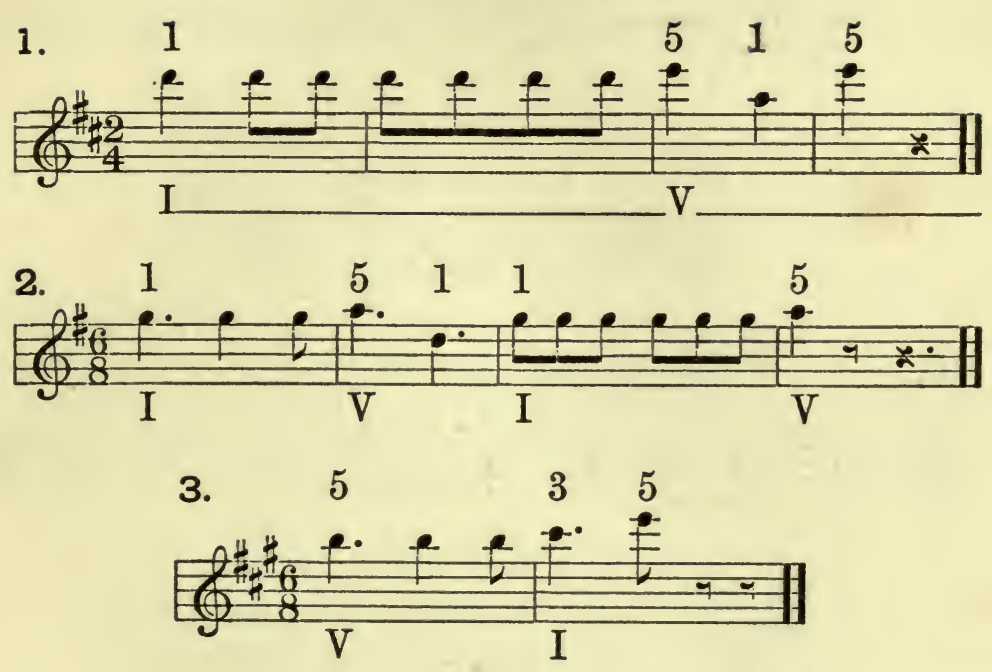

4.
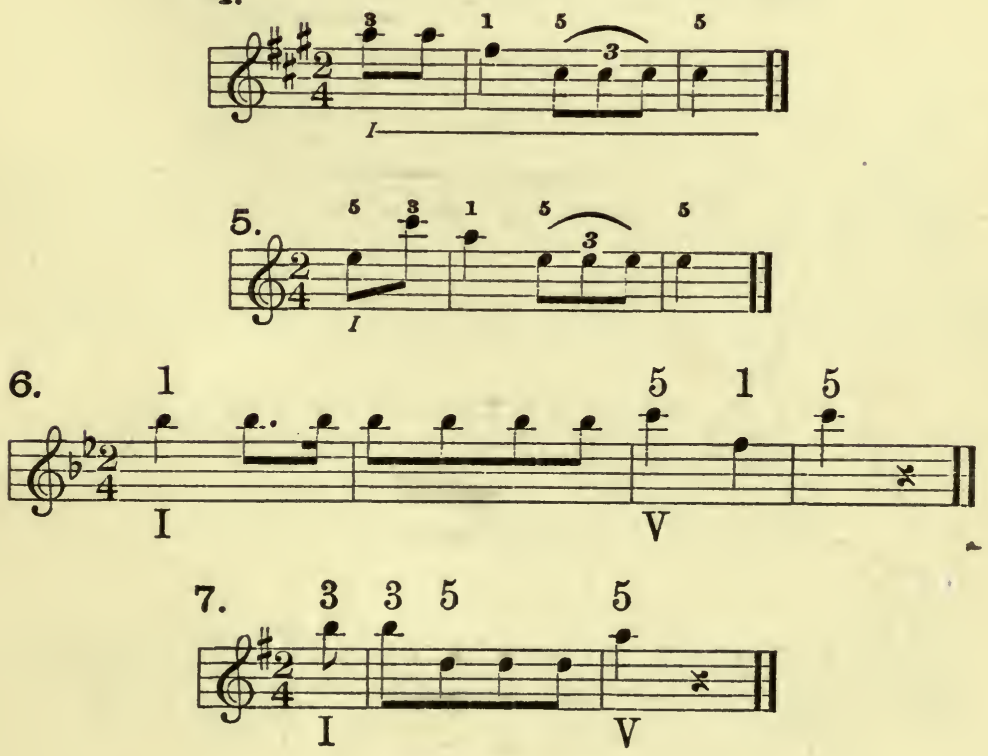
294

- THE NATURE OF MUSIC
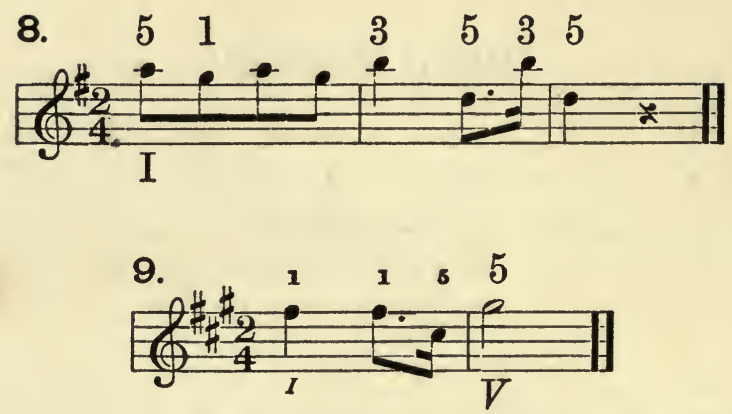

10.

Minor

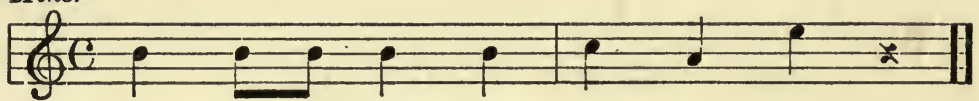

11.

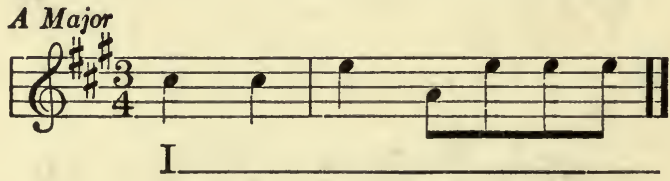

12.

A Major

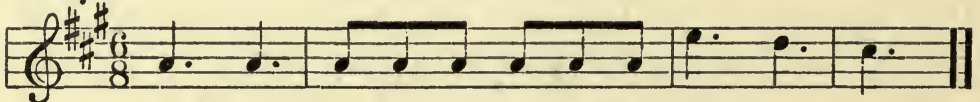

13.

Minor

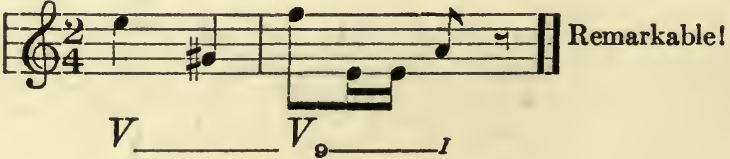

14.

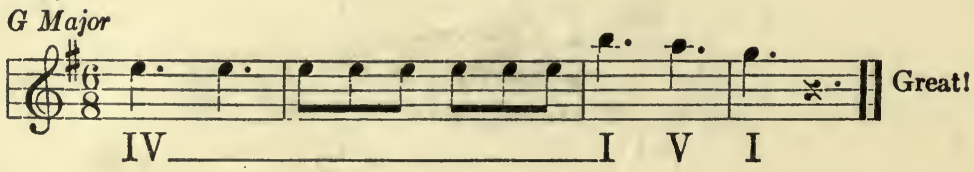


15.

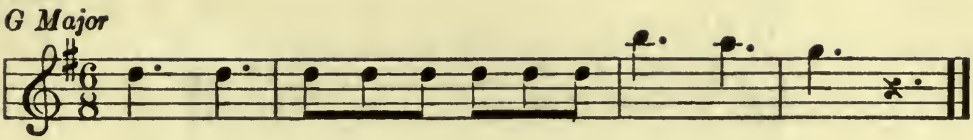

16.

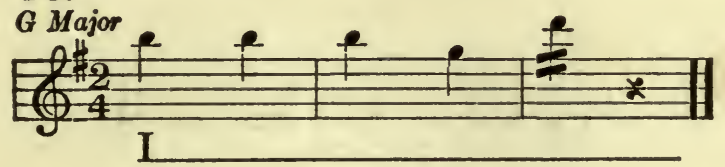

17.

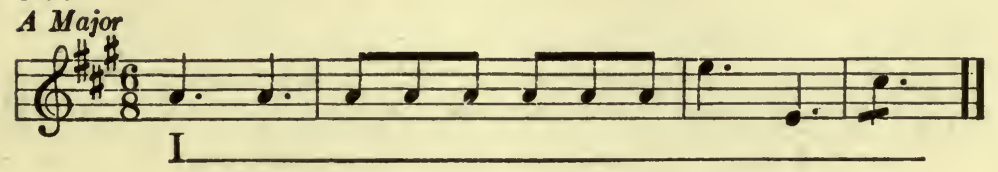

18.

A Minor

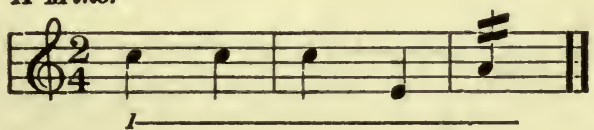

19.

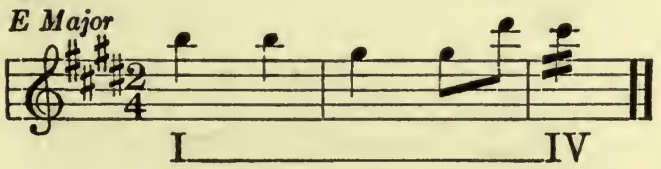

20.

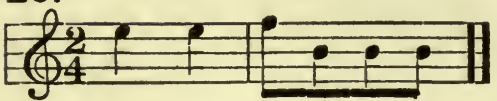

21.

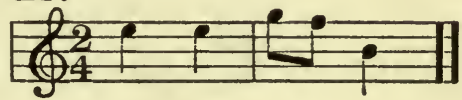

22.

A Major

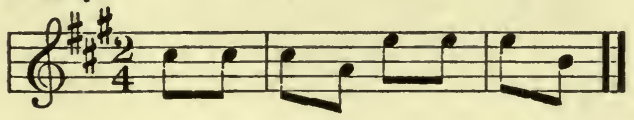

23.

D Major

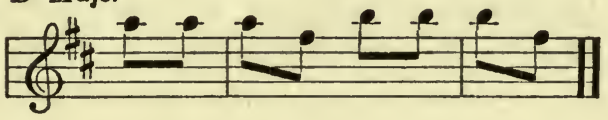


24.

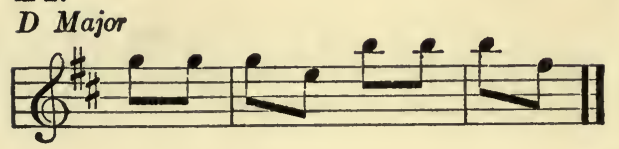

25.

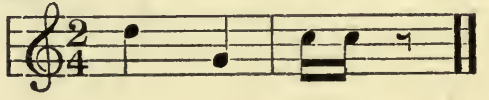

26.

A Major

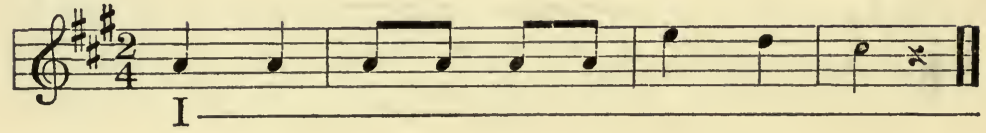

27.

A Minor

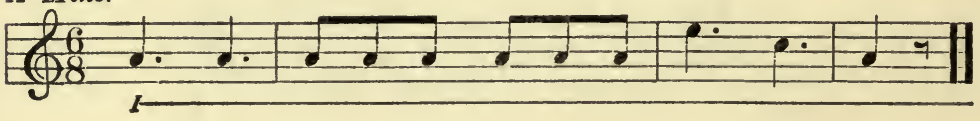

28.

Key of $G$

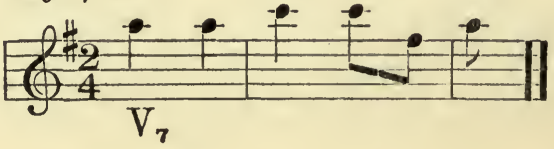

29.

Key of $G$

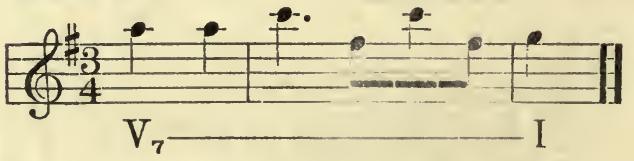

30.

Key of $G$

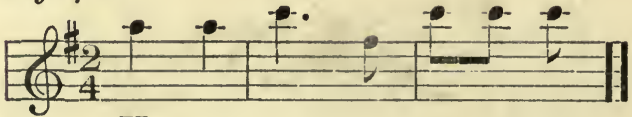

$V_{7}$ 
31.

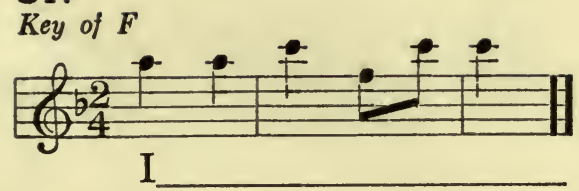

32.

G Minor

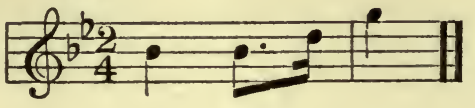

33.

A Minor

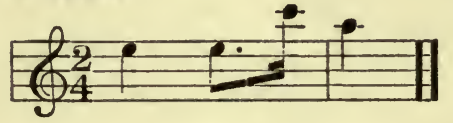

34.

F Major

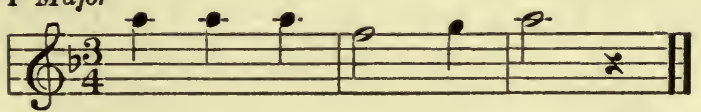

35.

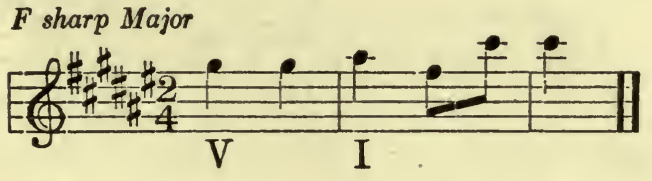

36.

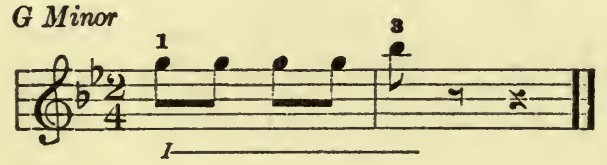

37.

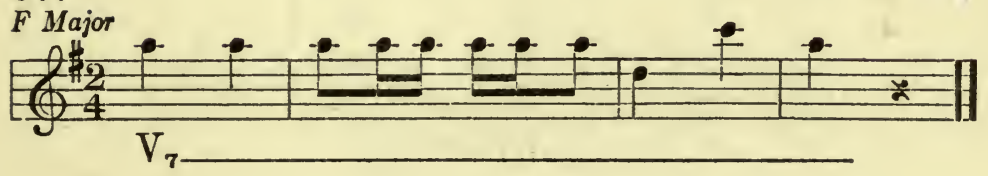


38.

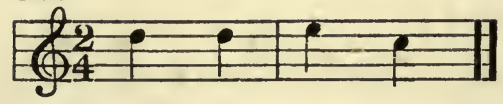

39.

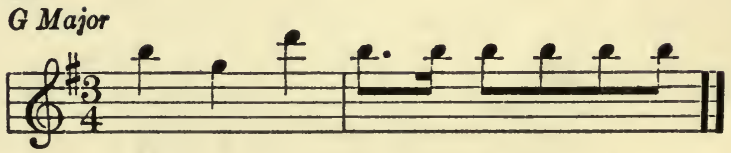

40.

F sharp Minor

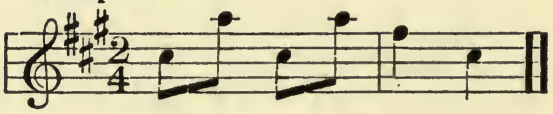

41.

F sharp Major

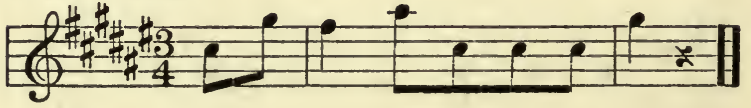

42.

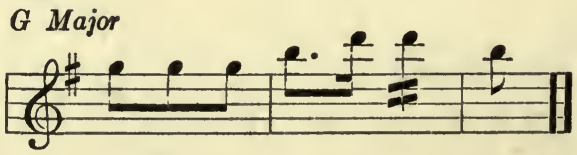

43.

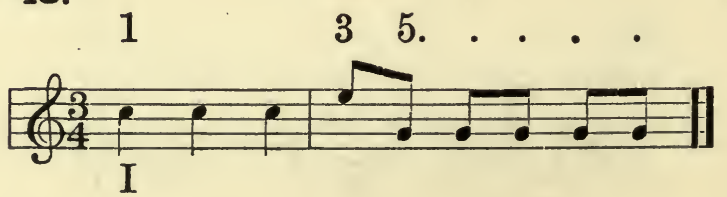

44.

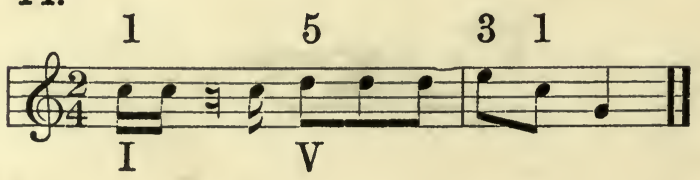



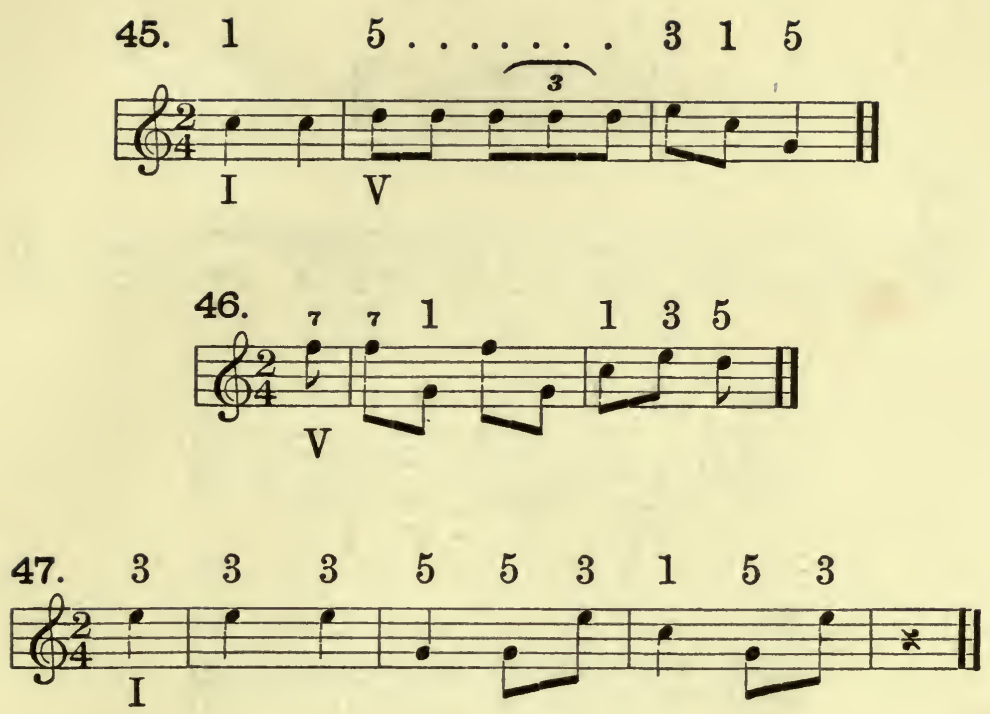

48.
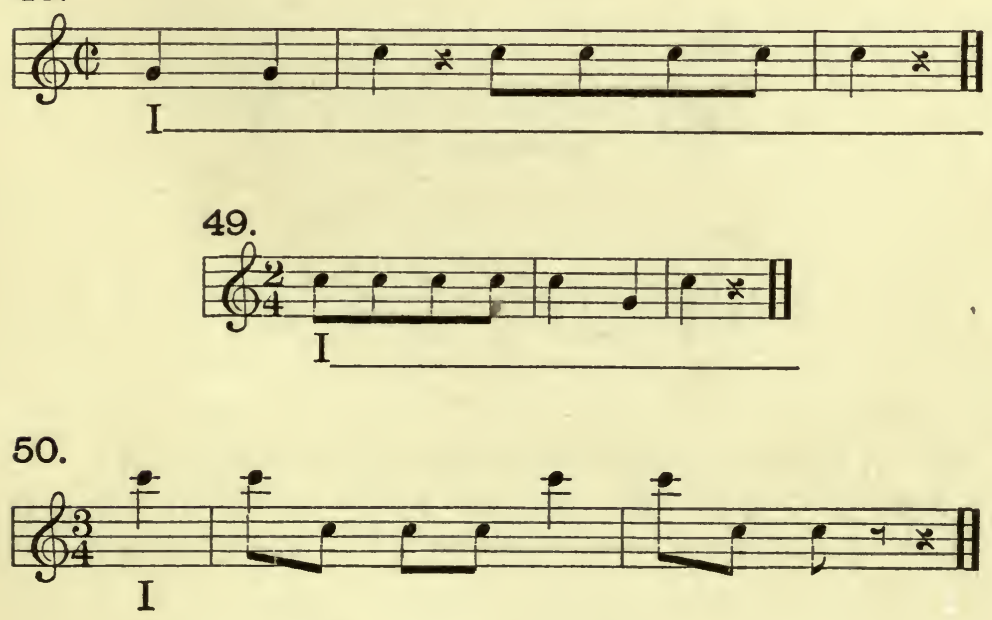

51.

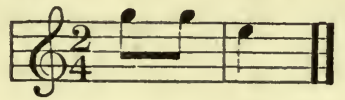


300

THE NATURE OF MUSIC

52.

8

53.
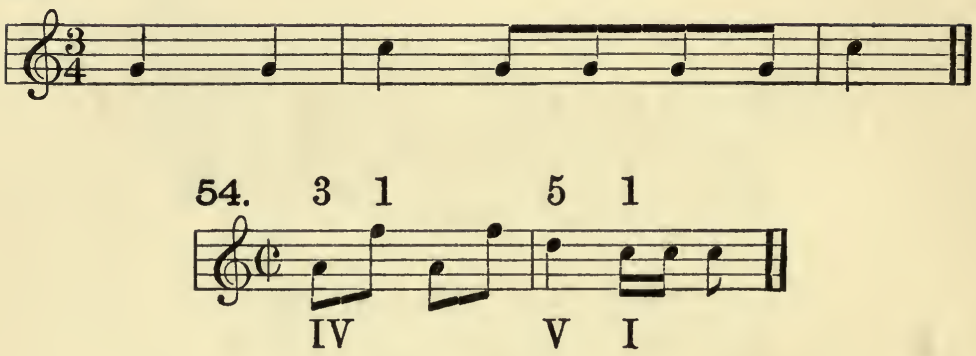

55.

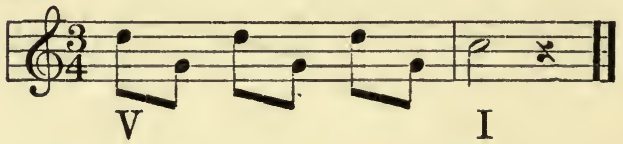

56.

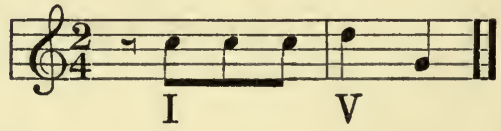

57.
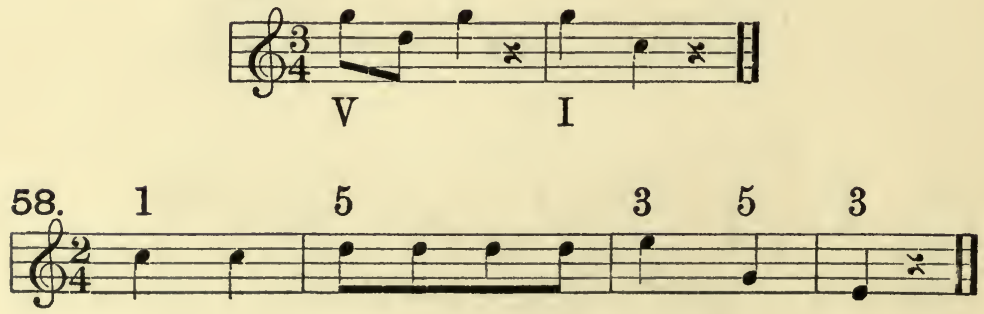

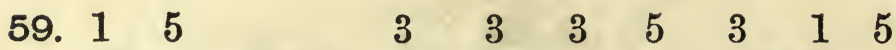

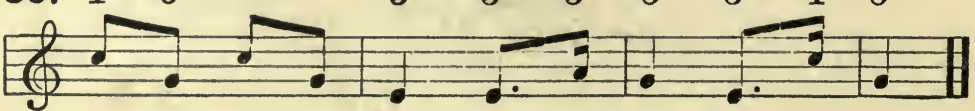


60.

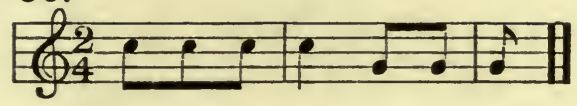

61. $3 \quad 3 \quad 5$

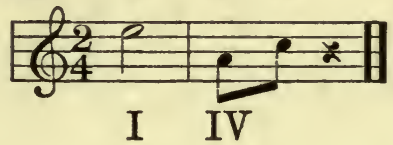

BIRDS OF IDLEWILD. 1903
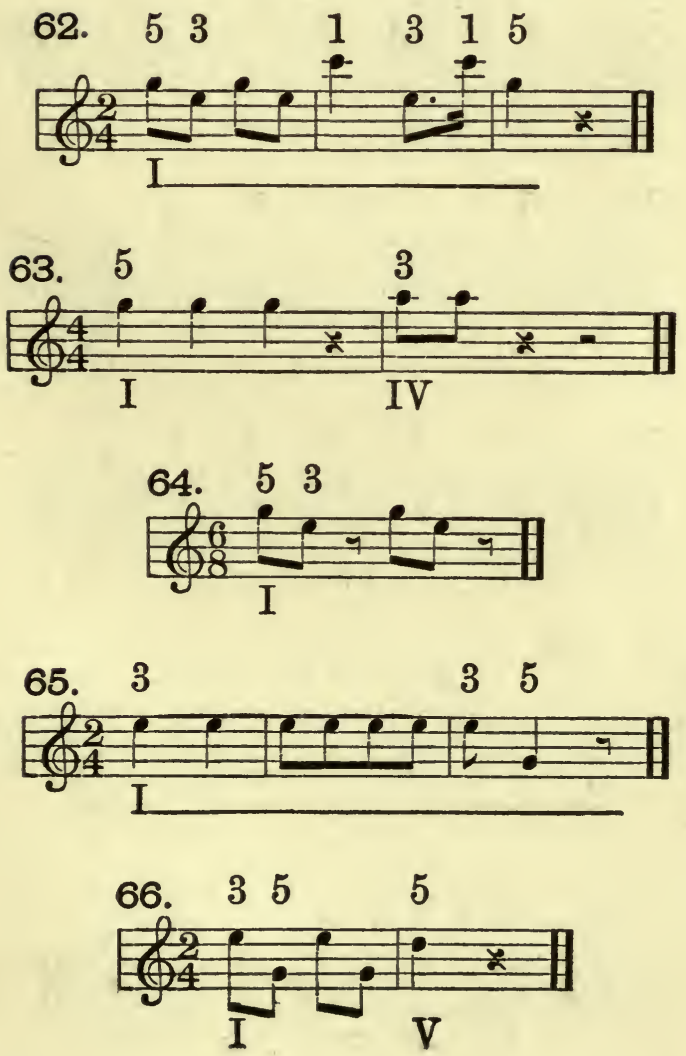
302

THE NATURE OF MUSIC
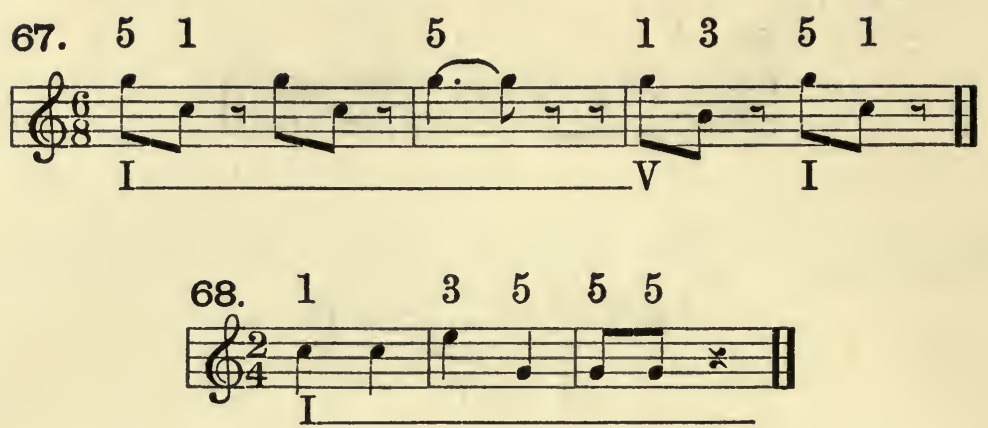

69. $\quad 5 \quad 3$
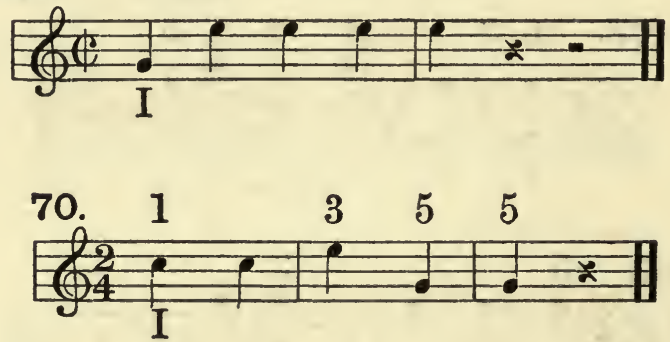

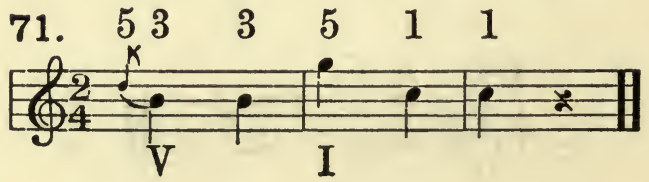

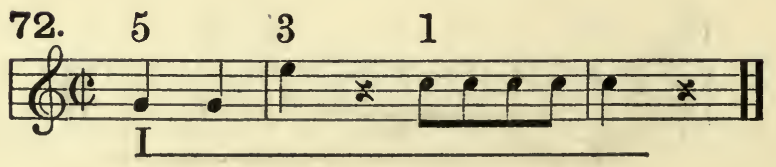

73. $\begin{array}{llllllll}5 & 1 & 5 & 1 & 3 & 5 & 3\end{array}$

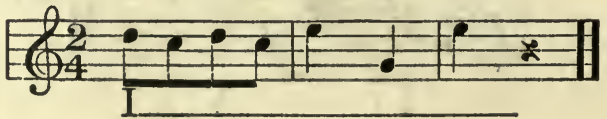



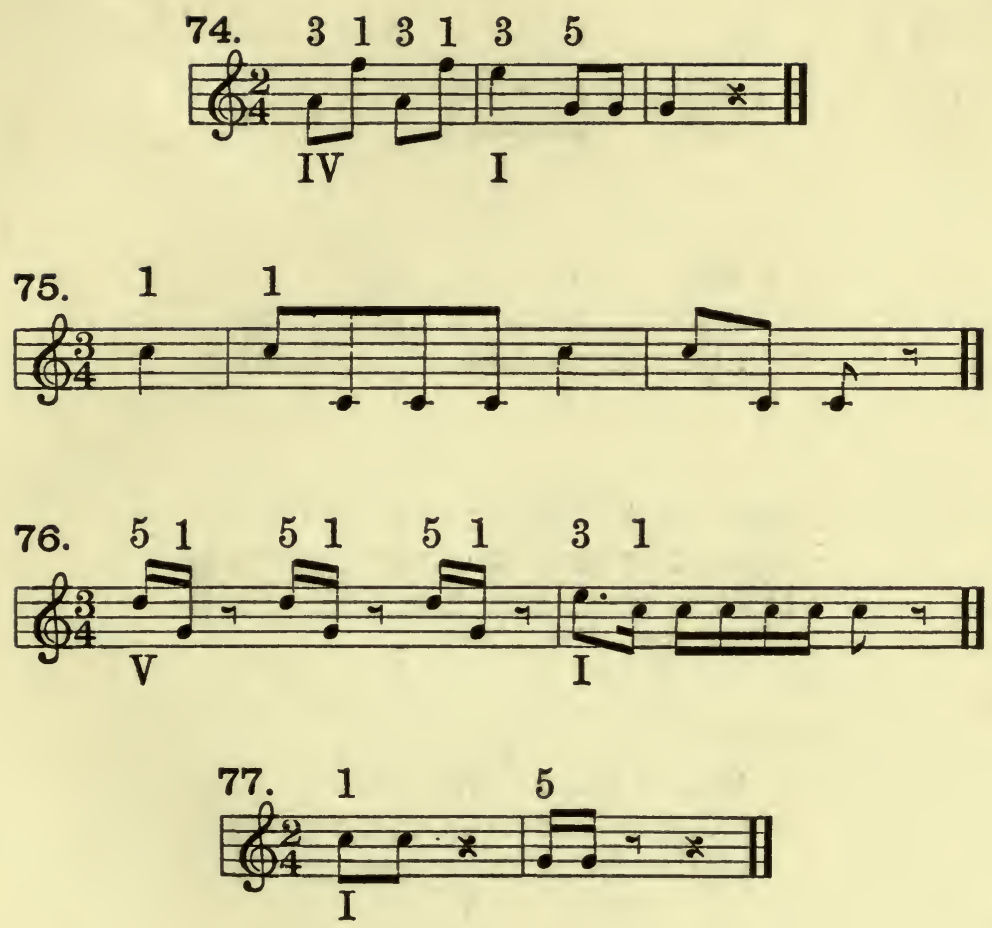

78.
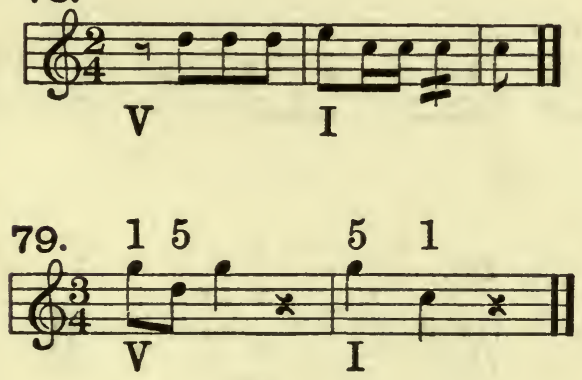

80.

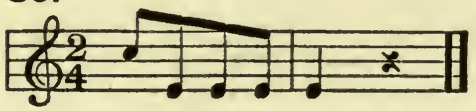


304

THE NATURE OF MUSIC
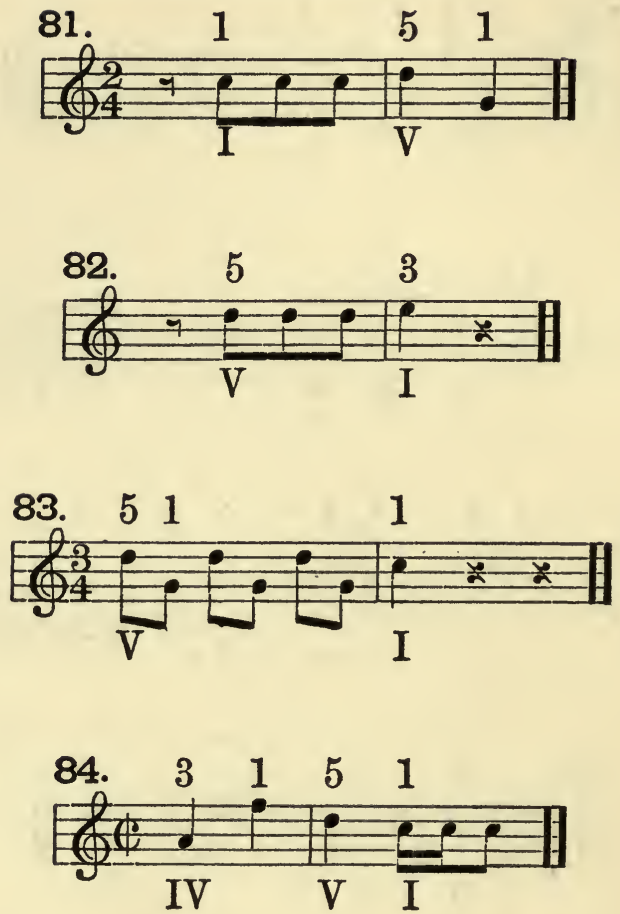

85.

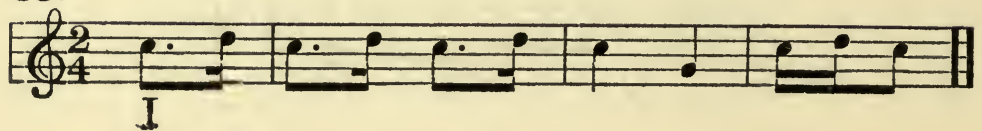

86.

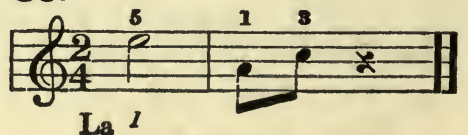




\section{EXPLANATION OF SYMBOL NUMBERS}

Roman $=$ major mode

Italic $=$ minor $\quad$ "

large $=$ major harmony or chord

small=minor " " "

large, crossed = augmented chord

Arabic $=$ harmonic or interval

e. $g . \mathrm{V}=$ major dominant harmony or chord of major mode

II = minor supertonic chord of major mode

$V=$ major dominant harmony or chord of minor mode

$V=\operatorname{minor}$ " " " " " "

$\mathrm{XX}=$ augmented mediant chord of minor mode

$5=$ fifth of major harmony

$s=$ " " minor 



\section{INDEX}

ACCENT, 31, 42-44, 99, 120; efficient, $24,25,27,54,55,95,102,105,108$, $109,112,113,117,125-127,130-133$, $149,176,178,188,194,206,218$, 219; measure, 149 ; relative, 43,44 , 99 ; rhythmic, $12,32,46,53,107-109$, 286; rhythmo-harmonic, 25, 105; syllabic, 149 ; time-, 32.

Acoustic numbers, 227.

Acoustic series, 20, 227.

Acoustic theory, 230.

Acoustics, 17, 227; laws of, 244; physical, 4, 19, 20, 21, 70; psychological, 19.

Fsthetics, 10, 21, 22, 75.

Alto, 278.

Ambrosian melodies, 147.

Analysis, acoustical, 9; of feeling, 9; harmonic, 58, 68, 83, 116, 137, 235, $250,259,265,272,274,275$; of $\mathrm{mu}-$ sic, 28; rhythmo-harmonic, 289.

Aristides, 148.

Aristotle, 148.

Aristoxenus, 148.

Arnold, Matthew, 175.

Bach, 5, 86, 98, 118, 146, 170, 174, 175, 196-198, 289.

Balance, 13, 31, 32, 42, 152, 162; perfect, $33,41,44$; relative, 44 ; rhythmic, 31, 32.

Balanced motion, 10, 30, 33, 38, 162.

Balanced sound, $30,33,38$.

Balanced time-periods, 32 .

Bass, fundamental, 277-279; given, 279-285, 287; thorough, 259, 267, $269,270,274$.

Beat, 130, 163, 168.

Beat-periods, 160, 162.

Beethoven, 5, 132, 146, 150, 170, 174, 175, 212, 213, 266, 276, 289.
Berlioz, 49, 171.

Biads, 245-247, 251-253; compound, 245-256; in minor, 248, 255, 256; parallel, 255.

Bird-melodies, 116.

Bird-songs, 56, 58, 59, 61, 171, 176.

Bond-tone, 63, 76, 122, 123, 132, 136, 190. 193, 235, 277; original, 122.

Brahms, 49, 171.

Bychord, 141.

Byharmony, 106, 109-113,116,117, 126, 127, 141, 187, 205, 287; relative, 111.

Bytone, 106, 107, 109-113, 116-123, $126,127,132,194,198,199,201$, 203, 204, 206-210, 255, 256, 261 ; diatonic, 118-120; report (harmonic, self-) of, 118, 119, 219; =(tone-cadence), 121.

Cadence, 29, 54, 56, 69, 103, 122, 129 , $142,177,180,206,208,211,214$, 216, 223; closing, 123; double, 136, 192; falling, 92, 97, 136, 187, 190; five original cadences, 91-96; harmonic, 130, 131, 133; original, of Minor Mode, 185-198; prototype, 185, 192; rhythm-, 42-45, 50, 53, 67, 111, 120, 121 ; rising, 92, 97, 136, 275 ; single, 136 ; thread of harmony, 54 ; tone-, $45-48,55,86,91,121$.

Cadence-chord, 99.

Cadence-harmony, 45-48, 58, 62, 111 ; original, 45-47; genesis of, 61-67. Cadence-moment, 42, 44.

Cadence-relation, 113.

Cadence-repose, 43, 53.

Cadence-tone, 46, 47, 57-59, 61-66, 92, 96-100, 106, 107, 113, 135, 136, 191, 192, 235, 257; (prototype), 191, 194, 208; (original), 46, 92, 98, 106, $135,136$. 
Calls and cries, 56.

Canon, 181.

Cantata, 157.

Canticle, 157.

Cantus-firmus, 288.

Cardinal principle, 15, 21, 24, 28, 162.

Carlyle, 159.

Chant, antiphonal, 181; primitive, 165 .

China, 16, 17, 212.

Chopin, 169, 171, 212.

Chord, 3, 4, 11, 20, 37, 49-51, 61, 62, 71, $73,84,90,92,102,104,134,135,137$, $143,149,191,209,231,233,234,236$, 266 , 278-280, 284, 285, 288; augmented, 249, 262; cadence-, 99 ; components of, 89, 91, 242, 245, 259; compound, 90, 141, 237, 240, 243245, 248, 255-257, 259-263, 272, 274; consonant or dissonant, 232, 245; derived from the original consonance and dissonance in one voice, 133-141; from the minor forms of consonance and dissonance in one voice, 231-236; diatonic, 202; diminished seventh-, $234,239,240,260$; diminished-diminished seventh-, 240; diminished-, small seventh-, 240; dissonant, 144, 232, 245; dominant-seventh-, 84, 239; double, 211, 212; fourth-sixth-, 238; ground-seventh-, 240; harmonic report of, 138, 139, 141, 234, 245, 259, 266; large ninth-, 240-242; large third-, 249; major, 227; major-small seventh-. 239; major subtonic-seventh-, 239; major tonic-seventh-, 255; minor, 177, 227; minor ninth-, 139, $140,141,234,240-244,247,275$; minor subtonic-, seventh-, 239; minor tonic-seventh-, 255; ninth-, 240-244; passing, 275 ; primary, 133, 248; repose-, 99 ; secondary, 248; secondary ninth-, 256; secondary seventh-, 253, 255, 268; self-reports of a, 233, 234, 247, 255 ; seventh-, 84, 139, 140, 234, 238-242 244, 247, 253, 255, 256, 260 , 268-270; simple, $90,141,144,243-$ $245,248,249,251-253,256$; simple and compound, defined, 243-276; sixth-, 238; small ninth-, 240-242; subdominant-seventh-, 254; submediant-seventh-, 254, 256; subsecond-, $261,262,265$, 267-270; subtonicseventh-, 235, 254; supersixth-, 261264, 267-271; supertonic-seventh-, 254 ; tone-, 86 ; tonic-, 66.

Chord-analysis, 68, 135.

Chord-basis of harmony, 69.

Chord-building, 140, 244.

Chord-cadence, 99, 136.

Chord-conception of harmony, 86 .

Chord-concepts, 91.

Chord-fifth, 234, 238, 240, 241, 248, 275.

Chord of the fifth-sixth, 240 .

Chord-forms, 71, 72, 135, 139.

Chord-harmony, 68-74, 147.

Chord-intervals, 89-91, 136, 137, 232, 237, 249.

Chord of the major ninth, 84.

Chord-material, 233, 277, 278, 282, 286.

Chord-ninth, 275.

Chord-position, 240-243, 266.

Chord prototype, 140.

Chord-root, 135, 136, 140, 232, 234, 237-243, 245, 248, 249, 258-261, 268, 274, 275, 278.

Chord of the second, 240.

Chord-seventh, 268, 275.

Chord-sixth, 248.

Chord-structure, 242, 257, 261, 263, 264, 265, 268, 271, 272.

Chord-theories, 89, 230.

Chord-third, 234, 238, 240, 241, 248, 274.

Chord of the third-fourth, 240.

Chord type, 239.

Chromatic, 39, 59, 93, 124, 132, 187, 190, 193, 201-204, 215, 219, 220, 221.

Chromatic scale-system, 95.

Classics, 49.

Composer, 75, 104, 150, 157, 159, 171 , 172, 175, 217, 261. 
Concept, 26, 44, 62, 78, 79, 139, 179, 181, 284, 287, 288; harmonic, 76, 91; music, 286.

Concerto, 146; piano-, 276.

Concomitants, 34, 37, 40, 45, 59, 62, 75, $79,113-115,117,124,131,140,148$, 149, 193, 194, 202, 206.

Confucius, 16.

Consonance, 4, 7-9, 18-21, 26, 27, 45, $50,53-56,61-64,66-69,75,77,85$, $86,102,112,113,115,117,120,124$, $125,127,133,141,148,165,178,189$, $192,205,214,222,223,287,288$; major, 7, 33-36, 40, 41, 45, 46, 55, $91,95,111,124,176,177,179,180$, 190, 204, 217, 219, 221-223; minor, $59,91,177-180,183-185,190,201$, 203, 214-218, 221-223, 231 ; origin of minor, 176-184; prototype, 95, 124, 133, 184, 185, 221, 231.

Consonance thread, 37, 143.

Cotta edition, 276.

Counterpoint, 287.

Dance, 4, 43, 116, 172.

Diatonic, 192, 220, 221 ; seven, 46, 75, $85,94,117,122,141,142,144$.

Diatonic bytone, 118-120, 208, 210, 218.

Diatonic cadence, 98, 99.

Diatonic chord, 202.

Diatonic division of octare, 95.

Diatonic harmony, 124, 125, 201, 203, 205, 216-218.

Diatonic major relation, 123, 134.

Diatonic major triad, 133.

Diatonic melody, 99.

Diatonic minor, 201-203, 235.

Diatonic minor melody, 202, 216.

Diatonic scale, 144.

Diatonic scale-system, 95.

Diatonic stage of tonality, 95 .

Dissonance, 4, 7, 8, 18-21, 26, 27, 45, $50,53,69,75,86,112,113,115,116$, $123-125,133,141,148,149,180,189$, 205 , 287, 288; acoustical, 9; fivetone, 95,221 ; four-tone, 95,117 ,
221 ; genesis of, 103, 120; genesis of original, in one voice, $61-67$; latent feeling of, $46,54,55$; major, 124, 180 , 190, 209, 214, 222, 223, 231 ; minor, $185,188,190,198,214,222,223,231$; one voice, $7,62,68,91,102$; origin in one voice of the minor form of, 185198 ; original, $9,35,55,77,85,91$, 103, 111; prototype, $95,124,134$, $185,188,221$, 231 ; regnant, 127, 128.

Dominant, major, $47,63,67,77,188$, $189,206,207,239,249,262$; major ninth of, 76, 82; major third of, 76 , 82; minor, 201, 216-218, 262; minor seventh of, 76 ; prototype, 206; pure fifth of, 76, 82; regnant, 188, 207, 210; regnant minor, 188, 206-218; rhythmic, 120; small ninth-chord of, 275.

Dominant-fifth, 76.

Dominant-harmony, $58,60,61,65,75$, $77,83,84,90,93,108,183,187-189$, 198, 249.

Dominant-ninth, 76.

Dominant-root, 76, 81, 88, 89.

Dominant-seventh, 76.

Dominant-seventh-chord, 84, 239.

Dominant-third, 76.

Dominant-thread, 47, 82, 84 .

Dominant-triad, 84, 235, 249.

Dorian scale, 229.

Downleader, 62, 64, 92, 95, 183, 285; chromatic, 275; prototype, 95, 192.

Drama, 156, 157.

Dreiklang, 269.

Drum, 165, 166.

Duplicates, 27, 71, 184, 185, 221, 231. Dynamics, 125.

Ear, 20, 73, 44, 77, 78, 86, 260, 268.

Ecclesiastical melodies, 116.

Ecclesiastical music, 148.

Elements, 2, 6, 41, 44, 50, 67, 74, 79, $130,150,176,180$; concurrence of, 129; succession of, 129; union of, 6 , 8.

Elements of music, 3, 7, 23, 48, 56 . 
Elevenths, 89, 93.

Enharmonic harmonies, 271, 274.

Enharmonic scale-system, 95.

Enharmonic stage of tonality, 95 .

Equilibrium, 10-14, 21, 24, 28, 30, 31, $33,41-43,48,51,112,113,151,153$, 164 ; cardinal principle, 36,162 ; = (harmony), 10-15, 30; harmonic, 125; relative, 133; rhythmic, 125 ; rhythmo-harmonic, 125 ; = shaping principle, $10,11,24,41,51,120,130,195$; stable, $43,54,67,116,127,178$; unstable, 43, 54, 67, 116.

Evolution, 1, 4, 5, 13, 15, 16, 39, 56, 70, $94,96,103,104,110,130,176,177$, 193, 215, 223-225, 233; harmonic, 40-42, 104, 225.

Evolution of perception, 52, 165.

Expansion of subrhythm and rhythm, 160-175.

Eye, 73, 74, 260, 268.

Feeling, 26, 34, 36, 40, 41, 44, 60, 68, $72,79,80,178,184$; (common, common music-, music-), $2,5,6,8-10$, $13,15,16,18-21,24,28,29,32,33$, $35,37,43,45,51-53,62,66,69,76$, $78,86,88,91,104,108,139,140,147$, $153,161,176,179,181,197,226,228$; common report of common, 17-22, 108, 147; rhythm-harmonic, 278; tone-rhythmic, 10, 11, 12.

Feeling of cadence, 62.

Feeling of dissonance, $46,54,55$.

Feeling of music per se, 7, 9, 22.

Feeling of rhythm, 33.

Feeling of repose, 62.

Fifth, 25-27, 29, 30, 35, 37, 40, 41, 47, $59,60,63,67,84,85,89,108,123$, $138,140,179,187,200,206,217$, 285, 287; chord-, 234, 238, 240, 241, 248 , 275; consecutive, 277 ; diminished, 137, 234; harmonic, 135, 234; large, 223, 224; parallel, 131; pure, $34,36,61,76-78,81,82,120,137$; small, 223.

Folk-melody, 172, 174.
Folk-song, 4, 15, 16, 77, 79, 81, 84, 116, 172.

Form, 5, 7-15, 17, 21, 24, 28, 49, 51, $66,68,70,75,79,83,85,89,90,99$, $103,104,133,134,145,155,160-162$, $165,167,170,171,173,178-180$, 206, 216, 217, 219, 220, 221, 224, 232, 234 ; chord, 71, 72; classic, 160 175 ; elemental, 20, 22, 30; harmonic, $4,8,9,10,23,25,30,33-35,41,42,45$, $48,50,62,67,73,83,93,111,112$, $122,124,129,139,182,214,233$, 286 ; prototype of harmonic, 95 ; original harmonic, 26, 95 ; rhythmic, 23 , $32,44,50,111,129,130,164,168$, 286; rhythmo-harmonic, 24, 279, 288 ; space-, 14; time-, 14; tone-rhythmic, 8; universal, 7, 12, 43.

Form of consonance, 7, 8, 53, 116, 125, 184, 185, 204. 205, 214, 222, 223, 231.

Form of dissonance, 7, 8, 53, 116, 125 , 214, 222, 223, 227, 231.

Form of regnant minor dominant, 216218.

Form in space, 13, 104.

Form in time, 13, 104.

Fourth, 36, 59; augmented, 138; pure, 137, 138.

Fugue, 181.

Fugue-subject, 118.

Fugue-theme, 198.

Fundamental bass, 277-279.

Fundamental forms of harmony, 85. Fundamental forms of tone, 53.

Fundamental principles, 8, 175, 288.

Gevaert, 146.

Given bass, 285-287.

Goethe, 11, 14.

Greece, 16, 17.

Greek melodies, 146-149.

Greek modes, 145, 146.

Gregorian chants, 148, 149.

Gregorian melodies, 147.

Harmonic, 34-36, 41, 45; compound, 90,263 ; concomitant, 59, 62; double, 
211, 248; elementary, 35, 37, 40, 41, 193 ; simple, 90, 263.

Harmonization, 74, 149, 156, 287.

Harmony, 1-7, 9, 13, 19, 20, 21, 24, 33$35,49,51,52,63,75,76,79,86,90$, $93,99,103,120,122,129,135,136$, $138,142,144,150,154,156,158$, $159,171-173,177,178,185,189$, $190,197,199,206,210,213,215$, $217,218,221,226,242,243,248$, 256, 269, 279, 283-289; acoustic theory of, 230 ; basis of, $33,68,69$, 102; cadence-, 45-48, 58, 62, 111; chord-, 68-74, 147; chromatic, 201, 202, 205, 219, 220, 271; compound of, $263,265,266,270$; concomitants of, 131, 140, 148, 149, 202, 211, 224, $284,285,287$; = (consonance), 91 ; contrapuntal, 70 ; diatonic-, 118, 124, $140,201-203,205,216,218$; = (dissonance), 91 ; dominant-. $58,60,61$, $65,75,77,83,84,90,93,108,183,187-$ 189, 198, 249; double, 211, 212; duplicate forms of, 184, 185; = equilibrium, 10-15, 30, 150, 151 ; enharmonic, 271, 274; expansion of, 77, 110 ; evolution of, 103, 176, 224, 233; five components of, 89-91; genesis of, 54, 102, 109; homophonic, 70, 102, 105, 205, 229, 230 ; major, 185 ; major tonic-, 54-57-61, 64, 65, 91, 98, 105 , $106,183,184,193,229$; minor, 124, 139, 185 ; minor tonic-, 178-180, 184187, 198, 214, 221, 230; multi-voice, 75,147 ; original (in one voice), 4 , $24,25,28,36-40,47,49,50,61,64$, $66-71,73-75,85,87,88,102,104$, $124,133,139-141,147-149,182,184$, 211, 244; original cadence-, 45-47; original forms of, 184-185; personal, 71,283 ; polyphonic, 70 ; potential, 26$27,74,77,110,181$; regnant, 24,25 , $53-55,58,60,65,67,83-85,88,98$, 104-113, 115-118, 125-127, 129-133, $141,149,183,186,188,193,194,198$, $201,208,209,214,220,221,223,224$, 255, 261-264, 267, 268, 272-276, 287; relative, $54,55,111$; repose-, $45-48$, 62,111 ; selective, 286 ; subdominant, $58,60,61,108,198,248$; theory of, 51 ; thread of, $35,37,38,41,54,63,79$, $80,81,84,96,107,109,124,133,134$, $137,139-141,143,178,183,188,193$, 224 ; = tone, 23, 28; tone-rhythmic, 10 ; tonic-, $33,45,54,56-58,60,61$, $64,65,83,84,93,106,179,183,186$, $187,193,214,229,230,249,260$; treatise on, $19,68,244$.

Harmony of sound, 23, 75, 147.

Hauptmann, M. 19, 244.

Haydn, 174.

History, 4, 40, 65, 66, 68, 111, 165.

Homer, 16.

Homophony, 4-6, 7, 68, 102-105, 194, 195, 202, 223, 226, 232-234, 249.

Instrument, 165, 166.

Interval, $36,59,76,88,89,93,96,113-$ $115,138,187,189$; chord-, 91, 137; diminished, 93; evolutionary sequence of, 60; harmonic, 91, 136, 137, 232; major, 75, 139; minor, 75, 139.

Interval of concurrence, 137.

Interval-number, 93, 139.

Interval-relation, 80.

Interval of succession, 137.

Key, 48, 61, 87, 96, 239, 262; fifth related, 123; interharmonic relations of one, 94.

Key-centre, 220.

Keynote, 27, 60.

Key-relation, 60, 88.

Leading tone, 61.

Liszt, 49, 203.

MacDowell, 49.

Major, cadence-seventh-chord, 135; pure diatonic, 203.

Major chord, 227, 232.

Major consonance, 7, 33-36, 40, 41, 45, 
$46,55,91,95,111,124,176,177,179$, $180,190,204,219,221,223$ (original), $35,55$.

Major dissonance, 124, 180, 190, 209, 214, 222, 223, 231.

Major dominant, 47, 63, 67, 77, 188, 189, 206, 207, 239, 249, 262.

Major dominant-harmony, 183, 187, 189.

Major dominant-thread, 235.

Major downleader, 192.

Major harmony, 185.

Major mode, 33, 41, 46, 56, 75, 85, 88, $91,95,124,139-141,176,178,181$, $182,186,187,191,210,214,215$, 236; (prototype), 95, 180, 181, 185, 191, 200, 214.

Major ninth, 76, 77, 82, 137.

Major second, 255.

Major sixth, 36, 138.

Major subdominant, 188.

Major subdominant harmony, 187.

Major subdominant - seventh - chord, 254.

Major subdominant triad, 235.

Major submediant-seventh-chord, 254.

Major subtonic, 253, 256.

Major supertonic triad, 251.

Major tenth, 36.

Major tetrachord, 214.

Major third, 34, 36, 61, 76-78, 81, 82, 120, 137, 138.

Major tonality, 67.

Major tonic, 41, 47, 60, 63, 65, 67, 77, $92,98,103,105-108,111,180,181$, 185.

Major tonic-harmony, 54, 57-61, 64, $65,91,98,105,106,183,184,193$, 229.

Major triad, 90, 133, 237, 251, 262, 268.

Major upleader, 187, 192.

Measure, 168, 286; dual, 161, 168; triple, 161.

Measure-period, 162, 260, 261.

Medicant, 144.

Medicant scale, 146.
Medicant-triad, 248-250.

Meistersinger, 146.

Melody, 1-6, 9, 14, 15, 24, 25, 28, 37, $39,40,41,47-52,54,56,60,64,67$, $71,72,74,78,79,85,91,93,98-100$, $121,124,130,132,140,147,148$, $154,155,172,177,178,180,186$, $187,192,193,197,198,200,202,203$, $205,206,208,209,211,214-217$, 220-224, 276, 280, 281, 284-289; analysis of, 65 ; ancient, 149 ; a composite, not an element, 23, 24; bird-, 116, 183; ecclesiastical, 116; embryonic, 106; folk-, 184; Greek-, 116, 149; homophonic, 6, 24, 215, 223, 227, 230, 233, 288; mediæval, 4; minor, 221; modern, 182; pentatonic stage of, 113; primitive, 64 , 104, 109, 176, 182-184, 225; pure diatonic minor, 216; regnant harmony of, 102-175.

Meloharmonic phrase, 187.

Meloharmonic point, 120, 142.

Meloharmonic resolution, 142.

Meloharmony, 24, 104, 120, 142, 197, 285.

Mese, 148.

Metre, 33, 168.

Minor, 123, 139, 195, 209; imitation of major, 180, 181, 185-187, 200, 205, 214 ; inverted major, 227 ; origin and nature of, 176-184; pendant, 181, 226, 228, 230; pure diatonic, 202, 203, 216; relative, 181.

Minor cadence, 180, 192.

Minor cadence-tone, 186-188.

Minor consonance, 59, 91, 177-180, $183-185,190,201,203,214-218$, 221-223, 231; (origin of), 176-184.

Minor dissonance, 185, 188, 190, 198, 214, 222, 223, 231.

Minor dominant, 187-189, 198, 200, 201-203, 204, 206-218, 220.

Minor dominant-triad, 235.

Minor downleader, 192.

Minor forms of consonance and dissonance, 185, 214, 222, 223, 231. 
Minor harmony, 124, 139, 185.

Minor harmonic percept, 214, 236.

Minor melodic scale, 201, 203.

Minor mode, 56, 59, 91, 124, 135, 141, $177-179,181,182,186,187,191,196$, 205, 210, 214, 217, 236.

Minor root, 180.

Minor seventh, 38, 76-78, 137.

Minor sixth, 138.

Minor small third, 180, 184, 200.

Minor subdominant, 187, 188, 204, 218, 222.

Minor subdominant harmony, 187,188 , 198, 204, 218, 219, 222.

Minor subdominant triad, 235.

Minor subtonic, 253, 256.

Minor subtonic-seventh-chord, 235.

Minor tenth, 36.

Minor tetrachord, 214.

Minor third, 36, 137, 138.

Minor tonic, $180,181,185,198,200$, $216,220$.

Minor tonic-harmony, 178-180, 184187, 198, 214.

Minor triad, 228, 231, 236, 237, 268.

Minor upleader, 187, 192.

Mode, defined, 91-98; major, 33, 41, $46,56,75,85,88,91,95,124,139-$ $141,176,178,181,182,186,187$, $191,210,214,215$, 236; minor, 56, $59,91,124,135,141,177-179,181$, $182,186,187,191,196,205,210$, 214, 217, 236; prototype major, 95, $180,181,185,191,200,214$.

Mode-idea, 85, 92, 94.

- Mode-relation, 88, 91, 94, 108, 180.

Mode-tones, 87, 93, 94.

Modes, 48; ancient, 147; Greek-, 145, 146.

Modulation, 183, 220.

Moment, musical, 149-160; rhythmic, $32,38,44,51,151$; rhythmo-harmonic, 23.

Motion, balanced, 10, 30, 33, 38, 162.

Motive, 23, 44, 152, 153, 214.

Mozart, 25, 170, 174, 289.

Music, absolute, 157; analysis of, 28,
66 ; art-, 15; basis of, 19, 20, 28, $56,58,85,102$, 223; books on, 181 ; chorded, 4, 141, 215, 223, 224, 235; classic form, 173-175; concrete, 233; development of, 9, 66, 105, 111, $166,171,175$; elemental form of, 22; essence of, 2, 3, 9, 14, 49, 104; evolution of, 1, 15, 49, 107, 220; first regnant harmony of, 55 , 61,83 ; five original cadences of, 92; form of, $5,7,9,15,21$; genesis of, $1,4,6-8,10,14,15$; instrumental, 166 , 243; message of, 10, 14, 22, 158; messenger of, 10, 14, 22, 149; modern, 4, 16, 70, 104, 116, 172-174, $203,212,215$; multi-voice, 25,85 , 116, 161, 223, 224, 226, 233; nature-, $15,16,17$; one, $15,16,17,28$; onevoice, $4,24,25,39,45,70,85$, $102,116,147,148,194,223$; origin of, $6-8,9,33$; pleasure in, 28,78 , 165; polyphonic, 1, 97, 223, 224; primitive, 56, 66, 86, 104, 110, 116, 165 ; principle of, $3,7,8,15,21,22$, $24,50,149$; rationale of, 17 ; seven octaves of, 141; stages of, 1, 6, 70, 103; study of, 1, 6, 21, 28, 289; voice of, $8,23,28,33,152,153,205$, 284.

Music of antiquity, 147.

Music-archæologist, 202.

Music art, 15, 16, 49, 100, 110, 154, $155,158,166,171,175,289$.

Music-concept, 286.

Music-consciousness, 6, 278, 285.

Music-culture, 175.

Music-drama, 156, 157.

Music-education, 40, 234.

Music-feeling, 2, 5, 6, 8-10, 13, 15, 16, $18,20,21,28,32,52,53,66,69,78$, $147,153,161,181,197,226$.

Music-history, 3, 40 65, 66, 68, 165. Music-lesson, 98-100, 277; work for students, 101, 164, 282-288.

Music per se, 7, 9, 21, 22, 67, 110.

Music-score, 268.

Music-sense, 165. 
Music-structure, 15, 173, 181, 270.

Music-theory, 3, 16, 20, 51, 69, 70, 230, 234.

Music-thought, 23, 24, 161, 171, 280.

Music-works, 13, 159, 170.

Musician, 2, 39, 51, 57, 66, 100, 159, 234, 289.

Ninth, 25-27, 29, 38, 41, 47, 63, 67, 76, $77,81,82,85,89,118,137,180,189$, 202-210, 223, 287; harmonic, 234; large, 223; original, 253; prototype, 208; small, 223, 260.

Notation, 60, 65, 229, 275, 276; staff, 88.

Nucleus, 141; septonal, 142.

Nucleus-triad, 261-264, 268, 269.

Numbers, 89,90 ; acoustic, 227 ; elementary group-, 167; harmonic, 37, $47,58,61,63,64,71,74,75,78,80$, $86-88,93,99,100,137,139,179$, $185,186,189,214,222,232,283-$ 286; interval, 93, 139; percept, 246; rhythm, 161 ; scale, 86-88, 94; thorough-bass, 238, 284.

Octave, 34, 35, 59, 81, 95, 118, 131, 141 , 143, 200; consecutive, 277; parallel, 231 ; pure, 36.

Octonal scale, 144, 146.

Octonal terminal, 144.

Opera, 157.

Orchestra, 166.

Organ, 166.

Original harmony in one voice. 28,39 , $40,47,50,64,66-69,73,75,85,88$, $104,124,133,140,148$.

Overtones, 20, 227.

Pedagogy, 277, 278:

Pentatonic melody, 109, 186.

Pentatonic period, 183.

Pentatonic scale, 64, 65, 109.

Pentatonic stage of melody, 108-110, 113, 114.

Percept, 26, 41, 44, 82, 284 ; five original harmonic, 77, 84, 85, 95, 122, 224, 227, 235, 249; prototype, 95; harmonic, $26,27,36,38,61,76,77$, $85,87,89,95,103,122,179,182$, $187,200,222-225,234,235,275$; harmonic, of minor origin, 222-224; major harmonic, 179, 222, 229; minor harmonic, 179, 200, 214, 216, 222, 229, 230.

Percept-numbers, 246.

Perception, 21, 28, 41, 53, 68, 73, 79, $93,165,166,178,197,228$; common, $19,20,22,29,37,43,45,64,66,69$, $86,89,91,108,179,181$; evolution of, 52,110 ; harmonic, $78,106,110$, 111, 230.

Perception of harmony, 24, 110, 111, 182.

Perception of relation, 76, 139.

Perception of rhythm, 33, 44.

Period, 42, 125, 152, 160, 161, 162, $165,173,182$; beat-, 160-163; cadence-, 121; dual, 29, 162; elementary, 170, measure-, 162, 260, 261; repose-, 121; rhythmic, $12,42,88$, $120,121,127-130,217$; rhythm-, 12, $32,33,125,127,129,153,193,250$, 286 ; subbeat-, 160, subrhythmic, 163 , 168; time-, 32, 33, 38; triple-, 29.

Personal election, 25.

Personal element of choice, 5 .

Personal equation, 5, 40, 70, 71, 205, 215, 230.

Personal prejudice, 5 .

Personal selection, 71, 72, 75, 85, 177, 230.

Peters' edition, 276.

Phrase, 16, 80, 122, 130, 152, 161, 162, 171-173, 187, 278.

Physical acoustics, 20, 21, 70.

Physical tone, 20.

Piano-concerto, 276.

Pianoforte, 95, 96, 166.

Pitch, 20, 30, 33, 34, 36, 53-55, 60, 61, $87,88,94,143,148,186$; fixed, 60 .

Pitch relation, 60, 88, 99, 141, 233.

Plagal ending, 136, 235.

Polyphony, 4, 103, 140, 215, 223, 224, 235. 
Potential harmony, 26, 27, 74, 77, 110, 181 ; principle of, $26,27$.

Primes, 93.

Principle, 3, 7, 12-14, 16, 17, 19, 21, $22,40,47,65,66,140,151,166,182$, 197, 198, 200; cardinal-, 15, 21, 28; fundamental, 8,175 ; rhythmo-harmonic, 286; shaping, 10, 11, 24, 28, $31-33,36,41,48,50,51,120,130$, $149,161,162,171-173,195$; universal, of form and relation, 12-14.

Principle of harmonic genesis, 27, 38, $65,105,125,181$.

Principle of music, 3, 7, 8, 15, 21, 22, 24, 50, 149.

Principle of potential harmony, 26, 27.

Principle of tone genesis, 95 .

Progression, 13, 48, 96-98, 112, 113, $115,119,142,152,187,192,220,275$.

Prototype, 95, 124.

Prototype cadence, 185, 192.

Prototype cadence-tone, 191, 194, 208.

Prototype chord, 140.

Prototype consonance, 95, 124, 133, 184, 185, 221, 231.

Prototype dissonance, 95, 124, 134, 185, 188, 221, 231.

Prototype dominant, 206.

Prototype downleader, 95, 192.

Prototype five original percepts, 95.

Prototype of harmonic forms and relations, 95.

Prototype of harmonic percept and step in minor, 200.

Prototype major harmonic percept, 200.

Prototype major mode, 95, 180, 181, 185, 191, 200, 214.

Prototype ninth, 208.

Prototype repose, 185.

Prototype upleader, 95, 192, 194.

Rameau, 264.

Regnant bytone, 287.

Regnant dissonance, 127, 128.

Regnant dominant, 188, 207, 210.

Regnant harmony, $24,25,53,54,55$,
$58,60,65,67,83-85,88,98,104-$ 113 , 115-118, 125-127, 129-133, $141,149,183-188,193,194,198$, $201,208,209,214,220,221,223$, 224, 261-264, 267, 268, 272, 274-276, 287.

Regnant harmony in one voice, 102133.

Regnant major dominant, 188, 206, 207.

Regnant major subdominant, 188.

Regnant major tonic, 108, 185.

Regnant minor consonance, 218.

Regnant minor dominant, 188, 206-218.

Regnant minor subdominant, 188, 218222.

Regnant minor tonic, 199-206.

Regnant ninth, 210.

Regnant root, 208.

Regnant subdominant-harmony, 108.

Regnant third, 210.

Regnant tones, 106-112, 116-118, 120$123,126,193,199,207,208,210$, $211,214,216,256,261,274,287$.

Regnant tonic-harmony, 102-133.

Relation, 5, 6-9, 15, 17, 20-30, 41, 48, $56,58,61,64,66,75-81,84-86,89$, $92,95,99,107,110-112,115,120$, $123,127-129,133,135,136,140,143$, $152,179,182,185,186,190-193$, $198,200,203,205,207,211,212$, 214, 233, 234, 248-251, 253, 255, $256,266,276,280,281,285,286$; elemental, 22, 23; fifth-, 123, 249; harmonic, 7, 22, 26, 27, 29, 35, 37-39, $50,60,62,65,67,76-78,83,87,88$, $93,100,105,106,109,111,112,119$, 122, 124, 141, 177, 247; prototype harmonic, 95; interval, 80 ; interharmonic, 91, 93, 94; key-, 60, 88; mode, $88,91,94,108,180$; prototype mode-, 185 ; original harmonic, 15,26 , $27,95,107,136$; rhythmic, $22,44,50$, $53,55,103,177$; rhythmo-harmonic, $14,23,24,98$; space-, 14, 22, 23, 30, 38 ; time-, 14, $22,30,38,79,104$; tone-, $22,24,30,42,45,48,56,58,62$, 
$67,78,89,94,98,104,180,214,224$, 278; tonic and dominant, 196.

Relation of cadence and repose, 44-47, 50, 53, 55, 63, 85, 91, 98, 103.

Relation in space (harmony), 79.

Report (common, harmonic, self-), 19, $112,120,179,186,195,202,220,227$, 230 ; common, of common feeling, 1722.

Report of biad, 246, 247.

Report of bytone, 118, 119, 219.

Report of chord, 134, 135, 138, 139, $141,233,234,245,247,255,259$, 266.

Report of common feeling and perception, $5,19,22,24,28,45,66,69,88$, 108, 135, 181, 230.

Report of harmonic numbers, 88,283 , 284.

Report of harmony, 24, 38, 47, 66, 67, $85,148,209,230,262,264,276,283$.

Report of homophony, 5, 6, 215, 230, 232, 288.

Report of melody, 108, 148-149, 176, $179,181,182,215,216,223,224,279$, 283, 284, 288.

Report of mode, 215.

Report of tone, 85, 89, 90, 135, 177, $214,216,233,246,247$.

Report of triad, 232, 233, 248, 262.

Repose, 41, 56, 61, 68, 92, 103, 116, $123,129,130,133,142,148,177$, $178,180,185,190,214,216,223$; rhythm-, 42-45, 50, 53, 67, 111, 120 , 121 ; tone-, $45-48,55,62,63,67,91$, 96-100, 121, 190-192, 201.

Repose-harmony, 45-48, 62, 111.

Repose-moment, 42, 44.

Repose-thread (of harmony), 54, 55, 67, 91, 97-99.

Resolution, 48, 54, 55, 62, 64, 93, 96$98,112,113,115,135,142,152,192$, 220, 235, 275.

Rhapsody, 203.

Rhythm, 1, 6-10, 12-14, 17, 20, 22$24,28,30,33,38,48,50-52,54,56$, $63.65,74,79,83,89,98-100,103$,
$104,130,148-153,158,160-168$, $171,176,180$, 229, 286-289; analysis of, 31-33; = balanced - motion, 10 , $30,33,38,162$; cadence, $42-45,50$, $53,67,111,120,121$; dual, 29, 32, $43,99,173$; music-, $30,32,42,50,51$, $158,165,167,171$; tone-, 7, 9, 10 , $14,15,29,48,152,154,155,171$, 172; triple, 29, 32, 99.

Rhythm-numbers, 161.

Rhythm-period, 12, 32, 33, 125, 127, $129,153,193,250,286$.

Rhythm-repose, 42-44, 45, 50, 53, 67, $111,120,121$.

Rhythmo-harmonic accent, 25, 105.

Rhythmo-harmonic analysis, 289.

Rhythmo-harmonic content of melody, 279, 288.

Rhythmo-harmonic equilibrium, 125.

Rhythmo-harmonic feeling, 278.

Rhythmo-harmonic form, 24, 279, 288.

Rhythmo-harmonic laws of causation, 224.

Rhythmo-harmonic point, 25, 105.

Rhythmo-harmonic principles, 286.

Rhythmo-harmonic relation, 14, 23, 24, 98.

Rhythmo-harmonic thought, 278.

Rhythmo-harmonic voice of music, 153, 205.

Richter [Ernst F. E.], 249.

Riemann, 181, 226, 230.

Root, 25-27, 29, 30, 34-37, 40, 41, 47, $51,60,61,63,67,75-77,80,81,84$, $85,88-90,93,108,113,118,123$, $142,179,180,185,189,217,223$, 227, 232, 234, 285, 287; chord-, 135, $136,140,232,234,237-243,245$, 248, 249, 258-261, 268, 274, 275, 278; harmonic, 135, 136, 181, 189, 232, 234, 258, 260, 272.

Round-song, 181.

Scale, 141, 142, 192, 205, 217, 230; ascending, 97, 228; descending, 97, 229; diatonic, 144, 192; Dorian-, 229; enharmonic, 215; great, 64; major, 
$26,86,143,203$; mediant, 146; melodic minor, 201, 203; octonal, 144, 146 ; original, of the tonic, 145 ; pendant minor, 228; pentatonic, 64, 65, 109; primitive, 64; septonal, 146; small, 64; supertonic-, 146; tonic-, 146; Zarlino-Riemann, 228, 229.

Scale-numbers, 86-88, 94.

Scale terminals, 143, 144.

Schopenhauer, 14.

Schumann, 49, 169, 171.

Selection, 75, 140, 149, 183; natural, $17,70,71,85$; personal, 70-72, 85, $176,177,230$.

Sense, harmonic, 69, 121, 147, 148, 182; music-, 165.

Septimenaccord, 269.

Septonate, The, 24, 98, 104.

Sequence, $6,9,25,40,51,52,60,64$, $65,102,105,181,278$.

Seventh, 25-27, 29, 30, 41, 47, 61, 63, $65,67,76-78,81,82,85,87,89,134$, $135,137,223,268,269$, 287; diminished, 234; harmonic, 234, 268, 269; minor, 76-78, 137; small, 222, 223; thorough-bass, 268.

Shaping principle, 10, 11, 24, 28, 31$33,36,41,48,50,51,120,130,149$, 161, 162, 171-173, 195.

Silence, $1,7$.

Sixth, 36, 59, 138, 139.

Sonata, 116, 155, 173, 174, 212, 266.

Songs, $4,15,43,53,56,157,165$; bird, $56,58,59,61,171,176$.

Soprano, 287.

Sound, 1, 7, 8, 21, 33, 34, 38, 43, 51, $55,165,166$.

Space, 12-14, 22, 23, 30, 38, 79, 104, 122, 150, 153.

Spencer [Herbert], 68.

Step, 36, 59, 60, 64, 81, 87, 92, 93, 96, $98,112,119,125,137,138,142,144$, $145,200,209,214,228,275$.

Strauss [Richard], 171.

Stringed instrument, 166.

Student, 39, 59, 73, 87, 93, 96, 99, 100, $101,139,163,164,277,279,280$,
282-289; work for, 101, 164, 261, 284, 286-288.

Study of music, 1, 6, 21, 28, 289.

Stumpf, C., 21.

Subbeat-period, 160.

Subdominant, 144, 187, 188, 204, 253; regnant minor, 218-220.

Subdominant-harmony, $58,60,61,108$, 198.

Subdominant seventh chord, 254 .

Subdominant triad, 235, 251, 262, 264.

Subfix-tone, 257.

Subharmony, 85, 88.

Submediant, 144, 253, 263.

Submediant seventh-chord, 254, 256.

Submediant triad, 249-250, 256, 263.

Subrhythm, 161-163, 167-170, 288; compound, dual, mixed, triple, 286.

Subsecond, 261, 268.

Subsecond-chord, 261, 262, 265, 267270.

Subtonic, 144.

Subtonic-chords, 253, 256.

Subtonic seventh-chord, 235, 254.

Subtonic-triad, 251-253.

Superfix-tone, 257.

Supersixth, 261, 268.

Supersixth chord, 261-264, 267-270, 271.

Supertonic, 144, 253.

Supertonic seventh-chord, 254.

Supertonic-triad, 251-253, 256.

Syllables, 43, 61, 86-88, 94, 99, 100 , $144,145,186,189,229$.

Symbols, 30, 33, 61, 73, 86-89, 94, 135, $145,159,161,164,180,275,276$, 279.

Symphony, 116, 155, 173, 174, 212, 266. Syncopation, 169.

Technique, 93, 100.

Temperament, 95, 96.

Tempo, 86.

Tenor, 287.

Tenths, 36.

Tetrachord, 142-146, 200, 202, 203, 214.

Tetrad, 269-272; compound, 272. 
Theme, 214.

Theory, 3, 16, 17, 20, 22, 51, 52, 69, 70, $89,181,200,226-228,233,234,244$, 269, 289; acoustic, 230; ZarlinoRiemann-, 181, 226, 230.

Theory of pendant minor, 226, 227.

Third, 25-27, 29, 30, 34-37, 40, 41, 47, $59-61,63,65,67,76,81,82,85,89$, $93,108,120,137-139,178,179,184$, $187,189,200,206,210,211,223,224$, 285, 287; double, 211, 212; harmonic, $135,137,234$; major, $34,36,61,76-$ $78,81,82,120,137,138$; minor, 36 , 137, 138; superadded, 257.

Thirteenth, 82, 89.

Thorough-bass, 259, 267, 269, 270, 274.

Thread, cadence, of harmony, 54; consonance, 37,143 ; dissonant, 143; dominant, 47, 82, 84; harmonic, 35 , $36,37,38,41,54,63,79,80,81,84$, $96,107,109,124,133,134,137,139-$ $141,143,178,183,188,193,224$; repose-, 54 ; tonic-, $47,59$.

Time, clock, 174; mathematical, 174; rhythmic, 174 ; rhythmic period of, 38 , 42.

Time-accent, 32.

Time-period, 32, 33, 38.

Time-relation, 14, 22, 30, 38, 79, 104.

Tonality, 1, 39, 41, 56, 60, 61, 65, 67, 77, 94-96, 103, 215, 224.

Tone, 5-10, 13, 17, 25, 28, 29, 35-37, $44,46,50,53,55,74,87,88,94-97$, $109,112,114,117-119,124,127$, $133,136-138,140-142,144,148$, $153,156,165,176,182,189,190$, $192,198,201,205,206,208,210,212$, $215,228,232,233,235,239,243,247$; accented and unaccented, 43; added, 262-264, 268, 274 ; analysis of, 3335 ; =balanced sound, 30,38 ; bond-, $63,76,122,123,285$; cadence-, 46,47 , $57-59,61-66,92,96-100,106,107$, $113,135,136,191,192,235,257$; (prototype), 191, 194, 208; chord-, 86; component, $85,103,106,234$; elementary, 34, 79; = equilibrium, 30, 125; harmonic thread of a, 35-36; harmonic, 38,86 ; harmonic complex of, 34 , $35,37,40,41$; harmonic pedigree, 224231 ; = harmony, 30 , 33; infix, 257; initial, 247; isolated, $34,37,40,41$, $45,55,59,60,108,177$; leading, 61 ; melodic-, 86 ; mode-, 87 , 93,94 ; original, 26, 27, 75, 76, 85, 107, 233; original cadence-, 46, 92, 98, 106, 135 , 136; original repose-, 46; physical, 20 ; pitching a, 54; regnant, 106-112, $116-118,120,121,123,126,193$, 199, 207, 208, 210, 211, 214, 216, $256,261,274,287$; repose-, 46, 62, $63,67,86,96-100,257$; seventh, 82 ; seven original, $26,27,75-86,103$, 107, 225, 226; single, 68, 79, 135, 139 ; stable, 257-260; subfix-, 257; superfix-, 257; terminal, 82; thirteenth-, 82 ; three stages of, 193, 194; unstable, 257-260.

Tone-cadence, 45-48, 55, 86, 91, 121. Tone-feeling, 28.

Tone-genesis, 33, 51, 54, 95.

Tone-material, 214, 220, 221, 257. Tone-moment, 23, 153.

Tone-region, 141-149.

Tone-relation, 22, 24, 30, 42, 45, 48, 56, $58,62,67,78,89,94,98,104,180$, 214, 224, 278.

Tone-repose, $45-47,55,62,63,67,91$, 96-100, 190, 192, 201, 221.

Tone-rhythm, 7, 9, 10-14, 15, 29, 48, $152,154,155,171,172$.

Tone-system, 1, 27, 39, 65, 95, 147, 205, 215, 224, 233.

Tonic, 84, 90, 93, 229, 253, 272; major, harmony, 33, 41, 45, 47, 54-61, $63-65,67,77,83,84,90-93,98$, $103,105-108,111,180,181,183-187$, $193,221,229$, 260; minor, harmony, $179,180,181,184-187,199-206,214$, 221, 230; rhythmic, 120.

Tonic-centre, 143.

Tonic-chord, 66.

Tonic components, 83.

Tonic-root, 76. 
Tonic-scale, 146.

Tonic-septonate, 144, 145.

Tonic-triad, 66, 84, 262, 268.

Triad, 133, 134, 136, 139, 140, 235241, 244, 248, 249, 264; augmented, 249, 262; basic, 240 ; diminished, 237 , 262; ground-, 238; major, 90, 133, 237, 251, 262, 268; major dominant-, 84, 235, 249; major subdominant-, 235, 264; major tonic-, 262, 268; mediant-, 248-250; minor, 237, 249, 251, 262, 268; minor dominant-, 235, 262; minor mediant-, 248, 249, minor subdominant-, 235, 262; minor tonic-, 262, 268; nucleus, 169, 262, 263, 268, 269; primary, 250, 251, 253; secondary, 249-251, 284; subdominant-, 235, 251, 262, 264; submediant-, 249, 250, 256,263; sub-tonic, 251-253; supertonic, 251-253, 256; tonic-, 66, 84, 262.

Triad positions, 238-241.

Tritonus, 144.
Undertones, 227, 228.

Upleader, 64, 92, 183, 208, 209, 239, 285; chromatic, 275; major, 187, 192; minor, 187, 192; prototype, 95 , $192,194$.

Vierklang, 269.

Voicing, close and open, 267.

Von Bülow, 276.

Wagner, 5, 49, 74, 140, 150, 171.

Weber, G., 50, 74.

Well-tempered Clavichord, 170, 198.

Wind instruments, 166.

Work for students, 101, 164, 282288.

World, energy, 11, 12.

World equilibrium, 12.

World harmony, 12, 14.

World principle, 11.

World rhythm, 12.

Zarlino, 181, 226, 230. 






\section{DAY USE}

\section{RETURN TO DESK FROM WHICH BORROWED}

\section{MUSIC LIBRARY}

This book is due on the last date stamped below, or on the date to which renewed.

Renewed books are subject to immediate recall.

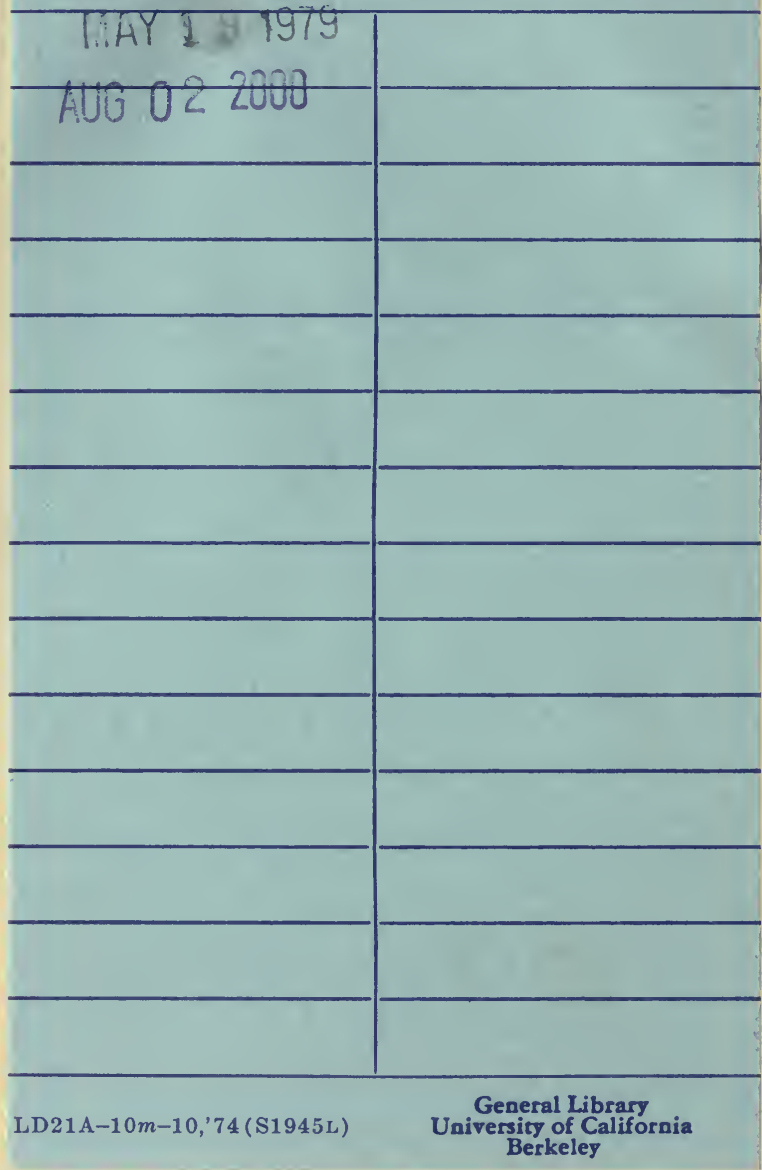




\section{0}

$M L 3800$

16

\section{UNIVERSITY OF CALIFORNIA LIBRARY}


